Universidade de São Paulo

Faculdade de Filosofia, Letras e Ciências Humanas

Departamento de Antropologia Social

Programa de Pós-Graduação em Antropologia Social

\title{
Entre tradições orais \\ e registros da oralidade indígena
}

Eva Gutjahr

Dissertação de mestrado, sob orientação de Profa. Dra. Dominique Tilkin Gallois, apresentada ao Programa de Pós Graduação em Antropologia Social da Universidade de São Paulo, para obtenção do título de Mestre

São Paulo

Julho de 2008 


\section{Entre tradições orais e registros da oralidade indígena}

Eva Gutjahr

São Paulo

Julho de 2008 
« je poussais plus loin mes divagations:

j'imaginais que cette parole

pouvait être un lien entre nos mondes,

destinée à des fins précises »

- Adolfo Bioy Casares 
Esta pesquisa se interroga sobre articulações entre características próprias a tradições orais e experiências de registro de enunciados orais indígenas a partir de dois 'casos', de escalas distintas: Xavante, habitando a aldeia de Pimentel Barbosa no Brasil Central, e Kanak, habitando as ilhas da Nova Caledônia na Melanésia. Internamente a cada 'caso', propus o estabelecimento de 'relações' ou 'rizomas' de modo a identificar 'efeitos' que experiências e produtos de registro de enunciados orais produziram junto a seus atores, efeitos este que qualifico como de 'proliferação', 'rechaço', ou 'descaso'. Ao pautar minha análise nos modos de interação mediados através do discurso segundo modalidades consideradas adequadas por aquelas populações em contextos específicos, busquei refletir acerca dos modos como vêm assumir sua 'tradição enunciada' em situações de oficialização e institucionalização de 'patrimônios' e 'identidades', assim como identificar modos com 'registros' são empregados por tais populações segundo formas de criatividade próprias e inovadoras. Meu objetivo foi uma reflexão crítica, a partir de dois casos tornados aqui 'comparáveis', concernindo as atuais políticas do 'patrimônio imaterial' pautadas em ações de valorização e salvaguarda de 'tradições orais' de populações indígenas.

This study focus on the relationships between oral traditions, and products and events related to the documentation of indigenous oral sayings from the starting point of two 'case-studies' of different scales: Xavante, from the Pimentel Barbosa village in Central Brazil, and Kanak, from the islands of New Caledonia, in Melanesia. For each of this 'cases' I intended the search for relations or 'rhizomes', in order to identify effects that documentation of oral statements, narratives and sayings produced in the point of view of their very actors. I call such effects 'proliferation', 'resistance' or 'indifference'. Basing my analysis in expressive and discourse-mediated interaction as considered adequate by these populations in specific contexts, I wished to reflect on "traditions as announced", in situations that demand the institutionalization of 'patrimonies' and 'identities', as well as identify ways that documentation practices and products are invested by these people according to their own dynamic forms of creativity and innovation. My objective was to establish, through making these two cases 'comparables', a critical reflection on the contemporary 'intangible cultural heritage' policies based on the safeguarding of 'oral traditions' and 'expressions' of indigenous people.

Palavras-chave [Key-words]

Tradições orais, registros da oralidade indígena, Xavante, Kanak, 'patrimônio imaterial'. Oral traditions, documentation of indigenous oral sayings, Xavante, kanak, 'intangible heritage'. 
Agradecimentos

Agradeço em primeiro lugar à minha orientadora, Dominique Tilkin Gallois. Foi a partir de seu investimento e confiança, desde o início de meu trabalho como bolsista no Núcleo de História Indígena e do Indigenismo, e depois junto aos Wajãpi do Amapá, que pude desenvolver toda a série de questionamentos que são hoje essa pesquisa. Agradeço também a ela pelos instrumentos teóricos, e pelas reflexões das disciplinas 'tradição, memória e oralidade' e 'redes de saberes ameríndios'. Agradeço também aos meus colegas nesses cursos por nossos ricos debates.

Agradeço aos Xavante, aos Kanak, aos Wajãpi a todos os povos indígenas por seus exemplos infindáveis de possibilidades de ser. Espero ver um tempo em que suas criatividades 'proliferem' para além do âmbito da reflexão antropológica.

Agradeço à Clarice Cohn e Vagner Gonçalves pelas contribuições durante meu exame de qualificação para este mestrado.

Agradeço aos pesquisadores ligados ao Núcleo de História Indígena e do Indigenismo pela escuta atenta e pela discussão de meu projeto de pesquisa, assim como pelos interessantes debates no âmbito das reuniões do Projeto Temático 'Redes de Relações Ameríndias' das quais pude participar.

Agradeço aos professores das disciplinas do mestrado pelos instrumentos teóricos e críticos que me auxiliaram no desenvolvimento desta pesquisa.

Agradeço aos funcionários do Departamento de Antropologia por sua ajuda nas questões práticas do mestrado.

Agradeço a CAPES pela minha bolsa de pesquisa.

Agradeço à Bonnie e Jean-Pierre Chaumeil por me haverem tão bem recebido em Paris, no EREA, pelo acesso ilimitado a que tive a todos os materiais da biblioteca, pelas apresentações e discussões no Séminaire des Américanistes.

Agradeço a todos os meus colegas do mestrado, companheiros fundamentais nesse percurso.

Agradeço aos meus amigos-amados e a todos que de uma forma ou de outra participaram em quem eu sou hoje.

Agradeço ao Ludo, que me acolheu em sua vida, em sua casa e em seu coração, pela amizade, carinho, tranqüilidade e bom humor, pela música, tardes de guitarra para me 'fazer companhia', e suas saladinhas delícia.

Agradeço à minha mãe, Mirian, ao meu pai Ivo (in memoriam) e às minhas irmãs Isadora e Melanie. É a essa minha velha e nova família que dedico este trabalho. 


\section{Índice}

\section{Introdução}

Resumo dos Capítulos | 15

Orientações Teórico-metodológicas |17

\section{Capítulo 1 | Patrimônio, Cultura, Tradição}

1.1 Sobre a noção de patrimônio | 19

1.2 Panorama da "Convenção para a Salvaguarda do Patrimônio Imaterial" | 23

1.3 Conhecimentos "Tradicionais"? | 25

1.4 Cultura e "Cultura" 27

1.5 Patrimônios Imateriais e 'comunidades' | 30

1.6 Criatividade como foco da valorização $\mid 31$

1.7 Quando produtos da prática etnográfica vêm servir 'valorização cultural' | 34

1.8 Formas de conhecer da antropologia: o lugar das práticas discursivas nativas | 37

Capítulo 2 | Langue, Parole, Oralidade | 41

\section{Capítulo 3 | Entre tradições orais e registros da oralidade Xavante}

3.1 Apresentação | 52

3.2 Características da Oralidade Xavante: o gênero ihi mrèmè / 55

3.3 Registros da oralidade por Laura Graham e seus 'efeitos' | 65

3.4 Registros da oralidade segundo uma metodologia 'dialógica' | 85

3.5 Registros da oralidade Xavante em um 'projeto' de valorização cultural | 100

\section{Capítulo 4 | Entre tradições orais e registros da oralidade Kanak}

4.1 Apresentação | 110

4.2 Gêneros da Tradição oral Kanak | 116

4.2.1 Gêneros Narrativos | 118

4.2.2 Cerimônias e o Accueil / 126

4.2.3 O Accueil em sua dimensão histórica e os discursos vivaa| 127

4.3 A noção de Maison na construção identitária de grupos | 135

4.4 Novas formas discursivas para antigas relações: deslocamentos | 139

4.5 A constituição de um 'patrimônio' e 'identidade' Kanak: ontem e hoje | 145

4.5.1 Retorno à história | 145

4.5.2 Localização do debate | 148

4.6 'Melanésia 2000', Tèa Kanaké, Jean-Marie Tjibaou | 151

4.6.1 Festival Melanésia $2000 \mid 153$

4.6.2 A encenação dramática de Tèa Kanaké| 164

4.6.3 O 'mito' de Tèa Kanaké segundo a obra «Kanaké, Mélannésien de Nouvelle Calédonie"| 167

4.7 Dos interlocutores de Maurice Leenhardt a Jean Marie Tjibaou e após: 'proliferações' | 180

4.8 Enunciados acerca da tradição segundo uma abordagem dialógica | 187

4.9 Registros da oralidade Kanak em um 'projeto' de valorização cultural | 194

Conclusão | 199

Bibliografia | 206 


\section{Introdução}

Esta pesquisa surgiu de meu interesse por questões relativas às formas próprias à oralidade entre grupos de tradição ágrafa, cuja expressão oral prevalece sobre sua forma escrita.

Concomitante à descoberta dessa ampla área de pesquisas, notadamente os "estudos de oralidade", passei a me interessar pelo incremento de experiências que, pautadas em proposições como "valorização cultural", "revitalização" ou "salvaguarda do patrimônio imaterial", possuem dentre suas ações o registro de enunciados orais indígenas.

Atualmente, temos assistido à multiplicação de casos em que populações e indivíduos indígenas vêm se engajar em projetos de 'coleta' e registro de seus 'saberes' e 'tradições orais', assim como realizar consultas à bibliotecas e fundos documentais de museus, universidades e instituições privadas em busca de fotos, filmes, textos e arquivos em áudio concernindo seus familiares ou antepassados (Anderson, 2005) ${ }^{1}$. Alguns antropólogos aproveitaram essas circunstâncias para doarem seus materiais etnográficos às comunidades com as quais trabalharam (De Largy Healey, 2004).

Esses 'saberes', 'enunciados' e 'tradições orais' documentados, em outras épocas ou recentemente, têm sido empregados na elaboração de livros e revistas, na constituição de acervos e fonotecas, na alimentação de bancos de dados e na constituição de CDroms. Essas iniciativas têm em vista tanto a preservação daquelas informações em suportes duráveis como sua disponibilização e divulgação para um público amplo, ou restrito às populações a que dizem respeito. Algumas dessas ações testemunham possibilidades originais de utilização de tecnologias de informação e comunicação ${ }^{2}$ (Anderson, 2005; Gallois, 2006; De Largy-Healey, 2004; Gutjahr, 2006).

Vemos desse modo como registros da oralidade indígena, produzidos de acordo com objetivos específicos e diversificados, podem vir eventualmente convergir ao serem reunidos através de propostas ditas 'culturais'.

\footnotetext{
${ }^{1}$ Por vezes estes eventos relacionam-se a questões legais em que há a necessidade de informações na forma de 'documentos'; mais freqüentemente, em demandas de reconhecimento territorial.

${ }^{2}$ Dentre tais possibilidades originais, ressalto aquelas relativas às 'data architectures' que concernem modos específicos de elaborar a arquitetura dos dados, promovendo alinhamentos entre dados, e entre dados e questões, de acordo com associações 'culturalmente' privilegiadas.
} 
Dentre tais registros da oralidade, há aqueles realizados por pesquisadores acadêmicos, em especial lingüistas e antropólogos, com vistas à produção de conhecimento científico segundo temas, abordagens e orientações teóricometodológicas específicas. Após concluídas as pesquisas, tais materiais etnográficos podem vir a ser doados às populações com quem os estudiosos trabalharam e, com o auxílio ou não destes mesmos pesquisadores, virem compor novos materiais, didáticos ou paradidáticos, voltados às próprias comunidades ou tendo em vista um público amplo (ou ambos).

Em outros casos, tais registros são realizados já sob a égide de políticas de 'valorização cultural', voltadas ao reconhecimento daquelas populações e à salvaguarda de suas formas de expressão cultural. Nestas situações a produção de registros não se pauta por hipóteses ou questões teóricas, mas sim pela promoção da 'viabilidade' destes 'conhecimentos' e 'formas de expressão', associada ao 'empoderamento' dos atores e comunidades indígenas. Membros das próprias 'comunidades' têm sido gradativamente chamados a participar como efetivos agentes nessas atividades de documentação.

Para além das políticas públicas atuais de 'valorização cultural', há casos em que a constituição de acervos documentais parte de iniciativas propriamente autóctones ${ }^{3}$. Freqüentemente tais ações visam a documentação atual de 'conhecimentos' e 'formas de expressão', mas também sua complementação por registros etnográficos e obras acadêmicas produzidas no passado, em que fragmentos ou seleções de peças da oralidade indígena vêm informar análises científicas ${ }^{4}$.

Nessas atuais experiências de valorização e salvaguarda, chamou minha atenção o amplo destaque, assim como os potenciais benefícios vislumbrados na documentação de 'tradições orais' e enunciados orais indígenas. De que modos se conjugam a ubiqüidade da ênfase nos registros às características de tais 'tradições', próprias à oralidade ${ }^{5}$

\footnotetext{
${ }^{3}$ Menos freqüentes no Brasil.

${ }^{4}$ Esses são todos exemplos de casos que compõem a presente pesquisa.

${ }^{5}$ Diversos fatores me incitavam em relação a essa temática de pesquisa. Primeiramente um interesse, desde fins de minha graduação, por questões relativas à linguagem e às formas e conteúdos de tradições orais, em especial no âmbito da etnologia indígena.

Em segundo lugar, ao fato de eu haver participado, e participar ainda enquanto parte de uma equipe, na execução de algumas das ações previstas no 'Plano de Salvaguarda do Patrimônio Imaterial dos índios Wajãpi do Amapá'. Aquele 'Plano' propõe, dentre suas ações, a formação de pesquisadores indígenas que, na esfera de suas pesquisas, realizam registros de conhecimentos transmitidos oralmente

Ressalto que a formação de pesquisadores Wajãpi, assim como os procedimentos e produtos decorrentes do registro de 'conhecimentos' e 'tradições orais' relativos a esta 'comunidade' não estão dentre os casos a serem analisados na presente pesquisa. Essa opção decorre do caráter recente e ainda em curso desta experiência, não apresentando ainda resultados que sejam passíveis de análise. Entretanto, exemplos relacionados à 'experiência' Wajãpi, assim como exemplos de procedências outras, deverão ser considerados e discutidos, em especial na forma de notas que dialogam com as reflexões internas aos capítulos 'etnológicos'. A experiência “Wajãpi” será possivelmente um tema para futuras pesquisas.
} 
Nesse trajeto cheio de meandros, meu interesse foi o estabelecimento de articulações ou rizomas entre caracterizações que foram feitas a respeito de 'tradições orais', modalidades de produção de registros ${ }^{6}$, e modos como esses registros são avaliados pelos atores indígenas.

A abordagem aqui adotada acerca das relações entre 'tradições orais' e ações de registro da oralidade indígena não concerniu supostas implicações que mudanças de mídia ou meio nos modos de transmissão poderiam imprimir em 'formas de pensamento"7.

Minha atenção voltou-se, antes, para as relações entre, de um lado, formas e conteúdos de 'tradições orais', ou seja, modos de produção de enunciados e de transmissão de 'conhecimentos' através da oralidade de acordo com contextos e formas considerados adequadas pelas respectivas populações e, por outro lado, eventos e produtos de registro de 'tradições orais', 'enunciados' e 'saberes', e as interpretações e usos que tais populações fiseram desses procedimentos e dessa 'tradição' documentada.

Meu foco nesta pesquisa consistiu tanto os modos imediatos como ações de registro foram avaliadas, 'experimentadas' ou 'acionadas' por aquelas populações, como possíveis efeitos, mediatos, na subseqüente transmissão de conhecimentos e na produção de novos enunciados orais. Meu questionamento tendeu, em especial, aos

Minha primeira experiência consistiu na participação, enquanto membro da equipe do NHII/ Núcleo de História Indígena e do Indigenismo- USP, nas ações do projeto "Documentação Wajãpi: Memória para o Futuro" entre 2003 e 2005 (Bolsa Técnica Nível III - Processo FAPESP n 03/07243-4). O objetivo daquele projeto era a catalogação, digitalização, organização e disponibilização de registros, na forma de materiais etnográficos, bibliográficos e documentais relativos àquela população, e que foram produzidos por antropólogos, outros profissionais ou pelos próprios Wajãpi. Este projeto consistiu na elaboração participativa (voltada à elaboração de data architecture o tanto quanto possível específica aos Wajãpi) e constituição de um banco de dados em língua wajãpi e portuguesa, para abrigar e promover a acessibilidade àqueles materiais (fotos, vídeos, arquivos sonoros, documentos históricos, artigos de divulgação ou científicos, teses, mapas, desenhos de arte gráfica e figurativos) para todos os Wajãpi, assim como para agentes e pesquisadores trabalhando junto a este grupo indígena.

Minha segunda experiência, em curso desde 2005, enquanto membro da equipe da organização nãogovernamental lepé (Instituto de Formação e Pesquisa em Educação Indígena), consiste na assessoria à execução de algumas das ações previstas no "Plano integrado de valorização de conhecimentos para o desenvolvimento socioambiental sustentável da comunidade Wajãpi do Amapá". Este Plano foi resultado da seleção das "Expressões gráficas e oralidade entre os Wajãpi do Amapá" como obra Prima do Patrimônio Oral e Imaterial da Humanidade pela Unesco, em 2003 e registrado pelo Iphan-MinC em 2002. Dentre minhas atividades, auxilio nas atividades de formação de um grupo de jovens Wajãpi à pesquisa. Os temas da cada pesquisa, escolhidos por cada pesquisador, concernem sujeitos, - ou 'jeitos de' -, próprios à sua cultura (rituais de iniciação, espécies de plantas da roça e narrativas sobre suas origens, narrativas relativas ao tempo das origens, narrativas históricas, etc). No âmbito de suas pesquisas estes jovens procedem à coleta e ao registro de tradições orais correspondentes àqueles temas junto aos jovijãgwerã, os 'sábios', os 'velhos'. Os procedimentos e produtos desta formação visam a elaboração, pelos Wajãpi, de um 'inventário de práticas culturais' a ser inscrito nos livros de registro do Iphan-MinC, e atualizado a cada 10 anos. A formação destes pesquisadores indígenas visa também a complementação e gestão daquele banco de dados, assim como promover sua formação em gestão técnica. Mas o principal objetivo é o fomento de uma reflexão acerca das formas de enunciação de sua cultura e das lógicas que a informam, e de seu projeto de futuro.

6 Sejam eles orientados por interesses 'acadêmicos', seja segundo modalidades próprias a ações de 'valorização' e 'salvaguarda' culturais.

${ }^{7}$ Jack Goody (1979). Ver discussão no capítulo 3. 
usos que foram feitos de tais procedimentos e produtos.

Interessaram-me tanto 'proliferações', ${ }^{8}$ modos como 'tradições orais' documentadas foram reproduzidas e multiplicadas, participando na cadeia de transmissão de conhecimentos e de que modos; quanto 'interrupções', maneiras através das quais aquelas mesmas populações negaram que contextos ou modalidades próprias à sua tradição oral fossem registrados, ou 'rejeitaram', 'rechaçaram' ou 'ignoraram' registros que foram feitos de seus enunciados orais, de modo que estes 'não entraram' na cadeia de transmissão de conhecimentos.

Reina certa confusão entre o emprego dos termos 'conhecimentos' e 'tradições orais'. Isso porque, ao se considerar as intrincadas relações entre idéias, enunciados, ações e modos expressivos que caracterizam a vida humana, como isolar conteúdos expressos através da oralidade de suas formas de expressão?

Em seu sentido mais amplo, a 'tradição oral' consiste nas 'convenções mais formalizadas e recorrentes relacionadas à expressão verbal, consideradas em seu contexto cultural' (Finnegan:1992, 3); ou no 'conjunto de expressões orais de uma cultura, se aplicando às interações sociais fundamentais, segundo os modos considerados adequados de sua forma e uso' (Monod-Becquelin, 2005:34).

Assim, 'tradição oral' refere-se às injunções entre formas expressivas da oralidade e interações sociais fundamentais em certo contexto cultural. Nesse sentido, se populações ocidentais, caracterizadas que foram segundo a importância dos desenvolvimentos decorrentes de um regime de 'escrita', têm na oralidade sua principal forma de comunicação, populações de 'tradição oral' concernem aquelas que privilegiaram a transmissão de seus saberes e práticas através da 'boca e da orelha' e da 'mão e da voz', mas cuja situação contemporânea é também marcada, seja em maior seja em menor grau, pela importância da escrita e de outras técnicas de registro, assim como das chamadas 'tecnologias de informação e comunicação'.

Entre sociedades que foram caracterizadas como de 'tradição oral', praticamente toda elocução é um gênero, identificável e passível de interpretação pelos membros daquelas culturas (Monod-Becquelin, 2005: 36). Decorre daí que, formalmente, não haveria como desvincular as formas expressivas das mensagens, 'conteúdos' veiculados através daquelas formas. Mensagens, propagadas (e transformadas)

\footnotetext{
${ }^{8}$ Ou seja, se continuam a serem 'empregados' na cadeia de transmissão, e de que formas. Bruno Latour (1994) utilizou o termo 'proliferação' ao tratar de 'híbridos'. Meu interesse é na 'multiplicação' ou 'reprodução' de atos de fala, tradições orais e conhecimentos que têm o registro como intermediário de transmissão. Segundo o Dicionário Michaelis da língua portuguesa:

Proliferação: 1 Ato, processo ou resultado de proliferar. 2 Produção rápida e repetida de partes novas, de botões ou de prole. 3 Reprodução ou multiplicação por divisão ou ramificação. 4 Fisiol Reprodução ou multiplicação de formas semelhantes, especialmente a de certas células e cistos mórbidos. 5 Anat Divisão de um elemento em um ou vários outros. 6 Bot Aparecimento de um botão de flor numa parte da planta que comumente não produz botões. 7 Multiplicação, reprodução.

${ }^{9}$ Como no desenvolvimento do 'pensamento científico' e na escrita da História.
} 
através de enunciados, adquirem sentido também e necessariamente pelo fato de serem expressos segundo formas, contextos e em interações sociais precisas.

Jan Vansina, trabalhando no âmbito de estudos da 'história oral', classificou oral messages, - conteúdos veiculados através de narrativas e enunciados dentre populações de 'tradição oral'-, segundo duas categorias. Estas seriam novidades ou interpretações. No caso de novidades, estas seriam transmitidas ou por um narradortestemunha ocular (eyewitness), ou trariam em si índices que remetem ao indivíduo que Ihe transmitiu a mensagem (hear say). No caso de consistirem em interpretações, seria o próprio narrador o produtor original daquela mensagem (Vansina, 1984: 3-4). Assim, para além de enunciados pertencerem a um ou outro gênero da tradição oral, aqueles índices, internos ao corpo das mensagens, participam também ao indicarem à audiência ou aos interlocutores os modos corretos de entendimento ou interpretação daquilo que é dito.

O termo problemático de 'tradição oral' é, sobretudo, o de 'tradição', já que essa noção implica uma idéia de perenidade ${ }^{10}$, enquanto a característica principal da oralidade é sua existência em contexto. Palavras 'voam'; quando ditas, duram o tempo do som que se dissipa com o ar.

Enunciados orais e os conteúdos assim veiculados são produzidos e transmitidos face às circunstâncias, aos atores em jogo e aos entendimentos e intenções dos atores no momento presente de sua enunciação (Bakhtin, 2006:127). Ou seja, produzidas em contexto, peças da 'tradição oral' nunca são as mesmas. Mas 'tradições orais' referemse também aos modos e gêneros tidos como adequados pelos atores no emprego da parole em relação às interações sociais que implicam ou propiciam, aos estatutos de seus participantes, aos contextos e espaços adequados de sua manifestação, a formas estéticas valorizadas. Desse modo, 'tradições orais, 'mutantes' que são, não deixam de estar ao mesmo tempo sob o crivo do julgamento de seus atores quanto à sua 'adequação'.

A opção pelos termos 'tradição oral' e 'conhecimentos' nesta pesquisa não é fortuita. Primeiramente por serem estas as expressões formalmente empregadas no texto da 'Convenção para a Salvaguarda do Patrimônio Imaterial'11. Em segundo lugar, pelo fato de meu interesse ter se voltado para as caracterizações específicas que vieram definir aqueles conceitos. Assim, se 'tradições orais' referem-se às 'convenções mais

\footnotetext{
${ }^{10}$ Lenclud (in Detienne, 1994: 25) já havia feito esta distinção: o primeiro sentido da noção de tradição, enquanto 'antiguidade', ou 'perenidade' de um passado, ou seja, seu uso enquanto um mot-outil é exatamente o que a tradição não é. Retenho, para fins de minha análise, a proposição geral de Lenclud: "que la tradition n'existe que proclamé est une chose, que le mécanisme de la proclamation suffise à l'instituer en est une chose autre" (1994:35).

${ }^{11}$ Que irei apresentar e discutir no próximo capítulo.
} 
formalizadas e recorrentes relacionadas à expressão verbal', se aplicando 'às interações sociais fundamentais' 'em seu contexto cultural', foram essas as mesmas características que busquei trazer ao debate, nas relações entre enunciados conforme caracterizados segundo contextos 'originais' de ocorrência ${ }^{12}$ e enunciados registrados.

Em minha abordagem, discuti a noção de 'conhecimento' através de uma reflexão crítica a respeito dos modos como 'conhecimentos tradicionais' foram avaliados em relação aos chamados 'conhecimentos científicos'.

Minha opção foi pela adoção do termo 'conhecimento', no singular, de modo a estabelecer um contraste com definições que vêm adjetivar 'conhecimentos'. Tendo em vista a característica necessariamente dinâmica de sistemas de conhecimento, emprego aqui a expressão 'formas de conhecer', cuja ênfase é menos em relação à antiguidade ou às características dos conteúdos veiculados do que aos modos como tais conhecimentos são localmente adquiridos e usados (Carneiro da Cunha e Almeida, 2002:24). Nesse sentido, busquei voltar minha atenção, em especial, para características próprias a tradições orais e aos modos como tais populações agem e reagem em relação a iniciativas e produtos do registro de seus 'conhecimentos' e 'tradições orais'. Minha hipótese é a de que tal diálogo pode vir informar, tanto quanto possível, modos considerados adequados por tais populações no que diz respeito à aquisição, à transmissão e ao enunciado de 'conhecimentos' em contextos específicos ${ }^{13}$.

No segundo capítulo desta dissertação procedo à revisão de uma bibliografia de referência acerca de metodologias, abordagens e termos adotados nos estudos de 'tradição oral' e 'oralidade'.

Segundo Jan Vansina, "oral tradition applies both to a process and to its products. The products are oral messages based on previous oral messages. The process is the transmission of such messages by word of mouth over time, until the disappearance of the message" (Vansina, 1984:3).

Propostas recentes de valorização e salvaguarda culturais propõem que 'tradições orais' sejam registradas ${ }^{14}$, visando incrementar sua viabilidade e, portanto, a

\footnotetext{
${ }^{12}$ Conforme caracterizados e analisados pelos autores a quem deverei recorrer em minha análise.

${ }^{13}$ Ou o quanto tradições orais podem informar lógicas e epistemes específicas?

${ }^{14}$ Contudo, o que é propriamente caracterizado como a etapa de 'registro' no que diz respeito às políticas públicas do patrimônio imaterial concerne uma descrição inicial, que vem caracterizar o bem cultural, significados e valores a ele atribuídos, formas e contextos de ocorrência, assim como 'seu suporte humano', que pode variar desde 'comunidades' a 'grupos' a 'indivíduos'. Tais elementos, após serem avaliados quanto à adequação aos critérios adotados por aquela política (relevância para a 'identidade nacional', ter sido transmitido oralmente ou através da prática, por mais de três gerações, ser reconhecido como tal por seus agentes, com seu o expresso consentimento e, desejavelmente, participação da comunidade) vêm receber o título oficial de 'patrimônio imaterial' nacional e sua inscrição no livro de registros do Iphan (para o caso barsileiro). Este não concerne o mesmo 'registro' que enfoquei nessa pesquisa. Aqui, o registro foi considerado na etapa subseqüente daquelas ações do patrimônio, enquanto medida de salvaguarda voltada à sua viabilidade e à manutenção dos contextos que tornam possível sua transmissão. No entanto, alguns elementos desse primeiro 'registro', assim como aqueles critérios serão também eles debatidos quando de
} 
continuidade de sua transmissão. Tais propostas parecem sugerir que 'tradições orais' também sejam passíveis de serem transmitidas através de novas mídias ou meios, não orais $^{15}$.

Considerando tais ações de documentação de 'tradições orais', me questionava o quanto tais procedimentos e produtos de ações de registro dariam conta de processos culturais reconhecidamente dinâmicos, e não somente de seus conteúdos. Pois ao serem desvinculados dos contextos, dos interlocutores e das relações originais que pautaram sua produção, tais 'produtos' não correriam o risco de adquirirem novos estatutos, tornando-se artefatos culturais homogeneizados, supostos exemplares de certa 'tradição'? E segundo que pontos de vista?

Partindo das revisões recentes do conceito de 'cultura', me questionava de que maneira ações de salvaguarda e valorização culturais pautadas no registro poderiam privilegiar, para além de 'informações' ou 'teores', dinâmicas culturais responsáveis pela contínua produção de conteúdos que se transformam, mantendo-se, porém, fiéis aos valores que informam formas de produção e transmissão de conhecimentos específicos.

Assim, esta pesquisa se propôs estabelecer um diálogo entre características próprias a tradições orais, e descrições de situações e eventos de registro de 'conhecimentos' e 'tradições orais', seus procedimentos e produtos, em relação a dois grupos culturais: Xavante, habitando o Brasil Central, e Kanak, habitando as Ilhas da Nova Caledônia, na Melanésia. Após a apresentação e reflexão desses dois casos, muito distintos entre si, visei uma reflexão a partir do levantamento de questões conjugadas, concernindo uma variedade de 'efeitos' das ações de registros junto às populações a que dizem respeito. Chamei 'transformação dirigida da oralidade' experiências de registro e de documentação de enunciados orais pautados por 'projetos'

Conhecimentos e tradições orais são, devido ao fato de seu registro, passíveis de serem extraídos de seus contextos e audiências originais, deslocados e recontextualizados, ocupando novos espaços, engajando novos atores e produzindo efeitos imprevistos.

Partindo do pressuposto $^{16}$ de que tais propostas e experiências julgam que procedimentos e produtos do registro podem produzir situações e efeitos de salvaguarda e valorização, essa pesquisa se interessou:

1. Pelas lógicas locais que regem os sentidos da produção, reprodução e transmissão de enunciados: caracterizações relativas à gêneros da tradição oral e às formas

algumas reflexões dessa pesquisa. Ressalto ainda que os casos enfocados nesta pesquisa não estiveram sujeitos à ações oficiais das políticas do patrimônio imaterial. Meu enfoque foi, antes, o olhar atento a respeito de 'casos', cujas configurações mostraram-se 'boas para pensar' acerca daquelas políticas de salvaguarda e valorização pautadas em registros de 'tradições orais'.

${ }^{15}$ Esses termos e questões deverão ser melhor discutidos adiante.

${ }^{16}$ A ser debatido nesta pesquisa. 
próprias e localmente valorizadas de produção de enunciados orais em contexto ${ }^{17}$ entre populações de 'tradição oral', e, especificamente, entre Xavante e Kanak, os 'grupos' culturais de que trata esta análise;

2. Por eventos de produção de registros de 'tradições orais' e 'conhecimentos' relativos à Kanak e Xavante: caracterizações acerca de quando registros foram realizados, por quem, em que circunstâncias, segundo quais propostas e que procedimentos, quem foram seus atores, e que efeitos foram descritos como decorrentes da própria situação ou ato de registro.

3. Pelos efeitos daqueles registros, a posteriori: deslocamentos de contexto e transformações a que tais enunciados estão sujeitos, possibilitados por sua 'fixação' em suportes que garantem sua perenidade e, conseqüentemente, pela possibilidade de serem reapropriados e recriados (ou rechaçados) por novos sujeitos em novos contextos, distintos dos de sua produção (em especial pelos 'grupos culturais' a que dizem respeito, mas também por 'outros').

4. Por conexões que poderão ser sugeridas entre formas próprias à 'tradições orais', e propostas e procedimentos de registro, seus produtos e efeitos. Nesse sentido me proponho pensar, também, de que forma iniciativas 'interculturais' agem e produzem efeitos segundo lógicas e formas de criatividade próprias àqueles grupos, em cada caso $^{18}$.

Em relação ao emprego do termo 'efeitos', não busquei com isso sugerir a existência de explicações definitivas ou únicas, nem de relações lineares de causa e conseqüência entre fenômenos. Segundo Marilyn Strathern, "we must pause over what is meant by 'explanation' to realize that there are different types of explanation, of which causal connection is only one. Between different logical forms, any fit is bound to appear partial" (Strathern, 2004:107).

Edgar Morin afirmou também que "jamais il ne faut appréhender les phénomènes en termes de causalité lineaire, tout l'acte rejaillit sur les conditions qui l'ont produit » (Morin, 2008 : 34). Se busquei estabelecer um diálogo entre 'tradições orais' e seus registros, não ignoro que, da mesma forma que eventos e relações em contexto (os imponderáveis da experiência) imprimem sua marca nos registros, o fato da produção de registros, de haver alguém por trás desta produção (alguém que anota, que segura o gravador, que pergunta) imprime também sua marca no contexto imediato e no resultado final, naquele 'produto'. Assim, 'efeitos' aqui se referiram conexões parciais ou

\footnotetext{
${ }^{17}$ Quem fala? Para quem se fala? Sobre o quê se fala? Como se fala? Quando se fala? Sobre o quê não se fala e porquê?

${ }^{18}$ Meu interesse em avaliar "transformação dirigida da oralidade" na forma de 'projetos interculturais', decorre da caracterização adotada por Carneiro da Cunha quando afirmou que 'projetos' "should be understood as any combination of cultural, political or economic endeavors that rely on external agents as well as the indigenous population" (2004:6), isto é, se constituem em esforços que seriam regidos por uma lógica de "cultura". Para a autora, a cultura sem aspas seria aquela para a qual sempre estiveram voltados os antropólogos, e cujos aspectos analíticos são inconscientes para seus praticantes. Já "cultura" remeteria às esferas conscientes que os grupos usariam para enunciar seus conhecimentos e suas formas próprias de vida, seu 'patrimônio cultural'. Irei debater melhor este ponto adiante.
} 
rizomas, evidências decorrentes de certo ponto de vista e das questões que foram colocadas por mim ${ }^{19}$.

Um dos objetivos da pesquisa foi o da descrição e interpretação a respeito dos modos como grupos indígenas demandam, reconhecem ou rejeitam como parte de seu 'patrimônio' cultural, produtos de 'transformações dirigidas da oralidade', mas que foram produzidos em contextos anteriores e/ou por 'outros', ou seja, foram produzidos por razões 'outras', não tendo em vista a documentação de 'patrimônios'. De que modo tradições orais registradas podem vir a ser concebidas como 'patrimônio' e, desse modo, serem 'constantemente recriadas pelas próprias comunidades ${ }^{20}$ ?

Visei com isso iluminar formas próprias e inovadoras de utilização e interpretação de procedimentos e produtos de registros que, caso tenham sido produzidos por 'outros', foram apreendidos ou rejeitados segundo formas específicas e localmente 'adequadas'. Interessaram-me essas novas configurações: debates acerca de legitimidade, mudanças em seus conteúdos e em suas formas, novas situações de transmissão, novos atores, novos usos, novos (e)feitos da parole, formas de criatividade imprevistas.

Claro está que tais situações e relações são extremamente complexas, envolvendo fatores múltiplos, não estando sujeitas a relações lineares de nexo causal. Por isso, pretendi aqui seguir os trajetos de tais registros, desde sua produção, deslocamentos e transformações, e tanto quanto possível, elaborar conexões entre partes de informações, sugerindo relações.

\section{Resumo dos Capítulos}

Esta pesquisa de mestrado foi desenvolvida em torno de dois pólos, e de conexões ou rizomas entre eles. De um lado, formas próprias à oralidade e às tradições orais de populações indígenas; de outro lado, eventos, procedimentos, produtos e efeitos do registro de tradições orais e conhecimentos dessas mesmas populações.

Organizei esta dissertação em seis blocos. $\mathrm{Na}$ presente introdução realizei uma apresentação geral da pesquisa, de suas principais questões e orientações teóricometodológicas.

No primeiro capítulo, subseqüente a esta introdução, procedi à apresentação dos atuais instrumentos voltados à salvaguarda e à valorização de patrimônios imateriais, assim como às questões que, provenientes dessas novas iniciativas, vieram pautar essa pesquisa. Ali, discuti temas relevantes como 'patrimônio', 'tradição' e 'conhecimento', assim como modos como experiências de registro operadas por parte de etnólogos em campo poderiam dar a ver formas de abordagem daquelas iniciativas atuais de

\footnotetext{
${ }^{19}$ Ver orientações teórico-metodológicas, adiante.

20 Segundo as formas processuais do patrimônio imaterial, na definição adotada pela Unesco, como veremos adiante.
} 
valorização. Também me propus uma reflexão acerca das transformações e empréstimos atuais de práticas (como a etnografia) e conceitos (como o de 'cultura') que, se foram considerados próprios à antropologia, hoje são aplicados em contextos expandidos, em outras áreas e para novos propósitos.

No segundo capítulo realizei uma revisão de uma bibliografia de referência sobre estudos de oralidade. Se minha pesquisa partiu de uma inspiração e questões próprias à antropologia, nessa revisão dialoguei com outras áreas do conhecimento como a lingüística e o folclore. Meu intuito foi o de esboçar um panorama das principais caracterizações, idéias e debates no interior dessa ampla área de pesquisas que é a 'oralidade'. Também apresentei naquele capítulo os argumentos que informaram a abordagem a respeito da 'linguagem' e da oralidade aqui adotados.

Em meu terceiro e quarto capítulos realizei a descrição dos eventos e situações que compõem o foco deste trabalho, eventos de registro da oralidade relativos a dois grupos culturais: Xavante, habitando o Brasil Central; e Kanak, habitando as ilhas da Nova Caledônia, na Melanésia. Para abordar aquelas experiências recorri às ricas descrições das formas, conteúdos e contextos relacionais concernentes às tradições orais daquelas populações através dos trabalhos de antropólogos e lingüistas que se debruçaram especialmente sobre essas questões junto àqueles mesmos grupos.

Ressalto ser essa uma pesquisa bibliográfica e documental. Em todos os momentos minha análise se apoiou em descrições e resultados de outros pesquisadores, especialmente da área da antropologia. Também me esforcei em trazer para este diálogo experiências de 'transformação dirigida da oralidade' pautadas por 'projetos'21, como a Revista Mwà Véé (para o 'caso' Kanak) e o livro de leitura Wamreme Za'ra (para o 'caso' Xavante). Foram excluídas desta análise experiências voltadas especificamente à produção de materiais para uso em escolas indígenas ${ }^{22}$.

Em seguida, em minha coclusão, propus um debate entre questões levantadas nos capítulos precedentes, questões estas que 'perpassaram' os casos Kanak e Xavante.

Meu objetivo, ao longo de toda a dissertação e em especial em meu capítulo final, foi o levantamento de questões relevantes para uma reflexão crítica a respeito de tais experiências e propostas de 'valorização cultural' e salvaguarda de patrimônios imateriais de populações indígenas pautadas no registro de 'tradições orais' e conhecimentos.

\footnotetext{
${ }^{21}$ Alguns desses 'projetos' estão imbricados ou atrelados, de alguma forma, à pesquisas teóricas. Tais redes de conexão serão descritas e debatidas nesta pesquisa.

${ }^{22}$ Este princípio se baseou na relevância e na crescente proliferação de experiências ditas de "valorização cultural" que se dão em contextos extra-escolares, tão relevantes quanto às voltadas para a produção de materiais didáticos, pedagógicos ou educativos, e, no entanto, ainda pouco trabalhadas, se comparadas à atual produção relativa à temática escolar indígena.
} 


\section{Orientações teórico-metodológicas}

Esta pesquisa não buscou estabelecer comparações entre dados etnográficos. A proposta foi, antes, estabelecer comparações a partir de questões, provenientes de relações internas aos materiais relativos a cada 'caso', Xavante e Kanak, a respeito de formas, conteúdos e relações implicadas em 'tradições orais', de um lado, e procedimentos de produção registros e seus efeitos, de outro lado.

Optei por organizar a apresentação daqueles 'casos' em torno de 'grupos culturais', informados aqui, especificamente, pelo fato de compartilharem 'tradições orais'. A questão sobre se o compartilhamento de 'tradições orais' pode informar a constituição de 'coletivos' (estabilizados) foi um dos principais temas debatidos na pesquisa. Os modos de organização dos debates internos a cada capítulo foi realizado no sentido do levantamento de 'questões' ${ }^{\prime 23}$, que se delineiam através do diálogo entre os materiais selecionados para cada 'caso'.

As noções de 'proliferação', 'rechaço' e 'interrupção' me pareceram produtivas para o tratamento conjunto daqueles dois casos, de modo a se referirem a maneiras como registros foram ou não recuperados na cadeia de transmissão de conhecimentos, e de que modos. A reflexão acerca daqueles eventos se pautou a partir do que, para mim, constituíram-se similitudes. Isso porque, como veremos, as questões que emergem neste debate podem ser similares, mesmo que os grupos e as características culturais próprias a cada um sejam dissemelhantes entre si.

Sucedendo à proposta de Radcliffe-Brown de que "without systematic comparative studies, anthropology will become only historiography and ethnography" (1958:16), a obra coletiva "Gender in Amazônia and Melanesia: an exploration of the comparative method', (Gregor e Tuzin:2001) foi um das primeiras a debater questões e estabelecer comparações entre povos indígenas da Melanésia e da Amazônia, a partir da temática de 'gênero'. Ao abordar seus materiais a partir de 'questões' que perpassam áreas etnográficas, os autores propuseram que a possibilidade de estabelecer comparações depende de descrições minuciosas, já que toda antropologia é e sempre foi, por excelência, comparativa: "describing stimulates new perspectives of findings from particular cultures" (2001:11). Através de descrições, tais autores buscaram identificar relações similares, mesmo que as 'coisas' relacionadas fossem distintas entre si: "relations between things may be similar, even if the things themselves are not" (2001:12). Marcel Detienne (2000) adotou uma perspectiva semelhante, ao afirmar que comparáveis, a serem construídos pelo analista, são possíveis de serem elaborados na medida em que os dados, de qualquer tempo ou lugar, sejam submetidos a uma mesma pergunta.

\footnotetext{
${ }^{23}$ A banca de meu exame de qualificação sugeriu que eu organizasse esses capítulos de forma a 'atravessar' grupos, já a partir das 'questões'. A problemática dessa apresentação era de que as questões apareceriam como um a priori. Em segundo lugar, porque as questões para minha análise deveriam ser extraídas antes de comparações internas entre os materiais concernindo cada 'grupo cultural', entre 'formas da tradição oral' e experiências de registro a que estiveram sujeitos, para em outro momento, operar conexões entre os dois casos.
} 
Os filósofos Gilles Deleuze e Félix Guattari, em "Mil Platôs" (2006), inauguraram a figura do 'rizoma' em oposição à da 'arvore-raiz', enquanto um modo não hierárquico, múltiplo, não binário e nem dicotômico de abordagem de fenômenos em relação, ao substituir conexões de causa-consequência por nexos "planos" e semióticos de toda natureza, em que sujeitos e objetos de ordens e escalas diversas, heterogêneos, 'fazem rizoma', ou seja, ligam-se entre si por algum ponto qualquer não préestabelecido. Segundo tais autores "um método de tipo rizoma é obrigado a analisar a linguagem efetuando um descentramento sobre outras dimensões e outros registros" (2006:16). É neste sentido de 'rizoma' que busquei estabelecer relações entre formas de produção de registros e modos de 'proliferação' ou 'interrupção' para cada um dos grupos tratados, tendo em vista aspectos relevantes de suas 'tradições orais'. Desse modo, questões foram levantadas aqui e ali, conforme relações, ou rizomas, iam sendo vislumbrados.

Franz Boas, em seu artigo "The limitations of the comparative method in anthropology" (1896) foi pioneiro ao estabelecer a crítica em relação à tese comumente aceita pelo humanismo iluminista e pelo evolucionismo, de que concepções acerca de causalidades e classificações constituíam-se bases sólidas ou pertinentes para o método comparativo. Tal pressuposto evolucionista apoiava-se na máxima de que "causas semelhantes possuem efeitos semelhantes". Segundo Boas, fenômenos similares poderiam surgir de processos dissimilares. Contudo este autor não se opunha ao método comparativo em si, mas aos seus pressupostos e limitações. Para Boas, sem um delineamento claro dos processos subjacentes e sem o conhecimento aprofundado de particularidades culturais e históricas, a comparação entre culturas seria impossível.

Minha própria metodologia concerniu dois momentos distintos. Durante o tratamento dos materiais internamente a cada caso, guiei-me pelas mesmas perguntas, o que possibilitou a construção de comparáveis entre os dois casos. Em um segundo momento, esforcei-me por cotejar e debater conjuntamente e entre si as questões levantadas internamente ao "caso" Xavante e ao "caso" Kanak. Assim, durante este percurso, me interessaram tanto similitudes quanto diferenças. Meu interesse, desse modo, convergiu com Tuzin e Gregor (2001) no sentido da investigação de relações, que podem ser similares sem que os eventos ou fenômenos relacionados sejam necessariamente semelhantes ${ }^{24}$.

\footnotetext{
${ }^{24}$ Ao mesmo tempo me pergunto se não haveria meios deliberadamente indígenas de suportes de memória, que poderiam corresponder ao que consideramos 'registros' ou 'documentos'.
} 


\section{Capítulo 1}

Patrimônio, cultura, tradição

\subsection{Sobre a noção de patrimônio}

O campo do patrimônio tem se tornado um objeto privilegiado de pesquisas no âmbito da antropologia ${ }^{25}$. Estudiosos já se dedicaram a iluminar os modos como a patrimonialização consistiu em um processo histórico, - cuja origem remonta à constituição dos Estados modernos na Europa do século XVIII-, pautado nos imperativos ideológicos de produção, via seleção e preservação de certos prestígios do passado, de uma memória coletiva e de noções de identidade e pertencimento a uma 'comunidade de cultura' (Babadzan: 2001).

Naquele contexto, a noção de cultura era associada ao progresso da humanidade e ao 'refinamento, ${ }^{, 26}$ cultural, vislumbrados nos desenvolvimentos das ciências, das artes e da tecnologia tal como vinham ocorrendo nos principais centros da civilização ocidental. Desse modo, Nações modernas buscaram identificar como constituintes de seu 'patrimônio' os maiores exemplos de 'civilização', - ciências, artes e técnicasencontradas em seus territórios. Assim, os 'bens' sujeitos à patrimonialização foram 'grandes obras', monumentos artísticos e construções valorizadas por suas características estéticas e de 'excepcionalidade', representativos das trajetórias históricas de suas elites nacionais.

O romantismo alemão de fins do século XVIII virá questionar a noção de cultura enquanto 'refinamento' pautado no fundamento da razão segundo valores da filosofia das Luzes, para um foco em noções de legitimidade e autenticidade, sentimento e experiência, a serem encontrados justamente entre populações rurais ou dentre os mais antigos ocupantes 'originais' de seus territórios. Assim, o romantismo será o precursor de um 'retorno às origens', ao inspirar-se em,- e assim fundar-, um 'patrimônio' representativo de uma Volkgeist' ${ }^{77}$, através da compilação de textos herdados de uma tradição oral 'ancestral', vindo assim prover materiais necessários à origem e desenvolvimento dos estudos de folclore ${ }^{28}$.

\footnotetext{
${ }^{25}$ No Brasil, no âmbito da Associação Brasileira de Antropologia, foi recentemente criado o Grupo de Trabalho "Patrimônio Cultural', em 2006.

${ }^{26} \mathrm{~A}$ antropologia enquanto disciplina havendo sido instituída a posteriori, e tendo tomado de empréstimo a noção de 'cultura' dos empregos correntes que eram dela feitos, essa noção de 'refinamento' em seu sentido 'aristocrático' e elitista foi o primeiro dos paradigmas que veio orientar as produções teóricas da disciplina. Nesse sentido, se a 'cultura' era associada à civilização ocidental, populações que não participavam desta 'cultura do refinamento' cultural, em estreita associação ao desenvolvimento das ciências, das artes e da tecnologia, foram vistas como ocupando estágios de civilização anteriores, mas que necessariamente culminariam, através da evolução e do progresso histórico, em nossa 'civilização'.

${ }^{27} \mathrm{O}$ romantismo alemão também surgiu enquanto uma crítica à uma filosofia da Luzes pautada na noção do indivíduo racional para uma inclusão de noções como de 'sentimento' e 'experiência', de um 'eu' subjetivo, dotado de uma 'verdade interior'.

${ }^{28} \mathrm{O}$ assim os estudos de folclore, em sua origem, interessaram-se por vestígios do passado na forma de textos, desvinculados de fenômenos culturais 'vivos'.
} 
'Cultura', até então associada ao refinamento 'humano', passa ser identificada aos valores de 'autenticidade' e 'legitimidade' a serem buscados no passado, de modo que 'traços' culturais tidos como 'importados', assim como transformações consideradas recentes eram vistos como 'corrupções' de uma suposta pureza cultural 'original' (Babadzan: 2001).

$\mathrm{Na}$ Europa, populações rurais e 'tradicionais' só vieram a ser reconhecidas como também produtoras de 'patrimônios' dignos de serem alçados a símbolos nacionais quando da necessidade de justificar aqueles valores de 'legitimidade' e 'autenticidade'. Tal processo alinhou-se também à necessidade de expansão da esfera de representação dos Estados, segundo os imperativos de associação entre identidades políticas e identidades culturais, para abranger todos os grupos culturais habitando seu espaço geográfico.

Dessa maneira o 'patrimônio cultural', em sua origem, concerniu uma seleção de traços característicos de um 'passado' a ser vangloriado, através de procedimentos de atribuição de valor no âmbito da esfera pública, inerente às trajetórias de formação e transformação das nações contemporâneas e das relações internacionais. A atribuição de valor patrimonial a determinado artefato ou prática cultural, tendo se fundamentado no conhecimento acadêmico, variou também de acordo com transformações históricas ${ }^{29}$, obedecendo aos preceitos jurídicos e administrativos específicos a cada época, tendo em vista o interesse público.

Alguns autores que discutiram a patrimonialização segundo esta esfera de ação do Estado ressaltam que o patrimônio não deve ser confundido com o que é caracterizado, - ainda na esfera do patrimônio-, como 'costume'. Isso porque enquanto a patrimonialização produziria um efeito conservador a posteriori, ao oficializar ritos e símbolos como nacionais, como representativos de uma identidade mais ampla distinta da de sua origem, 'costumes' estariam sujeitos a valores e representações em esfera local, atribuídos a lugares, práticas e saberes, constantemente recriados segundo trajetórias históricas e processos de troca nos quais se engajam e se engajaram atores e coletivos de tais populações (Hobsbawm e Ranger, 1984; Arantes, 2007).

Para o campo de estudos desta pesquisa, outro histórico também se impõe. Podemos situar aqui a criação da Organização das Nações Unidas ${ }^{30}$ e a 'Declaração Universal dos Direitos Humanos' em 1948, no seio de uma Europa do pós-guerra, com vistas a

\footnotetext{
${ }^{29}$ Podemos citar, no caso brasileiro, a rejeição ao anteprojeto para o Serviço do Patrimônio Histórico e Artístico Nacional elaborado por Mario de Andrade em 1937. A inclusão de um viés mais artístico e antropológico por ele proposto foi considerado 'avançado demais' para uma época em que o patrimônio era considerado indissociável da cultura material e das noções de belo, grandioso, excepcional e perene (Sant'anna, 2008: 4).

${ }^{30}$ A Organização das Nações Unidas é uma instituição internacional formada por 192 Estados soberanos, fundada após a $2^{\text {a }}$ Guerra Mundial para manter a paz e a segurança no mundo, fomentar relações cordiais entre as nações, promover progresso social, melhores padrões de vida e direitos humanos. Os membros são unidos em torno da Carta da ONU, um tratado internacional que enuncia os direitos e deveres dos membros da comunidade internacional.
} 
estabelecer mecanismos a serem acordados por todos os países para a mediação e a intervenção em conflitos e a promoção da paz. Uma de suas subsidiárias, a Unesco, teve e têm tido um papel relevante ao buscar lançar luz e intervir, tanto quanto possível, nos processos relacionados ao reconhecimento de direitos políticos de populações indígenas e minorias étnicas, sujeitas a que estiveram aos efeitos nefastos da colonização e durante muito tempo excluídas das arenas políticas de seus países, segundo o duradouro ponto de vista de uma suposta 'primitividade'.

Neste histórico, ressaltamos a importância da 'Recomendação sobre populações indígenas e tribais' de 1957, e a Convenção 169 da Organização Internacional do Trabalho, sobre 'povos indígenas e tribais em países independentes', voltadas à proteção dos direitos daqueles povos e à garantia de sua integridade enquanto 'povos'. Nesta paisagem, saliente foi 0 fato de que, com o apoio de tais organismos representativos das Nações Unidas, aquelas populações tanto foram chamadas quanto gradativamente impuseram sua participação nos domínios da esfera pública de seus países $^{31}$. Daí que seu reconhecimento político, assim como a necessidade dos Estados em nomear seus atores, passou pela constituição de identidades étnicas atreladas ao imperativo da sua enunciação enquanto identidades propriamente indígenas ou autóctones, portadoras de 'culturas' específicas ${ }^{32}$.

Estes movimentos recentes acompanharam o histórico de transformações do conceito de 'cultura' no âmbito da antropologia, assim como sua associação à 'identidades' (étnicas). A crítica ao evolucionismo e à noção de cultura enquanto 'refinamento' veio produzir uma 'democratização' daquela noção, com o advento do relativismo cultural. Cultura passa a significar tanto a singularidade humana quanto a diversidade das formas que poderiam assumir o 'fenômeno humano', de modo que culturas seriam diferenciadas, mas equivalentes, enquanto amostras de um mesmo 'fenômeno'. Entretanto, se em meados do século XX uma antropologia social britânica virá se interessar pelas variedades do fenômeno da cultura segundo uma noção de sistema, de partes articuladas entre si segundo uma lógica própria, a antropologia cultural norte americana virá conceber cultura como 'conjuntos de traços', que poderiam ser perdidos ou tomados de empréstimo de populações vizinhas. A 'cultura' passando a ser vista como algo que pode vir a ser 'perdido', 'minorias culturais' foram vistas como estando sujeitas a processos de 'aculturação'.

As críticas subseqüentes virão se focar sobre essa concepção reificada de cultura, segundo aquela idéia de 'traços' que podem ser perdidos, para vir atentar antes para as

\footnotetext{
${ }^{31}$ No Brasil dos anos 70, líderes indígenas e as primeiras organizações desses povos exerceram forte pressão sobre a política indigenista oficial, contestando a tutela exercida pelo Estado em função de suas supostas incapacidades e 'primitividade', que veio resultar nas mudanças, ainda que parciais, presentes na Constituição de 1988. Quanto aos Kanak, cujo caso será discutido adiante, o apoio dos instrumentos da ONU foi de fundamental importância na derrocada de sua luta independentista pela "Kanaky".

32 Dado que "a consciência de sua identidade indígena ou tribal deverá ser considerada como critério fundamental para determinar os grupos aos que se aplicam as disposições da presente Convenção" (Convenção 169, OIT, art. $1^{\circ}$ parágrafo 2).
} 
'fronteiras' que delimitariam 'culturas' (Barth, 1969). Temos assim o advento de uma noção em que culturas são vistas como entidades dinâmicas, transformando-se ao mesmo tempo em que se distinguem umas das outras através de traços diacríticos que delimitariam seus limites. Seria a consciência quanto a tais diferenças ou traços diacríticos que estaria na base da constituição de identidades étnicas, formuladas segundo sua diferenciação em relação a outras identidades (Carneiro da Cunha, 1986). Nesse sentido, coube também à antropologia de meados da década de 50 a associação entre 'formas de vida' e 'fonte de identidade', reiterando o advento da noção de 'identidades étnicas' (Strathern, 1995).

$\mathrm{Na}$ arena da política internacional das décadas seguintes, com a desintegração e redistribuição do poder colonial nos anos 60 e 70, temos também o advento dos 'estudos culturais', de caráter eminentemente político, que produziam estudos associados à reivindicações pautadas no reconhecimento político e nos direitos de minorias (também, mas não somente étnicas) à igualdade e à 'identidades culturais' diferenciadas.

No âmbito da Unesco, aqueles primeiros mecanismos voltados ao reconhecimento de direitos políticos de igualdade e de cidadania aos 'povos indígenas e tribais' passam a advogar também pelo respeito à "sua identidade social e cultural, aos seus costumes e tradições, e às suas instituições, 33 , que vêm então receber maior atenção no âmbito de Recomendações e Convenções subseqüentes daquela instância supranacional.

Podemos citar aqui a Convenção para a Salvaguarda do Patrimônio Mundial, Cultural e Natural, de $1972^{34}$, e a 'Recomendação sobre a Salvaguarda da Cultura Popular e Tradicional, de $1989^{35}$.

A Convenção para a Salvaguarda do Patrimônio Imaterial ${ }^{36}$ de 2003,- o qual discutirei adiante-, incorporou as críticas e revisões a que esteve sujeita esta última recomendação pela parte de peritos de diversos países, representantes de governos e antropólogos.

\footnotetext{
${ }^{33}$ Convenção 169 OIT, art. $2^{\circ}$ parágrafo $2 b$.

${ }^{34}$ Que ao ter sua atenção voltada a bens de natureza material desencadeou, por parte de alguns Estados membros liderados pela Bolívia, as primeiras demandas no sentido de um reconhecimento do 'patrimônio cultural imaterial' (Londres, 2008).

${ }^{35}$ Nesta última, a cultura popular e tradicional foi definida como: "o conjunto de criações que emanam de uma comunidade cultural e são fundadas na tradição, expressas por um grupo ou por indivíduos e reconhecidas porque atendem às expectativas da comunidade enquanto expressão da identidade cultural e social, das normas e dos valores que se transmitem oralmente, por imitação ou outros modos. Suas formas de expressão compreendem, entre outros: a língua, a literatura, a música, a dança, os jogos, a mitologia, os ritos, os costumes, o artesanato, a arquitetura e outras artes".

${ }^{36}$ Que precedeu a Proclamação das Obras-Primas do Patrimônio Oral e Imaterial da Humanidade, em três edições (em 2001, 2003 e 2005), que se limitava a distinções honoríficas reconhecidas à expressões do patrimônio imaterial representativos de Estados Nacionais, que procediam, internamente, à seleção prévia de dossiês e planos de salvaguarda, que eram então submetidos à análise e seleção pela Unesco.
} 
Dentre tais críticas $^{37}$, citamos a de seu caráter compartimentalizado, ao buscar identificar aspectos ou elementos isolados de culturas. Também ao fato de que 'cultura' era aqui identificada como "criações que emanam de comunidades culturais e são fundadas na tradição". Já vimos como, internamente à antropologia, revisões recentes do conceito de 'cultura' já apontavam para a preponderância de se considerarem, antes, processos criativos e dinâmicos através dos quais populações atualizam e recriam constantemente saberes e práticas, em detrimento da preservação de 'produtos' ou 'traços', elementos 'tradicionais' de um suposto passado ${ }^{38}$. Por fim, no que diz respeito à 'salvaguarda', entendida aqui ainda como 'preservação', aquela Recomendação de 1989 se pautava pela relevância de ações de documentação e pesquisa a serem realizadas por parte de pesquisadores e agentes do poder público, em que os sujeitos locais encontravam-se excluídos desses processos. Na Convenção de 2003 este ponto foi reformulado com vistas a incluir o reconhecimento do papel crucial das 'comunidades' portadoras e transmissoras das tradições e expressões para sua efetiva viabilidade, de modo que atualmente tais populações são chamadas à ação como agentes ativos nas iniciativas de identificação, documentação e salvaguarda ${ }^{39}$. A viabilidade de seus 'patrimônios imateriais', agora entendidos como 'living processes' ${ }^{40}$, passa a ser visto como dependente do engajamento das próprias populações a que dizem respeito. 'Patrimônios imateriais', considerados processos vivos, deixam de ser reconhecidos como da ordem da 'memória', para serem considerados como da ordem do 'projeto" 41 .

\subsection{Panorama da “Convenção para a Salvaguarda do Patrimônio I material"}

Nos últimos anos temos visto, portanto, uma ampliação em relação às políticas públicas na área do patrimônio. De uma ênfase na preservação do patrimônio material, dito de 'cal e pedra', à crescente atenção voltada ao 'patrimônio imaterial', em especial de populações indígenas, minorias étnicas e setores da 'cultura popular'.

\footnotetext{
${ }^{37}$ Ver documento 'Expert meeting on community involvement in safeguarding intangible cultural heritage: Towards the implementation of the 2003 Convention" (Unesco \& ACCU, 2006, Tokyo, Japão).

${ }^{38}$ No entanto, se a transformação da caracterização antropológica de cultura de 'formas de vida' a 'processos dinâmicos de criação e atualização de 'saberes' e 'práticas" foi incorporada pela Unesco, estas não deixaram de ser associadas à referências 'identitárias'.

${ }^{39}$ Com diversas problemáticas não completamente resolvidas, como a disputada formulação de conceitos para a identificação de 'comunidades', 'grupos' e 'indivíduos', assim como questões concernindo quem seriam os representantes 'legítimos' dessas comunidades no que diz respeito ao diálogo com outros agentes das ações de patrimônio. Essa questão deverá ser discutida adiante.

40 Vale ressaltar também, nesta paisagem, a importância da recente Declaração sobre o Direito dos povos autóctones, de 29 de junho de 2007, o qual não cabe aqui a discussão.

41 "O que importa preservar - sob a forma de patrimônios imateriais - não é apenas da ordem da memória, mas da ordem do projeto: é preciso garantir e tornar renovável o fato da diversidade cultural e não fixar a resultante atual de evoluções seculares, produto de diálogos constantes. É preciso garantir o que está adquirido para tornar este patrimônio renovável" (Guia de discussão para a $3^{\circ}$ Mesa Redonda dos ministros da Cultura "O Patrimônio Cultural imaterial: espelho da diversidade cultural". Unesco, setembro, 2002. Citado em Gallois (org): 2006).
} 
Aquelas mudanças impulsionadas especialmente pelos programas e instrumentos da Unesco refletem-se em políticas públicas em âmbito nacional, regional e local, postas em prática por parte de organizações governamentais e não-governamentais dos países membros das Nações Unidas.

A Unesco opera através de reuniões entre representantes de governos e especialistas, muitos deles antropólogos. Durante tais reuniões, em rodadas de discussões e debates, são elaboradas propostas que são então transformadas em instrumentos legais, que variam em seu caráter normativo. ${ }^{42}$

Os instrumentos e ações da Unesco têm tido um papel central na promoção de ações de salvaguarda e registro de patrimônios imateriais ou intangíveis. Tais ações e propostas têm sido respaldadas por um argumento que atribui à cultura ocidental uma força homogeneizadora, em que processos de 'globalização ${ }^{43}$, são considerados como indutores de deterioração, desaparecimento e destruição de formas de pensamento, conhecimentos e práticas culturais locais ou minoritárias. Tais propostas visam também contrabalançar o impacto de novos valores entre os jovens, que levariam ao enfraquecimento da cadeia de transmissão de 'heranças culturais' (Londres, 2008). Para a Unesco a salvaguarda, manutenção e recriação do patrimônio cultural imaterial contribui para o enriquecimento da diversidade humana, constituindo garantia de desenvolvimento sustentável.

O instrumento normativo mais recente na área da cultura proposto por aquela instância concerne a 'Convenção para a Salvaguarda do Patrimônio Imaterial', instituído em outubro de 2003. Sintetizo aqui os principais pontos daquela Convenção para os fins dessa pesquisa.

Segundo o texto daquela Convenção, o patrimônio imaterial é entendido como:

"as práticas, representações, expressões, conhecimentos e técnicas - junto com os instrumentos, objetos, artefatos e lugares culturais que lhes são associados - que as comunidades, os grupos e, em alguns casos, os indivíduos, reconhecem como parte integrante de seu patrimônio cultural. Este patrimônio cultural imaterial, que se transmite de geração em geração, é constantemente recriado pelas comunidades e grupos em função de seu ambiente, de sua interação com a natureza e de sua história, gerando um sentimento de identidade e continuidade e contribuindo assim para promover o respeito à diversidade cultural e à criatividade humana". ${ }^{44}$

\footnotetext{
${ }^{42}$ Tais instrumentos assumem a forma de 'declarações', 'recomendações' e 'convenções'. "Declarações' consistem em proposições gerais de caráter moral ou político, a que Estados Nacionais podem optar por tomarem para si sem, contudo, se virem obrigados legalmente. 'Recomendações' são dirigidas a um ou mais Estados membros, e visam encorajar a adoção de uma certa abordagem ou forma de atuação em uma esfera cultural específica; em princípio, uma recomendação não cria uma obrigação legal por parte dos Estados membros. O terceiro instrumento, as 'Convenções', concernem acordos entre dois ou mais Estados membros, e necessita da aprovação de um número mínimo de Estados-parte para que entre em vigor. Este acordo implica em restrições legais no que diz respeito à sua aplicação.

${ }^{43}$ Entretanto, segundo Marylin Strathern (1995), o global não é um dado, mas um ponto de vista. E todo ponto de vista parte de um local, podendo ser 'global' no que concerne sua escala de abrangência.

${ }^{44}$ A Convenção estabelece ainda que "será levado em conta apenas o patrimônio cultural imaterial que seja compatível com os instrumentos internacionais de direitos humanos existentes e com os imperativos de respeito mútuo entre comunidades, grupos e indivíduos, e do desenvolvimento sustentável". Caberia aqui uma série de reflexões, que não serão levadas a cabo tendo em vista o foco desta pesquisa. Uma das
} 
Ainda segundo a Unesco, o "patrimônio cultural imaterial" se manifesta nos seguintes campos:

"tradições e expressões orais, incluindo o idioma como veículo do patrimônio cultural imaterial; expressões artísticas; práticas sociais, rituais e atos festivos; conhecimentos e práticas relacionados à natureza e ao universo; técnicas artesanais tradicionais".

Em relação às ações de salvaguarda, o texto da Convenção afirma que:

"entende-se por "salvaguarda" as medidas que visam garantir a viabilidade do patrimônio cultural imaterial, tais como a identificação, a documentação, a investigação, a preservação, a proteção, a promoção, a valorização, a transmissão essencialmente por meio da educação formal e não-formal - e revitalização deste patrimônio em seus diversos aspectos. Para assegurar a identificação, com fins de salvaguarda, cada Estado Parte estabelecerá um ou mais inventários do patrimônio cultural imaterial presente em seu território, em conformidade com seu próprio sistema de salvaguarda do patrimônio. Os referidos inventários serão atualizados regularmente".

E ainda, no item 'outras medidas de salvaguarda', lemos:

"criar instituições de documentação sobre o patrimônio cultural imaterial e facilitar o acesso a elas".

\subsection{Conhecimentos 'Tradicionais'?}

Paralelamente às propostas de valorização e salvaguarda de 'patrimônios culturais imateriais', nos últimos anos têm crescido referências aos chamados 'conhecimentos tradicionais' relativos a povos indígenas e minorias étnicas. Nesses contextos, especial atenção tem sido dada aos 'saberes tradicionais associados à biodiversidade', revelados através de pesquisas em biologia, agronomia, farmacêutica, etc. Nesta paisagem, vislumbramos associações recorrentes entre 'conhecimentos' e a noção de 'recursos' (escassos), passíveis de comercialização, apropriação, preservação. O interesse por tais conhecimentos, revelados pela pesquisa científica e seu posterior emprego por setores da indústria e do comércio, têm suscitado controvérsias relativas a direitos de 'propriedade intelectual' e 'autoria, ${ }^{45}$. Internamente à antropologia, tais

críticas possíveis concerne o fato de que 'culturas' foram forjadas e localmente representadas, muitas vezes, contra outras 'culturas' e modos de representação; e de que formas de 'estabelecer relações' nem sempre consistem em formas 'morais', ou de 'solidariedade' (qualquer que seja ela).

${ }^{45}$ Anteriormente à Convenção sobre a Diversidade Biológica, que data de 1992, os recursos genéticos e os conhecimentos associados à biodiversidade eram entendidos como patrimônio comum da humanidade. No entanto, enquanto a maior parte de tais 'conhecimentos' encontrava-se nos países em desenvolvimento, os países desenvolvidos, que detinham os grandes centros de pesquisa e desenvolvimento tecnológico, vinham beneficiar a exploração econômica de tais 'conhecimentos' na forma de produtos comerciais. A partir de 1992 os recursos genéticos e os conhecimentos associados à biodiversidade passaram a ser propriedade dos Estados, cada um devendo estabelecer internamente seus mecanismos jurídicos de regulação de direitos e benefícios associados. 
eventos têm incentivado uma produção intelectual pautada em ricas descrições etnográficas e debates relativos aos modos como populações indígenas concebem e aplicam noções de 'autoria', 'criação' ou 'propriedade' de conhecimentos e saberes segundo linguagens e lógicas distintas daquelas que regem os chamados 'direitos de propriedade intelectual' (Hirsch \& Strathern, 2005). Tais questões também vêm incentivando uma produção intelectual que, reconhecendo a diferença, propõe formas de diálogo e estabelecimento de possíveis 'pontes' ou pontos comuns através dos quais 'direitos', segundo sua formulação por nosso sistema 'ocidental', possam ser reconhecidos e aplicados em relação à 'populações tradicionais', mas de formas cuidadosas e adequadas às concepções e realidades locais próprias àquelas muitas populações (Carneiro da Cunha, 2004) ${ }^{46}$. Tais reflexões também têm em vista a justa repartição de benefícios advindos do desenvolvimento de produtos comerciais que fazem recurso a tais 'conhecimentos', através da proposta de pagamento equitativo àquelas populações ${ }^{47}$.

Contudo, uma das persistentes problemáticas em relação à aplicação da noção de 'propriedade intelectual' aos chamados 'conhecimentos tradicionais' é a idéia de que conhecimentos tradicionais consistiriam em um inventário acabado ${ }^{48}$.

Arun Agrawal (1995) veio sustentar essa mesma crítica ao questionar as formas como o conhecimento indígena vinha sendo abordado no âmbito de pesquisas em teoria social e desenvolvimento. Segundo o autor, há uma tendência nesses estudos em construir o conhecimento indígena como fundamentalmente diverso de outros 'tipos' de conhecimento. Agrawal questiona a validade e a possibilidade mesma de separação entre conhecimento 'tradicional' e conhecimento 'ocidental' ou 'racional/científico', ao assinalar a permeabilidade e intersecção de todo conhecimento, não importando sua gênese. Aquela classificação buscaria separar e fixar no espaço e no tempo, assim como em relação a conteúdos (separar enquanto independentes, fixar enquanto estacionários e imutáveis) sistemas que não podem ser separados, pois não são fixos. Assim, rotular e classificar conhecimentos segundo 'tipologias' produziria categorias

\footnotetext{
${ }^{46}$ Carneiro da Cunha (2004) sintetizou os modos como "conhecimentos" não são necessariamente distribuídos de maneira homogênea entre indivíduos, famílias e grupos internamente a um coletivo indígena, podendo estar relacionados a categorias de idade, 'especialidades' (tais como a de xamã ou guerreiro) ou experiências esotéricas (como o sonho). Da mesma forma as concepções acerca da "propriedade" dos conhecimentos podem ser regidas por lógicas as mais variáveis tais como apropriação, empréstimo, doação, concessão temporária, etc. Sobre a mesma discussão ver também (Strathern M., Cunha M., Descola P., Afonso C.1998) e (Brown, M. 1998).

${ }^{47}$ Carneiro da Cunha (2002:25) lança luz para um sistema que vêm sendo adotado no sudeste asiático, chamado 'sistema de direitos intelectuais coletivos', em que se elimina a palavra 'propriedade'. Segundo aquele sistema, conhecimentos devem continuar em livre circulação; mas a partir do momento em que contribuem para o desenvolvimento de produtos comerciais, as populações a que tais 'conhecimentos' dizem respeito devem vir a ser equitativamente remuneradas.

${ }^{48} \mathrm{Em}$ um documento produzido em Reunião das partes signatárias da Convenção sobre a Diversidade Biológica, em novembro de 1996, lemos: "é importante entender que os sistemas de conhecimentos tradicionais são dinâmicos. O que é 'tradicional' no conhecimento não é sua antiguidade, mas o modo como ele é adquirido e usado. Muitos desses conhecimentos são de fato recentes" (citado em Carneiro da Cunha \& Almeida, 2002:24)
} 
que possuem pouca semelhança com a realidade e a troca permanente de experiências entre indivíduos e grupos humanos. Agrawal vai advogar por reflexão crítica sobre os usos de tais categorias, ao encorajar o reconhecimento de múltiplas formas de conhecer, 'com diferentes lógicas e epistemologias'(1995:433) ${ }^{49}$.

Ellen \& Harris (1996) ao realizarem também uma crítica à atual ênfase no 'tradicional' enquanto modo de adjetivar o conhecimento ressaltaram o fato de que dificuldades na definição de termos como 'indígena', 'nativo' ou 'aborígene ${ }^{, 50}$ encontram-se dentre as causas para o uso generalizado da noção de 'tradicional', em especial no que concerne 'conhecimentos' associados a um 'anthropological other' (1996:2).

Por fim, chegou-se à formulação mais em voga atualmente, que vem se referindo a tais conhecimentos como 'saberes locais', de modo a não isolá-los de seus contextos de produção, adoção, uso e transformação. Privilegia-se assim a noção de 'tradicional' segundo sua acepção de 'modos como conhecimentos são localmente adquiridos e usados'.

Entretanto, não se podem ignorar questões políticas relacionadas ao emprego de tais termos. Populações indígenas, ao assim identificarem-se visando aceder a direitos especiais ou 'diferenciados', assumem-se positivamente enquanto 'detentoras de conhecimentos tradicionais', enquanto parte de um processo de reconhecimento e valorização. É também nesse sentido, de 'dívida histórica', ou seja, pautada por uma questão antes moral, ética e política, do que propriamente 'científica', que tais mecanismos ilustrados pelas ações da Unesco e postos em prática por Estados nacionais vêm sendo empregados, de modo especialmente visível no caso brasileiro ${ }^{51}$.

\subsection{Cultura e "Cultura"}

Contudo, a recorrente insistência no 'tradicional' enquanto um mot-outil (Lenclud, 1994) não deixa de trazer em seu bojo e assim reiterar pré-julgamentos através dos quais tais populações foram apreendidas pelo senso-comum: seja de uma suposta perenidade do passado, seja de um atributo de 'diferença' como 'desigualdade', que vêm obscurecer a contemporaneidade indígena e a realidade de que 'saberes e práticas' sejam eles

\footnotetext{
${ }^{49}$ Carneiro da Cunha vêm expressar a mesma preocupação ao ressaltar que os chamados 'conhecimentos tradicionais' consistem antes em formas específicas e persistentes de geração de conhecimentos, e não de um suposto corpus estável que remonta ao passado (Carneiro da Cunha: 2004).

50 "Peoples identify themselves as indigenous to establish rights and protect their interests (...) Although it may be convenient to seek a technical definition of indigenousness in terms of prior occupancy, length of occupancy or capacity to remain unchanged, such matters are seldom politically neutral". (Ellen \& Harris, 1996:2)

${ }^{51}$ Há hoje um debate a respeito da exclusão de manifestações da cultura erudita do âmbito do patrimônio imaterial. Em uma reunião dos agentes do patrimônio imaterial da qual pude participar, constatei o fato do termo 'dívida histórica' vir a ser constantemente empregado por tais agentes. Daí que as decisões acerca das primeiras ações de patrimonialização foram também estabelecidas no sentido de 'dar conta', primeiramente, das 'culturas indígenas' ('ilustradas' na patrimonialização da pintura e arte gráfica Kusiwa dos Wajãpi) e da 'cultura popular' ('ilustrada' através do samba de roda do recôncavo baiano), historicamente excluídas das ações de patrimonialização. Em seguida, aquelas ações buscaram abranger 'referências culturais' populares e indígenas para 'dar conta' das diversas regiões do território nacional.
} 
indígenas ou não, estão submetidos a transformações quando em uso e circulação, segundo lógicas próprias e formas dinâmicas através das quais culturas emprestam e importam artes e conhecimentos.

Os modos como 'cultura' foi enunciada segundo linguagens diversas, sejam elas próprias às políticas públicas, seja pelos 'grupos culturais', ou ainda por antropólogos, estes foram tantos sujeitos de pesquisa internamente à disciplina quanto os feixes que a atravessam, vindo compor diferentes perspectivas e abordagens. Isso porque tais questões vêm elas mesmas conjugar opções fundamentais internas à disciplina. Dentre tais debates, ressalto o fato de que enquanto uma antropologia 'ativista' ou 'aplicada', defensora de direitos de povos indígenas, foi acusada de 'projetar' categorias próprias às formas de constituição de nossa 'sociedade' dita 'ocidental' ou 'euro-americana' sobre populações que operariam segundo outros interesses e outras lógicas; uma antropologia interessada em 'lógicas e epistemologias próprias' foi acusada de 'exotizar' e 'essencializar' tais populações, propondo a 'incomensurabilidade de mundos'.

Em relação a este debate e com vistas a essa pesquisa, recorro aqui, enquanto ferramenta analítica, à uma distinção realizada por Manuela Carneiro da Cunha em sua caracterização diferencial entre cultura e 'cultura' (Carneiro da Cunha, 2002, 2004) ${ }^{52}$. Para a autora, a cultura sem aspas seria aquela para a qual sempre estiveram voltados os antropólogos, e cujos aspectos analíticos seriam inconscientes para seus praticantes. Já "cultura" (com aspas) remeteria aos modos deliberados através dos quais grupos culturais 'enunciam' e, portanto, oficializam suas 'culturas,' a partir de um fundamento em 'identidades culturais', enquanto 'discurso político'53.

Essa diferenciação vem ao encontro da proposição que foi adotada nessa pesquisa, também enquanto ferramenta analítica, segundo a qual 'tradições' só existem enquanto 'proclamadas' (Lenclud, 1994: 35). Assim 'tradições enunciadas' dizem respeito à 'cultura' e aos procedimentos de patrimonialização operados através da enunciação de 'identidades'. A acepção aqui adotada quanto ao termo 'tradicional' (que deverei,

52 "Culture has to be understood as operating simultaneously at two levels. For the sake of the argument, let us call them a literal and a meta-level. Although the two are interconnected, it is difficult to ascribe 'literality' to one rather than to the other. Anyway, by 'literal' I mean what anthropologists up to some time ago used to call culture, something that, though dynamic and changeable, would inform values and actions. According to anthropologists, there is an internal organization to culture in that literal sense, an organization that will constrain and inflect changes. At another level, 'culture' as a whole is used diacritically to separate people, to discriminate in both the etymological and the current sense. This is 'culture' as political discourse. (...) I have argued elsewhere that at this meta-level too there is an organization, one that places specific 'cultures' in a mosaic of at once similar and dissimilar units: similar because they are comparable units of the same magnitude (other 'cultures') and dissimilar since it differences alone that allow for organization. Culture and 'culture' both are constrained by their respective organizations, and yet the two levels are not totally independent from each other". (Carneiro da cunha, 2002:8) No entanto, ambas acepções fundamentam-se em uma noção de cultura que têm nós, antropólogos, como sujeitos da enunciação. Seja quando estudamos outras 'culturas', seja quando distinguimos 'culturas' falando de 'cultura' para nós, ocidentais.

${ }^{53}$ Essa mesma distinção se 'replica' nos modos como a cultura foi caracterizada como um empreendimento voltado ao estabelecimento de comparações, sejam elas 'internas' ou 'externas'. Segundo Marilyn Strathern, culture "...consists in the ways people draw analogies between different domains of their worlds" (1992:47), i.e. 'comparações internas entre domínios'. Segundo Roy Wagner, "anthropology studies culture through culture" (1981:35), em relação às 'comparações externas' ou 'intraculturais'. Segundo Viveiros de Castro, "intercultural relations or intracultural relations are in strict ontological continuity." (Viveiros de Castro, 2004:2). 
contudo, evitar) deverá se referir às lógicas e epistemologias próprias através das quais culturas atualizam e recriam conhecimentos e práticas localmente, em situações em que os atores não se vêem chamados a enunciar a si e à suas 'culturas' (aspecto ao qual buscarei também voltar minha atenção nessa pesquisa). No entanto, reiterando Viveiros de Castro, "intercultural relations or intracultural relations are in strict ontological continuity." (Viveiros de Castro, 2004:2).

Se a antropologia foi, enquanto disciplina, fundada propriamente no centro da cultura ocidental $^{54}$, a partir de interesses identificados como 'ocidentais', ela esteve regida por 'formas de conhecer' próprias aos 'modernos' (e aos 'pós-modernos' e aos 'nãomodernos'), e segundo metodologias e abordagens teóricas que, apesar de sua extrema diversidade e variação ao longo do tempo, estiveram pautadas pelo 'método científico', baseado nos imperativos de demonstração e verificação, de evidência e lógica. Se, segundo Roy Wagner, "anthropology studies culture through culture" (1981:35), e considerando-se o empreendimento necessariamente comparativo de que é feito a disciplina, as constantes transformações históricas e 'culturais' próprias aos ocidentais tenderam a se refletir nas transformações internas à disciplina, nos modos de antropólogos 'lançarem seu olhar', reformularem seus conceitos e elaborarem suas questões e, portanto, nos modos de abordagem e nas caracterizações que foram feitas a respeito das populações estudadas. Assim, variações nos 'modos de conhecer' do ocidente e da antropologia produziram cada vez novos pontos de vista a respeito dos 'povos' estudados ${ }^{55}$. No entanto, ainda segundo Wagner (1981), processos criativos empregados por antropólogos na "invenção" das culturas são tão criativos quanto os processos empregados pelos nativos na construção de seus significados culturais ${ }^{56}$. Uma antropologia recente têm se dedicado a comparar modos comparativos vindo iluminar, entre outras questões, as formas como o 'outro' dos 'outros' não se refere necessariamente a 'nós, 57 . Entretanto, para fins desta pesquisa, meu foco é quando os 'outros' dos 'outros' somos nós. Isso porque a Unesco, assim como Estados nacionais, têm chamado populações ditas 'tradicionais' a se manifestarem enquanto 'coletivos' referenciados a partir de 'patrimônios imateriais' face à nós, ocidentais, como o outro termo da alteridade, e em consideração à ameaças de 'deterioração' decorrentes dessa mesma relação, e não de relações com seus outros 'outros' (como os seres que, dotados de agência, povoam seu cosmos).

Se a 'cultura' é o enunciado da 'tradição', Bakhtin afirmou que “(...) qualquer que seja o aspecto da expressão-enunciação consideradas, ele será determinado pelas condições

\footnotetext{
${ }^{54}$ Como a ONU e suas subsidiárias.

${ }^{55} \mathrm{E}$, é claro, a 'seu' próprio respeito: "since anthropology, like most other modern enterprises, is largely 'about' itself' (Wagner, 1981: xix).

${ }^{56}$ Deverei voltar a este ponto adiante.

${ }^{57}$ Ou seja, interessada em uma antropologia propriamente indígena. Me pergunto, podemos chamá-la antropologia? "the first question faced by the anthropologist is working out what constitutes, both in extension and comprehension, the concept of social (or cultural) for the people he/she studies; or put otherwise, what is the anthropology of this people" (Viveiros de Castro, 2004:1). "Perspectival Anthropology and the method of controlled equivocation".
} 
reais da enunciação em questão (...), a palavra constitui o produto da interação do locutor e do ouvinte" (2006:116). Nesse sentido, 'enunciados da tradição' ou enunciados da cultura também devem variar de acordo com a forma como interlocutores 'culturais' entram em diálogo com seus sujeitos, ou seja, as variadas formas como a 'cultura' do antropólogo dialoga com a cultura do nativo, iluminando, na relação, ambas.

\subsection{Patrimônios I materiais e 'Comunidades'}

$\mathrm{Na}$ esfera de debate própria ao 'patrimônio imaterial', estudiosos, representantes de governos e antropólogos têm se debruçado na produção de definições acerca dos sujeitos e coletividades a que aquele patrimônio se refere. A partir desses debates, especialistas têm acordado que 'comunidades', 'grupos' e indivíduos' devam ser definidos com base no 'patrimônio imaterial'.

No documento "Expert meeting on Community Involvement in Safeguarding Intangible Cultural Heritage: Towards the implementation of the 2003 Convention,58, lemos: "it was agreed that a sense of belonging together, or a sense of identity based on $\mathrm{ICH}$ (intangible cultural heritage) should be included in the definition of community" (2006:9). Assim, naquele documento 'comunidades' foram definidas como: "networks of people whose sense of identity or connectedness emerges from a shared historical relationship that is rooted in the practice and transmission of, or engagement with, their intangible cultural heritage,59.

A respeito das formas de participação e envolvimento das comunidades, são demandadas "a identificação apropriada das 'comunidades' e 'grupos'”, assim como "de seus devidos representantes", e a "garantia de que somente 'patrimônios imateriais' reconhecidos pelas comunidades sejam passíveis de inventario ou propostos a serem reconhecidos como tais" (2006:10).

Assim, segundo aquela definição, 'coletivos' culturais seriam identificados como decorrentes do compartilhamento histórico de práticas de produção e transmissão de 'patrimônios imateriais'. Gallois já havia ressaltado, entretanto, que 'não é da natureza dos saberes e práticas criadoras de significados culturais serem associados à identidade. Nem é sua função e característica constituírem-se enquanto 'patrimônio'60.

\footnotetext{
${ }^{58}$ ACCU/Unesco, Tokyo, 2006.

59. No mesmo documento, grupos foram definidos como 'people within or across communities who share characteristics such as skills, experience, and special knowledge, and thus perform specific roles in the present and future practice, re-creation and/or transmission of their intangible cultural heritage as, for exemple, cultural custodians, practitioners or apprentices". Foi sugerido ainda o emprego do termo 'network na descrição da relação de 'comunidades' a 'grupos', preferível à subset, concebido como estático. 'Indivíduos' foram indicados como aqueles que 'within or across communities who have disctinct skills, knowledge, experience, or other characteristics, and thus thus perform specific roles in the present and future practice, re-creation and/or transmission of their intangible cultural heritage as, for exemple, cultural custodians, practitioners or apprentices" (2006: 9).

${ }^{60} \mathrm{~A}$ autora também iluminou as formas como 'povos indígenas' entendidos enquanto sujeitos de direitos especiais ou 'diferenciados', associados a identidades e 'etnias' 'detentoras de conhecimentos tradicionais',
} 
Neste sentido, uma das questões pelas quais esta pesquisa se interessa é a relação entre características próprias à 'tradições orais', um dos âmbitos de manifestação de patrimônios imateriais segundo aquela Convenção, e modos de conformação de coletivos segundo aquelas mesmas 'tradições orais'. Também intento avaliar em que medida 'tradições orais' são efetivamente percebidas pelos sujeitos e 'coletivos' como potenciais 'patrimônios' ou como provendo um sentimento de 'belonging together', um 'sense of identity'.

Considerando-se que tradições orais são o 'conjunto de expressões orais de uma cultura, se aplicando às interações sociais fundamentais, segundo os modos considerados adequados de sua forma e uso' (Monod-Becquelin, 2005:34) parece-me que ao mesmo tempo em que formas consideradas adequadas ao emprego da parole podem efetivamente ser compartilhadas por 'uma comunidade, o fato de a 'tradição oral' se aplicar a modos de interações acarreta que os 'coletivos' variem de acordo com aqueles contextos de relação mediados pela linguagem. Neste sentido, como articulamse a necessária variedade e multiplicação de coletivos entre um contexto discursivo e outro e a noção de 'belonging together', prevista segundo o compartilhamento de 'patrimônios imateriais'?

De que modos tais experiências de identificação de coletivos a partir do compartilhamento de 'patrimônios imateriais', em contraste com a modalidade de conformação de identidades historicamente constituída como 'top-down', são experimentadas pelos próprios atores? Como tais questões são dadas a ver através dos modos como lidam ou como avaliam registros de suas 'tradições orais' que concernem antes, como vimos, formas adequadas de interação (ou seja, entre 'sujeitos' diferenciados através de variações naquelas formas)? Isso porque enunciados orais produzidos em dados contextos, quando registrados, são suscetíveis de atingir uma audiência distinta daquela para a qual foram produzidos, produzindo 'brechas' entre formas de interação e empregos adequados da parole. Esta será uma das questões fundamentais a serem debatidas nesta pesquisa, quando da análise dos casos Xavante e Kanak.

\subsection{Criatividade como foco da valorização ${ }^{61}$}

Um dos principais argumentos para a instituição da Convenção é o de "promover o respeito à diversidade cultural e o enriquecimento da criatividade humana". Assim, a Unesco visa garantir a diversidade para a promoção da 'criatividade'.

Uma série de autores no âmbito da antropologia vem associando 'cultura' a modos de criatividade e invenção. Roy Wagner foi um dos autores mais profícuos a tratar da

são resultado de processos históricos e políticos muito anteriores à instituição daquela Convenção (Gallois, 2005:5).

${ }^{61} \mathrm{Ou}$ "como pensar a Convenção para a Salvaguarda se seus pressupostos são 'euro-americanos', aplicados 'sobre' outras lógicas e pressupostos?" 
noção de "invenção" cultural (com base em uma antropologia simbólica). Invenção, para este autor, diz respeito à criatividade inerente à condição humana, à forma por excelência da constituição simbólica dos atores, e não a "descobertas" ex nihilo contingentes e fortuitas. James Leach (2003) também chamou a atenção para a concepção ocidental 'privilegiada' ${ }^{, 2}$ segundo a qual a criatividade seria contingente à vida dos atores. O autor ilustra o argumento ao abordar as associações entre as concepções de 'patente' e de 'direitos de propriedade intelectual'. No primeiro caso, ímpetos de criatividade individuais se 'cristalizariam' através de inovações em produtos; daí o fato de indivíduos 'criativos' deverem ser recompensados, em feedback, na forma de 'direitos', através dos benefícios que outros poderiam extrair daqueles produtos (a 'criatividade' permanecendo nos produtos, e não nos indivíduos). Os direitos de propriedade intelectual seguiriam essa mesma via de raciocínio: se a criatividade é contingente, indivíduos devem ser recompensados, senão economicamente, na forma de 'reconhecimento' pelas suas idéias, de modo a valorizarem-se antes às idéias (elas, criativas), contingentes e escassas, que podem passar a também serem entendidas enquanto 'propriedade'.

A Unesco não escapa dessa lógica, ao atribuir à cultura ocidental uma força homogeneizadora, em que processos de 'globalização ${ }^{63}$, são considerados como indutores de deterioração, desaparecimento e destruição de formas de pensamento, conhecimentos e práticas culturais locais ou minoritárias. Ou seja, 'patrimônios imateriais' (e com eles, seus 'representantes'), devem ser reconhecidos e valorizados ao promoverem a diversidade de 'idéias' e 'lógicas' diferenciadas, consideradas recursos escasso.

A política de 'salvaguarda de patrimônios imateriais' atenta para a valorização da diversidade cultural para o enriquecimento da criatividade humana. Será esse o mesmo interesse daquelas populações? Sendo que, parece-me, a 'diversidade' consistiu antes em formas de entrar em relação (de troca ou predação, via roubo, guerra, alianças) em que, tão ou mais importantes que os elementos ou conhecimentos 'trocados' entre si, o estabelecimento de 'relações', o foco na produção de pessoas?

Roy Wagner, através de uma antropologia simbólica, estabeleceu uma comparação bastante profícua no sentido do argumento aqui avançado. Segundo aquele autor, o fato de o a acepção de 'cultura' haver variado ao longo do tempo e haver sido tomada de empréstimo dos usos correntes que foram dele feitos pela antropologia não fizeram com que tais acepções fossem substituídas umas pelas outras, mas sim o acúmulo de seus significados, que vêm hoje promover a ubiqüidade da noção de 'cultura'. A primeira acepção de 'cultura' segundo aquele autor, de 'cultivo', foi inicialmente aplicado

\footnotetext{
${ }^{62}$ Ainda segundo a noção da simbolização convencional e diferencial de Wagner, que ressalta que, apesar de concomitantes, a atenção nunca está em ambas ao mesmo tempo. Uma forma de ação operaria o 'controle' da outra. Daí que mesmo entre os modernos a noção de criatividade contingente' é privilegiada, mas não a única.

${ }^{63}$ Entretanto, segundo Marylin Strathern (1995), o global não é um dado, mas um ponto de vista. E todo ponto de vista parte de um local, podendo ser 'global' no que concerne sua escala de abrangência.
} 
no âmbito da agricultura para então servir à adjetivação de uma característica propriamente humana, no sentido de 'refinamento' individual, e então coletivo. Em seguida, o 'refinamento' humano veio informar o paradigma evolucionista de 'progresso', conforme o seu 'modelo' no ocidente. Sua 'última' acepção, que concerne a crítica ao etnocentrismo e o advento do relativismo cultural, não vieram apagar, mas antes conviver com tais acepções anteriores (o que Wagner considera como a 'ambiguidade criativa' do termo). Deriva daí que, no ocidente, o termo 'cultural' vem corresponder ao que é tido como da ordem do 'produzido', em contraposição ao 'inato', este último correspondendo, aqui, à esfera familiar e sentimental, relacionada ao amor e distinta do domínio da 'produção' e do 'trabalho'. 'Cultura' vem dessa forma informar o que fundamenta a própria história do ocidente. 'Trabalho' não significa aqui a produção de 'gentes', mas os desenvolvimentos nos campos da ciência, das artes, das técnicas e da tecnologia. O 'trabalho' e a atribuição de valor ocorrem justamente nessas áreas. Nossas instituições culturais, museus, universidades, bibliotecas, conservatórios são voltados à manutenção daquilo que é considerado nossa história, nossa 'cultura'. O enfoque ocidental seria na manutenção e produção de idéias e sua transformação em 'desenvolvimento'.

Estabelecendo um contraste em relação aos Daribi da Nova Guiné, o autor irá ressaltar que ali o fato de que mulheres possam ser 'trocadas por bens' é um modo de criatividade distinto e contrastado ao modo de criatividade 'dominante' ocidental. Atentando para a tradução adequada segundo os valores atribuídos pelos Daribi, Wagner afirma que o que ali é visto como mais importante não são os bens trocados, mas sim as mulheres, as pessoas. O âmbito do 'trabalho' é, ali, própria à esfera familiar, ao que é produzido (e não 'inato'). Assim, Wagner afirma que "It is people, and the experiences and meanings associated to them that they do not want to lose, rather than ideas and things. My New Guinean friends transfer the names of the newly dead to the newly born, and also find it necessary to invent the deceased in the form of ghosts, so that they are not wholly lost. We do much the same thing with books, which are our 'ghosts', our past, wherein so much of what we call "Culture" lives". (Wagner, 1981, 1726).

Esse contraste fica evidente nas atuais comparações estabelecidas entre a biodiversidade e a diversidade cultural, segundo a noção de sustentabilidade. Quando lemos, por exemplo, em um discurso de Koichiro Maatsura, diretor geral da Unesco: "A diversidade cultural, como patrimônio da humanidade, é tão necessária à humanidade quanto a biodiversidade à natureza ${ }^{64 "}$ (2006:12). Segundo o Relatório de Brundtland (1987), sustentabilidade refere-se à: "suprir as necessidades da geração presente sem afetar a habilidade das gerações futuras de suprir as suas". Ou seja, promover a

\footnotetext{
${ }^{64}$ Ver introdução do livro "Lenguas y tradiciones orales de la Amazonía. Diversidad em peligro? (Vacheron, 2006).
} 
diversidade hoje para garantir a 'criatividade' de amanhã: "o que importa preservar sob a forma de patrimônios imateriais - não é apenas da ordem da memória, mas da ordem do projeto: é preciso garantir e tornar renovável o fato da diversidade cultural e não fixar a resultante atual de evoluções seculares, produto de diálogos constantes. É preciso garantir o que está adquirido para tornar este patrimônio renovável” 65 .

\subsection{Identificação das medidas de salvaguarda com etnografia. E casos em que produtos da prática etnográfica vêm servir à valorização da 'cultura'.}

Se as medidas para a salvaguarda do 'patrimônio imaterial' visam a perpetuação das condições de sua (re)produção e garantia de sua transmissão, enfatizando assim 'processos', notável é o destaque dado à sua 'materialização', através da constituição de 'produtos'. Em especial, quando lemos dentre as medidas de salvaguarda propostas no texto da Convenção "a identificação, documentação, investigação", a "elaboração de inventários", e a "criação de instituições de documentação sobre aquele patrimônio imaterial".

Atentando para aquelas medidas de 'identificação', 'documentação' e 'investigação' de 'patrimônios imateriais', reconhecemos as atividades que se tornaram pilares da definição mesma do trabalho do antropólogo social moderno, cuja identidade profissional, desde Boas e Malinowski, fundamentou-se na prática da etnografia e no espaço central ocupado pelo trabalho de campo em nossa disciplina. Pois não seria 'identificar', documentar' e 'investigar' práticas, conhecimentos e tradições orais algumas das atividades em que estiveram ocupados antropólogos, cotidianamente, em suas atividades 'de campo'? 66

Essa reflexão me levou a considerar o quanto os procedimentos, assim como os produtos de práticas etnográficas não consistiam, eles mesmos, formas potenciais ou virtuais privilegiadas de 'salvaguarda' e 'valorização', quando posteriormente recuperados através de práticas a que chamo de "transformação dirigida da oralidade". Especialmente nos casos, para os quais atenta esta pesquisa, em que eventos de fala são trazidos para primeiro plano, registrados ipsis literis ${ }^{67}$ pelo etnógrafo, em suas fitas, cadernos, estudos e monografias.

\footnotetext{
${ }^{65}$ Guia de discussão para a $3^{\circ}$ Mesa Redonda dos ministros da Cultura "O Patrimônio Cultural imaterial: espelho da diversidade cultural”. Unesco, setembro, 2002. (Citado em Gallois (org): 2006).

${ }^{66} \mathrm{E}$ ao propor que os 'sujeitos do patrimônio' tornem-se os agentes efetivos dessa produção, tornariam-se, eles, etnógrafos? Deverei debater este ponto nos capítulos Xavante e Kanak.

${ }^{67}$ É preciso aqui uma ressalva: o quanto uma fala oral pode ser 'literalmente' transcrita ou registrada, fiel à todas suas características originais como entonação, ironia, gesticulações, contextos, e, em especial, quando a língua original não é a mesma da transcrição?
} 
Pois não é raro que registros de 'tradições orais' e 'conhecimentos', realizados em contextos de pesquisa, sejam "deslocados" para servirem a novos objetivos, em novos contextos. Temos, por exemplo, o caso de registros produzidos por etnólogos durante suas pesquisas de campo que, por uma ou outra razão, 'retornam' (ou são 'retornados') aos grupos. Assim, se inicialmente tais materiais foram produzidos segundo um propósito de pesquisa e em momentos históricos muito particulares, em um segundo momento estes materiais podem passar a assumir novos estatutos. Podem se tornar motivo de 'diversão', aprendizado ou 'memória', quando da leitura de documentos ou da escuta informal de fitas ou vídeos pela população local; podem compor justificativas em processos envolvendo questões legais, como de reconhecimento territorial; e podem também adentrar o campo de 'projetos culturais', quando vêm compor fonotecas, exposições, bibliotecas, bancos de dados, livros de 'mitos', de biografias, compilações de narrativas, etc.

Meu interesse passou a voltar-se para tais trajetos, em que materiais produzidos em contextos etnográficos vêm posteriormente servir a 'projetos', e em que propostas e ações de salvaguarda de 'patrimônios imateriais' passam a demandar a produção de registros 'em campo', atividade até há pouco identificada como própria ao ofício do etnógrafo ${ }^{68}$.

Para fins desta pesquisa, passaram a atrair minha atenção as experiências de registro de conteúdos e formas da oralidade realizadas no âmbito da reflexão acadêmica e dos modos com que tais produtos são apropriados (ou não, quando 'rechaçados') e reelaborados para servirem experiências ditas "culturais", a que chamo de 'transformação dirigida da oralidade'. Isso porque, se há similitudes no que concerne a idéia da captura de eventos de fala e de seu registro ou transcrição para novos contextos, distintos do de sua produção, as práticas e produtos de registro realizados sob a égide da produção de conhecimento científico não têm como objetivo ${ }^{69}$ a produção de materiais com vistas à 'valorização cultural', ou não são necessariamente adequados a constituição de um chamado 'patrimônio'.

De modo geral, etnógrafos 'vão a campo' já informados por projetos de pesquisa concernindo temas específicos. Tais temas, assim como as abordagens teóricas que serão aplicadas na análise dos dados, são reflexos dos ambientes de debate acadêmico de seu tempo e das 'escolas' às quais estes pesquisadores estão ligados. Estes fatores imprimem também sua marca nos procedimentos metodológicos de

\footnotetext{
${ }^{68}$ Cabe aqui um grande parênteses, no sentido que não é possível desvincular as atividades de 'campo' das proposições e objetivos efetivamente teóricos que vêm informar os procedimentos, metodologias e opções na produção de dados etnográficos, objetivos estes distintos daqueles que vêm informar 'projetos', fundamentalmente 'não-teóricos'.

${ }^{69}$ Nesta pesquisa, entretanto, há casos de produção etnográfica que são também voltados, de um ou outro modo, à valorização, ainda que não seja este seu objetivo primeiro. Tais imbricamentos constituem também o foco desta análise.
} 
apreensão de 'dados', determinando, até certo ponto, o caráter mesmo daqueles dados registrados em campo.

No entanto, a pesquisa de campo, considerada como uma 'experiência', está sujeita a uma série de imponderáveis e imprevistos, devido às complexas relações travadas entre etnógrafos, nativos e outros personagens em contextos sociais e históricos precisos, dos quais o pesquisador não possui nenhum controle. Ao mesmo tempo, o próprio fato do pesquisador 'estar lá' promove 'experiências imprevistas' para os sujeitos da pesquisa. Imponderáveis estes que, também eles, vêm influenciar a feição daqueles dados 'colhidos' em campo.

Por outro lado, me questionava também se o fato mesmo de documentar enunciados orais já não produziria efeitos sobre seus atores e sobre os contextos 'originais' de sua ocorrência. Corresponde o registro a uma 'documentação' factual de uma realidade objetiva? De que modo registros produzem mudanças de status nos procedimentos e nos sujeitos dos registros e, portanto, em seus produtos?

Tendo em vista o caráter bibliográfico e documental de minha pesquisa, constatei que não haveria como acessar nem caracterizações a respeito das tradições orais, nem as experiências de 'transformação dirigida da oralidade' de forma 'objetiva'. Isso porque etnografias pressupõem opções teóricas e metodológicas de cada autor que, ao trazer registros de 'atos de fala' para o corpo de suas monografias e análises, visam com isso também amparar suas próprias hipóteses.

No percurso desta pesquisa, as implicações desta constatação fundamental sugeriramme novos rumos, alargando o escopo das reflexões a que de início me propunha ${ }^{70}$.

Daí meu interesse, no que diz respeito à bibliografia consultada que vêm tanto caracterizar formas e conteúdos próprios à 'tradições orais' quanto trazer a 'fala nativa' para o corpo de seus textos, pelas próprias orientações teóricas e metodológicas

\footnotetext{
${ }^{70}$ Minha proposta inicial para este mestrado consistia numa análise comparativa entre cinco casos de 'transformação dirigida da oralidade', a serem confrontados às bibliografias especializadas concernindo formas e conteúdos da tradição oral daqueles respectivos grupos culturais. Meu intuito era o de restringir tais experiências àquelas circunscritas à 'projetos', ou seja, sem vínculos com a prática e reflexão acadêmicas. Começados os trabalhos da pesquisa, constatei que as experiências pelas quais deveria pautar minha análise ou não estavam suficientemente documentadas ou não tinham resultados passíveis de análise ou, no mais das vezes, resultados a que eu pudesse ter acesso. Ao mesmo tempo, procedendo à revisão bibliográfica dos materiais relacionados aos grupos culturais elegidos para minha pesquisa, passei a atentar para orientações teóricas que consideram a prática discursiva nativa como central para suas análises. E passei a atentar também para os modos como orientações teóricas regem procedimentos metodológicos, ou seja, modos específicos de proceder registros da oralidade. Passei a me interessar então por trabalhos em que os procedimentos, eventos e contextos concernindo registros e documentações daquelas práticas enunciativas, conhecimentos e tradições orais encontravam-se minuciosamente descritos nos estudos, o que veio a restringir os 'grupos culturais' sobre os quais se pautam as questões dessa análise para Kanak e Xavante. Por fim, ainda durante a revisão bibliográfica para esta pesquisa, tive acesso a informações acerca de situações que suscitaram minha reflexão, concernindo tais situações de deslocamento, (re)apropriações (ou rejeições) e transformações a que tais produtos relativos ao registros operados por etnógrafos em campo estão sujeitos quando em posse de seus 'sujeitos', situações essas que me permitiram repensar a questão da 'valorização cultural' de forma mais significante e criativa.

Esses meandros da pesquisa me levaram também a questionar a respeito do lugar e dos modos de prática etnográfica em nossa disciplina. E dos modos variados de conhecer e conhecimento, as relações entre processos e produtos, não só daqueles grupos culturais, mas de nossa própria disciplina.
} 
daqueles autores. Desse modo, pude também pensar as relações entre tais opções no que diz respeito aos modos como tais pesquisadores realizaram registros, e as formas com que tais registros são 'postos a funcionar', 'proliferam' ou são 'rechaçados' pelos sujeitos indígenas, e em quais contextos.

\subsection{Formas de conhecer da antropologia:}

\section{- lugar de práticas discursivas nativas}

Bauman e Sherzer (2000:xv) lançaram luz sobre o programa estabelecido por Dell Hymes, a chamada 'etnografia da fala', para todo pesquisador se propõe uma pesquisa de campo: conhecer as concepções locais acerca da língua e suas regras de uso, da parole, seria o primeiro passo para uma adequada clareza na apreensão das situações e informações durante o trabalho de campo, principalmente no caso de as informações provirem da observação-participante, que envolve necessariamente diálogos com "informantes", mesmo nos casos em que tais diálogos não são reportados na escrita etnográfica.

Já autores alinhados à chamada antropologia 'pós-moderna' são enfáticos ao chamarem a atenção para a importância da relação entre os contextos de acesso aos dados etnográficos durante o trabalho de campo, fundamentalmente observações e interações discursivas, e os regimes escriturais no projeto antropológico. James Clifford (1998) apontou para o modo como a experiência incontrolável que é o trabalho de campo é transposta para um regime textual segundo formas variáveis de "autoridade etnográfica". Poderíamos traçar aqui um paralelo com as concepções de Bauman (1986) a respeito da relação entre eventos narrativos (situações de execução de narrativas), eventos narrados (estruturas de ação recontados) e os textos através os quais tais eventos são enunciados. Segundo Bauman, "events are not the external raw materials out of which narratives are constructed, but rather the inverse: events are abstractions from narratives. It is the structures of signification in narrative that give coherence to events in our understanding" $(1988: 5)^{71}$. Segundo a relação sugerida por Bauman, a escrita etnográfica poderia ser pensada como criadora de sentido, a ser compartilhada pelo antropólogo e seus pares, a respeito de experiências vividas 'em campo'. O que a corrente pós-moderna prega seria a transparência dessa construção de sentido nas práticas escriturais.

Os autores desta orientação irão se contrapôr à maneira como através de estratégias retóricas e textuais, diálogos localizados e informações ou interpretações obtidas em relações especificas entre etnólogos e informantes, possuindo personalidades e interesses próprios, são nublados ao serem incorporados na escrita etnográfica. Assim, tais autores iluminam diálogos e contextos, criticando os modos como a antropologia

\footnotetext{
${ }^{71}$ Bauman chama a atençao para o fato de que além da narrativa prover coerência ao evento ela pode também ser um instrumento para o obscurecimento, a confusão e a dúvida sobre o que aconteceu.
} 
tendeu a transformá-los em 'monólogo do autor', seja através do recurso ao discurso indireto livre, em que a voz específica de um informante, ou a mistura de vozes de uma série de informantes é absorvida na escrita do antropólogo na forma de um "eles" genérico; seja através de discursos ou diálogos reportados, transcritos no corpo do texto e que vêm ilustrar ou confirmar a perspectiva teórica savant, de modo a omitir o aspecto construído, mesmo "negociado" dos conhecimentos produzidos em campo. A importância dos contextos históricos precisos da estada do antropólogo em campo, assim como o papel de certos informantes que vêm por vezes desviar a temática inicial do pesquisador de modo a induzir, de uma ou outra forma, "o objeto" ou o objetivo que virá finalmente ser desenvolvido na pesquisa é também um tema privilegiado de tratamento dos "pós-modernos".

Por outro lado, 'estudos de tradição oral' e em especial abordagens alinhadas à "etnografia da fala", - materiais que se constituem contrapontos fundamentais à minha analise (ao descreverem minuciosamente formas, conteúdos e relações que assumem e engajam 'tradições orais'), são aqueles que mais claramente trazem para o primeiro plano de suas escritas "falas capturadas". Entretanto, tais fragmentos são em geral trazidos ao corpo do texto de modo a embasar e demonstrar hipóteses relacionadas aos seus temas de pesquisa. Segundo Dennis Tedlock, "los sociolonguistas- la gente que hace etnografias del habla- presentam instancias del discurso como si ellos mismos no hubieram estado en el campo" (1987:276). Tal crítica visa salientar, específicamente, o fato de tais pesquisadores interessarem-se, em geral, pelo que é chamado de 'naturally ocurring discourses', ou seja, justamente os discursos que buscam, na medida do possível (e é esta medida a que atenta Tedlock), isentar o pesquisador do diálogo. O enfoque aqui pode também ser formas 'dialógicas', mas aquelas realizadas entre membros da própria 'comunidade'.

Neste percurso passei a adotar uma visão mais atenta acerca dessas duas orientações, situadas em limites opostos no que concerne esta pesquisa, pelo fato de em ambas a produção discursiva nativa ocupar um lugar fundamental, mas segundo pressupostos teóricos, procedimentos e metodologias extremamente distintas entre si.

Trabalhos na linha da "etnografia da fala", através de ricas descrições dos gêneros da tradição oral e práticas expressivas das populações estudadas, abordam relações entre formas e conteúdos de enunciados da oralidade, analisando modos de interação formais ou cotidianos aos quais aqueles gêneros correspondem, a importância do papel dos interlocutores ou audiência nas variações da performance oral, assim como relações entre 'texto' enunciativo, eventos narrativos e eventos narrados. O fato, levantado por Tedlock (1987:276), de os autores escreverem como se "não tivessem estado lá", ou seja, os modos de sua implicação nos contextos de produção e 'registro' de eventos discursivos deverá ser uma das questões a serem discutidas nessa análise. Em seguida, as abordagens ditas dialógicas ou 'pós-modernas', segundo tratamentos teóricos que buscam dar conta dos contextos específicos de apreensão dos dados 
etnográficos, da personalidade e individualidade de seus informantes, revelando através da escrita as interações discursivas entre antropólogo e informante(s) e os debates através dos quais, entre uma "teoria nativa" e as opções analíticas do antropólogo, o autor desenvolveu sua análise. O fato de tais abordagens, em geral, eximirem-se de um tratamento mais fino das características do regime discursivo local, principalmente devido à sua feição mais ampla de se elaborarem em torno de diálogos entre etnólogo e informante, será também um elemento para o qual voltei minha atenção na análise.

O terceiro exemplo de materiais pelos quais se pauta as questões desta pesquisa consiste em experiências de 'transformação dirigida da oralidade', realizadas no âmbito de 'projetos'.

Meu interesse em avaliar a "transformação dirigida da oralidade" na forma de "projetos" ${ }^{, 2}$, decorre da caracterização adotada por Carneiro da Cunha quando afirmou que 'projetos' "should be understood as any combination of cultural, political or economic endeavors that rely on external agents as well as the indigenous population" (2004:6). Desse modo, estes tendem a se constituir em esforços que, segundo esta autora, não seriam regidos por uma lógica de cultura, mas sim por uma lógica de "cultura"73.

Essa questão concerne o que vem se caracterizando chamar processos de "objetivação da cultura". Esse é o caso de experiências recentes que priorizam a adoção de metodologias 'participativas', vindo a chamar seus sujeitos a realizarem seleções a respeito do que deva vir a ser salvaguardado, que adotem um olhar critico em relação a seus "acervos culturais", seu "conhecimento", seu "patrimônio imaterial", a enunciar sua "cultura".

No que concerne os deslocamentos e transformações a que se interessa a presente pesquisa, sublinho o fato de que algumas dentre tais experiências de 'projetos' vêm se imbricar aos trabalhos realizados por antropólogos no âmbito de suas pesquisas acadêmicas.

Considerando que propostas recentes de valorização cultural e salvaguarda pautam-se no registro de 'tradições orais' e 'conhecimentos', atividades fundamentais à prática e reflexão antropológicas, meu intuito aqui é o de seguir procedimentos de registro e seus efeitos, mas adotando uma via paralela ${ }^{74}$. Em quais casos registros realizados por antropólogos foram apreendidos pelos 'grupos' a que dizem respeito, e 'postos a

\footnotetext{
${ }^{72}$ Carneiro da Cunha também foi uma inspiração para minha análise quando afirmou «the interrelated dynamics of project and village politics is still an underdeveloped theme in anthropology" (2004:7).

${ }^{73}$ Como já afirmado, para aquela autora a cultura sem aspas seria aquela para a qual sempre estiveram voltados os antropólogos, e cujos aspectos analíticos são inconscientes para seus praticantes. Já "cultura" remeteria aos modos como grupos enunciam para outros sua 'cultura', sua 'tradição', enunciando assim o que se quer seu 'patrimônio'.

${ }^{74} \mathrm{O}$ único modo que encontrei de realmente avaliar tais questões, dado o fato recente da instituição da "Convenção para a Salvaguarda do patrimônio Imaterial' e, portanto, da falta de finas descrições de tais experiências, de dados 'acessíveis', e mesmo de 'resultados' propriamente ditos, concernindo tais experiências.
} 
funcionar' em novos contextos e situações, inclusive 'patrimoniais', e de que modo? Em que sentido a etnografia e o registro, enquanto procedimentos (alinhavados às propostas teóricas correspondentes) produziram efeitos? Que relações são possíveis de serem estabelecidas entre formas de apreensão de 'dados' (em especial, 'atos de fala') e os modos como tais 'atos de fala' registrados são posteriormente 'postos a trabalhar', de que modo, em que contextos? Que debates suscitam?

Daí meu interesse pelos modos como tais populações interessaram-se, 'fizeram proliferar' ou rechaçaram registros de suas tradições orais, assim como os modos como diferentes formas de 'diálogo' e metodologias de registro produziram 'ações' e 'reações' diversas em seus sujeitos. Pois se levarmos em consideração a situação contemporânea dessas populações, em que a leitura e a escrita e, em menor grau, o acesso e a utilização de novas tecnologias de informação e comunicação não são tanto 'novidades', tais instrumentos (e as informações que circunscrevem) não necessariamente recebem os mesmos usos nem estão obrigatoriamente sujeitos aos mesmos regimes 'textuais' e de autoridade (Cavalcanti-Schiel: 2006) dos propagadores originais 'euro-americanos' daquelas tecnologias. Se apreciarmos aquelas tecnologias enquanto ferramentas, o quanto 'ferramentas' podem ser postas a trabalhar de acordo com formas e procedimentos, 'criatividades', considerados pertinentes por cada grupo cultural?

Nesse aspecto, meu foco é menos na 'tradição oral' enquanto enunciação produzida "de boca a ouvido", do que ao que é ou não considerado 'pertinente' de acordo com dinâmicas e regimes próprios àquelas 'tradições' para cada grupo cultural, em novos 'substratos'.

Os modos e relações através dos quais se dão os procedimentos de fabricação daqueles produtos e, em seguida, os modos como são avaliados, rejeitados, ou 'postos a trabalhar' constitui-se assim uma entrada privilegiada para se pensar processos, 'formas de conhecer' e de criatividade. Formas de conhecer, por um lado, dos produtores originais de tais registros em seus contextos específicos de produção, ou seja, os modos que a etnografia e, conseqüentemente, a antropologia assumiram durante momentos e configurações diversos durante sua 'história', assim como as 'formas de conhecer' próprias aos 'nativos' naqueles contextos, e nos contextos de recuperação atuais. 


\section{Capítulo 2 \\ Língua, Parole e Oralidade}

Os trabalhos precursores a iluminar questões relativas às formas próprias à oralidade focaram principalmente - e durante muito tempo - problemas que diziam respeito à escrita, especialmente no âmbito da teoria literária. Posteriormente, e muito em conseqüência de suas descobertas, estudos relativos à oralidade ganharam gradativamente destaque, abrindo caminho às elaborações teóricas que viriam tratar de questões exclusivas à comunicação em sua forma oral.

As descobertas de Milman Parry (1928) tiveram um papel fundamental ao iluminar características próprias à oralidade a partir do que se convencionou chamar a "questão homérica". Sua perspectiva inovadora foi a de atribuir aos poemas épicos considerados obras clássicas da tradição literária ocidental, as llíada e Odisséia de Homero, aspectos próprios da expressão em sua forma oral: o uso de versos hexâmetros, a ausência de linearidade narrativa, - mas de uma forma comparada à da "caixa dentro da caixa"-, o emprego de "fórmulas", - tanto no que diz respeito aos temas quanto às próprias construções -, dando assim início aos estudos de "literatura oral".

Depois dele, uma série de estudiosos veio se dedicar ao tratamento das diferenças entre regimes de escrita e regimes orais, dentre eles Jack Goody (1979) e Walter Ong (1998), mas segundo um enfoque que parte da 'escrita'. Estes autores irão propor relações entre o "progresso do conhecimento" e o desenvolvimento dos "modos de comunicação", segundo a proposição de que "toda alteração no sistema de comunicação humana tem necessariamente repercussões no conteúdo transmitido" (Goody, 1979:19). Segundo essa abordagem, o regime escrito foi caracterizado por tornar possível o exercício da autocrítica e o desenvolvimento de uma 'razão gráfica', através do olhar distanciado em relação ao pensamento e da formulação de conceitos abstratos, tidos como necessários ao estabelecimento de formações sócio políticas complexas, com poderes centralizados e hierarquizados, e ao desenvolvimento do pensamento científico e, em decorrência, afirmando sua ausência e sua impossibilidade dentre populações de tradição ágrafa. Tais proposições chegaram a ser qualificadas de "determinismo tecnológico" (Finnegan,1992:34) ${ }^{75}$.

Jack Goody, em sua obra "A Razão Gráfica', irá debater principalmente com LéviStrauss, ao argumentar que as distinções deste último entre o pensamento científico e o pensamento selvagem, ilustradas pelos personagens do engenheiro e do bricoleur, deveriam ser explicadas, antes, por diferenças entre regimes de 'razão gráfica' e regimes orais.

Jack Goody foi bastante criticado em relação ao seu tratamento das distinções entre

\footnotetext{
${ }^{75}$ Sabe-se hoje que populações indígenas ou nativas, em todas as partes do mundo, são sociedades que optaram por formas de organização política na qual a existência de um poder centralizado nos moldes de um Estado foi descartada histórica e filosoficamente (Sztutman, 2005; Gallois, 2006).
} 
regimes orais e regimes 'gráficos' e de suas supostas conseqüências, somando-se ao debate o qual se convencionou chamar "grande divisor"76. Se algumas contribuições deste autor são de significativa importância na reflexão aqui adotada, meu interesse nas relações entre oralidade e registro de tradições orais não se refere às supostas implicações das mudanças de mídia, ou dos 'sistemas de comunicação humana' em 'formas de pensamento'. No entanto, uma das questões colocadas por aquele autor adquire relevo para fins desta pesquisa, no que concerne experiências de registro de enunciados orais: "será o sentido de um enunciado dissociável da relação social na qual ele é produzido?" (1979:21).

Meu interesse por esta questão consiste nas 'conexões' que podem ser estabelecidas entre contextos e relações sociais originais que pautaram a produção de enunciados quando de seu registro, e eventos posteriores de deslocamento e realocamentos, em que tais enunciados registrados são recuperados e reinseridos na cadeia de transmissão oral. Penso que as características de situações de interação 'originais' quando do fato do registro podem ser pensadas como um dos índices possíveis na avaliação das causas a respeito do porque certos registros 'proliferam' enquanto outros são 'ignorados' ou 'rechaçados'.

A lingüística, em seus primeiros tempos e em função dos objetivos a que se propunha, não assinalava como constando dentre seus focos de interesse o falante e o ouvinte, nem a parole ou contextos de execução de enunciados orais, considerados contingentes e fortuitos, e conseqüentemente desconsiderados da análise da langue.

Atribui-se a Ferdinand de Saussure a inauguração da lingüística enquanto disciplina específica. Afastando a linguagem (enquanto faculdade humana inata) e a língua em uso (a parole) das preocupações imediatas desta área de estudos, a lingüística de Saussure se propõe uma descrição completa da língua, a partir de um corpus limitado, o sistema da língua. Uma das premissas primordiais elaboradas por Saussure é a da 'arbitrariedade do signo lingüístico', ou seja, a ausência de motivação intrínseca na relação entre uma imagem acústica, - o significante-, e seu conceito, - o significado. Deriva daí que a ligação entre uma imagem acústica e um conceito seria decorrente de convenções, variando assim de uma língua à outra.

Por buscar tratar da prática da oralidade e das relações entre enunciados orais e contextos enunciativos, minha opção metodológica deverá se fundamentar nos autores que tratam mais da "parole" do que da língua, e do ato de enunciação que alia a fala aos gestos, aos contextos, à interlocução. Adoto aqui a distinção realizada por Émile Benveniste entre o emprego da formas e o emprego da língua. A seu ver, previamente

\footnotetext{
76 "Por que as sociedades sem escrita são chamadas a fornecer os materiais necessários para o estudo da relação 'oral" e "escrita"? Que sejam sem escrita não significa justamente que suas tradições são alheias a esta divisão?"(Goldman, 1999:88).
} 
à enunciação, a língua não é mais do que sua potencialidade. Assim, afastando-se das descrições lingüísticas que trataram do emprego das formas da língua partindo de regras que correlacionam variações morfológicas e latitudes combinatórias, ou seja, relações entre gramática, morfologia e sintaxe, e que teoricamente poderiam produzir um inventário completo dos usos da língua, o autor volta-se para a própria língua em uso, a enunciação.

"L'enonciation et cette en mise en fonctionnement de la langue pour une acte individuelle d'utilisation" (...) "le discours, dit-on, qui est produit chaque fois qu'on parle, cette manifestation de l'enonciation, n'est-ce pas simplement la parole?'(Benveniste, 1974:80).

Essa deverá ser a perspectiva a respeito do uso da língua empregado aqui, a atenção mobilizada para o ato de produção de enunciados, a partir de locutores que mobilizam a língua por sua própria conta ${ }^{77}$. Dessa forma, a enunciação se define em relação à língua como um processo de apropriação do aparelho formal da língua por narradores que enunciam sua posição através de índices específicos.

Será somente a partir de um crescente interesse nas implicações do sujeito, sua ancoragem espaço-temporal, assim como da relação do sujeito ao enunciado, -a enunciação-, que virá a parole ser incluída na análise lingüística, segundo uma perspectiva diacrônica.

As relações entre pensamento, linguagem e cultura, de grande interesse para estudiosos de diversas áreas do conhecimento, deram origem a abordagens diametralmente opostas, ainda hoje motivo de debates e controvérsias. Assim temos por um lado a idéia de que a visão de mundo de uma população seria moldada a partir das categorias de sua língua, popularizada pela hipótese de Sapir e Whorf. Segundo tais autores, a tradução entre culturas é impossível, já que a natureza dos objetos está inseparavelmente ligada à estrutura da linguagem (Whorf, 1956; Sapir, 1951) Em sentido oposto, a corrente teórica da gramática generativa, que tem em Noam Chomsky (1971) seu principal representante, irá insistir sobre o caráter inato da faculdade da linguagem, refutando qualquer influência da língua sobre o pensamento e formas culturais. Este autor propõe uma caracterização aproximada à da relação entre "langue" e "parole" de Saussure, ao estabelecer a distinção entre "competência" e "performance".

Tanto Saussure como Chomsky descartam de seus focos de interesse a 'performance' (a língua em uso), ao conceber a língua e a linguagem enquanto entidades substantivas. Tais autores, adotando o ponto de vista do sistema e uma perspectiva sincrônica, focam antes semelhanças do que diferenças nos usos da linguagem. Seu interesse são as "estruturas profundas", os modos como as variadas frases, não importando a forma como são produzidas, por quem, para quem, em qual contexto, poderiam ter o mesmo significado, ou seja, tratar-se-iam de variações de uma forma

${ }^{77}$ E em função de seu contexto e de sua interlocução. Ver Bakhtin, adiante. 
normativa idêntica. As tessituras lingüísticas, "estruturas superficiais", consideradas em sua variabilidade, seriam "idênticas" contanto que atingissem o mesmo efeito referencial em todas as suas instanciações.

O estruturalismo na antropologia, inspirado por Saussure, também irá prescindir da textura lingüística das narrativas e da personalidade e do desempenho dos narradores. A palavra, no estruturalismo, é entendida pelo seu viés de signo, seu sentido buscado em suas relações aos outros signos do sistema, de modo que os atores são excluídos do processo de significação. Lévi-Strauss, em suas Mitológicas (1964, 1967, 1968, 1973), realiza paráfrases dos mitos ameríndios não pretendendo reproduzir os valores expressivos ou estéticos do relato indígena.

$\mathrm{Na}$ lingüística, também a função referencial da linguagem, -sua característica de elaborar proposições acerca dos 'fatos do mundo'-, foi predominante enquanto esta se restringiu à análise de textos desvinculados de seus contextos específicos de produção. Claro está que a lingüística não se ocupa tão-somente de 'textos' oralmente produzidos, mas suas possibilidades estiveram durante muito tempo restritas ao texto, não importando se estes se tratavam de textos originalmente orais ou escritos. Uma das frases mais célebres a ilustrar tal posição, emprestada de Jaques Derrida em seu Gramatologia (1967), é a de que "il n'y a pas de hors-texte", isto é, de que nenhum sentido pode ser extraído de um texto que não lhe pertença já.

A característica 'referencial' da linguagem também presidiu durante muito tempo os estudos de folclore. Em sua origem, ao se interessarem por estórias, lendas, cantos e mitos na forma de textos resgatados de um passado longínquo e erigidos enquanto máxima expressão da "alma de um povo", -sua Volksgeist-, prescindiam da prática etnográfica, considerada excluída dos objetivos a que se propunha a disciplina.

A conhecida "polêmica Propp-Lévi-Strauss"78 pôs em evidência diferenças nas abordagens da antropologia e do folclore em relação a narrativas. Vladimir Propp, em sua Morfologia do Conto Maravilhoso (1928), em que realiza uma análise da estrutura dos contos russos, se preocupou ora com aspectos histórico-genéticos de narrativas, analisadas a partir das variações em suas 'formas', ora com as relações entre funções e personagens e suas variantes, considerados em relação aos 'conteúdos'. A principal crítica de Lévi-Strauss à análise dos dados de Propp foi de o autor haver desvinculado 'forma' de 'conteúdo'79 em seu tratamento dos 'textos' narrativos, reiterando assim a ligação do autor ao chamado "formalismo russo" ${ }^{\prime 80}$. Outra questão apontada pelo

\footnotetext{
${ }^{78}$ Lévi-Strauss discutiu a análise de Propp em seu texto "A estrutura e a forma" (1960).

79 A importância da consideração simultânea de 'forma' e conteúdo' serão explicitadas adiante, ao apresentar as contribuições de Mikhail Bakhtin para esta análise.

${ }^{80}$ Movimento iniciado na Rússia da Revolução em 1917, tendo desaparecido nos anos 30, que defendia, como idéia central, o projeto de uma ciência da literatura que a despojasse de tudo que não fosse estritamente literário, tendo em Roman Jakobson um de seus principais expoentes e em Mikhail Bakhtin um crítico voraz.
} 
antropólogo foi a de Propp prescindir de dados etnográficos em suas pesquisas. Hoje, estudos de folclore e antropologia tendem muitas vezes a se sobrepor em relação aos temas pesquisados, especialmente no campo de estudo da presente proposta e a partir da adoção de uma perspectiva renovada entre diversos folcloristas. Essa nova orientação tem em Richard Bauman um de seus expoentes, quando este afirma: "We must recognize that the symbolic forms we call folklore have their primary existence in the action of people and their roots in social and cultural life. The texts we are accustomed to viewing as the raw materials of oral literature are merely the thin and partial record of deeply situated human behavior" (1986:13).

Assim, em razão de certos rumos adotados no âmbito da lingüística e do folclore quanto às abordagens de práticas discursivas e narrativas, estes têm se aproximado dos interesses analíticos da antropologia, a partir de uma abordagem pragmática pautada na parole, na prática etnográfica e no trabalho de campo.

No que se refere à função referencial da linguagem, orientação predominante nos estudos de folclore, esta veio a ser questionada em meados da década de 50 quando John Austin desenvolveu a chamada "Teoria dos atos de linguagem". Segundo esta abordagem, para além da função referencial ou informativa da linguagem, as falas seriam capazes de ação (social) ${ }^{81}$. Austin irá esmiuçar o poder e efeito da fala ao iluminar a força ilocutória e a performatividade da parole. A força ilocutória evidenciada por este autor consiste nos processos interpretativos inferênciais, ou seja, induções que permitem a um interlocutor 'tudo compreender' a partir de um enunciador que 'não diz tudo', em função de saberes compartilhados (ou supostos como tais). Já o caráter performativo da fala, os 'speech acts' ou 'atos de fala', referem-se à capacidade propriamente accional da parole. Dentre suas capacidades performativas, Austin aponta a privacidade (quando uma frase é proferida em uma língua ou de forma somente compreensível para quem é dirigida), a ordem, ou o estabelecimento de uma mudança permanente em um status social, como as palavras trocadas pelos noivos durante a cerimônia de casamento.

A noção de 'atos de linguagem' veio operar como um marcador diacrítico em relação à concepção tradicional da língua como descritiva e predicativa. Assim, no âmbito da antropologia, estudiosos passaram a atentar para os efeitos ou a eficácia de atos de fala ao considerá-los como formas de ação, ao tratar de temas como a magia, o ritual, o poder ou o 'político'.

Será a partir destes estudos que etnólogos passam a acordar acerca da importância da consideração do estatuto da parole para os próprios falantes de uma língua, membros de uma 'cultura'. No âmbito da antropologia, Bronislaw Malinowski foi um dos primeiros autores a vislumbrar o rendimento de uma perspectiva performativa relativa aos atos de linguagem. Em "Coral Gardens and their Magic" Malinowski irá afirmar: "since words

${ }^{81} \mathrm{Ou}$, como afirma Laura Graham, "how to do things with words" (Graham, 2003:171). 
exist and are in a sense agents in themselves which establish connections between both man and man, and man and the world, and are capable of acting upon them...words are parts of actions and equivalent to actions" (Malinowski, 1965b:9).

Já Stanley Tambiah (1968) irá explorar as implicações da performatividade quanto aos 'poderes mágicos das palavras' em seus estudos do ritual como sistema cultural de comunicação simbólica.

A consideração das forças ilocutórias e performativas de atos de fala para a etnologia e a etnolingüística produziu uma série de avanços e de novas abordagens, também ao lançar luz sobre a importância de práticas de 'esquecimento' pautadas em regras de interdição enunciativa, vindo iluminar aspectos relevantes acerca dos componentes e noções de pessoa, como na interdição da enunciação de nomes de pessoas vivas ou mortas; ou referentes a cosmologias, quando em narrativas concernindo tempos da criação ou anteriores, ou domínios de outros seres, 'falar é agir'.

Minha própria abordagem, em função das questões a que me coloco, afasta-se de uma perspectiva sincrônica da língua, e considera relevante a abordagem relativa aos 'atos de fala'. Alinho-me a uma visão atenta à interface entre a linguagem e a produção e manutenção de relações sociais, que não são apreensíveis através de textos, mas de atos de fala vinculados aos seus contextos de produção, que devem ser etnograficamente iluminados.

A diacronia e a inclusão da percepção dos atores nos estudos de linguagem e de outros fenômenos culturais têm na semiótica de Charles Pierce uma de suas importantes contribuições. Segundo Pierce, os atores sociais interpretam signos a partir da percepção de relações entre um signo e seu objeto, ou significado ${ }^{82}$. Partindo deste quadro analítico, uma série de autores passou a identificar o caráter complexo e multifuncional de instâncias do discurso, procurando nos efeitos práticos, presentes ou futuros, o significado de uma proposição, ao invés de remetê-los a um jogo de relações internas ao discurso; ou seja, para além de sua possibilidade de "referenciar" a realidade, suas formas de 'ação social'. Michael Silverstein (1976), contudo, veio evidenciar de que modo a simples "adição" do caráter performativo a categorias semântico-referenciais da linguagem deixavam de demonstrar que a função referencial era somente um dos tipos de performance lingüística, entre outras. Não seriam os aspectos referenciais da linguagem que seriam "usados", segundo sua característica de "speech acts", para "realizar" outras funções. Segundo Silverstein, atos de fala são "speech acts", e a função semântico-referencial não é subjacente a toda expressão lingüística, é somente uma de suas possibilidades. Como apontado anteriormente, esta característica da linguagem somente pôde ser acessada segundo uma perspectiva "pragmática", interessada tanto por processos como por seus 'produtos'.

\footnotetext{
82 Segundo Pierce (1931-1958), três tipos de relações podem ser obtidas entre um signo e seu objeto. Quando a relação é dita de similaridade física o signo é chamado "icônico"; quando a relação é percebida como de co ntigüidade espaço-temporal o signo é chamado de "index" ou índice; quando a conexão entre o signo e seu objeto é baseado em uma regra mental, o signo é chamado simbólico. (Coelho Netto, 2001:58).
} 
Ao mesmo tempo, a "Teoria dos atos de linguagem " de Austin, formulada segundo uma filosofia da linguagem com foco na tradição democrática ocidental, considera 'atos de fala' como produzidos a partir de intenções e experiências individuais, abordagem caracterizada como 'subjetivismo individualista'. No âmbito da antropologia, a consideração a respeito de tradições orais como se aplicando às 'interações sociais fundamentais, segundo os modos considerados adequados de sua forma e uso' irá lançar luz sobre modos variados de constituição de sujeitos e coletivos em situação através de atos de fala, de modo a evidenciar contrastes entre formas de emprego da linguagem entre populações ocidentais, pautadas por noções como de verdade, legitimidade e subjetividade transcontextuais, e lógicas outras que informam o emprego e os modos de interpretação da parole entre populações de 'tradição oral', assim como de formas do 'político' no que se refere ao emprego da linguagem, diferenciadas daquelas que predominam entre os 'modernos' no âmbito da democracia ocidental.

Uma das caracterizações a respeito da enunciação de maior valia para esta pesquisa concerne aquela de Bakhtin, quando afirmou: "a personalidade que se exprime, apreendida, por assim dizer, do interior, revela-se um produto total da interrelação social (...). A enunciação individual não é de maneira alguma um ato individual" (2006:126).As proposições de Mikhail Bakhtin (2006:114) a respeito do caráter necessariamente dialógico da enunciação são um dos estímulos fundamentais para minha análise. Este autor iluminou a relação entre "forma" e "conteúdo", ao rechaçar as orientações do subjetivismo individualista e do objetivismo abstrato. Segundo os autores ligados ao subjetivismo individualista, a enunciação se apresentaria como um ato puramente individual, como uma expressão da consciência individual, de seus desejos, de suas intenções, de seus impulsos criadores, de seus gostos, etc. Já autores ligados ao objetivismo abstrato, como Saussure e Chomsky, concebem a enunciação como orientada pelo sistema das formas fonéticas, gramaticais e lexicais, ou seja, pelo sistema normativo de leis lingüísticas.

Bakhtin irá se distanciar dos dois pólos ao estabelecer que "o conteúdo a exprimir e sua objetivação externa são criados a partir de um único e mesmo material. Qualquer que seja o aspecto da expressão-enunciação consideradas, ele será determinado pelas condições reais da enunciação em questão (...), a palavra constitui o produto da interação do locutor e do ouvinte" (2006:116).Volto-me, dessa forma, à necessária relação entre contextos de produção de enunciados orais e as formas e conteúdos de tais enunciados. Assim, enunciados orais nunca são os mesmos. Segundo afirmam Becquelin e Molinié em "Mémoire de la Tradition" (1993): "Dans la transmission orale, le narrateur est créateur même s'il s'imagine ne faire que répéter. Ce que les acteurs de ces sociétés appellent 'répéter' n'est d'aileurs pas nécessairement une reproduction a l'identique. Ce double rôle empêche à la fois l'imitation exacte et l'innovation totale, puis que le narrateur n'a ni les moyens de la fidélité absolue ni le droit d'inventer" (1993:12). 
Neste sentido, enunciados orais, mesmo que pautados em gêneros formalizados e com conteúdos considerados 'adequados' àqueles gêneros, variam de acordo com os atores em jogo na comunicação e seu entendimento e intenções em relação às circunstancias mais amplas em que se inscrevem tais interações. Desse modo não considero o contexto enquanto um mero cenário ou plano residual nos quais práticas discursivas se desenvolvem. Os contextos de produção de enunciados orais circunscrevem todos os elementos do jogo comunicativo.

Nessa pesquisa buscarei atentar especialmente para as circunstâncias especificas, conforme reportadas nos documentos e análises bibliográficas consultados, nas quais se desenrolam atos discursivos, e que se constituem índices para sua inteligibilidade. Assim, ao relacionar os atores em jogo, os discursos e as instâncias de produção de enunciados orais, buscarei levantar questões pertinentes no que concerne às relações e percepções que os atores constroem, entre si, de si e de outros, através de práticas discursivas e de seus registros.

Como opções terminológicas derivam de opções teóricas e metodológicas, assinalo aqui os termos e focos mais comuns aos estudos da oralidade, enfatizando os campos com os quais esta pesquisa deverá dialogar. Ruth Finnegan (1992) realizou uma síntese das terminologias e escopos deste amplo tema que é a oralidade. Dentre aquelas, as que mais se aproximam dos objetivos a que esta revisão e estudo se propõem são: "oral literature", "performance and performance events" e "narrative and narration" e "oral tradition" 83 .

Estudos sob a denominação de "oral literature" enfatizam os aspectos 'literários', ou seja, as qualidades artísticas e criativas de narrativas orais, mas cuja ênfase recai em sua forma 'textual'. Já as abordagens sob a denominação "narrative" e "narration" evidenciam o aspecto processual do ato de transmissão do conhecimento, para além de seu conteúdo. Os estudiosos de "performance" e "performance events" serão de grande importância em minha análise, como buscarei explicitar mais adiante. Tais pesquisadores partem do pressuposto de que não é possível analisar a expressão oral desvinculada das questões retóricas e estéticas do ato enunciativo, e enfatizam a importância do papel da audiência e da interlocução quanto à variabilidade nas formas e conteúdos enunciativos. Vale sublinhar que esses autores consideram a performance como a essência mesma dos atos comunicativos em sua forma oral e não enquanto mero contexto enunciativo.

Já o termo mais amplo 'tradição oral', como anteriormente explicitado, consiste nas 'convenções mais formalizadas e recorrentes relacionadas à expressão verbal, consideradas em seu contexto cultural' (Finnegan:3), ou no 'conjunto de expressões orais de uma cultura, se aplicando às interações sociais fundamentais, segundo os modos considerados adequados de sua forma e uso' (Monod-Becquelin, 2005:34). Minha opção pelo uso do termo 'tradição oral', concerne ao fato de meu interesse

${ }^{83}$ Emprego aqui os termos em inglês, da mesma forma adotada pela autora. 
voltar-se especialmente para "regras" ou os modos localmente valorizados e tidos como adequados no emprego dos usos da língua nos variados contextos de interação da vida social. Incluem-se aí gêneros discursivos, dialógicos e narrativos considerados adequados às circunstancias da vida social, tanto cerimonial como secular, determinadas pelas posições e relações sociais entre os atores. Assim, interessam-me tanto formas coloquiais quanto formais na produção de atos de fala.

É preciso ressaltar, juntamente com Monod Becquelin e Phillipe Erickson (2000) que as fronteiras entre diálogos cerimoniais e diálogos do cotidiano devem ser apreendidos etnograficamente. Tal distinção costuma corresponder mais a um recurso metodológico de "purificação" utilizado pelos savants para demarcar o objeto de suas análises do que a distinções nitidamente marcadas na prática expressiva das populações estudadas. Desse modo, diálogos tidos como "cerimoniais" podem se configurar tão criativos e fortuitos quanto diálogos informais. Da mesma forma, diálogos coloquiais e cotidianos, tais como saudações, podem aparecer como altamente marcados no que concerne a seus aspectos formais de enunciação. Uma série de autores irá optar por trabalhar a partir de gêneros discursivos localmente nominados, de forma que sua especificidade emerge dos próprios falantes. Daí meu interesse em caracterizações e descrições que dêem conta das concepções locais acerca da linguagem, da parole, e das regras do saber-fazer comunicativo.

Para além da relação entre formas e conteúdos tidos por "adequados" no uso da língua segundo uma certa comunidade de falantes, interessa-me sobremaneira o caráter "emergente" (Bauman: 1986) do discurso em sua forma oral. Alinho-me, dessa forma, aos autores que se voltam para a pragmática da interação verbal, atentos ao fato de que atos de fala são inequivocamente produzidos em face às circunstâncias e aos atores em jogo, ou seja, são a cada vez novos atos de fala. Dessa forma, a relação entre variação e manutenção, no que concerne à produção de enunciados e de seu registro será uma das questões para as quais esta reflexão devera apontar.

As noções de performance segundo as duas acepções desenvolvidas pelos estudiosos da linha da arte verbal serão as mesmas a serem adotadas em minha analise. A primeira caracterização concerne seu aspecto "emergente", de atualização do sistema discursivo local a cada nova execução verbal. A segunda acepção, caracterizada como "verbal art", ilumina a importância da relação entre narrador e audiência e os aspectos artísticos da arte da fala. Nesse caso o narrador tem sua atenção voltada para uma certa audiência, sentindo-se responsável pela produção de uma amostra esteticamente elevada de sua arte verbal, estando sob o crivo do julgamento desta audiência quanto à consecução das qualidades desejadas. Adquirem relevo nessas caracterizações de performance o fato de não partirem de instâncias formais anteriores ou exteriores, de forma que performance é tomada como uma sempre nova execução, e de modo que os índices de inteligibilidade quanto à sua conformidade e seus aspectos artísticos devem ser buscados na avaliação dos atores locais. 
Vale sublinhar que segundo esses autores, narrador(es) e interlocutor(es) não pertencem necessariamente a uma mesma "comunidade de fala" local e homogênea.

Durante muito tempo, narrativas foram consideradas ícones de eventos, ao reportar, através de regras do discurso, estruturas de ação. Tal orientação tendia a ignorar as especificidades dos atores em interação, sua criatividade e a importância dos contextos na produção de sempre novos enunciados e narrativas. Richard Bauman reinscreve a importância da criatividade dos atores e dos contextos ao relacionar narrated event $e$ narrative event. $\mathrm{O}$ autor chama a atenção para o fato de que se eventos são arranjados a partir de estruturas de ação, organizadas através de relações de causalidade e temporalidade, narrativas, por outro lado, são estruturas verbais, organizadas segundo regras discursivas, em atos de fala realizados em circunstâncias concretas e especificas. A sugestão de Bauman, extremamente pertinente na reflexão a ser aqui desenvolvida, é a de que "an alternative view is that events are not the external raw materials out of which narratives are constructed, but rather the inverse: events are abstractions from narratives. It is the structures of signification in narrative that give coherence to events in our understanding" $(1986: 5)^{84}$.

Os escritos de Walter Benjamin, segundo seu conceito de 'historia aberta', serão um recurso valioso na reflexão acerca das questões a serem aqui discutidas. O autor discute a relação entre a experiência e memória quando afirma: "pois se um acontecimento vivido é finito, ou pelo menos encerrado na esfera do vivido, o acontecimento lembrado é sem limites, pois é apenas uma chave para tudo o que veio antes ou depois" (1996:37).

Em seu texto "O Narrador" (1996:197), Benjamin irá discorrer sobre a afirmação de que "a arte de narrar está em vias de extinção", cotejando os desenvolvimentos da noção de "experiência" à ascensão do romance e da informação e ao declínio da narrativa (na constituição do indivíduo 'moderno'). A partir da caracterização do narrador russo Nicolai Lesskov, Benjamin ilumina a relação entre narrador e ouvintes, assim como a partilha e recriação da "experiência" através da narrativa: "o narrador retira da experiência o que ele conta: sua própria experiência ou a relatada pelos outros. E incorpora as coisas narradas à experiência de seus ouvintes" (1996:201). As relações que o autor estabelece entre "a mão e a voz", o saber-fazer e o saber-narrar, e a importância dos contextos históricos que influenciaram os modos de transmissão e partilha de conhecimento através da narrativa, assim como através do romance e da informação, serão de grande valia e inspiração para minha análise.

Uma das orientações sobre as quais esta pesquisa buscará refletir é a concepção de que a percepção de identidades culturais está profundamente imbricada a dinâmicas

\footnotetext{
${ }^{84}$ Bauman chama a atençao para o fato de que além da narrativa prover coerência ao evento ela pode também ser um instrumento para o obscurecimento, a confusão e a dúvida sobre o que aconteceu.
} 
expressivas próprias, especialmente à prática discursiva. Neste sentido, tal abordagem atenta especialmente para a relação entre as formas expressivas e a percepção dos atores quanto à manutenção de tais formas. Isso não significa que as mensagens veiculadas sejam irrelevantes, mas que, para além dos elementos cognitivos e semânticos veiculados nos discursos, como valores, crenças, representações e significados, seria preciso atentar minuciosamente para as formas, contextos e modos de transmissão de significados culturais através de práticas expressivas. Se os conteúdos variam de uma execução à outra, variação essa fundamental no dinamismo inerente à cultura, a atenção voltada à manutenção de formas expressivas seria fiadora de um sentimento de continuidade cultural para seus atores, ao relacionar práticas expressivas passadas a práticas atuais, antigas interações a novas, contextos passados a contextos presentes, e em que conformidade e criatividade seriam

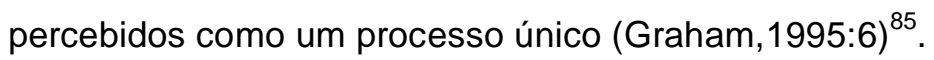

Essa caracterização é aqui relevante quando consideramos que registros de 'tradições orais', de modo geral, foram realizados tendo em vista a preservação e o acesso antes a seus 'conteúdos' do que às formas de expressão. Interesso-me, neste sentido, pelo interesse que os próprios atores demonstram por suas 'tradições orais' registradas. Se formas expressivas seriam fiadoras de um sentimento de continuidade cultural para seus atores, como tais formas poderiam ser privilegiadas através de projetos de salvaguarda e valorização culturais? Qual a ênfase de tais populações quando 'enunciam' suas 'culturas'?

$85 . . . \mathrm{l}$ am able to posit that processes of cultural transmission involve the replication of discoursive forms over time. The practice of passing a set of discourse forms from one generation to the next promotes feelings of cultural continuity, even though the messages incoded in those forms may change over time(...)the continuity of forms promotes feelings of persistance..." (Graham, 1995:6). 
Capítulo 3:

ENTRE TRADIÇÕES ORAIS

E REGISTROS DA ORALIDADE XAVANTE

\subsection{Apresentação}

Todos os materiais sobre os quais se pauta este capítulo referem-se aos Xavante da aldeia de Pimentel Barbosa, na TI Rio das Mortes, no Estado do Mato Grosso, Brasil Central $^{86}$. Meu objetivo foi o estabelecimento de diálogos entre formas próprias à tradição oral e eventos e produtos de registro de enunciados orais Xavante.

As experiências consideradas concernem registros da oralidade produzidos em âmbito de pesquisa antropológica, assim como situações de translação e recontextualização de tais registros para além de seu 'deslocamento' primeiro, quando fragmentos de enunciados orais são trazidos para o corpo dos trabalhos acadêmicos enquanto recursos à produção de conhecimento teórico. Assim, duas situações de

\footnotetext{
${ }^{86}$ Trago aqui algumas referências da história Xavante recente, desde os primeiros contatos com setores da sociedade nacional, assim como indicações da literatura etnológica e antropológica a respeito desta população indígena. Os Xavante tornaram-se conhecidos oficialmente em fins da década de 40, a partir da campanha de empreendida pelo Serviço de Proteção ao Índio promovida durante o Estado Novo voltada ao desbravamento, ocupação e desenvolvimento da região centro-oeste do Brasil. Entre as décadas de 1940 e 1960 diversos grupos locais Xavante estabeleceram, em momentos diferentes, relações com setores da sociedade nacional, dentre eles missionários católicos e protestantes, e agentes do SPI. (O primeiro grupo a estabelecer o contato com aqueles agentes em 1946, habitantes da antiga aldeia de São Domingos, hoje Pimentel Barbosa, identificam-se a si como aqueles que primeiro pacificaram os brancos). Os diversos agentes do contato vieram influenciar diferencialmente os grupos locais Xavante contactados. Para além daquelas diferenças, notadas por etnógrafos, frutos de especificidades históricas e notadamente do estabelecimento de relações duráveis de certos grupos locais e aldeias com missionários católicos ou protestantes, os diversos grupos locais Xavante são caracterizados segundo a literatura antropológica como uma 'totalidade social' pelo fato de compartilharem padrões de organização social e instituições, práticas cerimoniais e cosmologias, além de uma língua comum. Suas comunidades são politicamente autônomas, apesar de se reunirem em certas ocasiões tendo em vista objetivos comuns. Os Xavante autodenominam-se A'uwe ou A'uwe uptabi, estabelecendo um contraste com os Xerente, que se autodenominam Akwe. Na literatura antropológica formam um conjunto etnolingüístico conhecido como Acuen, pertencendo à família lingüística Jê, do tronco Macro-Jê. Segundo a versão mais aceita, o nome "Xavante" Ihes foi atribuído por não-índios visando sua diferenciação dos demais Acuen, particularmente os Xerente, dos quais se separaram por volta de 1820 ainda na Província de Goiás. Hoje tais grupos definem a si mesmos como 'Xavante', em especial face os brancos, os quais chamam warazu. Em sucessivas ondas migratórias, grupos locais foram se direcionando para a região do leste matogrossense próxima à Serra do Roncador, ocupada até os dias atuais. Em 2007 a população Xavante contava aproximadamente 13.000 indivíduos, espalhados em 165 aldeias em nove Terras Indígenas (In:Laura Graham, enciclopédia virtual 'Povos Indígenas no Brasil', 2008). Maybury-Lewis foi um dos primeiros etnógrafos a haver realizado pesquisa de campo junto a este grupo indígena, em especial na aldeia de São Domingos, hoje Pimentel Barbosa ou Etenhiritipã. Sua obra fundamental, A Sociedade Xavante (1984), que analisa aspectos centrais da vida social Xavante, constitui ainda uma das principais referências antropológicas sobre esta população, tendo sido elaborada enquanto parte de um projeto comparativo acerca de estruturas sociais Jê no âmbito do Harvard-Central Brazil Project. Outros pesquisadores de fundamental importância na literatura antropologia e etnográfica Xavante são Aracy Lopes da Silva $(1986,1992)$, em especial sua análise a respeito dos parceiros i'amo e seu lugar na organização social Xavante; Regina Müller (1983, 1995), que analisa o sistema de comunicação visual enquanto forma de linguagem; Oswaldo Ravagnani (1978), que versa sobre a história Xavante anterior aos contatos com a sociedade nacional na década de 40; Giaccaria e Heide (1972), que vêm caracterizar aspectos da cosmologia Xavante; e Laura Graham (1990, 1993, 2003) que dedicou suas análises às formas discursivas e expressivas Xavante, havendo realizado a maior parte de suas pesquisas junto aos habitantes da aldeia de Pimentel Barbosa.
} 
recontextualização foram aqui identificadas. Primeiramente, quando eventos e produtos de registro receberam novos usos, mediatos e imediatos, atribuídos pelos próprios atores indígenas; em segundo lugar, quando tais registros vêm posteriormente participar em um projeto de 'transformação dirigida da oralidade' voltado à 'valorização cultural'.

O foco nas formas próprias à tradição oral abre à reflexão das experiências de "captura" dessa fala Xavante. Assim, busquei considerar tanto os modos como narrativas e discursos foram documentados, de acordo com as abordagens e metodologias empregadas por cada um dos pesquisadores, mas também como se deu o processo contextualizado de produção desses discursos 'nativos' no momento de sua documentação. O envolvimento dos atores Xavante deve ser sublinhado, pois se as propostas de registro e documentação de 'tradições orais' aqui discutidas vêm de 'fora' (no sentido de não se constituírem iniciativas própria ou unicamente Xavante), as reflexões promovidas por e para tais experiências são determinantes no caráter desses discursos, produzidos para cada fim. Desse modo ressalto que 'tradições orais' não constituem um corpus estático, prontas para serem capturadas e registradas ${ }^{87}$. Pelo contrário, são sempre novas versões de narrativas e discursos produzidos em face às circunstâncias e em função dos atores em comunicação (Bakhtin, 2006:116), inclusive de acordo com as propostas e entendimentos acerca dessas pesquisas ou iniciativas de transformação dirigida. Veremos aqui de que modo abordagens distintas realizaram registros também muito diversos entre si, e que podem lançar luz sobre os modos como os próprios Xavante interpretam e agem de acordo com seus entendimentos e expectativas quanto a estas propostas.

O primeiro material considerado neste capítulo consistiu no livro "Performing Dreams" (2003) de Laura Graham ${ }^{88}$, que realizou ali caracterizações da tradição oral Xavante segundo perspectiva teórica da 'etnografia da fala'. A autora examinou a construção de um discurso coletivo e polifônico, elaborado em sua forma mais acabada na arena política Xavante, o warã. Esta obra foi aqui considerada segundo dois pontos de vista. Se por um lado a autora descreve e analisa instâncias da tradição oral Xavante, por outro lado suas exposições trazem à tona eventos decorrentes de sua presença mesma enquanto propositora e realizadora de registros. Assim, procedimentos e produtos de registro de atos de fala realizados em um âmbito de pesquisa vieram produzir 'efeitos' por e para os sujeitos da aldeia de Pimentel Barbosa, efeitos estes a serem aqui apresentados e debatidos.

\footnotetext{
${ }^{87}$ E mesmo quando compiladas a partir de uma noção de corpus, variam de acordo com os contextos e os interlocutores ou os produtores de registros (Lévi-Strauss, 1986: 150).

${ }^{88}$ Com especial atenção ao capítulo "Depersonalizing the dream: the politics of narrative performance". A versão inicial deste texto aparece em American Ethnologist 20 (4): 717-741. (1993), sob o título "A public sphere in Amazônia? The depersonalized collaborative construction of discourse in Xavante". No livro Performing Dreams (2003), ele aparece reelaborado e ampliado, no capítulo 5 "Depersonalizing the dream: the politics of narrative performance". Para fins de análise, ambas as versões serão consideradas.
} 
O segundo material abordado foi a tese de doutorado "Romhõsi'wa - A criação do mundo segundo os velhos narradores Xavante" (2003). Nesta tese, em que foi adotada uma metodologia de campo característica de uma antropologia dita dialógica, enfoquei especialmente as modalidades de diálogo e registro de narrativas e debates entre indivíduos Xavante e o pesquisador. Sua pesquisa de campo se pautou na ativa participação de Rupawê, Serezabdi, Sereburã, Serenhimirãmi, Hipru, Paulo Sepretaprã e Azevedo Peprê, 'velhos' Xavante e um jovem tradutor. Essa tese consiste em uma análise de uma dezena de mitos relativos à criação, no âmbito da antropologia da religião ${ }^{89}$.

O terceiro material discutido neste capítulo consiste no livro "Wamrêmé Za'ra: nossa palavra - mito e história do povo Xavante" (1998), proposta de "transformação dirigida da oralidade' com vistas à valorização cultural. Esta obra consistiu no registro de um corpus de relatos míticos e históricos. Tendo Sereburã, Hipru, Rupawê, Serezabdi e Serenhimirãmi como 'autores/narradores', este livro é resultado da compilação de (certos) registros realizados por Arthur Eid durante sua pesquisa (para sua tese Romhõsi'wa), e apresentado como uma experiência participativa entre indivíduos Xavante e o Núcleo de Cultura Indígena - NCl/SP, voltado à valorização do conhecimento e da cultura Xavante.

Um dos meus interesses aqui foi o de avaliar de que forma os processos, assim como os produtos resultantes de experiências de registro produzem ou podem vir a produzir efeitos internamente aos grupos, efeitos estes que caracterizo como de 'proliferação', 'descaso' ou 'rechaço'. Todos estes efeitos são da ordem de 'eventos'. Nesse sentido, o que proponho aqui são relações possíveis de serem estabelecidas na forma de rizomas, ou seja, enquanto modo não hierárquico, múltiplo, não binário nem dicotômico de abordagem de fenômenos em relação, ao substituir conexões de causaconsequência por nexos "planos" e semióticos de toda natureza, em que sujeitos e objetos de ordens e escalas diversas, heterogêneos, 'fazem rizoma', ou seja, ligam-se entre si por algum ponto qualquer não pré-estabelecido (Deleuze e Guattari, 2006). Com isso, e ao confrontar proposições relevantes extraídas do debate entre estes materiais e do debate entre os materiais relativos ao caso Kanak, pretendo levantar e debater questões salientes relacionadas às atuais experiências de 'valorização cultural' e salvaguarda pautadas no registro de tradições orais e conhecimentos de populações indígenas de tradição oral.

Com 'efeitos', não tenho em mente uma condição reativa dos atores face uma indução externa, o que conduziria a considerar o esvaziamento da condição de sujeito da agência indígena. É exatamente aquela situação de sujeito que me interessa aqui, modos como propostas e produtos de registro de 'tradições orais' e 'conhecimentos', vindas de outros e com vistas a objetivos distintos daqueles dos atores indígenas,

${ }^{89}$ Tese defendida em julho de 2003, na Unicamp, sob orientação do Prof. Dr. Robin Wright. 
podem não só vir tornar visíveis, mas constituírem-se possibilidades inovadas para a produção de formas de ação, lógicas e sentidos criativos e próprios aos Xavante.

\subsection{Características da oralidade Xavante e o Gênero ihi mrèmè}

Tendo em vista que meu objetivo geral nesta pesquisa foi o levantamento de proposições a partir do confronto interno entre materiais relativos a dois 'casos', Xavante e Kanak, e não um estudo exaustivo das 'tradições orais' de cada uma dessas populações, deverei atentar especialmente aqui, no que diz respeito à caracterização das formas próprias à oralidade e às práticas discursivas Xavante, ao gênero ihi mrémé, gênero que em sua forma mais elaborada (mas não somente, como veremos adiante) é executado na arena política Xavante, o warã. Essa opção derivou da centralidade mesma atribuída a esse gênero segundo os estudos realizados por Laura Graham.

Assinalo outros gêneros da tradição oral Xavante, como o 'speech taboo', praticado entre o pai da esposa e o marido da filha, e o da-ñopre (nome genérico para canto e dança coletivos, organizados em três gêneros específicos: da-praba, da-dzaróno e dahipopo). Este último gênero merecerá aqui algumas considerações, não cabendo a ele o foco principal da exposição e análise.

O texto de Laura Graham "A public sphere in Amazônia? The depersonalized collaborative construction of discourse in Xavante" (1993), reelaborado no capítulo 5 de seu livro "Performing Dreams" (2003), tem por objetivo demonstrar a forma como práticas discursivas Xavante realizadas na arena política warã, representam pragmaticamente 0 discurso enquanto produção intersubjetiva emergente. Especificamente, o foco de análise da autora é demonstrar as inter-relações entre práticas discursivas e as esferas do individual e do coletivo para este grupo. A autora avança sua abordagem ao descrever a forma como os discursos elaborados no warã são executados segundo o que caracteriza como "co-performances". Em tais situações, o discurso é literalmente constituído por uma diversidade de vozes, e apresentado enquanto fenômeno extra-individual e emergente.

A proposta da autora é demonstrar e examinar as relações entre forma, conteúdo e contexto na produção de um gênero de discurso específico e formalizado, através dos instrumentos metodológicos e teóricos próprios às pesquisas na linha de arte verbal, e mais especificamente à "etnografia da fala". Seu intuito também é o de demonstrar, na esfera política Xavante, a forma como o lócus da ação política reside em uma interação social emergente, e não em agentes individuais tal como idealizado pelo modelo da tradição democrática ocidental. A autora também apresenta a relação entre as noções de "negatividade" e "notabilidade", que caracterizam os discursos naquela arena política. 
Desse modo, Graham constrói seu texto contrapondo os modos próprios de constituição de um discurso político Xavante (a nível local), à teoria de Habermas a respeito da constituição do sujeito político moderno $(1984,1987)^{90}$.

Para caracterizar o modus operandi da arena política Xavante, a autora recorre ao princípio da "negatividade" ${ }^{91}$. A "negatividade" consistiria, segundo ela, na negação do caráter individual do discurso político, de forma a conferir a este seu grau de legitimidade. Assim, Laura Graham irá demonstrar como os Xavante representam o discurso na warã enquanto produção de ordem antes coletiva do que individual.

Aliado ao recurso de "negatividade", a autora aponta para um efeito que virá complementar àquele: o de "notabilidade". A notabilidade advém justamente do fato de que, apesar de os discursos no warã se caracterizarem por elementos de multivocalidade, não são todos os Xavante que detêm os conhecimentos formais para sua realização. Assim, aquele indivíduo cuja fala constitui o locus principal do discurso irá incorporar ${ }^{92}$, a partir de determinados recursos lingüísticos e expressivos, os comentários paralelos produzidos por outros justamente para este fim. Essa maestria da arte verbal Xavante, a ihi mrèmè, "palavras dos velhos", consiste no fato de saber se valer dos recursos de produção de discursos coletivos, o que confere ao seu produtor 'notabilidade', ou seja, um alto grau de prestígio individual, assim como à facção o qual este busca representar naquela arena.

Em relação à polivocalidade, que será demonstrada pragmaticamente pela autora através do recurso da transcrição literal, - na língua e com traduções em inglês-, de trechos de falas "coletivizadoras" produzidas no warã, a autora afirma ainda a prevalência dessa forma discursiva entre indivíduos Xavante, notadamente adultos e idosos, em praticamente todos os encontros de dois ou mais indivíduos: "speech, in political meetings and in most (if not all) gatherings of two or more individuals, is truly polyvocal in the Bakhtinian sense"(1993: 718).

Através deste gênero discursivo os indivíduos se apresentariam dissociados do conteúdo de suas falas, de forma a que a possível responsabilidade individual ("accountability") pelo conteúdo de uma argumentação seja compartilhada pelo grupo como um todo. A polivocalidade, segundo a autora, produz um efeito de coesão social

\footnotetext{
${ }^{90}$ Este último define o processo de constituição daquele sujeito político através da emergência de uma esfera pública de debates entre iguais, e historicamente constituída a partir do desenvolvimento do capitalismo e do declínio do feudalismo. Tal esfera pública teria como fundamento a noção de construções discursivas individuais, cujas proposições são concebidas segundo princípios de racionalidade, verdade, legitimidade, sinceridade e autenticidade.

${ }^{91}$ Elaborado por Michael Warner (1990) em sua análise a respeito da natureza pública da imprensa em fins do século XVIII nos Estados Unidos.

92 Segundo Maybury-Lewis, o chefe é o orador principal no 'conselho dos homens' e somente ele tem o privilégio de expor suas idéias sem o discurso concomitante de um opositor. Os homens não são forçados a aceitar estas opiniões e eles podem, - e de fato o fazem-, discutir com o chefe e rejeitar suas sugestões (1984: 249).
} 
que reforça relações igualitárias entre seus membros $^{93}$, em contraposição à característica mais geral do faccionalismo altamente marcado na organização social dualista Xavante. "The organization of speech blends the voices of members of opposed factions to counteract the centrifugal forces of factionalism, reinforcing egalitarian relations among senior males and holding the community together" $(2003: 166)^{94}$.

Em um segundo momento, quando a autora vai caracterizar propriamente o warã, o tom de sua análise adquire um efeito quase literário, através do recurso ao "presente etnográfico". Assim, o leitor se vê transportado para a aldeia de Pimentel Barbosa em um dia comum da vida Xavante, enquanto a autora descreve os homens chegando para o warã na praça central da aldeia, pela manhã ou fim de tarde, como é sua disposição fixa em círculos concêntricos de acordo com categorias de idade e vínculos faccionais ${ }^{95}$, o que se debate, de que forma. A autora ainda ilustra outras situações em que a fala típica do warã, a ihi mrèmè, se realiza fora dela, descrevendo encontros entre os "homens maduros" e as impressões dos mais jovens em relação aos recursos lingüísticos empregados pelos velhos nestas ocasiões. "Elderly men, those who have sharpened their skills as ihi-mrèmè speakers, also employ it in many other situations when they wish to throw around the weight of their age and wisdom and to stress the importance of their speech. Elderly men use it privately with members of their faction, telling traditional tales, giving instructions to youths, and making ceremonial greetings. It is the hallmark of old age among Xavante men",96 (2003: 161).

Contudo, quando jovens eram questionados a respeito dos indivíduos que se destacavam na proficiência da produção de discursos ihi-mrèmè, estes atribuíam menos importância aos aspectos formais ou estéticos da produção de discursos, do que aos indivíduos em si, indicando sempre os 'velhos' de sua própria facção como sendo os melhores produtores (2003:165).

A autora ainda traz sete exemplos curtos de produção de discursos no warã, em língua Xavante e traduzidos para o inglês, em geral de dois ou três narradores (1993:729735). Dessa maneira, Graham ilustra os modos como o discurso é coletivamente construído. Na produção desses discursos, o narrador principal fica de pé, mirando o horizonte, enquanto os outros permanecem deitados, de olhos para o céu, e aquele que se tem levante vai incorporando falas paralelas de seus interlocutores. Assim, todos

\footnotetext{
${ }^{93} \mathrm{~A}$ 'igualdade' dirá respeito somente àqueles considerados "homens maduros", pertencentes às classes de idade i-predup-te, i-predu, e i-hi, que efetivamente participam no warã. Contudo, segundo Laura Graham, os homens somente se tornam efetivamente 'audíveis' no warã na medida em que ultrapassam a classe de idade i-predup-te para i-predu. Jovens, mulheres e crianças são interditados de participarem do warã.

${ }^{94}$ Questiono-me a respeito do fato de Laura Graham traçar um contraste entre a arena política Xavante e esfera de ação política moderna, pautada por discursos 'individuais' mas, ainda assim, caracterizar os Xavante como 'indivíduos' e a ihi mrèmè segundo a função de reforçar relações igualitárias e de 'manter a comunidade unida'. Discutirei este ponto adiante.

${ }^{95} \mathrm{Em}$ que indivíduos 'representando' facções se dispõem de modo intercalado, e em que os mais velhos vêm ocupar a parte mais próxima ao centro do círculo, enquanto os mais jovens encontram-se mais afastados do centro.

96 "Warodi slipped into this style every time he made a statement of two or more sentences ". (2003: 161).
} 
falam ao mesmo tempo, e o narrador principal se apropria do que é dito ${ }^{97}$ por outros na construção de frases curtas e com características tonais e lexicais próprias ${ }^{98}$. Segundo a autora: "his individual voice is absorbed as speech accumulates the voices of others. Members of the audience become so involved in the narrative that they contribute to its development". (1993:731). Alguns exemplos servem também para a autora demonstrar como seus assistentes mais jovens não dominam os recursos expressivos do warã, realizando inferências semânticas deduzidas e por vezes enganosas, ou utilizando expressões coloquiais para "traduzir" os principais pontos do discurso dos velhos para a autora.

Um dos diferenciais dos estudos de arte verbal reside na compreensão da expressão discursiva enquanto ação social ${ }^{99}$. Desse modo Graham interessa-se antes pelas formas de expressão, entendidas como formas de ação social, do que pelo teor semântico do que é dito. Pois serão as relações entre forma expressiva e discursiva e ação social, apreensíveis através da ihi mrèmè, que irão se constituir em recursos para a hipótese da autora, de que o sujeito político Xavante tem tanto mais prestígio individual quanto maior sua capacidade de produção de um discurso coletivizador através do emprego de formas expressivas adequadas. E ainda, uma das orientações fundamentais desta abordagem consiste na concepção de que a percepção de continuidade cultural (ou de 'senso de identidade') está profundamente imbricada a dinâmicas expressivas próprias, especialmente à prática discursiva. Neste sentido, tal abordagem atenta especialmente para a relação entre as formas expressivas e a percepção dos atores quanto à manutenção de tais formas. Isso não significa que as mensagens veiculadas sejam irrelevantes, mas que, para além dos elementos cognitivos e semânticos veiculados nos discursos, como valores, crenças, representações e significados, seria preciso atentar minuciosamente para as formas, contextos e modos de transmissão de significados culturais através de práticas expressivas. Se os conteúdos variam de uma execução à outra, a atenção voltada à manutenção de formas expressivas seria fiadora de um sentimento de continuidade

\footnotetext{
${ }^{97}$ Questões, proposições, complementos e variações quanto ao conteúdo.

98 "Formally distinct from conversational Xavante, ihi-mrèmè is characterized by extensive repetition and parallelism, a unique voice quality, and a special intonation pattern. These features give it a distinct acoustic shape. The orators manipulate linguistic texts to achieve systematic, indeed musiclike sound patterns" (2003:161).

99 "In dealing with expressive practices, it is important to distinguish between the content of a message or expression, and discourse practice, the form in which a message is expressed in the process of cultural transmission. (...) I am concerned with actual utterances, which I consider to be, in themselves, forms of social action. This perspective differs from those that focus on a cognitive point of view which posits that cultural transmission involves passing on a set of shared beliefs, values and ideas about the world which are understood to be embodied within the content of a message - for example, in the content of a myth. The message is considered to be of utmost importance, while the form in which the message is communicated is hardly relevant" (2003:6)
} 
cultural, ao relacionar práticas expressivas passadas a práticas atuais, antigas interações a novas, contextos passados a contextos presentes ${ }^{100}$.

É preciso sublinhar aqui o diferencial desta abordagem no que diz respeito às relações entre formas expressivas e a percepção de continuidade cultural dos atores. Laura Graham, ao propor que a atenção deva voltar-se antes às formas expressivas e discursivas que aos conteúdos transmitidos através de tais formas, se afasta de uma noção de cultura pautada em 'traços diacríticos' que delimitariam fronteiras entre identidades 'étnicas', para voltar sua atenção, antes, aos modos como os próprios atores estabelecem relações entre contextos passados e contextos presentes, sugerindo um sentido de identidade fundado em uma percepção de continuidade de formas expressivas e discursivas entre gerações através do tempo, ao evidenciar os modos como sujeitos indígenas estabelecem relações entre suas formas de expressão e aquela de seus antepassados e ancestrais, e não em contraposição a 'outros' ou à 'outras' identidades, pautada nas diferenças entre traços diacríticos que estabeleceriam 'fronteiras'.

O recurso ao ihi mrèmè seria ainda responsável pela regulação de relações sociais entre indivíduos e entre seus respectivos grupos políticos, de forma que as decisões no warã consistem (ou aparentam ser) decisões coletivas, evitando-se com isso o surgimento de disputas e acusações ${ }^{101}$. Tal propriedade do narrador Xavante passa também, e principalmente, pelo domínio de formas próprias do falar que somente os mais velhos detêm, já que seu aprendizado requer uma prática de longos anos. Os homens mais jovens, que gradualmente adentram a esfera política do warã, da classe de idade i-predup-te, evitam 'tomar a palavra' pois o fato de não apresentarem os conhecimentos corretos quanto à prática expressiva implicaria no efeito inverso ao da notabilidade, qual seja, a perda de prestígio por parte da facção que este deve representar nessa arena, mesmo que de forma 'negativizada'.

$\mathrm{Na}$ aldeia de Pimentel Barbosa, a reunião no warã tem lugar todas as manhãs e fins de tarde. Laura Graham descreve, contudo, de que modo durante praticamente todas as tardes homens maduros e idosos costumam se reunir nas casas de indivíduos proeminentes de sua própria facção, e passam o tempo discutindo assuntos os mais diversos. Dentre os tópicos de tais discussões, a autora cita âmbitos da política faccional, questões envolvendo a FUNAI, questões práticas relacionadas a expedições

100 "... I am able to posit that processes of cultural transmission involve the replication of discoursive forms over time. The practice of passing a set of discourse forms from one generation to the next promotes feelings of cultural continuity, even though the messages incoded in those forms may change over time (...) the continuity of forms promotes feelings of persistance..." (Graham, 1995:6).

${ }^{101}$ Segundo Maybury Lewis, é ali que são tomadas decisões, em geral sugeridas pelo chefe e reelaboradas através da ihi mrèmé de acordo com sugestões paralelas. São definidas caçadas e viagens, e também tomadas decisões a respeito do calendário cerimonial. Contendas somente são trazidas para essa arena quando adquirem certa amplitude, já que tais casos só chegam ao 'conselho dos homens' depois de se tornarem uma questão entre facções. Contendas femininas e internas às facções são em geral resolvidas fora deste espaço (1984:259). 
coletivas de caça e pesca, o calendário de eventos cerimoniais, etc. Nessas ocasiões, os homens conversam em voz baixa, deitados lado a lado e de olhos fechados, e suas vozes se misturam e se entretecem, da mesma forma como o ihi mrèmè praticado no warã.

Adquire relevo, para fins desta pesquisa, a interdição da gravação de tais discussões pela pesquisadora. Segundo Laura Graham: 'for their participants, these private meetings were confidential. Here they worked out positions and strategies which they would present in the men's-council's meeting. In these discreet meetings, the business of factional politics was done' (1995:88). Assim, enquanto Graham era bem-vinda a gravar as discussões realizadas no warã, as 'prévias' Ihe eram embargadas, apesar de não haver interdição de sua mera escuta, sem o gravador ${ }^{102}$.

Os Xavante apreciam enormemente que o ihi mrèmè seja gravado no warã, mas não em suas reuniões vespertinas. Interessante é o fato de que enquanto os 'velhos' empregam essa forma discursiva 'to throw around the weight of their age and wisdom and to stress the importance of their speech', os jovens interessam-se menos pela qualidade artística de performances de ihi mrèmè do que pelos indivíduos mesmos produtores de tais discursos, selecionando sempre internamente à sua própria facção os 'melhores' produtores de discursos coletivizadores ${ }^{103}$. Acredito que estes jovens atentem mais para o fato daqueles velhos se destacarem em função do 'prestígio' que detêm, qualidade necessária ao requerimento da qualidade de 'líderes' de aldeia. Para aceder a tal posição, a maestria no gênero discursivo ihi mrèmè é necessária, mas não suficiente $^{104}$.

Parece-me, desse fato, que o aspecto fundamental do ihi mrèmè para os Xavante é menos sua qualidade artística ${ }^{105}$ (e, em certa medida, as decisões ali concluídas ${ }^{106}$ ) do

\footnotetext{
102 "I wished to tape-record these secluded meetings. My requests met with firm denial. "In the warã central plaza, you can 'listen' with the tape recorder, only in the warã". "The houses of other prominent senior men buzzed with similar gatherings throughout the day. As I visited other houses I was welcome to lie by the men's side to listen, but with my ears only. In the warã, when positions were publicly articulated, I was welcome to record' (2003:88).

${ }^{103}$ Viria essa asserção contrastar com a proposição de Laura Graham a respeito da importância das formas expressivas enquanto fiadoras de um sentimento de 'continuidade cultural'? Seria a continuidade das formas a responsável por este sentimento de continuidade cultural, mesmo que o elemento 'enfocado' e valorizado pelos jovens seja mais os indivíduos produtores de tais formas, do que as formas em si? O interesse seria mais pela 'notabilidade' acumulada do que por seus 'recursos'?

104 "To become a village leader, a position characterized more by prestige than any real power or authority, a man must take the initiative to speak up in the men's council (...), a man must be perceived as one who represents the interests of the community at large. Confidence, the support of one's faction and skill in addressing the council not as a self-interested individual but as a member of a group are among the essential ingredients for success in Xavante's society. The more fully socialized the individual, the more he can represent his own interests as those of a broader group; he can thereby increase both his prestige and his opportunities to manifest his sociability" (2003:151).

${ }^{105}$ No sentido da criação artística individual.

${ }^{106}$ Segundo Maybury-Lewis (1984), o chefe irá enunciar a palavra final 'consensual' deste Conselho, mesmo que esse resultado não diga respeito às suas próprias propostas iniciais.
} 
que o fato de ser este o 'modo adequado'107 e, portanto, valorizado de 'entrada em relação' ou de 'tecer relações' entre facções através do discurso coletivizador e no warã. A exposição dessa ihi mrèmè vespertina, me parece, evidenciaria as posições de cada grupo político em relação àquele resultado decisório final, o que viria esvaziar o caráter 'contextual' e 'espontâneo' a que se pretendem os discursos produzidos no warã. Considero o embargo do registro de tais discussões vespertinas intrafaccionais como um daqueles possíveis 'efeitos' relacionados a situações de registro, a que caracterizo como 'rechaço'.

Tal 'efeito' é relevante para os fins desta pesquisa, em especial no que diz respeito às atuais propostas de valorização e salvaguarda de patrimônios imateriais pautadas no registro de conhecimentos e tradições orais. Se considerarmos o lugar central que a forma expressiva e discursiva ihi mrèmè ocupa na tradição oral Xavante, a qualidade oratória consistindo em um dos pré-requisitos fundamentais a qualquer Xavante que pretenda assumir uma posição de prestígio e, enfim, uma das principais marcas da hierarquia etária entre esta população, este modo expressivo seria um dos focos propícios à salvaguarda de 'patrimônios imateriais' em relação a esta população indígena, em especial em sua rubrica 'expressões e tradições orais' e 'formas de expressão', de acordo com o texto da Convenção da Unesco de $2003^{108}$. Segundo o texto da Convenção, propostas de salvaguarda visam também o incremento da transmissão, pois, como vimos "entende-se por "salvaguarda" as medidas que visam garantir a viabilidade do patrimônio cultural imaterial, tais como a identificação, a documentação, a investigação, a preservação, a proteção, a promoção, a valorização, a transmissão - essencialmente por meio da educação formal e não-formal - e revitalização deste patrimônio em seus diversos aspectos". Segundo esta proposição, parece-me que supõem que 'registros' possam se constituir também como formas de potencializar o aprendizado de 'tradições orais', em especial pelas populações mais jovens. Questiono-me se seria de alguma forma possível o aprendizado de recursos expressivos ihi mrèmè através de gravações das falas coletivizadoras executadas no warã, dada a 'confusão de diversas falas paralelas' que caracteriza aqueles discursos segundo Graham ${ }^{109}$.

Já vimos como tradições orais consistem no 'conjunto de expressões orais de uma cultura, se aplicando às interações sociais fundamentais, segundo os modos considerados adequados de sua forma e uso' (Monod-Becquelin, 2005:34). O fato de se aplicarem a formas de 'interação social' consideradas adequadas não implica a

107 Um critério estético, contudo pautado menos na noção de criação individual que de percepção de manutenção.

${ }^{108}$ E o decreto 3551/2000 relativo à Política Nacional do Patrimônio Imaterial no Brasil.

${ }^{109}$ E ainda, se a detenção deste recurso expressivo passa por seu aprendizado ao longo do tempo, vindo caracterizar a posição hierárquica dos 'velhos' ihi, o quanto seu aprendizado através de novos meios não viria afetar as formas locais de alocação de valor que caracterizam a fala como forma de acúmulo de potência política, enquanto capacidade de produzir mais e mais relações de modos considerados corretos pelos atores? 
manutenção também dos contextos e interlocutores em que tais 'interações' devam ocorrer? O quanto o deslocamento de 'tradições orais' para novos contextos, - mesmo quando tais tradições vêm assumir a forma de registros-, não esvaziaria as próprias interações que são ali tecidas? $O$ fato de a ihi mrèmè empregada nos espaços vespertinos de debates internos às facções ter sua gravação por pesquisador interditada não aponta para essa restrição de translação entre contextos efetivamente contrastados de interação, ainda que a forma expressiva empregada seja a mesma? Um dado muito interessante para fins desta análise consiste no fato de os próprios Xavante realizarem um 'controle' acerca do que pode, do que deve e do que não deve ser registrado.

Apesar de Laura Graham focar sua reflexão na produção do discurso coletivizador Xavante, não era seu intuito dialogar com eles acerca de suas perspectivas teóricas de análise. Assim, a autora busca trazer ao leitor uma 'entrada' acerca das formas como os discursos ocorrem internamente a uma 'comunidade de fala', o que a autora caracteriza como "naturally occurring speech". Os fragmentos de discursos transcritos literalmente intentam antes ilustrar certo argumento; não concernem enunciados dirigidos ao leitor (no sentido de que os Xavante não falam ao leitor ${ }^{110}$ ). Ao mesmo tempo, talvez não fosse possível chegar aos mesmos resultados analíticos senão deste modo já que, segundo Graham, os Xavante sentiam-se incomodados ao serem questionados a respeito dos discursos produzidos no warã. Sentiam-se desconfortáveis com tais questionamentos e negavam veementemente comentar tanto as falas de outros quanto as suas próprias ${ }^{111}$. A autora afirma que os Xavante não possuem o distanciamento necessário para perceberem a relação entre suas formas discursivas e a produção de uma força que se contrapõe ao faccionalismo Xavante, ao menos no âmbito da warã. Segundo a autora:

"while Xavante recognize that the way elders speak, ihi mrèmè, differs from everyday conversational speech, they do not have a developed metadiscourse with which to describe its salient characteristics. Xavante are not metalinguistically conscious of the formal characteristics of ihi mrèmè, but they are clearly aware of the style" (1993:164).

\footnotetext{
110 Entretanto, é preciso fazer aqui uma ressalva, acerca do fato de Laura Graham 'estar lá', com seu gravador, influenciar o caráter desses discursos, mesmo quando não era ela a 'interlocutora'. Laura é aqui uma 'audiência' e seu gravador uma 'audiência' potencial, segundo o ponto de vista dos Xavante de Pimentel Barbosa, e em especial de Warodi (discutirei melhor este ponto adiante). Interessante pensar, nesse caso, 'a quem falam os Xavante'? E ainda, em iniciativas de valorização pautadas no registro: a quem são dirigidas essas falas registradas? No presente caso, parece-me que, segundo a proposição da autora de analisar 'naturally occurring discourses" tais enunciados eram produzidos para 'si mesmos'; mas com a clareza de que seriam ou poderiam ser escutados 'longe', por outros.

111 "Men rarely claim responsability for speeches they have given in the warã. Similarly, participants decline to comment about the speeches of others. If asked to summarize or to remark upon an individual's speech in a previous men's-council meeting, men often respond that they didn't hear it, don't remember or were asleep. They may suggest inquiring the speaker himself, who, when asked, downplays his role in the proceedings. No one ever admits having paid attention to any one individual or having had a position of prominence at the meeting" (2003:165).
} 
No que diz respeito a projetos de valorização cultural em que membros de comunidades indígenas são chamados a participar como efetivos agentes em ações de salvaguarda, o que o fato de os Xavante não serem 'metalinguistically conscious' das características formais do gênero ihi mrèmè implicaria? Reconhecem os Xavante a forma expressiva ihi mrèmè como central à sua 'cultura'? ${ }^{112}$

Segundo as premissas gerais da política de salvaguarda do patrimônio imaterial no Brasil, "o patrimônio cultural diz respeito, sobretudo, aos sujeitos sociais que produzem e mantém este patrimônio. (...) Assim, o reconhecimento dessas artes, ofícios, saberes e formas de expressão como patrimônio deve fazer sentido e ter significado, antes de tudo, para os seus detentores, ou seja, para aqueles que são, em última instância, responsáveis por sua existência e continuidade"(Sant'Anna, 2008) ${ }^{113}$.

Considerando-se que ações de salvaguarda visam o incremento da transmissão de 'patrimônios imateriais', e de que 'tradições orais' concernem no 'conjunto de expressões orais de uma cultura, se aplicando às interações sociais fundamentais, segundo os modos considerados adequados de sua forma e uso' (Monod-Becquelin, 2005:34), de que modos ações de salvaguarda poderiam efetivamente produzir a valorização e o reconhecimento pelos atores a respeito não somente de valores, crenças e significados, mas dos modos 'considerados adequados de sua forma e uso'? E ainda, se tais formas expressivas aplicam-se especialmente no âmbito do que Graham caracteriza como os 'naturally occurring discourses', como poderiam tais formas serem privilegiadas no âmbito de 'projetos', que segundo Carneiro da Cunha "should be understood as any combination of cultural, political or economic endeavors that rely on external agents as well as the indigenous population" (2004:6)? Isto é, que se constituem em esforços que, segundo esta autora, não seriam regidos por uma

\footnotetext{
112 Como veremos adiante, em seus enunciados e no que diz respeito à sua 'cultura' os sujeitos Xavante referem-se especialmente aos 'always living creators' e os ancestrais, assim como aos 'fundamentos da vida Xavante contidos em suas histórias míticas' (enunciados da tradição). Viver do mesmo modo como os criadores viviam e das formas indicadas por eles através do sonho é a forma avançada pelos Xavante de Pimentel Barbosa para continuarem a serem 'sempre Xavante'; Contudo como ressalta Graham, também através da continuidade de formas discursivas e expressivas, que provêm aos atores um sentimento de persistência e de continuidade cultural através do tempo, ainda que em seus enunciados ressaltem antes a relação de continuidade com os criadores (de modo geral), em que menos atenção é dada por eles, 'metalinguisticamente', às formas expressivas e discursivas.

${ }^{113} \mathrm{O}$ fato de sujeitos indígenas indicarem através de enunciados que o que é fundamental em suas 'culturas' são suas relações com ancestrais e criadores, parece vir promover a proliferação de experiências de valorização cultural pautadas em registros de narrativas míticas. Tais enfoques vêm acarretar a presumida inferência, do 'senso comum', de que o único modo de estabelecimento de relações entre sujeitos indígenas e seus ancestrais e criadores seja através da continuidade de transmissão de conteúdos míticos através de narrativas, enquanto referência a um 'passado' (em detrimento de experiências de relação ou interação que se dão em esferas mais 'laicas' da vida cotidiana como sonhos, festas, interpretações acerca de eventos da 'natureza', etc.). O enfoque de tais experiências, no registro de narrativas míticas, tende a reiterar o aspecto supostamente imutável de tais narrativas e, consequentemente, de seus sujeitos, muito em razão da dificuldade inerente aos próprios instrumentos de registro, de 'dar conta' dos modos narrativas são algo 'vivo', que variam de um contexto a outro, e que vêm expressar algo sobre o momento presente da enunciação e da relação entre interlocutores (Bauman: 1986). Deverei discutir melhor este aspecto quando do 'caso' Kanak.
} 
lógica interna à cultura, mas sim por uma lógica de "cultura"114 e de enunciado da cultura enquanto discurso político. Deverei voltar a este ponto adiante, a partir da discussão acumulada.

Outro recurso empregado pelos narradores Xavante consistia em atribuir sua fala à palavra dos ancestrais. Segundo Graham, este expediente agiria no sentido do eclipsamento da individualidade da argumentação para ao mesmo tempo conferir-lhe legitimidade. Interessante notar que nos fragmentos de discursos apresentados pela autora o emprego de referências aos criadores e aos ancestrais aparecem em todos os casos. Segundo Graham, o recurso a referenciais "ancestrais" não se encontraria desvinculado da argumentação política, seu emprego antes legitimando a 'negatividade' e a 'notabilidade' dos sujeitos dos discursos. Laura Graham evita fazer constatações no que concerne o caráter semântico da apropriação de tais referenciais míticos e cosmológicos no âmbito da arena política. Segundo Graham:

"This [o recurso à palavra dos ancestrais e aos always living creators] is a rhetorical device that further distances a speaker from the content of his speech (...) a man becomes less accountable if he presents his argument in this way"(1993:735).

No capítulo "Depersonalizing the dream", do livro "Performing Dreams" (2003), Graham expande sua análise, ao apontar para o fato de que o caráter coletivo da produção de discursos extrapola a esfera do político em seu sentido estrito. A autora descreve e analisa, neste capítulo, como se dá o ensinamento de três cantos apreendidos em sonho segundo o gênero da-ñopre por Warodi, seguido do relato de um sonho, em forma narrativa. Neste último, os sênior men que participam da cerimônia se valem dos mesmos recursos expressivos "coletivizadores" utilizados na produção do ihi mrèmè na construção coletiva daquele relato de sonho (Laura Graham ressalta o caráter aparentemente inovador do emprego do ihi-mrèmè no relato de sonhos, em geral transmitidos na forma de cantos da-nópre). Para os Xavante, os sonhos encontram-se dentre as esferas privilegiadas de aprendizado, que se dá através da revelação dos ancestrais $^{115}$, que mostram, explicam e esclarecem tanto questões relativas ao tempo das origens e do passado remoto quanto aquelas que concernem o presente e o porvir, através de sua aparição e do ensinamento de cantos para aqueles que sonham ${ }^{116}$.

\footnotetext{
${ }^{114}$ Como já afirmado, para aquela autora a cultura sem aspas seria aquela para a qual sempre estiveram voltados os antropólogos, e cujos aspectos analíticos são inconscientes para seus praticantes. Já "cultura" remeteria aos modos como grupos enunciam para outros sua 'cultura', sua 'tradição', enunciando assim o que se quer seu 'patrimônio'.

${ }^{115}$ Ancestrais e criadores que não chegam a serem identificados e nomeados, sobretudo pelos sonhadores mais jovens.

${ }^{116}$ Laura Graham apresenta os modos como da-ñopre, cantos recebidos dos imortais e dos criadores höimanapupö em sonho pelos indivíduos adultos, são transmitidos pelos 'sonhadores' da classe de idade ipredup-te (os 'wapte sponsors) para os jovens wapte habitando a hö, as casas dos solteiros. Após ensaiarem diversas vezes o canto e a dança, os jovens wapte irão cantar e dançar no pátio da aldeia, em frente a algumas casas, e em direções opostas. Essa prática expressiva pode ocorrer muitas vezes ao dia, a cada vez que um i-predup-te possui um canto de sonho a ensinar, e a prática dura por todo o tempo em que o grupo de wapte habita as casas dos solteiros. Os wapte, pré-iniciados, desenvolveriam assim 0 conhecimento expressivo para, após a sua iniciação, desenvolverem eles mesmos os recursos necessários
} 
Contudo, se os mais jovens recebem cantos dos imortais em seus sonhos, Warodi, principal interlocutor da pesquisadora, irá apresentar aquela sua experiência como uma interação com os imortais e criadores do mundo Xavante através do sonho ${ }^{117}$.

$\mathrm{Na}$ descrição daquela transmissão de uma experiência de sonho na forma de uma narrativa por Warodi a outros sênior men no âmbito da marã ${ }^{118}$, e do emprego do gênero coletivizador ihi-mrèmè pelo grupo, a autora aponta para elementos que vão sendo levantados nas falas paralelas e incorporados ao âmbito da transmissão/produção coletiva deste sonho, elementos relativos a esferas mais laicas da vida cotidiana, como avaliações que os Xavante fizeram de eventos recentes à época. Ou seja, modos de relação com os ancestrais e criadores que concernem o tempo presente, e que deverão ser discutidos a seguir.

\subsection{Registros da oralidade por Laura Graham e seus 'efeitos'}

Gostaria de apontar aqui alguns aspectos relacionados aos 'efeitos' dos procedimentos de registro de Laura Graham junto aos Xavante de Pimentel Barbosa, conforme relatados pela própria autora, visando ressaltar alguns elementos relevantes para o objetivo desta pesquisa, a reflexão acerca de ações de registro de 'tradições orais' voltados à valorização e salvaguarda de patrimônios imateriais.

É preciso novamente ressaltar que antropólogos vão a campo e 'produzem' dados etnográficos alinhados a propostas de pesquisa elaboradas, de modo geral, em momentos anteriores à sua estadia em 'área'. Assim, metodologias de 'coleta de dados', assim como os temas e focos de tais registros, são pautados segundo objetivos teóricos precisos. Isto não impede, entretanto, que pesquisadores realizem registros que não estejam atados aos seus objetivos primeiros, registros resultantes dos múltiplos e difusos interesses demonstrados por seus interlocutores. Se Laura Graham intentava, num primeiro momento, focar sua análise nos naturally occurring discourses, logo no início de seu trabalho de campo a autora deparou-se com um verdadeiro frenesi

para o recebimento de cantos dos criadores e imortais em sonho (durante a iniciação, a perfuração da orelha, que os Xavante comparam à 'antenas', é um dos elementos que indicam a entrada dos iniciados na esfera dos potenciais 'sonhadores'). Desenvolvendo os recursos para sonhar, seus cantos serão então ensinados para as gerações descendentes wapte quando eles mesmos atingirem a classe de idade $i$ predup-te. Nesse sentido, o repertório de cantos é inovado a cada nova geração que adentra a casa dos solteiros. Graham sugere que a prática expressiva do canto e dança da-ñopre moldaria as formas através das quais a experiência do sonho é experimentada, possivelmente vindo a influir nos modos mesmos como estes sonhos vêm a ser apresentados à consciência individual. Cantos 'produzidos' e transmitidos por cada indivíduo da classe de idade ipredup-te e performados coletivamente pelos wapte, fonte de prestígio para os 'sonhadores-transmissores', também produziria um efeito de coesividade internamente às classes de idade e entre classes de idade de metades ágamas, coesividade que perde sua força conforme os indivíduos avançam nas classes de idade, quando o faccionalismo tenderia a suplantar a solidariedade entre membros de uma mesma classe de idade.

117 "Warodi portrays himself as one who actually moved into the realm of the distinguished immortal creators (...) By manipulating formal devices in his speech Warodi alignes his identity with that of the originators of the Xavante world, Warodi becomes a creator himself' (2003:176).

${ }^{118}$ Clareira na mata próxima a aldeia utilizada em cerimônias interditadas à participação de mulheres e crianças. 
decorrente do fato de deter os recursos para gravar, anotar, transcrever e traduzir discursos e narrativas de seus interlocutores Xavante. À época de sua pesquisa, gravadores não eram acessíveis à população da aldeia. $A$ autora relata que nos primeiros tempos de sua estadia uma grande parte de suas fitas e pilhas foi 'consumida' por demandas de indivíduos que intentavam 'terem suas vozes gravadas' para 'serem levadas para o outro lado do oceano' (ou seja, discursos desvinculados de uma situação intracultural 'natural'), para serem 'publicadas' (mesmo que, em geral e de acordo com a proposta da autora, não o fossem). Assim, podemos avançar que parte das gravações foi realizada segundo uma intencionalidade propriamente indígena. Dessa maneira, poderíamos afirmar que o 'controle' da produção de registros foi relativamente compartilhado entre pesquisadora e interlocutores Xavante. Os Xavante foram agentes do registro tanto no que concerne grande parte do que veio a ser registrado (quando interlocutores pediam a Laura Graham para registrar discursos produzidos especialmente para o gravador), quanto no que concerne a âmbitos que não poderiam ser registrados (as discussões prévias à warã, por exemplo), para além da proposta teórica da autora. Nesse sentido, se o etnógrafo não aparece como interlocutor no discurso, ele é interlocutor pelo fato de estar lá, e 'deter' o gravador, assim como a virtual mediação entre o discurso e seu público potencial, segundo o ponto de vista nativo ('os brancos' para os Xavante; os 'antropólogos' para a autora).

O que eu gostaria de apontar com essa discussão, é de que não é possível estabelecer, a priori, conexões causais lógica e unicamente determinadas entre as propostas teóricas e metodológicas adotadas por pesquisadores em campo, e o resultado de seus procedimentos de registro na forma de 'produtos'. Esses produtos podem resultar de agenciamentos múltiplos, que vêm imprimir áreas de interesse de seus executores (os pesquisadores), mas também possibilidades privilegiadas ou 'inovadoras' que atores indígenas vislumbram plausíveis através desses procedimentos 'vindos de fora'. Pois se a modalidade adotada nos procedimentos de registro vêm 'de fora', com objetivos 'para fora' (para a reflexão antropológica e segundo enfoques teóricos previamente definidos), os procedimentos e produtos podem servir para múltiplos fins, segundo a interpretação dada pelos próprios atores. Como no caso da parceria Laura Graham-Warodi, quando a autora relata que interesses distintos vieram convergir. Daí a possibilidade de se pautar por procedimentos e produtos de registro realizados em situação de pesquisa para pensar as atuais propostas de valorização e salvaguarda que requerem o registro de 'tradições orais'. Quais as possibilidades vislumbradas pelos próprios atores na produção e nos produtos de 'registro' de seus enunciados? Que modos de produção de registro, e quais formas de registro produzem 'efeitos' junto aos seus sujeitos ${ }^{119}$ ? E quais efeitos são estes? Tais eventos podem ser acessados em especial em casos em que pesquisadores trazem para o corpo de suas

${ }^{119}$ Efeitos estes que, como vimos, implicam especialmente a agência indígena. 
análises descrições a respeito dos agenciamentos desses registros por parte de atores indígenas, assim como o 'espaço' permitido a tais agenciamentos de acordo com as abordagens e com as formas de 'entrada em relação' entre pesquisador (ou executores de registros de 'tradições orais') e sujeitos indígenas.

Laura Graham relata um fato importante ocorrido em fins da década de 80, que seria o aumento do prestígio da aldeia de São Marcos principalmente devido à forte liderança de Mario Juruna. Um dos exemplos centrais de relato de sonho apresentado pela autora concerne o de Warodi, em que as palavras "transmitidas" pelos ancestrais e complementadas a partir de contribuições de todos os outros membros do warã remetiam à forma como os Xavante de Pimentel Barbosa, apontados pelos ancestrais em sonho (e reiterando seus próprios argumentos) como sendo os verdadeiros descendentes da raiz da tradição Xavante, deveriam fazer com que suas "estórias fossem ouvidas", e assim "trazer abaixo as outras aldeias"120.

Os três tipos de materiais aqui discutidos para o 'caso' Xavante referem-se a propostas realizadas junto à população de Pimentel Barbosa que, ao produzirem discursos tendo como audiência potencial os 'brancos', e dado todo o aparato midiático de que estes dispõem, assumem-se enquanto os verdadeiros descendentes da raiz da tradição 'Xavante', os 'Xavante' por excelência, mesmo que a população das outras aldeias não participe destes processos nem seja contemplada por seus benefícios. Quais conseqüências tais 'monopólios' de identidade (ou de cultura, enquanto percepção de continuidade de formas expressivas, ou da 'reavivação das celebrações' por Pimentel Barbosa, através de gerações ao longo do tempo) podem produzir no que diz respeito a experiências de valorização cultural pautadas no registro de 'tradições orais', quando tais 'tradições enunciadas' avançam uma 'identidade', ou a continuidade de formas de expressão que, segundo o ponto de vista de seus atores, não é necessariamente compartilhada por outras aldeias ou 'comunidades'?

Laura Graham afirma que fazê-la compreender sua visão de mundo tornou-se uma missão para Warodi, seu principal interlocutor, e que desse modo suas intenções e as de Warodi convergiam. Warodi, após certo tempo de interlocução ativa com a autora, em que esta habitava sua casa e fora acolhida como 'filha' em termos classificatórios, afirmou haver recebido um novo nome dos criadores imortais em sonho: Tsiputõri $\tilde{o}^{121}$. Assim, o fato de Laura Graham oferecer os meios de preservar a memória de Warodi para as gerações futuras através da gravação e da escrita poderia, do ponto de vista do próprio Warodi, tornar seu conhecimento, assim como uma parte dele mesmo,

120 "Etepa: of course/it is always we [the elders]/it is always we who enliven the celebrations/and [thus] surpass the other villages.

Sipuba: so our ancestors/our ancestors/ through our lives they will be remembered/like this we will bring down [rise above] the other villages/ we will let our stories be heard/ this is the way it will be" (2003:170). Ou seja, o fato de que são eles, os Xavante de Pimentel Barbosa, que, ao 'enliven the celebrations', 'through their lives, remember the ancestors'.

${ }^{121}$ Que a autora traduz por "never ending': o que nunca tem fim. 
imortal $^{122}$ (1995:17). Warodi vislumbrava na documentação realizada pela antropóloga a possibilidade de divulgar ao mundo exterior que ele próprio, assim como os membros de sua 'comunidade', são os verdadeiros descendentes dos primeiros criadores. $\mathrm{He}$ 'wished to position his people within a global context' (1995:16).

De fato, nos capítulos finais da obra de Laura Graham, a autora descreve e analisa um evento de transmissão de três cantos comunicados pelos criadores em sonho para Warodi, que são então ensinados a outros senior men no marã, segundo a forma ihimrèmè. Assim, outros vêm participar na produção discursiva daquele relato de cantos adquiridos em sonho, fazendo deles antes expressões coletivas do que individuais. Em seguida, a autora irá salientar os modos como, através do emprego de deíticos e da assunção do 'eu-criador' na primeira pessoa, Warodi vem se integrar aos ancestrais ao transmitir sua mensagem experimentada em sonho, de modo que seu self deixa de ser aquele de Warodi para assumir-se sob seu novo nome de Tsiputôri õ, um hoïmanapupo, um 'always living creator'. Em seguida, a autora relata o evento excepcional que deu nome à sua obra, Performing Dreams, que consistiu na encenação, com a participação de todos os indivíduos de Pimentel Barbosa (crianças, jovens, adultos, mulheres e idosos), de uma daquelas experiências acessadas em sonho por Warodi. O caráter excepcional deste evento, segundo Graham, consiste no fato de que tal forma expressiva não consta do leque de formas expressivas que constituem o calendário cerimonial Xavante. Assim, aquela encenação foi também produzida devido à presença da antropóloga (apesar de Warodi focar, em seus enunciados, sobretudo os jovens) tendo em vista os recursos audiovisuais (fotografia e gravação) e midiáticos de que dispunha a autora para propagar a mensagem de que os Xavante de Pimentel Barbosa eram os verdadeiros descendentes dos criadores 'always living', e que continuariam vivendo como fizeram seus ancestrais, assim como Warodi, integrado aos criadores imortais através da propagação de sua memória pelos seus e por Laura Graham (2003: 175-206) ${ }^{123}$.

Graham chama também a atenção para a forma como o emprego do gravador era altamente valorizado na esfera do warã. Seus integrantes, por vezes, mostravam-se mais interessados em escutar um discurso polivocal gravado do que uma performance efetiva. O gravador também gerava um sentimento de que aquilo que estava sendo produzido ali ultrapassaria as fronteiras da esfera local, e que seria levado para "o outro lado do oceano", o que fazia com que os indivíduos se empenhassem especialmente no caso de seus discursos estarem sendo registrados.

\footnotetext{
122 "The quest for immortality motivates elders to pass on their memory to the youth" (1995:17).

${ }^{123}$ A autora se refere a essa intenção explícita de seus interlocutores através da mensagem divulgada durante os momentos preparatórios da encenação coletiva do sonho de Warodi (enquanto criador), quando este afirma:

Warodi: "you [youths] are going to paint with these/Now you are all the descendents of the first creator/This fact/This fact they [the youths that speak Portuguese] will teach to her [Laura Graham]/If she understands what you [youths] say/ it is to be published". Sipuba (irmão de Warodi): "it is for thaf" (2003:172).
} 
Os habitantes de Pimentel Barbosa referem-se a si mesmos como a verdadeira "raiz da tradição Xavante" face às outras 'comunidades' ou aldeias. Segundo eles, isso se justifica pelo fato desta aldeia ocupar a mesma região da histórica aldeia de Tsõrepre, à qual os diversos grupos Xavante, hoje distribuídos em 9 Terras Indígenas e diversas aldeias em constante processo de cisão (e reagrupamento, em menor escala), referemse como sendo o local de ocupação ancestral previamente à sua dispersão e atual distribuição em reservas distintas. Outro argumento para sua legitimação enquanto verdadeiros A'uwe uptabi (termo em língua para referirem-se a si mesmos), os habitantes de Pimentel Barbosa vêem a si como aqueles que tiveram pouca ou nenhuma influência da parte de missionários, já que nenhuma missão conseguiu se estabelecer em sua aldeia ou proximidade de forma permanente. Os habitantes de Pimentel Barbosa também se assumem como descendentes diretos dos agentes que primeiro estabeleceram o contato e a pacificação dos brancos (2003:20-63).

Segundo Graham, nas narrativas e discursos produzidos pelos habitantes daquela aldeia, tais prerrogativas são trazidas à baila especialmente quando da competição por recursos governamentais e não-governamentais frente a outras aldeias Xavante $(1995: 29)^{124}$. Parece-me, deste fato, que tanto na demanda por 'antropólogos', quanto no caso de 'projetos', os Xavante de Pimentel Barbosa (e provavelmente, também os de outras aldeias) recorrem a tais 'projetos' e agentes externos também como forma de se valorizarem não somente frente aos 'brancos', como internamente às suas 'comunidades' frente a outros grupos e aldeias.

Os Xavante se vêem atualmente envolvidos em parcerias as mais diversas: com biólogos e botânicos, colaborando para a formulação de planos de desenvolvimento sustentável; com videastas e programadores, registrando rituais que são vistos por eles, mas principalmente utilizados na divulgação de "sua cultura" para os "brancos", gravando discos com a banda Sepultura, fazendo apresentações de rituais nas grandes cidades e criando páginas na internet (Graham, 2001).

Segundo Clarice Cohn, 'os Xavante têm conseguido ganhar visibilidade na mídia a partir da combinação de uma ênfase na tradição e inovações na divulgação e na colaboração com profissionais das mais diversas áreas. Ou seja, a inovação e a comunicação com o exterior e nas relações interétnicas é utilizada para mostrar sua indianidade por meio da divulgação de sua tradição e cultura mantidas - ou melhor,

\footnotetext{
${ }^{124}$ Simon Harrison sugere que "ethnic groups may sometimes conceive themselves as in conflict not so much because they have irreconcilably different identities, but rather because they have irreconcilable claims or aspirations to the same identities' (1999:239).
} 
divulgadas como mantidas-, perpetuadas, em resposta à expectativa de imutabilidade ${ }^{125}$ que descobriram nos brancos' (Cohn, 2001:41, ênfase minha).

Tal proposição dialoga potencialmente com a afirmação de Jack Goody quando este escreveu, - com foco nas mudanças proporcionadas pelo regime de escrita-, que "qualquer mudança no sistema de comunicação humana tem necessariamente repercussões no conteúdo transmitido ${ }^{126 " ~(1979: 46) . ~ N e s t e ~ s e n t i d o, ~ i n o v a c ̧ o ̃ e s ~ e m ~}$ formas de divulgação podem vir a se constituir como produtoras mesmas de inovações, a meu ver, não só nos conteúdos, mas em formas expressivas criativas e relevantes, e não somente para a divulgação exterior, mas também para si. Como foi o caso da performance do sonho que, ao se constituir enquanto uma 'inovação' nos modos de transmissão 'tradicionais', produzida também para a antropóloga, concerniu, antes, um recurso didático voltado para os jovens de Pimentel Barbosa para que estes, segundo Warodi, aprendam que são 'a verdadeira raiz do povo Xavante' e para que continuem vivendo segundo os 'always living creators ${ }^{\text {,27 }}$. O quanto os próprios Xavante reconhecem tais 'inovações' como significativas, para $\mathrm{si}^{128}$ ? Pareceu-me que essa

\footnotetext{
${ }^{125}$ O quanto a 'inovação' que foi a encenação da vida dos criadores always living não se constitui uma forma de divulgação de 'imutabilidade' e indianidade, segundo a percepção dos próprios Xavante de Pimentel Barbosa?

126 Isso porque, havendo cada ator Xavante 'desempenhado' um personagem-criador, suas ações correspondiam a formas individuais, ainda que consideradas potencialmente compartilhadas, de interpretação e, portanto, de encenação de eventos da vida dos criadores, vindo tornar 'pública' uma representação individual.

127 Adquire relevo aqui o fato de a apresentação de rituais nas grandes cidades, como é o caso da participação Xavante no evento 'Rito de Passagem' organizado pela ONG Ideti parecer haver se constituído como um 'aprendizado' acerca de formas 'didáticas' de expressão cultural Xavante para os brancos (http://www.ideti.org.br/projetos/rito/hist_rit.html). Interessante o fato de tal prática (cujo surgimento talvez remonte ao 'contato' com antropólogos em suas aldeias) ser 'reapropriada' internamente, no caso da performance de sonho de Warodi, para o ensinamento para os jovens do própria aldeia acerca do 'always living creators'.

${ }^{128}$ Há aqui um paralelo produtivo no que diz respeito à relação entre 'patrimônios materiais' e 'patrimônios imateriais'. Isso porque atualmente, no que tange as chamadas 'arts premiers', há um debate relativo à avaliação quanto à autenticidade de tais peças, em especial segundo o ponto de vista de colecionadores. Para serem consideradas efetivamente 'autênticas', estas devem haver tomado parte em um 'sistema simbólico' 'interno', ou seja, sido empregadas seja em usos 'laicos' e cotidianos na forma de utensílios, seja em 'práticas rituais'. São consideradas 'inautênticas' peças que, por mais que se assemelhem às originais, foram produzidas deliberadamente para colonizadores ou para o mercado de arte. Peças consideradas 'falsas' são aquelas produzidas 'deliberadamente para enganar', que não são reconhecidas como parte da 'tradição' de certo povo ou população (Derlon \& Jeudy-Baldini, 2008). Chama a atenção o fato de que tal debate foi trazido para o interior do espaço museal em uma exposição recente, em que toda uma sala é dedicada a estes 'verdadeiros-falsos' objetos, explicando seus estatutos, proveniência e particularidades ("Collection d'Art Africain du Musée de Grenoble, un patrimoine dévoilé", com fim previsto para out/2008). Mas de que modos as próprias populações avaliam esta 'autenticidade'? Anne-Gaelle Bilhaut relata que, junto aos Zápara do Equador, certas peças de arte Zápara em posse do Museu do Quai Branly foram 'autenticadas' como 'patrimônio' para si, como efetivamente Zápara, a partir do momento em que um de seus sujeitos 'sonha' com tais peças, sua autenticidade 'consignada' pelos ancestrais em sonho (2007:311323). De que modo políticas do 'patrimônio imaterial' irão avaliar tais 'novidades', considerando-se que práticas de registro necessariamente produzem 'repercussões no conteúdo transmitido' (Goody, 1979:46)?. Considerando-se o registro de 'tradições orais', o quanto seus atores consideram que tais registros são realizados 'para si' ou para 'outros'? No caso de produzidos para 'outros', de que modo tais registros são avaliados por seus sujeitos? O fato de entre os Zápara o sonho vir a consignar certa peça como 'própria' apontaria para a necessidade de 'tradições' e 'patrimônios' deverem passar por modos próprios de conhecer para serem 'autenticados', para serem considerados relevantes para si? Deverei voltar a este debate no final do presente capítulo.
} 
performance foi bastante valorizada pela população de Pimentel Barbosa, em especial pelo fato de que, através dela, as vidas dos criadores foram 'revividas', e os criadores, desse modo, efetivamente 'reavivados' ${ }^{129}$. Mas pergunto-me se tais 'performances' são, posteriormente, incorporadas ao 'calendário cerimonial', ou realizadas 'para/entre si'. Parece-me que não. Constituem-se assim 'enunciados da tradição'?

No que diz respeito àquelas disputas entre 'grupos' e aldeias Xavante, veremos, entretanto, que há certos aspectos relativos aos modos de expressão e enunciação, fundamentalmente a ihi mrèmè, que impedem que tais cisões entre aldeias sejam propriamente 'discutidas', 'enunciadas' em situações de interação mediadas por discursos segundo formas próprias à tradição oral, mas não entre 'outros'. Este aspecto vem complementar também o fenômeno exposto por Laura Graham, segundo a qual os Xavante negam veementemente comentar tanto as suas próprias falas como a de outros, especificamente aquelas produzidas no warã.

No epílogo de "Performing Dreams" (2003) Laura Graham explicita de que modo sua pesquisa e o fato de "haver estado lá" produziu ainda efeitos bastante inesperados. A autora relata que certo tempo após o final de sua pesquisa, Cipassé, filho do irmão de Warodi, havia solicitado as fitas gravadas pela autora, principalmente aquelas que registravam narrativas de Warodi (agora recém falecido) sobre a vida dos criadores always living, para a constituição de um arquivo de documentos sobre 'a vida Xavante'. ${ }^{130}$ Graham realiza as cópias de fitas e as envia a Cipassé. Ao retornar alguns meses mais tarde, a autora não vê nenhum arquivo tal como imaginara. Por outro lado depara-se com um rapaz, Riridu, irmão de Cipassé, e de um grupo de idade que ainda não poderia ser considerado dos "homens maduros" (Riridu pertencia à classe de idade pritaipwa, anterior à classe i-predup-te, esta última a partir da qual os homens começam a participar do warã, mas ainda sem tomar parte nas falas ihi mrèmè), mas que havia praticamente se estabelecido como a uma liderança 'espiritual' local, havendo desenvolvido também uma maestria verbal do gênero ihi mrèmè no warã. Poucos dias depois a autora descobre que esse rapaz tem consigo todas as fitas que foram enviadas à aldeia, que escuta incessantemente. As fitas tratavam-se justamente de gravações acerca da vida dos criadores narradas por Warodi, considerado até sua morte a principal liderança local ${ }^{131}$. Riridu era considerado pelos seus como alguém que transmitia conselhos dos 'always living' hoïmanapupö aos habitantes de Pimentel

\footnotetext{
${ }^{129}$ Graham relata também o fato haver sido chamada por Warodi a vir presenciar esta perfomance, com seu gravador (2003:106).

${ }^{130}$ A autora comenta sua perplexidade, segundo o fato de que, durante os seis anos em que pesquisou e realizou registros junto aos Xavante, estes demonstraram muito pouco interesse em escutar narrativas registradas, preferindo em seu lugar a escuta de registros dos cantos da-no'pre.

${ }^{131}$ Graham relata sua perplexidade ainda do fato de Riridu não se embaraçar quando da descoberta da autora de sua posse das fitas. Ao contrário, quando esta reconhece as fitas em posse de Riridu como aquelas que ela mesma havia realizado junto à Warodi, Riridu mostra-se bastante contente, não reagindo como se "houvessem descoberto seu 'segredo", mas como um reconhecimento mútuo da importância de Warodi.
} 
Barbosa. Alguns membros da comunidade, pertencentes a uma facção minoritária, confidenciaram em âmbito privado sua opinião a respeito de Riridu à Laura Graham, de que este era uma 'farsa' (2003:227-237)

Tais descrições dão a ver formas próprias e criativas através das quais ferramentas de 'registro', associadas à possibilidade vislumbrada pelos atores para 'enunciar' suas tradições (como no caso da perfomance do sonho, produzida a princípio como recurso didático para a antropóloga) podem produzir novas formas de expressão cultural, em novos contextos (não 'tradicionais'). O quanto tais formas 'inovadoras' serão elas 'valorizadas' no âmbito dessas propostas de salvaguarda e valorização cultural dado que são essas propostas, também, que irão prover e promover ações de 'registro' de 'patrimônios imateriais', também elas em novos contextos? E ainda, o quanto serão elas consideradas 'próprias' e apropriadas, em especial no que diz respeito à 'atualização' regular de inventários, voltados ao 're-exame'?

"Os bens culturais imateriais possuem uma dinâmica de criação, atualização e transformação que faz com que o registro seja sempre o retrato de um momento e, por isso, deva ser refeito periodicamente com a finalidade de acompanhar mudanças ou adaptações que os processos sociais, econômicos e de trocas culturais imprimem nessas manifestações. Esse re-exame também é importante para se avaliar os impactos promovidos pelo processo de patrimonialização nesses bens. (...) para que seu registro como patrimônio cultural seja re-avaliado e confirmado" (Sant'Anna, 2008: 8).

Parece-me, aqui, que o próprio procedimento de registro já poderia ser abordado como uma primeira 'novidade', ou seja, de que ele já é uma inovação desde seu berço ao promover novos contextos. Pois 'projetos' consistem, como vimos, 'contextos' não 'tradicionais' já que, ao envolverem tanto sujeitos indígenas como agentes externos, podem vir agenciar a produção de 'enunciados da tradição'. Mas, como vimos também, "intercultural relations or intracultural relations are in strict ontological continuity." (Viveiros de Castro, 2004:2). Nesse sentido, atores culturais podem vir ativamente se apropriar desses contextos e instrumentos não somente para 'enunciar suas tradições', mas também para promover inovações relevantes em suas dinâmicas próprias de transmissão (para ensinar aos jovens; ou para potencializar a possibilidade de se alçar a um estatuto de 'criador', no caso de Warodi), enquanto certos aspectos de tais potenciais 'inovações', - ao que me parece -, são ora 'ignorados', não produzindo nenhum interesse por parte de seus atores para além de uma valorização 'para fora' (como veremos adiante), ora excluídos por eles enquanto passíveis de registro e de divulgação (no caso das discussões internas às facções). A meu ver, eventos e situações de registro deveriam ser considerados, em si mesmos, não como o 'retrato' 
de um momento, mas já como um 'novo momento' ou campo de ação potencial, especialmente quando consideramos os agenciamentos operados pelos atores quanto à seleção e o controle do que pode e do que não pode vir a ser tanto 'divulgado' (entre si), quanto patrimonializado (para 'outros', enquanto 'enunciados da tradição') ${ }^{132}$.

Em relação ao que foi exposto até o momento, gostaria de chamar a atenção para alguns pontos relevantes para esta análise, tendo em vista uma reflexão crítica a respeito de projetos de valorização e salvaguarda de 'patrimônios imateriais' pautados no registro de tradições orais e conhecimentos.

Alguns tópicos me parecem aqui relevantes para esta discussão, considerando-se a relação entre 'tradições orais' e modos de interação considerados adequados por seus sujeitos. Primeiramente, gostaria de refletir a respeito de quais âmbitos discursivos os Xavante consideraram apropriados ao registro naquelas situações, e a quais modalidades de 'coletivos' (ou de 'sujeitos expandidos', como veremos) correspondem tais âmbitos. Em segundo lugar, interessam-me formas de 'transformação' ou 'inovação' de práticas expressivas e de modos de transmissão possíveis de serem operadas ou potencializadas através de ações de registro, e as interpretações que fazem os próprios Xavante daquelas inovações.

Vislumbro aqui algumas modalidades de 'coletivos' (ou de 'sujeitos expandidos') que concernem: Warodi, enquanto líder de aldeia, representante dos interesses de Pimentel Barbosa (e Warodi-criador) ${ }^{133}$; facções (em contextos de interlocução prévias à warã), 0 coletivo 'Pimentel Barbosa' representado no warã (em que facções são 'negativizadas' através de discursos coletivizadores, e 'notabilizadas' através de seus representantes), e o coletivo 'Xavante'134.

Assim, a primeira focalização a ser aqui considerada concerne Warodi, principal interlocutor da pesquisadora. Esta última havendo gravado, - a pedido daquele -, uma série considerável de narrativas a respeito dos criadores höimanapupö segundo o

\footnotetext{
${ }^{132}$ Contudo, se esta percepção é partilhada por alguns agentes que lidam com ações ligadas ao registro e à salvaguarda de patrimônios imateriais, persiste ainda uma noção de que tais ações devam privilegiar 'patrimônios' segundo sua forma 'tradicional', em especial quando lemos, dentre os critérios que guiam a seleção de bens culturais passíveis de serem registrados: a 'continuidade histórica mínima de três gerações' (cerca de 75 anos)' e o 'enraizamento no cotidiano das comunidades' (Lima e Alves, 2008:7).

${ }^{133}$ Laura Graham emprega o termo 'village leader' em referência à Warodi. O termo 'líder' ou 'líderança' pode por vezes provocar certas confusões, visto que, em geral, os 'velhos', que acumulam recursos expressivos e conhecimentos que lhe conferem certo 'prestígio' não são os mesmos que são 'formados' para realizarem a interface entre a comunidade Xavante e os agentes que trabalham em tais comunidades ou 'os brancos' em geral, principalmente enquanto representantes de organizações indígenas. Warodi é um 'líder' para dentro ou para 'fora'? Talvez Warodi intentasse, através do trabalho com Laura Graham, acumular esses dois 'papéis', que em geral não convergem. No caso Wajãpi, vemos atualmente uma confusão entre o emprego do termos 'jovijã' ('velho', 'homem sabido') e o de 'liderança' (membros do Conselho das Aldeias Wajãpi- Apina, que representam os Wajãpi 'para fora'). Interessante que as lideranças, em geral mais jovens, não são confundidas com os jovijã, mas os jovijã são por vezes chamados lideranças, em especial se concentrarem também o papel de 'chefe' de aldeia (que são também visados no caso de comunicação com agentes 'brancos').

${ }^{134}$ Infelizmente a população geral aldeia de Pimentel Barbosa enquanto um 'coletivo' foi excluída desta análise, em decorrência do foco de Laura Graham serem as formas expressivas e discursivas na arena política warã.
} 
gênero formal ihi mrèmè. A partir da possibilidade encontrada em sua interlocução com a antropóloga e no trabalho de documentação e divulgação daquela, Warodi sonha com um novo nome, Tsiputõri ó 'the never ending', vislumbrado enquanto uma forma de dar continuidade à sua memória e a si mesmo para além do espaço-tempo de sua vida e da esfera local da aldeia. Aqui o sujeito da enunciação seria Warodi, considerado na 'interface' entre duas posições, de sênior men e Tsiputõri'õ, criador höimanapupö (um 'always living creators) ${ }^{135}$. A autora remete ainda ao uso da primeira pessoa na narrativa do sonho, em que Warodi se coloca não enquanto um recebedor, mas enquanto um produtor, ao lado dos imortais, de mensagens para os vivos a respeito de como os Xavante devem 'ser sempre Xavante'. Considero estes eventos também 'efeitos' do trabalho e da produção de registros operados por Laura Graham junto a Warodi. Atente-se para o fato de que os discursos gravados de Warodi a respeito da vida dos criadores concernem narrativas, em que não há interlocução na forma de diálogos $^{136}$. E ainda, de que o agente de tais registros foi Warodi, na medida em Laura Graham os realizou a pedido daquele (ou 'emprestou' seu gravador a ele).

O fato de o jovem Riridu haver se tornado uma forte liderança 'espiritual' local, e sua maestria na arte verbal ihi mrèmè haver se desenvolvido a partir da escuta das fitas de Warodi gravadas pela autora não pode ser desprezada, especialmente se considerarmos aquela nova identidade assumida por Warodi (agora falecido) através daquele nome revelado em sonho. Riridu torna-se um forte líder espiritual, e, através de performances ${ }^{137}$, afirma que recebe mensagens de Warodi e de Apöwa (pai de Warodi), - o que, de certa forma, não deixa de ser verdade. Gostaria de chamar a atenção aqui para o que eu caracterizo como uma 'proliferação', ou seja, o fato de narrativas de Warodi registradas por Laura Graham terem sido reinseridas na cadeia de transmissão

\footnotetext{
${ }^{135}$ Graham faz referência aqui a Aracy Lopes da Silva para discutir a importância do 'nome'. Conforme envelhecem, homens acumulam mais e mais 'amigos cerimoniais', o que vem crescentemente mitigar as marcadas distinções entre parentes e afins. As práticas de doação e tomada de 'nomes', assim como de amigos formais, alinha membros de metades exógamas, promovendo unidade entre homens estruturalmente opostos. Quando se torna um pritaipwa iniciado, o jovem recebe seu primeiro nome adulto do irmão de sua mãe. Durante a sua vida, um homem irá doar muitos nomes a novos recipientes, assim como tomar novos nomes de doadores mais velhos. Desse modo ele se torna parte de uma linhagem masculina distinta de sua descendência patrilinear. Essas práticas relacionam tanto gerações descendentes e ascendentes que portaram os mesmos nomes quanto, ao atravessar divisões em metades exógamas, contribuem para a identidade social adulta. Quando um homem atinge a classe de idade ihi (velhos), ele não mais recebe nomes, apenas os doa. " $A$ man ends his life as he begins: with no name" (2003:177). Entretanto, através dos meios oferecidos por Graham, Warodi pôde 'promover' sua própria imortalidade (acredito que os meios oferecidos por Graham foram necessários, mas não suficientes, dado seu estatuto de líder e sua classe de idade ihi, à iminência da morte). Isso porque através de seu 'nome' recebido em sonho Warodi promoveu-se ao status de höimanapupö, que corresponde ao dos membros individualizados da coletividade imortal, ao contrário dos wadzaparipwa, coletivo de imortais 'indiferenciados'. Segundo Graham, são as ações cerimoniais que relembram a vida e os atos dos criadores o que permite a eles serem os 'always living'. Um individuo é imortal enquanto sua memória e seu nome persistem ao serem transmitidos através de gerações. Quando esquecido, ele vem compor a classe dos wadzaparipwa. Mas Warodi, ao alinhar-se aos criadores always living, cujas vidas são relembradas através das cerimônias, 'tornou-se' já um imortal höimanapupo, antes de vir a falecer (2003:223).

${ }^{136}$ Segundo reportado, mas não evidenciado pela pesquisadora.

${ }^{137}$ Também inovadoras segundo nos reporta Laura Graham, tendo em vista as práticas expressivas 'tradicionais' ao calendário cerimonial Xavante.
} 
através de apropriação e recontextualização operadas por Riridu. Veremos, a partir das próximas experiências a serem aqui apresentadas, que este não é sempre o caso, mesmo quando tais registros são produzidos tendo em vista sua reapropriação pela população local. Por que as narrativas gravadas de Warodi 'proliferaram'? O fato de haver sido ele o autor de tais narrativas, para além das intenções da pesquisadora, assim como o fato de terem sido realizadas em língua Xavante, e sem interlocução, poderiam se constituir índices relevantes para tal interpretação? Infelizmente Graham não dá maiores explicações a respeito das características de tais narrativas nem acerca de como tais gravações foram realizadas.

Um elemento que me parece relevante foi o fato de Warodi haver adquirido um nome de 'imortal' tanto através de sua interlocução com a autora quanto através da gravação de suas narrativas, ou seja, os modos como o 'enunciado' da cultura para 'outros' (já que Warodi quer que suas falas sejam levadas 'através do oceano' para serem 'publicadas', de modo a posicionar sua comunidade em um 'contexto global') pode vir potencializar formas de alocação de valor através de regimes considerados localmente adequados, no caso específico aqui, através do recebimento de um nome. $O$ fato de Warodi receber um novo nome, em sonho, elevando-o à categoria de höimanapupö, não se deveu exatamente à percepção daquele interlocutor quanto às possibilidades de novos regimes textuais ${ }^{138}$ de apoiar formas locais de alocação de status, de 'magnificação, ${ }^{139}$ ? O quanto o estatuto de 'imortal' de Warodi propiciou a reapropriação de tais fitas por Riridi, para além de seu conteúdo ${ }^{140}$ ?

Mas e quando novos regimes textuais distorcem formas locais de autoridade, desobedecendo modos corretos e valorizados segundo as formas próprias à tradição oral no que concerne a circulação de conhecimentos? A apropriação das fitas por Riridu não se constituiu em uma forma criativa de reelaboração de modos tradicionais de transmissão do conhecimento?

\footnotetext{
138 "A idéia de 'regime textual' não tem necessariamente a ver com texto escrito, mas sim com um fundamento mais geral e elementar, da formalização do discurso, seja em uma forma específica da execução oral, seja por outros meios e outros suportes (gravação áudio ou visual; ou grafismo, pictografia, tecelagem, formulas xamânicas, música, ritual, canto cerimonial, etc)". (Cavalcanti-Schiel, 2007: 9).

139 Sztutman (2006) discute a magnificação ao analisar a produção de grandes guerreiros entre os Tupi antigos. Magnificação concerneria formas de constituição de pessoas singulares, através da acumulação de 'nomes e marcas', de modo que tais pessoas se diferenciariam não em natureza, mas em escala, ao se engajarem na produção de coletivos. Penso que, com todas as diferenças, em especial ao fato de o lugar do 'nome' entre os Jê não ser o mesmo que entre os Tupi, o termo 'magnificação' caberia aqui pelo fato de Warodi haver recebido um 'nome' de criador através de sua interlocução e de seu trabalho com Laura Graham, e de haver assim acumulado 'agência', i.e. 'capacidade de agir ou de afetar a ação de outrem' (Gell, 1998 In Sztutman, 2006); no caso, ao afetar a ação de Riridu e daqueles 'afetados' pela ação deste último.

140 Poderíamos aqui comparar a 'autentificação' de objetos Zápara realizados através de sonho pela consignação dos ancestrais, à 'autentificação' ou ao acúmulo de 'agência' das narrativas gravadas de Warodi, devido ao fato de sua elevação a um estatuto de imortal através de seu recebimento de um novo nome, em sonho?
} 
Segundo Graham, a aprendizagem acerca dos modos corretos de expressão do ihi mrèmè exige uma prática de longos anos no warã. Ao mesmo tempo, versões de narrativas mítico-históricas são transmitidas aos jovens durante muitos anos, em que estes se deitam ao lado de seus pais, tios e avós, durante as tardes, para escutarem tais narrativas. Riridu, sobrinho mais novo de Warodi, não teve tempo de escutar suficientemente tais narrativas relatadas por Warodi para desenvolver seu total domínio, pois ainda era muito jovem quando da morte daquele ${ }^{141}$. Também não pertencia à faixa de idade a partir da qual os homens iniciados passam a ser 'ouvidos' no warã segundo contextos tradicionais. Uma facção minoritária da aldeia, oposta à de Warodi, afirmava que Riridu era uma farsa (mas somente em âmbito privado, em 'confidências' para a antropóloga). Por que seria ele uma farsa? Por não pertencer à categoria de idade adequada à produção de discursos ihi mrèmè? Ou pelo fato de pertencer à facção 'dominante', naquele momento ${ }^{142}$ ? Gostaria de ressaltar aqui que, mesmo através de uma 'inovação', são aqui mantidos tanto os modos considerados adequados ao emprego da parole quanto os regimes locais de autoridade e alocação de status. De um lado, tanto não se discutem as 'falas' e enunciados de outros, em sua presença. ${ }^{143}$ De outro lado, Riridu torna-se, - indiscutivelmente-, uma liderança, ao deter os conhecimentos (sobre a vida dos criadores) e recursos expressivos adequados para tanto. Interessante é o fato de Warodi e Riridu pertencerem a uma mesma família; mas o que aconteceria se pertencessem a facções opostas ${ }^{144}$ ? O quanto o conhecimento transmitido segundo 'caminhos' inadequados não se constitui uma 'farsa'? ${ }^{145}$

\footnotetext{
${ }^{141}$ Isso não impede que ele tenha aprendido narrativas de outros 'parentes'.

142 Lembremos que os jovens apontam sempre indivíduos de sua própria facção como os melhores produtores de discursos ihi mrèmè.

${ }^{143}$ Para a antropóloga, não se discutem as falas de outros na warã. Mas sim 'confidências' a respeito do Riridu, deste último ser considerado uma 'farsa' para os membros de uma facção minoritária.

${ }^{144}$ A autora relata que, durante seu trabalho com Warodi, não havia nenhum jovem na aldeia de Pimentel Barbosa que pudesse realizar o trabalho de tradução das narrativas de Warodi gravadas pela autora. Por fim, Lino Tserepubdzi, um jovem da aldeia de São Marcos, aldeia cuja rivalidade com Pimentel Barbosa é histórica, concordou em auxiliar na tradução. Warodi e seus irmãos resolvem então realizar uma reunião para discutir esse problema. Ao final, eles concordam que Lino realize a tradução, e justificam sua decisão com base no parentesco. A partir de então, Lino passou a ser chamado aibö por Warodi ('filho do irmão' e mesmo classificatório para 'filho' adulto) enquanto este passou a chamar Warodi iimamaãmo ('meu outro pai', FB) (2005:13).

${ }^{145}$ Em relação à formação de pesquisadores Wajãpi, temos notado que, apesar de tais pesquisadores acessarem uma grande variedade de versões de narrativas e discursos relativos aos seus temas de pesquisa, eles tanto estabelecem uma nítida separação entre o que é 'aprendido em casa' e o que é 'aprendido na pesquisa' (no sentido de que, quando chamados a produzirem certa narrativa, 'reproduzirão' a versão aprendida 'em casa'), quanto valorizam enormemente a identidade dos narradores, parece-me que atribuindo mais importância a tais identidades do que às variações no conteúdo entre aquelas versões. Como afirmou Vansina (1984) em relação à transmissão através da oralidade entre populações de tradição oral, e como reiterou Gallois em relação aos Wajãpi (1994), em eventos testemunhados por outros haveria índices internos ao texto (no caso Wajãpi, "e-i": ele disse; ou seja, não se utiliza o discurso indireto ou reportado, mas sempre o discurso direto, cuja intenção é a transmissão ipsis literis) que remetem tanto àquele que primeiro testemunhou o que é relatado na mensagem, quanto àquele que transmitiu a mensagem ao atual narrador. Em relação aos pesquisadores Wajãpi, mesmo no caso de narrativas transcritas, 'misturar' versões de narradores distintos é impossibilitado pela forma mesma como tais narrativas são 'textualmente' construídas e apresentadas, segundo o papel fundamental de tais índices internos aos textos. Quando afirmo a 'intenção' pela literalidade do discurso reportado em direct speech, apoio-me na afirmação de Becquelin e Molinié: "Dans la transmission orale, le narrateur est créateur même
} 
Outra 'inovação' nesse sentido concerne o fato de Warodi haver 'aproveitado' a presença da autora para transmitir seu 'sonho' e em seguida encená-lo, com a participação de toda comunidade, através de uma performance que não consta no leque de práticas expressivas 'tradicionais' a este grupo indígena. Segundo Graham, Warodi 'produziu' essa novidade tanto para os jovens de Pimentel Barbosa quanto para ela, pesquisadora; a 'performance' do sonho constituindo-se em um modo 'didático' de ensinar a 'cultura Xavante' para a antropóloga. Como poderíamos interpretar essa 'performance'? Não concerniria ela uma forma através da qual o imperativo de 'enunciação da cultura' agiria na cultura? Ou os modos como o imperativo de 'expressão cultural' para fora consiste, necessariamente, em algo 'novo', e que é justamente este aspecto que pode fazer dele algo internamente valorizado? Mas quais 'novidades' não são valorizadas? Pois Warodi 'aproveita' essa situação para inaugurar ${ }^{146}$ uma forma expressiva, voltada para os jovens que, se bem entenderam a mensagem, deveriam ensinar à pesquisadora, para que seja publicado.

A segunda focalização aqui no que diz respeito aos 'coletivos' tornados visíveis através de formas de interação mediadas pela linguagem concerniria todos os habitantes de Pimentel Barbosa, que se vêem e se afirmam a si como a verdadeira raiz do povo Xavante, segundo o fato de habitarem a região identificada com a aldeia focal de Tsõrepre, além da afirmação de terem sido eles os 'iniciadores' do contato com os brancos (salvando-os dos Xavante de outras aldeias) e de terem tido pouco ou nenhum contato com os missionários (1995:31). É sempre esse 'coletivo' avançado no warã, assim como por Warodi (e nunca sua facção, explicitamente), o que faz dele uma liderança 'legítima'. Veremos adiante que o fato de se considerarem a 'raiz do povo Xavante' faz com que os habitantes desta aldeia se outorguem o direito 'legítimo' de falar por todos os Xavante. Além disso, eles consideram a si mesmos como mais 'tradicionais' por não haverem permitido a instalação de missionários em sua aldeia (ou seja, reivindicam uma 'continuidade cultural' mais efetiva do que de 'outros' grupos ou aldeias Xavante) $)^{147}$.

Em terceiro lugar, 'coletivos' que concernem facções, cuja atuação na esfera política local, o warã, e segundo o gênero narrativo ihi mrèmè, é 'negativizado' pelo discurso

s'il s'imagine ne faire que répéter. Ce que les acteurs de ces sociétés appellent 'répéter' n'est d'aileurs pas nécessairement une reproduction a l'identique. Ce double rôle empêche à la fois l'imitation exacte et l'innovation totale, puis que le narrateur n'a ni les moyens de la fidélité absolue ni le droit d'inventer" (1993:12, ênfase minha). Infelizmente Laura Graham não provê mais detalhes a respeito das formas como 'texto' das fitas de Warodi são reproduzidas por Riridu e da existência ou não de tais índices, que informam o discurso direto ou reportado.

${ }^{146}$ Seria interessante saber se os Xavante continuam a realizar performances de sonhos. Interessante também, no que concerne a idéia de 'inauguração', o fato de Riridu elaborar, segundo Graham, performances nas quais se apresenta como tendo 'recebido' mensagens de Warodi (não mais através do sonho, mas segundo uma espécie de 'incorporação' em que mistura movimentos de Karatê e estruturas musicais 'emprestadas' de outros grupos indígenas, acessadas através de fitas e reelaboradas para avançar mensagens propriamente e na língua Xavante) (Graham, 2003: 227-236).

${ }^{147}$ Mas não apresentam estes 'outros' depreciativamente através de enunciados, apenas afirmam que vão 'trazer abaixo' outras aldeias ao reviverem a vida dos imortais em performance. 
polifônico, mas cuja existência efetiva pode ser vislumbrada através da 'notabilidade ${ }^{148,}$ que adquirem os narradores enquanto representantes de suas respectivas facções, de acordo com a qualidade da produção de discursos 'coletivizadores'. Em relação a essa 'negatividade', e no que diz respeito às formas que assumem esses coletivos, adquire relevo o fato de a autora ser interdita de gravar as discussões prévias ao warã realizadas no âmbito familiar das casas correspondendo às facções, durante toda a tarde. Entretanto, a interdição era somente de gravar, não de escutar. Nesse sentido, imagino que o 'risco' seria o de essas gravações chegarem a pessoas erradas, mas quem seriam tais pessoas? Haveria motivo para que tais gravações não pudessem ser levadas "para o outro lado do oceano"? ${ }^{149}$

Gostaria também de chamar a atenção para a afirmação segundo a qual os Xavante não possuem um metadiscurso que dê conta da descrição das características salientes do gênero ihi mrèmè, de não serem 'metalinguisticamente conscientes' de seus aspectos formais. Ao mesmo tempo, tal gênero é nominado, e eles são claramente 'despertos' quanto ao seu estilo específico. Não estariam os Xavante, no entanto, atentos quanto aos efeitos indesejáveis da circulação interna dos debates intrafaccionais realizados no âmbito das casas no momento anterior à warã? Some-se aqui ainda o fato de os Xavante negarem veementemente comentar as falas de outros no warã, assim como suas próprias falas. O quanto as falas ihi mrèmè no âmbito da política faccional vespertina concerniriam 'âmbitos' da cultura não passíveis de enunciação, seja por desconstruírem uma 'negatividade' necessária à 'notabilidade' (quando concernem decisões pela facção dominante), seja por tornarem visíveis

148 Pierre Clastres (1974), ao realizar uma filosofia política das sociedades sem Estado, consideradas sociedades contra o Estado, irá desenvolver uma reflexão acerca da "palavra vazia do chefe". Clastres aponta que nas sociedades contra o Estado o chefe não teria o direito de falar, mas sim a obrigação de falar. A esse dever de palavra do chefe, Clastres complementa: essa palavra é ritualizada, -formalizada-, e vazia (de conteúdo semântico). Sztutman (2006) irá discutir com Clastres ao propor que se em 'sociedades contra o Estado' a posição de líder político não se funda em poder de coerção, isso não significa negligenciar processos de 'diferenciação e aquisição de prestígio' ou de 'personificação política'. Sztutman trata de tais processos como formas de 'magnificação' através da aquisição de nomes e marcas. Questionome se a característica de notabilidade que adquirem sujeitos e facções, identificada por Laura Graham através do emprego do gênero ihi mrèmè na warã, não consistiria em uma forma de 'magnificação' ou de aquisição de 'notabilidade' que advém justamente do fato de que um líder não deve coercitivo, de que não deve 'tomar decisões'? Daí o fato de as reuniões vespertinas serem interditas de gravação pela autora? Sztutman apresenta esse 'poder' como oposto ao panóptico proposto por Foucault: "em vez de um poder invisível que tudo controla, pois tudo vê, um poder neutralizado e controlado por todos, porque tornado visível, um poder destituído de sua força, de sua 'agência'”(2006:1). Daí que a notabilidade só existe associada à negatividade; e a negatividade só existe na medida em que os verdadeiros espaços de 'tomada de decisão' e de 'posição' permanecem ausentes. Decorreria daí, então, sua interdição em gravar as reuniões vespertinas nas casas dos indivíduos de cada facção. Mas revela também a agência de Warodi: suas falas gravadas recuperadas por Riridu não são coletivas, ele não está aqui 'negativizado'.

${ }^{149}$ Segundo a análise de Maybury-Lewis (1984, 238-250), pareceu-me que, justamente, as contendas que são efetivamente levadas ao debate no warã são aquelas que não puderam ser resolvidas fora deste espaço, contendas (envolvendo, em geral, acusações de feitiçaria ou 'roubo' de bens, assim como de mulheres) que adquirem proporções que podem acarretar conseqüências mais drásticas, como o abandono da aldeia por um certo grupo e, em tempos idos, guerras e matanças. Imagino que naqueles espaços vespertinos intrafaccionais questões envolvendo indivíduos ou grupos de outras facções são debatidos entre seus membros, mas o risco de que tais disputas assumam proporções indesejáveis faz com que seus membros não desejem que tais debates cheguem aos ouvidos do resto da 'comunidade'. Pois, segundo Maybury-Lewis, "todas as disputas pessoais que se tornam casos julgados pelo conselho dos homens se tornam, ipso fato, questões faccionárias" (1984: 245). 
coletivos que agiriam no sentido da desconstrução daquela que se quer sua 'identidade' para si e para os outros,' a dos "Xavante" de Pimentel Barbosa, os 'legítimos' descendentes dos always living creators? A interdição à Laura Graham de gravar os discursos prévios à warã não se constitui uma forma local de 'gestão' de novos regimes textuais no que diz respeito à alocação de autoridade?

Parece-me, aqui, que há um contraste entre 'coletivos' tais como eles são 'dados a ver' em situações específicas, através das formas próprias à tradição oral (que concernem modos de interação), e 'coletivos' tais como são elaborados em 'enunciados da tradição', ou como consideram que devam ser enunciados na forma de um 'nós': 'nós' de Pimentel Barbosa ou 'nós', os Xavante 'legítimos' (quando a 'interação' é com 'outros ${ }^{150}$ ). Adquire relevo aqui a questão do compartilhamento ou não de práticas expressivas e discursivas em contextos de interação mediados pelo discurso.

Em relação à inexistência de uma metalinguagem capaz de discutir os efeitos da ihi mrèmè na arena política warã, seria tal inexistência efetiva ou sua discussão é exatamente o limite quanto 'ao que se fala' (ou 'se grava') e 'para quem' (qual sua audiência efetiva ou potencial)?

Maurice Bloch (1975) propôs que funções não-semânticas, não-referenciais da linguagem formalizada ("formalized language") cumpririam um controle e uma restrição, "ocultos" para seus atores, no conteúdo veiculado em tais eventos políticos, de modo a tornar improvável o desacordo entre seus participantes. O fato de Graham ser interdita de gravar as discussões prévias à warã não atestaria que, por mais que eles não possuam uma metalinguagem a respeito dos efeitos da ihi mrèmè, que tais efeitos não são necessariamente 'ocultos' para seus atores?

Greg Urban (1986), em relação às populações indígenas sul-americanas, apontou que a linguagem formalizada em diálogos cerimoniais, entendida enquanto ação social, seria utilizada em situações de conflito potencial, em "maximally distant social relations within a given society" (1986:371), se constituindo em um "sign-vehicle, a model 'of and for' linguistic and more generally social solidarity" (1986:371). Contudo, a forma expressiva ihi mrèmè não é empregada somente no caso de 'maximally distant social relations', mas internamente às facções, assim como a cada vez que velhos, - ihi-, "wish to throw around the weight of their age and wisdom and to stress the importance of their speech" (2003:161). O aspecto 'oculto', segundo termo de Bloch, foi interpretado por Urban como um recurso metacomunicativo de ação social, sugerindo que é o 'metasinal' em si mesmo que impede a formulação de uma imagem de seu caráter 'acional', ou de ação, desse modo regulando-o ao mesmo tempo em que este ocorre.

${ }^{150} \mathrm{Em}$ que, contudo, não põe em questão a 'legitimidade' dos enunciados de 'outros' Xavante; elaboram antes reflexões a respeito dos 'caminhos' da transmissão, esses, 'mais' ou 'menos' legítimos de acordo com a percepção de maior ou menor proximidade aos originais, 'ancestrais'. Deverei discutir melhor este ponto adiante. 
Neste sentido a 'forma ritualizada' do discurso 'esconderia' o caráter potencialmente disruptivo presente nas relações entre interlocutores em diálogo, de modo a regulá-las e apontar para a solidariedade que incitam, se constituindo, dessa forma, um 'modelo' para a conversa, - e as relações-, para além do âmbito cerimonial.

Brenneis e Myers (1984) revisaram as proposições de Maurice Bloch, buscando refinar a discussão a respeito dos aspectos "políticos" no que diz respeito às formas e funções da linguagem em relação à "populações tradicionais"151. Assim, esses autores apontam que a "fala" naqueles contextos políticos seria menos um meio de coerção ou de tomada de decisões do que uma forma de reprodução de relações sociais e de regulação e alocação de valores ${ }^{152}$. A questão relevante, apontada pelos autores, é a de qual valor social é objeto de competição e alocação, e como ele é produzido e negociado ${ }^{153}$. Ao mesmo tempo, tais autores se afastam da ênfase em estratégias individuais, em que atores foram vistos segundo o objetivo de 'maximização de valores', pelo fato de tais abordagens prestarem pouca atenção "to how actors recognize and establish rates of exchange" (Brenneis \& Meyers, 1984:7), já que uma série de relações podem estar em jogo na ação política: "in no society are all social relations equivalent in content or substance" (Brenneis \& Meyers: 1984, 2-11). Assim, esses autores enfatizam que a visão do indivíduo racional é um artefato de nossa ênfase cultural ocidental, de modo que a atenção na intenção transcontextual e contínua do indivíduo obscureceria, no que diz respeito à linguagem, seu caráter de atividade fundamentalmente social.

Em relação às abordagens de Bloch (1975) e de Urban (1986), Marilyn Strathern também estabeleceu uma crítica que considero relevante aqui, quando afirmou sua preferência pelo termo 'socialidade' ao de 'sociabilidade', ao procurar exatamente se distanciar daquela noção de relação baseada na experiência de empatia. Segundo ela, "fazer a guerra, por exemplo, é estabelecer uma relação tão relacional quanto fazer a

\footnotetext{
${ }^{151} \mathrm{Na}$ região do Pacífico, o que se constitui um recurso pouco 'boasiano' de minha parte. Contudo, seus argumentos me pareceram cabíveis à presente análise, ao mesmo tempo em que a literatura antropológica ameríndia a respeito de 'language and politics', em especial Urban (1986), apresentava fraturas em relação à minha abordagem, como veremos em seguida.

152 Os autores criticam os modos como os uso 'solto' que Bloch faz da noção de 'formalização' para descrever tanto a 'fala' quanto a 'situação' perde de vista os inúmeros, distintos e variáveis atributos de um 'speech event' (como no caso da forma hi mrèmè, que é empregada tanto nas discussões intrefaccionais vespertinas quanto no âmbito do warã, assim como pelos velhos para 'divulgar o peso de sua idade e sabedoria'). Em relação à 'populações tradicionais', os autores remetem às diversas formas sociopolíticas que estas podem assumir, para além da distinção 'clássica' e parcialmente operativa entre sociedades 'igualitárias' e sociedades de 'hierarquia' ou ranque. Os autores ressaltam ainda que em sociedades ditas 'igualitárias', a 'igualdade' tende a prevalecer somente entre certas categorias de indivíduos, tais como 'senior men'. Também chama a atenção para o fato de que uma grande variedade no conteúdo de relações podem estar em jogo na ação política: "in no society are all social relations equivalent in content or substance" (Brenneis \& Meyers: 1984, 2-11).

153 Parece-me que, justamente, a competição é pela notabilidade, mas que precisa 'passar', antes, pela 'negatividade', durante o espaço do warã, quando as posições entre facção dominante/facção minoritária já estão dadas. O que é interessante é que tais posições se invertem quando das disputas pela ascensão àquela posição. Isso porque Maybury Lewis relata que as características do chefe como árbitro imparcial, que caracterizam um bom chefe, são "diametralmente opostas às características do comportamento que teve que adotar quando aspirava à chefia" (1984:265), ou seja, de uma 'notabilidade' à uma 'negatividade' notável.
} 
paz" (1999:10). Nesse sentido, me questiono a respeito da noção de Urban acerca de a linguagem formalizada se constituir como forma de solidariedade, quando a concebe como um 'sign-vehicle, a model 'of and for' linguistic and more generally social solidarity" (1986:371). Marcela Coelho de Souza vêm reiterar essa mesma perspectiva quando afirmou, em relação aos Xavante: "O quanto tal "comunidade" é mais do que o efeito do sucesso de um tal discurso parece-me entretanto uma boa questão. Não porque eu compartilhe com Urban (1996) a idéia de que grupos devam ser vistos como meros efeitos discursivos, mas porque suspeito de que a "comunidade autônoma" dos Jê é mais um resultado do faccionalismo do que algo ameaçado por ele. Isso é sem dúvida uma verdade de fato, na medida em que, historicamente, as comunidades que se mantêm unidas, enquanto se mantêm unidas, o fazem pelo, e não contra, o faccionalismo, seja através do equilíbrio entre duas facções, seja através do domínio de uma" (Coelho de Souza, 2002:622) ${ }^{154}$.

Como vimos, a construção de 'identidades indígenas' ou de 'identidades étnicas' foi fruto de processos históricos e políticos relacionados à constituição de Estados modernos e da necessidade de tais Estados em 'nomear' seus atores; assim como de atores indígenas definirem-se a si enquanto participantes de 'identidades' particulares, portadoras de 'culturas', para a defesa de seus direitos à diferença cultural e à igualdade política. A pesquisa antropológica e etnográfica também contribuiu na formalização de tais 'identidades étnicas', a partir da caracterização e análise relativos a aspectos lingüísticos, de organização social, de cosmologia e de eventos cerimoniais compartilhados, que vêm caracterizar certo 'grupo cultural' como uma 'totalidade' (ver nota 1 do presente capítulo, em relação aos 'Xavante') ${ }^{155}$.Vimos como coube também à antropologia, em especial a partir de meados da década de 50 , a associação entre 'formas de vida' e 'fonte de identidade', reiterando o advento da noção de 'identidades étnicas'(Strathern, 1995).

\footnotetext{
${ }^{154}$ Parece-me, deste fato, que se as comunidades de mantém unidas, enquanto se mantém unidas, tal 'união' seria fruto menos do 'é dito e como' do que do 'não é dito e onde (em quais contextos)'. Apóio meu argumento na caracterização de Maybury-Lewis (1984, 238-250), segundo a qual as contendas que são efetivamente levadas ao debate no warã são aquelas que não puderam ser resolvidas fora deste espaço, contendas (envolvendo, em geral, acusações de feitiçaria ou 'roubo' de bens, assim como de mulheres) que adquirem proporções que podem acarretar conseqüências mais drásticas, como o abandono da aldeia por um certo grupo e, em tempos idos, guerras e matanças. Imagino que naqueles espaços vespertinos intrafaccionais questões envolvendo indivíduos ou grupos de outras facções são debatidos entre seus membros, mas o risco de que tais disputas assumam proporções indesejáveis faz com que seus membros não desejem que tais debates cheguem aos ouvidos do resto da 'comunidade'. Pois, segundo MayburyLewis, "todas as disputas pessoais que se tornam casos julgados pelo conselho dos homens se tornam, ipso fato, questões faccionárias" (1984: 245).

${ }^{155}$ Como eu mesma faço no decorrer desta dissertação, através do emprego do termo 'os Xavante', por não dispor de outra alternativa. Dentre tais alternativas possíveis, considero valioso o emprego da noção de 'coletivos' que vêm se definir contextualmente, ou seja, da noção de 'identidades' como algo necessariamente flutuante, enquanto constelações de redes de conexões variáveis de um momento a outro e que não se 'estabilizam' para além de um dado momento. Mas para situar os atores, 'Os Xavante', foi preciso uma referência compartilhada, ainda que não seja ela adequada.
} 
Em relação à discussão aqui considerada, vimos como o termo 'Xavante' foi empregado inicialmente por não-índios, visando uma diferenciação deste grupo com os Xerente (as categorias indígenas empregadas nesta distinção concernem o termo A'uwe, em contraste à $A k w e$, em relação aos Xerente). Vimos também que os "Xavante" consistem em comunidades políticas autônomas, que podem vir eventualmente se reunir em função de interesses compartilhados, em especial em situações envolvendo relações com agentes ou setores da sociedade nacional. Entretanto, a crescente participação de atores indígenas na arena nacional, atores estes que vêm se atribuir o nome 'Xavante' especialmente quando de suas relações com agentes externos, não acarreta necessariamente que tais atores vejam a si como uma 'totalidade, 156 .

Parece-me que a Convenção para a Salvaguarda do Patrimônio Imaterial da Unesco de 2003, ao atentar antes para as formas dinâmicas e processuais de produção e de transmissão de conhecimentos e práticas, em especial no que diz respeito à 'tradições orais' que, como vimos, consistem antes em formas de interação consideradas corretas do que à 'corpus de conhecimentos', deverá se ver às voltas com questões que dizem respeito às relações entre identidades étnicas indígenas concebidas em contextos políticos de abrangência nacional, tal como 'os Xavante', e clivagens, que concernem os modos como indivíduos e coletivos estabelecem gradientes de semelhança e de diferença entre si, e em que a noção de identidade se expande e se contrai de acordo com as potenciais redes conexões, que não se estabilizam, variando de um contexto ao outro ao mesmo tempo em que concomitantes, se vários contextos forem tomados em conjunto. Contudo, de que maneira 'outras comunidades' Xavante agiriam se um 'bem de natureza imaterial' enraizado na 'comunidade' de Pimentel Barbosa fosse

\footnotetext{
${ }^{156}$ Nem que se comportem como 'indivíduos' Xavante 'modernos', ao menos não em todas as suas relações mediadas pela linguagem. Em "How should an indian speak?" (in: Warren \& Jackson, 2002), Laura Graham debate, no âmbito de interações discursivas entre indivíduos indígenas e "não-indígenas, as escolhas que os atores indígenas fazem acerca dos modos de emprego da linguagem e de estilos retóricos. A autora discute os efeitos de tais opções, como o emprego da língua 'nativa' ou língua 'nacional', do recurso ou não a tradutores e a utilização de referentes simbólicos e cosmológicos, que variam de acordo com as percepções que tais atores estabelecem acerca de seus interlocutores e das expectativas variadas concernentes ao emprego de formas discursivas e estilos retóricos particulares. Segundo a caracterização bakhtiniana da natureza pública da circulação discursiva, as idéias e palavras do "outro" participam necessariamente nas construções dos discursos durante interações mediadas pela linguagem, segundo contextos, interpretações e circunstâncias específicas. Pareceu-me que a questão do compartilhamento de recursos expressivos relacionados ao emprego de 'gêneros' da tradição oral pode vir a produzir formas variadas de conformação de 'sujeitos' e 'coletivos', clivagens internas àqueles que são considerados 'grupos culturais' exatamente de acordo com os modos de interação e usos da linguagem que prevalecem a cada caso (e que podem, de acordo com as circunstâncias, corresponder ao que foi caracterizado como 'categorias sociais' como facções, ou o âmbito doméstico, etc.). O quanto o fato de 'outros' não compartilharem recursos expressivos indígenas faz com que interações mediadas pela linguagem façam (efetivamente) do nativo um 'indivíduo moderno', e ao fato daquelas 'totalidades' só aparecem como 'totalidades' em certas circunstâncias (em geral em relação ao 'outro'), como na noção de 'sociedade Xavante', por exemplo? Um exemplo interessante concerne os modos como Richard Price, para aceder aos conhecimentos relativos ao chamado 'First-Time' teve de se adequar às formas corretas de entrada em 'relação' próprios 'aos Saramaka' (Price, 2002).
} 
reconhecido como 'patrimônio' pelas políticas de salvaguarda de patrimônios imateriais $?^{157}$

No que concerne os Xavante, aquelas variadas configurações de 'coletivos' (indivíduos 'notabilizados' e 'negativizados', facções, conjunto de homens maduros que participam do warã, 'aldeia' de Pimentel Barbosa, 'Xavante') são dados a ver de acordo com contextos específicos de interlocução, ou seja, só aparecerem enquanto 'coletivos', - no que diz respeito ao âmbito desta pesquisa ${ }^{158}$-, exatamente através de contextos relacionais mediados através do discurso. Por fim, tais discursos concernem eles 'grupos' cristalizados ou modos corretos de 'entrada em relação', que, estas, vêm iluminar os 'coletivos', variáveis a cada contexto ${ }^{159}$ ?

E, por fim, o quanto coletivos explicitados através de contextos discursivos corresponderiam aos coletivos considerados por ações de salvaguarda de patrimônios imateriais, em especial em sua rubrica 'tradições e expressões orais', segundo definidos no âmbito da Convenção?

Gostaria de relacionar aqueles 'coletivos' aos atuais debates a respeito do envolvimento das comunidades nas ações de identificação, documentação e salvaguarda de 'patrimônios imateriais'. Discussões recentes foram realizadas no sentido de produzirem conceitos para as noções de 'comunidades', 'grupos' e 'indivíduos' a que se refere o texto da Convenção (ACCU/Unesco report, 2006: 17-18). Ali, 'comunidades', foram identificadas como "networks of people whose sense of identity or connectedness emerges from a shared historical relationship that is rooted in the practice and transmission of, or engagement with, their intangible cultural heritage" ${ }^{\prime 160}$.

Nesse sentido, e segundo aquela definição, as potenciais 'identidades' deverão ser resultado do 'bem cultural' ou do 'patrimônio imaterial' considerado a cada caso. Esta

\footnotetext{
157 Um potencial exemplo poderia concernir os Wajãpi, que tiveram suas expressões gráficas e orais registradas. Contudo, os 'outros' Wajãpi habitam a Guiana Francesa, não sendo passíveis de serem contemplados pela política brasileira.

${ }^{158}$ Pois de modo mais amplo tais clivagens concernem categorias que foram consideradas como da ordem da estrutura social (em especial no caso de facções). Mas como vimos, a própria estrutura social varia de acordo com o ponto de vista considerado: categorias de idade, âmbito 'privado' e âmbito publico, facções, etc. Esta pesquisa se propôs, ao focar em coletivos iluminados através de formas discursivas e suas interações, a noção (emprestada de Sztutman, 2005) de 'sujeitos expandidos', enquanto parte de uma mesma lógica de abordagem de 'coletivos'. No que concerne sua coerência, no sentido de sujeitos que se expandem através da captação ou interação com seres míticos, considero que tal aspecto pode ser vislumbrado também em outro 'ponto' do termo, quando a aldeia de Pimentel Barbosa se propõem 'trazer abaixo' outras aldeias segundo sua encenação ou performance do sonho, ao de haver 'trazido à vida', os always living creators, a aldeia podendo ser concebida como um 'coletivo magnificado'.

159 Tendo em vista o constante abandono de aldeias por facções e/ou indivíduos que vêm compor novos 'coletivos', em seu novo espaço de residência.

${ }^{160}$ Grupos foram definidos como: "people within or across communities who share characteristics such as skills, experience and special knowledge, and thus perform specific roles in the present and future practice, recreation and/or retransmission of their intangible cultural heritage as, for exemple, cultural custodians, practitioners or apprentices". E indivíduos foram definidos como: "those within or across communities who have distinct skills, knowledge, experience or other characteristics, and thus perform specific roles in the present and future practice, re-creation and or transmission of their intangible cultural heritage as, for exemple, cultural custodians, practitioners and, where appropriate, apprentices".
} 
proposição me interessa, sobretudo, na medida em que me proponho pensar a importância da manutenção de jogos dinâmicos de constituição de 'coletivos' distintos de acordo com certos contextos de relações mediados através do discurso. Considerando-se a forma expressiva ihi mrèmè, o quanto ela informa um sentido de 'conexão' ou de 'identidade' entre indivíduos no aqui e agora, para além do espaço do warã? E ainda se, segundo Graham, essa percepção de continuidade ou de connectedness deriva antes de um sentimento de conexão com os ancestrais através do tempo, na medida da percepção de manutenção de formas expressivas e discursivas tal como eles o fizeram?

Parece-me interessante a posição de Brenneis e Meyers (1984), a respeito da "fala" em contextos políticos concernir menos um meio de coerção ou de tomada de decisões do que uma forma de reprodução de relações sociais e de regulação e alocação de valores sociais. Neste sentido, se o emprego correto de formas e conteúdos de 'tradições orais' em certos contextos relacionais concernem antes formas de reprodução de relações e alocação de valores, parece-me que quando tais falas registradas trabalham 'contra' a reprodução de relações e a alocação de valores (sua desconstrução 'para trás' e não sua construção 'para frente'), elas parecem ser interditadas pelos próprios atores, como no caso dos registros da ihi mrèmè vespertina, que poderia trabalhar contra a 'negatividade' e, portanto, a 'notabilidade'. Deste fato, parece-me que a importância atribuída pelos atores aos registros de tradições orais diz mais respeito a 'quem' se enuncia, e menos ao 'que' se enuncia através daqueles âmbitos.

Nesse sentido, seria o caso de registros de 'tradições orais' não deverem ser considerados como 'documentos' no que diz respeito a conformação de grupos, pois os 'grupos' concernem antes 'coletivos', que variam de acordo com contextos de relações, necessariamente mutantes? Mas de que modo produzir registros que sejam relevantes para a viabilidade de tradições orais, e que, ao mesmo tempo, sejam adequados aos contextos de interação considerados corretos por seus atores? A primeira evidência é o fato de que é preciso respeitar os contextos de expressão de 'tradições orais' que os próprios atores assinalam como interditos ao registro, ou ao acesso por outros sujeitos ou 'coletivos' internamente à sua própria 'comunidade'161 (e, eventualmente, no exterior).

\footnotetext{
161 'Problemática' esta cuja solução sugerida é menos evidente do que pode parecer, dado que tais âmbitos 'interditos' ou gêneros da tradição oral circunscritos a certos contextos relacionais são aqueles a que especialmente se dedicaram pesquisadores como lingüísticas, etnolingüistas, antropólogos e estudiosos de 'tradições orais', em estudos cujos resultados eram voltados à produção de conhecimento acadêmico. Em seus estudos e monografias, fragmentos ou textos de 'tradições orais' são trazidos ao corpo de seus textos e análises em função de fundamentos propriamente teóricos cujos objetivos não contavam (de modo geral) a possível participação de seus dados ou produtos de suas pesquisas em 'projetos' com vistas à 'transformações dirigidas da oralidade' voltadas à valorização ou à 'patrimonialização' de 'práticas' ou 'saberes'. Esta questão adquire importância na medida em que essas novas políticas do 'patrimônio
} 


\subsection{Registros da Oralidade segundo uma metodologia 'dialógica'}

Arthur Shaker Fauzi Eid, em sua tese de doutorado "Romhõsi'wa - A criação do mundo segundo os velhos narradores Xavante" (2003), analisa os princípios fundantes da cosmogonia Xavante, esta última desenvolvida e 'debatida' junto aos velhos narradores e tradutores $A$ 'uwe (como os Xavante se autodenominam). O corpus de tal cosmologia, composto de dez mitos relativos à criação, foi selecionado e traduzido juntamente com indivíduos Xavante da aldeia de Pimentel Barbosa com os quais o autor trabalhou, e aparece no corpo do texto de sua tese.

Arthur Eid se propôs realizar uma análise conceitual da noção Xavante de romhõ, de modo a evidenciar a importância da noção de transformação, que considera central para a cosmogonia dos povos indígenas sul-americanos. Seu intuito foi também o de lançar as bases para uma antropologia espiritual fundada no conceito de "metafísica dos povos milenares".

Arthur Eid explicita que espera que seu trabalho sirva "como parte da memória do saber Xavante para as futuras gerações" e que "realize os esforços dos velhos narradores Xavante e seus tradutores em trazer seu saber espiritual a todos, indígenas e nãoindígenas" (2003: 21). O autor afirma ainda que "o registro dos relatos míticos na forma de livro tem desdobramentos, alguns positivos, outros negativos. Por um lado, contribui para certa preservação da memória do saber mítico, divulga através desse meio de comunicação algo da cultura A'uwê para um número maior de pessoas que não teriam acesso a esse universo, preserva e oferece aos jovens Xavante e à sua escola um material de apoio, e também traz uma pequena fonte de recurso como direito autoral aos que nele trabalharam" (2003:41) $)^{162}$.

Neste sentido, considero que o trabalho do autor também se pauta pela possibilidade efetiva de 'valorização cultural', ao apontar sua utilização para os mais diversos fins (escola, preservação da memória, recursos financeiros, divulgação), ainda que não seja este seu objetivo primeiro.

Na primeira parte de sua tese o autor apresenta um resumo de sua hipótese, que consiste em confrontar a noção de criacionismo propondo, em seu lugar, a de transformação, que aponta como noção central para a compreensão da cosmogonia Xavante. Em seguida, discute a literatura sobre o povo Xavante, os desafios

imaterial' demandam aos agentes (do poder público, de ONGs, etc), -àqueles que deverão reunir as informações necessárias à instrução do processo de Registro-, a compilação de informações e dados produzidos por aqueles 'especialistas', informações estas que vêm compor dossiês que podem, eventualmente, tornarem-se 'públicos'. A mesma 'problemática' pode ocorrer na medida em que as próprias 'comunidades' vêm atualmente demandar o 'retorno' de materiais etnográficos ou registros produzidos em situações de pesquisa, seja para a composição de 'arquivos de memória', de bancos de dados, de materiais de divulgação, etc. Esta pesquisa interessa-se justamente por esta passagem ou por estes 'trajetos', em que dados produzidos em situações etnográficas e de pesquisa são então descontextualizados para virem compor novos materiais, voltados à 'valorização'.

$162 \mathrm{O}$ autor também discute, com base em alguns autores como Jack Goody, as conseqüências de fixar através da escrita narrativas produzidas original e contextualmente em sua forma oral. 
contextuais de lidar com um corpus mítico e a problemática questão da tradução deste corpus para o português. $O$ autor discute também os desafios do trabalho de campo e da dinâmica de trabalhar conjuntamente com os velhos narradores e tradutores.

Adiante, o autor analisa especificamente a noção de "transformação", realizando um diálogo com diversos autores que analisaram essa questão (a partir de corpus de narrativas mitológicas de povos indígenas sul-americanos). Finalmente, ainda na primeira parte de sua tese, Arthur Eid desenvolve uma densa reflexão teórica, recorrendo a autores que realizaram análises sobre a "religião dos povos milenares" no sentido de constituir uma noção de metafísica mais universal.

$\mathrm{Na}$ segunda parte de sua tese, o autor apresenta o corpus mítico selecionado para análise, transcrevendo as dez narrativas produzidas pelos velhos Xavante e traduzidas por Paulo Supretaprã, um Xavante mais jovem. Logo após a apresentação de cada uma das dez narrativas, o autor insere o que chama de "exegese dos $A$ 'uwê", que consiste em comentários de seus interlocutores, - Rupawê, Serezabdi, Sereburã, Serenhimirãmi, Hipru, Paulo Sepretaprã e Azevedo Peprê-, a respeito das narrativas, seguidas de um comentário do próprio Arthur Eid ${ }^{163}$.

Essa segunda parte de sua tese interessa-me, sobretudo, por levantar questões interessantes quando confrontada com a caracterização da tradição oral Xavante segundo realizada por Laura Graham, assim como em relação às formas diferenciadas de metodologias de registro operadas pelos pesquisadores, principalmente no que concerne os modos adotados para a "apreensão" da fala nativa.

Cito o argumento utilizado por Arthur Eid para transcrever as narrativas segundo the foram originalmente transmitidas. $O$ autor afirmou que:

"Pretendemos com isto contemplar alguns objetivos que consideramos importantes: em primeiro lugar, os compromissos com os velhos narradores e a aldeia. Os velhos da aldeia Êtenhiritipa ${ }^{164}$ estão preocupados com a marcha dos tempos. As novas gerações já enfrentam o desafio de se verem entre duas culturas conflitantes. Para os velhos, uma das perdas mais preocupantes é a do conhecimento dos fundamentos da vida A'uwê que estão contidos em suas histórias míticas. Para salvaguardar essa memória, os velhos estão colocando muito de seus esforços no registro dessas histórias, e

\footnotetext{
${ }^{163} \mathrm{Na}$ estrutura de sua tese, sua análise teórica vem antes da parte em que há a apresentação de cada uma das narrativas, seguidas das exegeses dos $A^{\prime} u w e$ e dos comentários do autor. É interessante notar que a conclusão final da tese consiste em uma única página, enquanto o capítulo acerca da noção de 'transformação' na cosmogonia Xavante, o objetivo teórico a que o autor se propõe, aparece justamente muito bem desenvolvido antes da parte em que as narrativas são apresentadas. Qual foi o intuito do autor, com essa apresentação? Serviriam as narrativas para sustentar a hipótese já defendida? Ou cumpririam o papel de salvaguardar a memória Xavante, através de seu registro por escrito? Ou serviriam para registrar a real participação dos indivíduos Xavante na reflexão a respeito da noção de transformação e garantir assim maior legitimidade à hipótese defendida?

${ }^{164}$ Êtenhiritipa corresponde ao nome Xavante para a aldeia de Pimentel Barbosa.
} 
querem que seja da forma correta ${ }^{165}$. Esperam também que esse registro ganhe a forma de um livro ${ }^{166}$ que servirá futuramente de recurso para uso didático de seus professores junto às suas crianças e adolescentes, bem como de explicitação da riqueza de seu mundo mítico para os "brancos", os warazu, como instrumento de conscientização para um maior respeito à sua cultura indígena, sobre a qual recai o peso do preconceito, violência e voracidade da sociedade moderna" (2003:21, ênfase minha).

E ainda:

"Trabalhar sobre a cosmologia indígena colocou para mim muitos desafios. Ao longo desses anos, em minhas conversas com representantes indígenas, ouvi muitos deles contestarem que muitas das interpretações que foram feitas sobre suas culturas eram construções que não correspondiam à realidade e ao modo com que eles compreendem a si mesmos. Isso incluía as traduções e as interpretações sobre elas construídas" (2003:30, ênfase minha).

Temos aí a apresentação dos argumentos para a realização de uma metodologia de trabalho etnográfico dita "dialógica", ou seja, construída a partir de diálogos e reflexões conjuntas entre o pesquisador e seus interlocutores Xavante. Assim, sua pesquisa busca não só apresentar uma reflexão teórica acerca da noção de transformação, mas de uma reflexão 'teórica' cuja 'base' se quer coletiva ${ }^{167}$.

Essa é uma questão bastante relevante. O que diriam os velhos Xavante a respeito da interpretação que Laura Graham faz acerca de seu discurso político no warã? E, em segundo lugar, como poderia a autora realizar uma análise da arte verbal Xavante

165 Laura Graham faz um relato semelhante: 'from our discussions of my interest in committing their narratives 'as they speak them' to writing, the elders had devised a plan to use my skills to their advantage" (Graham, 2003:172, ênfase minha). Parece-me relevante o fato de os Xavante insistirem que suas 'tradições orais', discursos e narrativas sejam transcritas da 'forma correta', ou ipsis literis, para sua vantagem. Nesse sentido parece-me que atores indígenas só consideram como efetivamente 'seu' e potencialmente 'proliferáveis' enunciados registrados ipsis literis. Veremos que a 'literalidade' de tais discursos varia em sua forma de acordo com o interlocutor/mediador do registro a cada caso, também no 'caso' Kanak.

166 Justamente o livro Wamreme Za'ra, segundo a afirmação de Eid de que "parte do material que gravei naquele ano de 1997 foi utilizado para a elaboração do livro Wamrêmé Za'ra” (2003:29). Esta obra constitui o foco subseqüente de minha análise, acerca de registros da 'tradição sob a ótica de projetos de 'transformação dirigida da oralidade'.

${ }^{167}$ Eid comenta que "o parecerista da Fapesp me perguntou se não seria muito mais difícil para os Xavante entenderem e avaliarem as interpretações que os antropólogos fazem sobre sua mitologia e cosmologia. E se eu estaria explicando a eles os parâmetros com que os antropólogos realizam suas interpretações. Posso dizer que na medida do possível procurei traduzir para eles, em cada contexto pertinente, os modos de interpretação utilizados pelos antropólogos (nesse caso, principalmente os trabalhos de D. Maybury-Lewis e L.Graham) sobre aqueles temas que diziam respeito ao nosso trabalho. Claro que a inteligibilidade deles dependeria do modo com que eu colocaria as interpretações e os fundamentos que as sustentam. Esforceime por fazê-los com justeza e equanimidade. Considerei sempre essa questão da tradutibilidade de cognitividades um tema fundamental, pois é a base do significado do meu trabalho e compromisso pela construção de pontes do saber metafísico e defesa do patrimônio espiritual dos povos tradicionais. Espero que isso transpareça no próprio corpo deste texto" (2003: 41-42). Ou seja, Eid vislumbrava uma tradutibilidade de cognitividades que têm em vista seu 'alvo', ou a 'linguagem e cultura' do próprio pesquisador, e não sua matriz. Realiza uma tradução 'deles' para eles segundo sua própria cognitividade de pesquisador.... 
através de um diálogo com eles se estes se negavam a realizar quaisquer comentários a respeito de suas falas e de outros nesta arena e se, segundo a autora, 'eles não são metalinguisticamente conscientes' em relação aos 'efeitos' desta forma expressiva em sua arena política (apesar de, como discutido, possuírem clareza acerca de seus 'efeitos' indesejáveis)?

Segundo afirma Arthur Eid em sua tese:

"Esse trabalho também acrescentou muitas elucidações aos velhos e ao tradutor, graças a esse esforço conjunto de irmos adentrando com cada vez mais profundidade nos meandros dos enredos cosmogônicos. Observei que essa visão mais ampla e estruturada da trama cosmogônica não é algo totalmente dado e consciente para os narradores e o tradutor" (2003:35).

Nesse sentido, a ausência de consciência à que se refere Arthur Eid corresponderia, ao contrário da 'consciência metalinguistica' a que aponta Laura Graham, à uma consciência quanto ao 'enredo' da trama cosmogônica. Em relação a que, então, estariam os Xavante 'conscientes' ${ }^{\text {'168? }}$

Em um seminário de Lévi-Strauss intitulado 'Ordem e Desordem na Tradição Oral', de 1975-1976, aquele antropólogo, em discussões com seus alunos, confrontou modos distintos através dos quais corpus mitológicos foram recolhidos em épocas e condições diversas, e que se apresentariam segundo dois aspectos contrastados. Ora como "acúmulos de fragmentos disparatados", ora como "conjunto de relatos que se encadeiam”. Em relação a este último corpus, chamado ali 'clássico'169 em contraste com o primeiro, a que chamaram "barroco"170, Lévi-Strauss indica que no corpus clássico "o colaborador executa as indicações do etnólogo; ele mesmo se torna etnólogo quando busca constituir uma coletânea tão completa quanto possível, na qual põe no mesmo plano as tradições de seu grupo familiar ou social e as obtidas junto a informantes que são membros de clãs diferentes ${ }^{171}$. Ademais, esses documentos são dispostos numa ordem que tenta ser objetiva" (1986:150). No segundo caso, do corpus

\footnotetext{
168 Lembrando que "o patrimônio cultural diz respeito, sobretudo, aos sujeitos sociais que produzem e mantém este patrimônio. (...) Assim, o reconhecimento dessas artes, ofícios, saberes e formas de expressão como patrimônio deve fazer sentido e ter significado, antes de tudo, para os seus detentores, ou seja, para aqueles que são, em última instância, responsáveis por sua existência e continuidade" (Sant'Anna, 2008)

${ }_{169}$ Mitos publicados por Boas entre 1895 e 1916 e por Barbeau pouco mais tarde.

170 De que os próprios índios seriam os autores, de modo mais ou menos direto a validar reivindicações territoriais, políticas ou econômicas. Segundo reportado no texto, os termos 'clássico' e 'barroco' foram escolhidos para produzir contraste, sem nenhum juízo de valor pejorativo.

${ }^{171} \mathrm{O}$ quanto tais 'corpus clássicos', ao condensarem narrativas de 'coletivos' diferentes, não se tornam impossibilitados de serem reapropriados e retransmitidos, de não proliferarem? Seja por não remeterem aos indivíduos produtores (aqueles que, como vimos, são mais valorizados do que suas 'formas expressivas' e por não conterem em si os índices linguageiros que permitiriam sua apropriação), seja por corresponderem a um coletivo que não se vê como um 'coletivo' para além de seu momento de interlocução com o outropesquisador?
} 
barroco $^{172}$, este se apresenta na forma de um relato contínuo, segundo uma ordem que se quer resolutamente histórica: "uma história que qualificaríamos de história de eventos (événementielle): nela, a ordem social é, a cada instante, ao mesmo tempo construída e questionada por um devir' (Lévi-Strauss,1986: 152).

Nesse sentido, o que consideramos como 'mito' ou 'enredo cosmogônico' não seria, para eles, uma 'história', e ainda, uma história que não diz respeito somente ao passado, mas ao presente e ao porvir? ${ }^{173}$ De uma história 'aberta'? Walter Benjamin discute a noção de 'história aberta' e a relação entre a experiência e memória quando afirma: "pois se um acontecimento vivido é finito, ou pelo menos encerrado na esfera do vivido, o acontecimento lembrado é sem limites, pois é apenas uma chave para tudo o que veio antes ou depois" (1996:37) ${ }^{174}$. Parece-me que a performance do sonho orquestrada por Warodi consistiu exatamente nessa possibilidade de 'história aberta', pois, segundo Laura Graham, "as they sang and danced the songs with the creators in mind, the performers brought them into the present (...) actions such as these, that recall the memory of their lives and creations - enable the creators to continue living. Their immortality resides in the practices that keep memories of their lives and creations alive' (2003:223). No caso de registros de 'patrimônios imateriais' voltados à salvaguarda, de que modos se poderia manter a história 'aberta', ao mesmo tempo em que 'registrada' ${ }^{\text {175}}$ ?

No caso de Eid, acredito que poderíamos associar a construção coletiva daquele corpus de narrativas míticas Xavante com a caracterização de Lévi-Strauss a respeito do corpus clássico ${ }^{176}$. Ou seja, de que para os próprios Xavante não se trata de uma

\footnotetext{
${ }^{172}$ Em referência ao Men of Medeek, 1962, de W. Robinson, tradições orais ditadas por Wright, um chefe índio.

${ }^{173}$ O que viria conjugar a afirmação a respeito do âmbito do sonho para os Xavante, em que os ancestrais mostram, explicam e esclarecem tanto questões relativas ao tempo das origens e do passado remoto quanto aquelas que concernem ao presente e ao porvir, através de sua aparição e do ensinamento de cantos para aqueles que sonham (revelação que veio produzir a performance do sonho orquestrada por Warodi).

174 Tal proposição dialoga potencialmente com Bauman (1986:5) quando afirma as relações entre narrativas, eventos narrados e textos narrativos: "events are not the external raw materials out of which narratives are constructed, but rather the reverse: events are abstractions from narratives. It is the structures of signification that give coherence to events in our understanding". Bauman afirma ainda: "[narrative] may also be an instrument for obscuring hedging, confusinh, exploring or questioning what went on..."

${ }^{175}$ Parece-me que multiplicando a produção de registros em diversos contextos, mas de modo que o interesse esteja voltado menos por seus resultados enquanto 'produtos' do que pelos próprios processos, tanto de 'inovação' (segundo a afirmação de Jack Goody de que 'qualquer mudança nos modos de comunicação necessariamente produz modificações no conteúdo transmitido" (1979:46)) e tendo em vista o interesse que desperta o emprego de tais ferramentas para os atores indígenas, quanto de reforço na 'transmissão', vinculado à sua produção contextual. Debato melhor esta proposição na conclusão da presente dissertação.

${ }^{176}$ Lévi-Strauss irá apresentar ali as características de uma história 'em relação direta com o mito', a partir do que o autor caracteriza como a 'ordem' e a 'desordem' na tradição oral. O 'problema' segundo situado por Lévi Strauss concerne o fato de aquilo que nós chamamos de 'mítico' ser concebido por eles como história, mas uma história que contrasta com as características fundamentais do que nós ocidentais concebemos como 'história': seu imperativo de 'verdade' e de "coerência'. Segundo Becquelin (1993:36): "Cette problématique nous incite à travailler non plus en fonction d'une histoire que nous jugeons "réelle "
} 
'trama cosmogônica', mas da(s) história(s) ${ }^{177}$. E, ainda segundo Lévi-Strauss, "nesta história oral sem arquivos, - nessa 'história mítica' ou neste 'mito historicizado'-, "eles também não concebem a noção de uma história única; e somente esta, do ponto de vista ocidental, seria capaz de satisfazer a exigência de verdade" (ibid: 1986: 155).

Arthur Eid afirmou que "eles não são muito afeitos a ficarem dando explicações sobre seus mitos"178 (2003:36). Assim o pesquisador, ao debater e buscar constituir uma versão tão completa quanto possível, e em que versões diversas de sujeitos provenientes de grupos familiares distintos são construídos em uma única versão coletiva, esse 'enredo cosmogônico' não se constituiria em algo outro, movido por uma 'exigência de verdade'? Um produto inexistente em situações 'endêmicas' e que somente faria sentido em seu contexto 'intercultural'?

Considerando-se o fato de sua proposta teórica de análise centrar-se sobre a noção de transformação a partir do princípio do romho ${ }^{179}$, pautada na possibilidade de contribuir para estudos comparativos acerca de cosmogonias indígenas sul-americanas, tal enfoque vêm evidenciar o fato do interesse do autor repousar, fundamentalmente, nos conteúdos de tais narrativas, e não em suas formas de expressão ou nos modos como tais narrativas são produzidas em situação de 'naturally occuring discourses", de acordo com seus variados contextos efetivos de produção e reprodução. Deste modo, os outros objetivos, não-teóricos, a que o autor se propõe (como quando afirma que espera que "ele sirva como parte da memória do saber Xavante para suas futuras gerações; que ele realize os esforços dos velhos Xavante e seus tradutores em trazer seu saber espiritual a todos, indígenas e não-indígenas", etc.) são antes secundários. Nesse sentido, o fato de o autor haver privilegiado a construção de uma versão a mais 'completa' possível alinha-se de forma coerente a seu objetivo teórico primeiro. No entanto, meu interesse aqui concerne aqueles outros objetivos, e os modos possíveis de estabelecimento de relações entre a metodologia empregada na produção de registros e seus 'efeitos' junto aos atores Xavante, os quais veremos adiante.

(sélection chronologique et factuelle, en demeurant jamais perçue comme telle par les acteurs), mais en fonction des mécanismes mêmes de la transmission tel qu'elle est répresentée dans ce cultures ».

177 "Que 'se furta quando tentamos discernir com um pouco de precisão os eventos que ela relata" (ibid: 153)

178 Porque mitos, ou melhor, 'história(s)', não são explicáveis ao concernirem, para eles, 'fatos'? Vimos que os pesquisadores Wajãpi também não se enveredam em 'explicações' sobre seus mitos. Afirmam que o que é sabido, hoje, é conhecido porque alguém assim relatou, alguém que testemunhou o ocorrido e o transmitiu. Não se questionam os 'mitos' ou fatos em si, mas, por vezes, elaboram-se interpretações a respeito de tais 'testemunhas-oculares' (delas haverem se 'enganado' ou 'mal-compreendido' os eventos testemunhados, ou de os haverem relatado de maneira imprecisa ou incompleta, etc.).

179 "Qualidade ontológica que confere aos criadores o poder de se transformarem em múltiplos seres manifestando-os em suas formas específicas. Os seres míticos conjugam em sua natureza própria uma dupla natureza, de ser e devir, pois manifestam os seres fenomênicos a partir de si mesmos, e no caso de certos criadores especiais, sem perderem sua natureza original. Os romhõsi'wa possuem um saber prévio do quê eles têm que fazer para criar o mundo, e é este saber rowa'õno que os orientará, e cada um deles fará o que tem de ser feito". (2003:11) 
Eid relata ainda haver apresentado e discutido com eles outras versões dos mitos de criação que já haviam sido publicadas, como o livro Áuwe Uptabi, escrito pelos salesianos, e a versão ouvida por Maybury-Lewis (1984). Após a discussão, Paulo Sepretaprã traduz o que os outros discutem:

"Quem contou essa história? ${ }^{180}$ Sereburã falou que desconhece essa história da origem (...). Nós discutimos sobre essa história da origem. Já fazia muito tempo que os velhos não contam, não falam nada (...). Antes era uma nação só, o Xavante. Hoje em dia estão espalhados em todo lugar. Quem tinha o conhecimento dessa origem, dessa força, eram os descendentes dele, da família dos antepassados. Hoje tem uma disputa de poder entre as aldeias, antigamente não tinha isso. Hoje querem crescer o nome, falar bem do seu local, da sua aldeia e de seu povo Xavante. O povo aqui é tradicional, descendente da raiz da nação Xavante. Por isso ele tem vontade de falar em nome de toda a nação Xavante. Sereburã fica envergonhado de ouvir o jeito que são contadas essas histórias, não é assim. Se os outros estão dispostos a cada um falar de sua aldeia, que seja assim. Eles podem contar uma história diferente, mas aqui vai se estar falando o que é certo, o que é real. Isso é da tradição mesmo. Sereburã desconhece essa história que dois homens vieram do arco-íris. O tataravô dele, até o pessoal daqui, que é uma família só, desconhece essa história. Isso é uma invenção que eles misturaram, baseado na história deles de Deus. Mas não é assim. Sereburã fica muito preocupado, outra aldeia conta de um jeito, em vez de falar uma coisa só, o outro conta de um jeito. Então, quando a história tradicional dos Xavante vai ser respeitada? Quando vai ser falado o real? Que cada um fala de um jeito, o que o warazu (o branco) vai pensar? Vai falar que é tudo mentira, um fala de um jeito, outro fala do outro" (2003:75).

Ainda segundo discutido por Lévi-Strauss e seus alunos, "eles [populações de tradição oral] concebem tão pouco a noção de fiç̧ão que seu vocabulário carece uma de palavra para designá-la e para distingui-la da pura e simples mentira (...). Eles aceitam que as tradições de diferentes clãs sejam autênticas, limitando-se a crer que as suas são mais corretas que a de seus vizinhos. Portanto, eles vêem apenas um equívoco onde nós vemos contradição" (ibid: 1986: 155)

Naquele caso, o problema colocado pelo interlocutor de Eid a respeito daquela narrativa da origem deriva do fato de os 'velhos' de Pimentel Barbosa desconhecerem a história da origem ${ }^{181}$. Adquire relevo, aqui, os modos como se conjugam as noções de 'exigência de verdade' segundo uma expectativa derivada de seu contato com os 'brancos' (o que warazu vai pensar? Vai falar que é tudo mentira), comentários estes decorrentes do projeto de constituição de um corpus antes 'clássico' do que 'barroco' (em que os próprios atores indígenas 'se tornam' etnólogos, introjetando e

\footnotetext{
${ }^{180}$ Acredito ser bastante relevante o fato de Sereburã questionar a identidade do produtor da narrativa.

${ }^{181}$ Porque se seus descendentes, os 'verdadeiros descendentes da tradição' não transmitiram essa história, não haveria como saber. Nem por eles mesmos, nem por 'outros' Xavante.
} 
exteriorizando enunciados segundo um ponto de vista em acordo com aquele a que se querem seu público-alvo ${ }^{182}$, em confluência com uma característica própria a tradições orais, a possibilidade de cada narrador contar sua própria versão dos fatos, 'limitandose a crer que as suas são mais corretas que as de seus vizinhos" contanto que não se constituam em 'mentiras' ("Eles podem contar uma história diferente, mas aqui vai se estar falando o que é certo, o que é real') ${ }^{183}$.

Um outro elemento importante aqui concerne a memória. Parece-me que Sereburã atribui a Pimentel Barbosa a característica de 'tradicional' pelo fato de que os habitantes de outras aldeias habitavam, antes, todas juntas, a aldeia de Tsorepre, local hoje identificado à Pimentel Barbosa. Assim, parece-me que do ponto de vista dos atores as narrativas sobre essa origem deveriam, pelo fato de concernirem os mesmos 'eventos', constituírem-se em uma memória compartilhada, supostamente similar em sua 'origem' ('da tradição mesmo'). O quanto o afastamento espacial e de trajetórias históricas entre aldeias não vêm produzir distintas memórias do passado e, portanto, de potencialidades de construção de futuros também distantes entre si, descontínuos?

Já vimos no âmbito de discussões a respeito da definição de 'comunidades' próprias ao 'patrimônio imaterial"184: "it was agreed that a sense of belonging together, or a sense of identity based on ICH (intangible cultural heritage) should be included in the definition of community" (2006:9). Assim, naquele documento 'comunidades' foram definidas como: "networks of people whose sense of identity or connectedness emerges from a shared historical relationship that is rooted in the practice and transmission of, or engagement with, their intangible cultural heritage" ${ }^{\prime 185}$.

No caso Xavante, parece-me que mesmo que estes (virtual ou potencialmente) compartilhem a prática e a transmissão, ou o engajamento, em formas expressivas e discursivas que informam sua tradição oral, há rupturas (constantes, dado a durável

\footnotetext{
182 Segundo a caracterização bakhtiniana da natureza pública da circulação discursiva, as idéias e palavras do "outro" participam necessariamente nas construções dos discursos durante interações mediadas pela linguagem, segundo contextos, interpretações e circunstâncias específicas.

${ }_{183}$ Parece-me que sua atenção se focaliza para as brechas 'cristãs' que se introduziram na cadeia de transmissão em relação à outras aldeias Xavante. Pois afirmam que sua versão é a 'da tradição mesmo', ou seja, mais coerente 'ou idêntica' àquela dos ancestrais.

184 Documento "Expert meeting on Community Involvement in Safeguarding Intangible Cultural Heritage: Towards the implementation of the 2003 Convention". ACCU/Unesco.

${ }^{185}$. No mesmo documento, grupos foram definidos como "people within or across communities who share characteristics such as skills, experience, and special knowledge, and thus perform specific roles in the present and future practice, re-creation and/or transmission of their intangible cultural heritage as, for exemple, cultural custodians, practitioners or apprentices". Foi sugerido ainda o emprego do termo 'network na descrição da relação de 'comunidades' a 'grupos', preferível à subset, concebido como estático. 'Indivíduos' foram indicados como aqueles que 'within or across communities who have disctinct skills, knowledge, experience, or other characteristics, and thus thus perform specific roles in the present and future practice, re-creation and/or transmission of their intangible cultural heritage as, for exemple, cultural custodians, practitioners or apprentices". (2006: 9).
} 
cisão entre aldeias, e agrupamentos, em menos escala) no que diz respeito à percepção de continuidade histórica daquele compartilhamento ${ }^{186}$.

O que me parece bastante relevante é o fato de que a forma expressiva ihi mrèmè (marco da 'idade avançada' e o modo por excelência de interação política mediada através de discurso, meio pelo qual atores Xavante, assim como suas facções, adquirem 'notabilidade'), necessita justamente, para sua eficácia, que haja uma 'paridade' com a característica da 'negatividade', que é alcançada pelo fato de os discursos naquela arena realizarem-se através de 'polifonia' e de 'co-performances'. Efetivamente, seria esta forma de expressão que impede que, 'entre si' versões de uns e de outros venham a ser refutadas, precisamente pelo fato de serem elas antes coletivamente construídas através daquela prática discursiva e expressiva. Segundo aquela afirmação de Arthur Eid (em nota acima), parece-me que os Xavante não vêem problemas em refutar as versões de outras aldeias, e efetivamente o fazem, mas não concordam com a produção de uma versão coletiva, já que, segundo a forma ihi mrèmè, tal evento hipotético acarretaria em uma 'medida de forças' mais ampla quanto à 'notabilidade', que envolveria facções dominantes (e dominadas) de diversas 'comunidades' e 'aldeias'187.

Poderíamos imaginar que os debates internos às facções correspondem a parcelas de memória que não são compartilhadas e não querem ser, perfazendo, portanto, coletivos que se querem diferentes. Mas que vão então se conjugar em um só coletivo somente através dos procedimentos e recursos expressivos e discursivos postos em prática no warã, espaço em que a gravação de discursos polifônicos é valorizada por seus atores.

\footnotetext{
${ }^{186}$ Segundo Arthur Eid, "durante os dois primeiros anos de pesquisa, optei por apenas trabalhar com a versão dos narradores de Pimentel Barbosa. Considerei que criaria muitas confusões colocar no início do trabalho essa outra versão do Jerônimo. Feito essas narrações e primeiras elaborações, ficou muito claro que havia diferenças muito marcantes entre essas duas versões. E não eram apenas diferenças de ponto de vista, mas na maioria apareciam como divergências factuais, deslocamentos de contextos de personagens, mistura de partes de um mito com outro e outras questões. Por outro lado, eu tinha consciência que colocar essa outra versão de Jerônimo para a avaliação dos velhos trazia implícito um duplo problema: a sempre possível contestação de uma aldeia quanto às refutações da versão de outra aldeia, e uma certa animosidade política que no futuro poderia acirrar o facciosismo entre as várias comunidades Xavante. Mas também ocultar da aldeia de Pimentel Barbosa o que era apresentado como o patrimônio mítico do povo A'uwê não me parecia correto. Como se posicionar diante disso? É verdade que nos inícios da minha vivência com os $A$ 'uwê cheguei a pensar, e mesmo propor, que reuníssemos os velhos das várias aldeias da Reserva Rio das Mortes (Pimentel Barbosa, Tanguro, Caçula e Wederã) para a reflexão e elaboração de uma versão em que todos estivessem de acordo no final. Mesmo porque, como meu início de contato com a aldeia de Pimentel Barbosa se deu pelo Wazaé, Cipassé e Sidaneri, sentia-me de certo modo devedor de suas presenças nesse trabalho. (...) Tive de optar por abandonar essa idéia de trabalhar conjuntamente com Wederã, pela precariedade da tradução e pela tensão política que geraria. E somou-se a isso também 0 fracasso da tentativa empreendida pelo grupo de trabalho do projeto "Xavante - 50 anos de contato" (que realizou junto com a comunidade o livro Wamrêmé Za'ra) de reunir dirigentes das aldeias da Reserva Rio das Mortes para esse concílio da concórdia para uma versão comum." (2003:39; ênfases minhas).

${ }^{187}$ Segundo Maybury-Lewis os Xavantes têm parentes em outras comunidades e sabem que têm parentes potenciais (wanimimhã) mesmo nas aldeias em que não conhecem nem uma única pessoa. Este é um fator extremamente importante para seu raciocínio. Sentem que essas comunidades, qualquer que seja a distância a que delas se encontrem, são parte de seu sistema social. Seus membros não apenas falam a mesma língua e têm as mesmas instituições, mas endossam o mesmo conjunto de idéias a respeito do equilíbrio de poder dentro de cada aldeia (1984:266).
} 
O mesmo aspecto pode ser vislumbrado no que concerne às diversas aldeias e comunidades Xavante: o fato de que supostas situações de 'naturally occurring discourses' que envolvessem mais de uma aldeia necessitaria a construção de uma versão 'coletiva' e polifônica, mas que viria também definir os 'pesos' e 'medidas' de força nas relações entre 'negatividade' e 'notabilidade' entre coletivos e facções distintas, acarreta que os Xavante não demonstrem nenhum interesse por um 'concílio da concórdia por uma versão comum'. Deriva daí que, a meu ver, 'projetos culturais', que levem em consideração formas expressivas e discursivas próprias, no que depender dos atores Xavante, continuarão a serem realizados com esta e aquela aldeia, com este e aquele 'coletivo' independentemente, e independente do fato de todos identificarem a si como 'Xavante'.

Convém avaliarmos aqui os parâmetros que foram indicados na tese de Arthur Eid no que se refere às dinâmicas do trabalho de campo para o registro das narrativas e sua tradução.

O autor afirma que os narradores Xavante, após haverem discutido na warã se concordavam em auxiliar o pesquisador para a elaboração de sua pesquisa, estabeleceram uma dinâmica de trabalho, com alguns indivíduos selecionados, e que consistia em dois encontros diários, pela manhã e na parte da tarde, em que os narradores e o tradutor trabalhavam e re-trabalhavam suas narrativas acerca da criação. Eid afirma que "no modo tradicional de narração do mito, o narrador e os homens adultos ficam deitados de costas, os mais novos ficam deitados sobre o lado. Mas em nossas reuniões, os narradores não seguiram esse modo. Simplesmente sentávamos nas cadeiras que trazíamos da escola" (2003:34).

Eid também afirmou que: "não foi que os velhos tivessem sentado na minha frente e fossem refletindo em uma linha de consciência contínua os significados dos mitos, tal qual aparece nas exegeses. Houve um permanente diálogo entre nós (...). Mas no momento de apresentar essas exegeses, optei por fazê-lo de um modo que não fosse nos moldes de perguntas e respostas, mas em uma versão construída por tópicos temáticos que provieram dos vários momentos do aprofundamento do diálogo e compreensão dos mitos" (2003: 19-20, ênfase minha).

E ainda, ao contrário do que afirma Laura Graham em relação ao gênero ihi mrèmè, discurso "coletivizador" que seria adotado em praticamente todos os encontros de dois ou mais velhos, Arthur Eid afirma que era "sempre um só que narrava" (2003:35), e que pedia que narrassem "no ritmo de trechos não muito longos para evitar muitas perdas na memória do tradutor" (2003:35).

Uma possibilidade de compreensão destas características seria supor, juntamente com Vincent Crapanzano (1988:68) quando este analisa as "negociações de convenções 
dialógicas", que os Xavante sucumbiram ao 'gênero discursivo do antropólogo', apesar de sua narrativas originais haverem sido elaboradas em língua Xavante. Mas me parece o contrário; não que os Xavante tenham sucumbido, mas que, tendo em vista o objetivo teórico do autor, seu foco no conteúdo de narrativas míticas e não em suas formas de expressão, o antropólogo impôs certo 'gênero discursivo'. Isso porque, ao levar em consideração o fato de os Xavante "contestarem que muitas das interpretações que foram feitas sobre suas culturas eram construções que não correspondiam à realidade e ao modo com que eles compreendem a si mesmos", Eid propõe um projeto em que as interpretações (reelaboradas pelo autor no texto final) de seus interlocutores são trazidas para o corpo do texto. Mas qual seria essa 'sua realidade' e os modos como 'compreendem a si mesmos' ${ }^{\text {'188 }}$ ?

Em abordagens ditas 'dialógicas', como é o caso de Eid, parece-me que os interlocutores são chamados a produzirem enunciados orais segundo uma concepção de uma 'verdade interior', que se pauta em uma concepção da linguagem como produção individual, racional e verdadeira ${ }^{189}$. E em que, como vimos, o 'contexto' de produção de discursos e enunciados, e as relações entre contexto e texto (Bauman:1986) são vistos como pano de fundo ou transcontextualmente estáveis, de modo que o fato de produzirem narrativas 'sentados', na 'escola', 'narrando sempre um só' não consiste em um problema segundo o objetivo teórico a que se propõe o pesquisador. Também transparece na opção de Eid um intuito de construção de uma versão coletiva das narrativas míticas que seria pública, 'democrática' e, portanto 'justa', parafraseando uma visão segundo a qual indivíduos modernos racionais agiriam (e também produziriam discursos individuais) pautados por uma intenção de 'maximização do valor'. Desse modo, o fato de trabalharem em grupo 'regularia' a competição entre indivíduos de modo a produzir uma versão que não privilegia este ou aquele interlocutor, mas a todos. A única ressalva desta metodologia (que, como já afirmado, alinha-se de modo coerente aos objetivos teóricos a que se propõe o pesquisador) no que diz respeito ao seu emprego em projetos de 'transformação dirigida da oralidade' que propõem a 'valorização cultural' internamente à(s) aldeia(s) é o de que ela 'não corresponde à realidade', ou não às formas através das quais narrativas 'míticohistóricas' são produzidas, vividas e avaliadas pelos atores indígenas ${ }^{190}$. Becquelin

\footnotetext{
${ }^{188}$ Certamente não através de elaborações de explicações acerca de seus mitos, segundo a afirmação de que "eles não são muito afeitos a ficarem dando explicações sobre seus mitos" (2003:36).

${ }^{189}$ Habermas $(1984,1987)$ já havia definido os princípios que pautam produções discursivas 'modernas', a partir da emergência de uma esfera pública de debates entre iguais, e historicamente constituída a partir do desenvolvimento do capitalismo e do declínio do feudalismo. Tal esfera pública teria como fundamento a noção de construções discursivas individuais, cujas proposições são concebidas segundo princípios de racionalidade, verdade, legitimidade, sinceridade e autenticidade.

${ }^{190}$ Como no caso dos cantos da-nõpre recebidos em sonho pelos indivíduos dos ancestrais e criadores. Nesses cantos, referências a eventos míticos ou à características de certos ancestrais são fragmentos, fragmentos de narrativas passadas sedimentadas na memória. Durante a performance do sonho, Graham relata que são tais fragmentos, sedimentados na memória dos indivíduos, o que permitia tanto aos 'atores' quanto à audiência, ao terem tais criadores em mente, imbuírem tais figuras de significado (não necessariamente os mesmos para todos os indivíduos), trazendo-os à vida e ao presente.
} 
(1993:36), refere-se à importância da consideração de narrativas históricas não mais em função de uma história julgada 'real' por nós (seleção cronológica e factual e, de fato, jamais percebida desse modo pelos atores), mas em função dos mecanismos mesmos de transmissão, tal como representados por estas culturas. Em relação aos modos de transmissão, adquire relevo o fato de Eid fazer recurso a 'perguntas e respostas', uma opção metodológica que se afasta de formas contextualizadas através das quais narrativas míticas são tanto produzidas em naturally occurring discourses, quanto aos modos como conteúdos e referências míticas são, em situação, 'puxados' da memória, vindo produzir sentido no que diz respeito à experiência de sonhos, ao informarem modos de ação adequados em festas ou eventos do calendário cerimonial (ou a performances), ou enquanto recursos para interpretações a respeito de eventos e fenômenos da vida cotidiana ou da 'natureza'.

Parece-me que aquilo que certos antropólogos avaliaram como uma desconsideração do papel fundamental dos interlocutores nativos, em que conhecimentos acessados através de diálogos com informantes no texto final do antropólogo vinham se transformar em um monólogo do 'autor', acarretou que desconsiderassem, isso sim, o fato de tais informantes não se apresentarem necessariamente como 'indivíduos modernos'. Antropólogos de orientação dialógica, ao buscarem trabalhar junto a seus informantes em pé de 'igualdade' e respeito, acabam com isso vindo considerá-los como iguais a si mesmos ${ }^{191}$. Não seria este o caso quando Lévi-Strauss afirmou que "eles também não concebem a noção de uma história única; e somente esta, do ponto de vista ocidental, seria capaz de satisfazer a exigência de verdade"? (1986:155). Eid busca construir com eles uma 'história única', mas cuja exigência 'de verdade' é dele pesquisador, e não a deles, Xavante.

Isso porque, como vimos, "dans la transmission orale, le narrateur est créateur même s'il siimagine ne faire que répéter. Ce que les acteurs de ces sociétés appellent 'répéter' n'est d'aileurs pas nécessairement une reproduction a l'identique. Ce double rôle empêche à la fois l'imitation exacte et l'innovation totale, puis que le narrateur n'a ni les moyens de la fidélité absolue ni le droit d'inventer' (Becquelin \& Molinié 1993:12). Desse modo, o fato de eles dizerem que suas construções 'são as mais verdadeiras' não possui o mesmo significado para o pesquisador e para seus interlocutores. A noção de verdade de Eid, ao pautar-se em uma horizontalidade entre indivíduos (ou seja, na idéia de que a 'verdade' proviria da produção democrática de uma só narrativa, 'a mais completa possível'), perde de vista justamente a 'exigência de verdade' Xavante, cuja ancoragem é menos entre um indivíduo e outro, que quanto à percepção de permanência e repetição através do tempo, pautada na percepção dos atores de continuidade do emprego de formas expressivas e com recurso ao discurso direto, que

191 Crítica corroborada por Crapanzano (1979:xv), quando este aponta para o fato de que, no que diz respeito à 'trocas dialógicas', estas correrem o risco de serem compreendidas como a 'realidade cultural' do outro (citado em Strathern,M. 1987:32) 
garantiriam a fidelidade aos conteúdos e formas empregados pelas gerações ascendentes e pelos ancestrais. Neste sentido, as versões deverão variar tanto através da impossibilidade de repetição idêntica, ou seja, da personalização de cada narrativa de acordo com o narrador em cada caso, assim como à variabilidade das fontes de onde provém o 'conhecimento' de cada um dos narradores (este ou aquele ancestral), e em que a 'verdade dos fatos' não é questionada, mas sim, e se for o caso (no que diz respeito aos conteúdos), aos modos como este ou aquele ancestral experimentou e relatou o evento narrado (Vansina, 1984).

Veremos os 'efeitos' de 'interrupção' ou de 'descaso' dos atores indígenas Xavante quanto ao produto da 'transformação dirigida da oralidade' decorrente da compilação de tais registros realizados por Arthur Eid. No caso específico aqui discutido, uma pesquisa em que narrativas indígenas produzidas em contextos 'deslocados' e cuja metodologia de registro alinhou-se a objetivos teóricos precisos, mas que vêm se outorgar a si e a seus produtos, secundariamente, objetivos de 'valorização cultural'. Pois tais materiais podem terminar por produzir, antes, o desinteresse daqueles que se imagina serem seu potencial público-alvo ${ }^{192}$.

Arthur Eid afirmou que grande parte das narrativas elaboradas em seu trabalho de campo e transcritas no corpo de sua tese serviram de material para o livro Wamrêmè Za'ra (o qual examinarei mais adiante). Assim, o procedimento adotado em sua prática etnográfica (narrativas gravadas, discussões, tradução) foi o mesmo adotado para a elaboração daquele livro (cuja publicação foi anterior à defesa da tese, mas não ao início do trabalho de campo daquele autor).

No entanto, Arthur Eid escreve em sua tese:

"Acompanhando a trajetória do livro Wamrêmé Za'ra dentro da aldeia desde sua publicação, observamos que seu uso pelos jovens ou na escola é muito restrito. Os Xavante ainda não demonstram grande interesse por ler livros, mesmo sendo da própria cultura de sua aldeia, o que não significa que isso não venha a mudar no futuro" $(2003: 40)^{193}$.

Esse é um dos eventos a que chamo de 'interrupção' ou 'descaso', ou seja, situações em que registros produzidos (também) para serem reapropriados por seus sujeitos não 'proliferam', ou seja, não são reinseridos na cadeia de transmissão oral, ao não lhes interessarem, sendo 'ignorados'.

No que diz respeito ao 'caso' Xavante, vislumbro aqui algumas questões relevantes acerca de projetos de valorização e salvaguarda pautadas no registro de 'tradições

\footnotetext{
192 O que não significa necessariamente que não produzam certa valorização 'para fora'.

193 Uma questão de grande importância aqui concerne o fato de que a forma final de tais narrativas, apesar de haverem sido gravadas, foi a de um texto escrito, enquanto outros registros que 'proliferaram' concernem narrativas gravadas. Essa distinção visual-sonoro ponto poderia efetivamente requerer um argumento que tomasse outra direção, que não caberá aqui devido às limitações desta pesquisa.
} 
orais' de populações indígenas. Primeiramente o fato de que 'tradições orais' ao concernirem gêneros, modos de interação e formas de expressão e de produção discursiva adequados a certos contextos, no âmbito das quais certos (não todos) conteúdos são produzidos e reproduzidos, vêm iluminar o fato de que narrativas 'míticohistóricas' (e suas compilações), dependendo do modo como atos de fala, seus contextos e interlocutores são apresentados, não virão se constituir efetivos registros de 'tradições orais'.

Essa questão é relevante na medida em que vislumbramos, por exemplo, a metodologia do Inventário Nacional de Referências Culturais que vêm sendo aplicado nos processos de instrução de Registros do Patrimônio Imaterial de populações indígenas e setores da 'cultura popular' pelo Iphan ${ }^{194}$. Vale ressaltar, primeiramente, que um dos critérios de admissibilidade e pertinência que vêm sendo adotados na avaliação dos pedidos de Registro do Patrimônio Imaterial do Brasil, previstos no decreto 3551/2000, refere-se ao fato de que tal patrimônio deva 'ser transmitido através da oralidade ou informalmente' (Lima e Alves, 2008:7) ${ }^{195}$. E ainda, que "a anuência da comunidade produtora do bem não pode ser de 'fachada' (...). Significa dizer que os produtores e os demais envolvidos com o bem cultural têm que participar do processo inteiro, desde o início e em todas as suas etapas - seja na expressão formal de concordância com o pedido, seja como informantes preferenciais do processo de pesquisa sobre o bem" (Lima e Alves, 2008:6). ${ }^{196}$

Nessa paisagem, identificamos uma dificuldade no que diz respeito ao 'patrimônio imaterial' relativo à povos indígenas, em especial em sua rubrica 'tradições e expressões orais'. Considerando-se a suposta situação em que os Xavante demandariam o registro de um 'bem de natureza imaterial', poderíamos imaginar diversas possibilidade de 'bens patrimoniálizáveis', como alguns de seus cantos, que já foram registrados na forma do CD 'Etenhiritipa'. Contudo, segundo Laura Graham, seriam as formas de expressão cultural, para além dos conteúdos necessariamente dinâmicos transmitidos através daquelas formas, que promoveriam uma percepção de continuidade para seus atores ao longo do tempo. Dentre tais formas, Graham ressalta a importância da prática expressiva e discursiva ihi mrèmè. Mas já vimos o fato de os

\footnotetext{
${ }^{194}$ Instituto do Patrimônio histórico e artístico Nacional, órgão do ministério da Cultura no Brasil.

195 Além de outros critérios como de 'relevância nacional para a memória, identidade e a formação da sociedade brasileira'; 'continuidade histórica mínima de três gerações (cerca de 75 anos)'; 'enraizamento no cotidiano das comunidades' e ser 'marca de expressão de práticas ou vivências culturais coletivas' (Lima e Alves, 2008:7).

${ }^{196}$ E ainda, em um documento produzido em um curso acerca das políticas do patrimônio imaterial no Brasil promovido por técnicos e especialistas do Iphan, lemos: "Em 2001 o Iphan lançou uma metodologia de inventário específica para o patrimônio Imaterial, o Inventário Nacional de Referências Culturais, INRC, um instrumento de pesquisa, documentação, mobilização social e gestão de políticas para a área. Um dos resultados teóricos /conceituais da aplicação do INRC é a noção de 'bem cultural', que á atribuído ao traço cultural característico em uma cultura transformado em objeto patrimonializado - reconhecido como referência de uma identidade cultural singular (...). Para a pesquisa dessa natureza os objetos de investigação por excelência são os documentos, as entrevistas e as performances, através da observação participante" (Viana, 2008:5, ênfase minha).
} 
Xavante sentirem-se extremamente incomodados em comentar tanto suas falas quanto as falas dos outros na warã. Nesse sentido, uma metodologia pautada em entrevistas e informantes privilegiados, parece-me, não poderia dar conta daquele gênero discursivo e expressivo, que não seria então considerado um 'bem de natureza imaterial'. Essa questão não apontaria a problemática, no que diz respeito à patrimonialização de formas expressivas, de que, primeiramente, tais formas devam ser 'reconhecidas pelos seus atores' como relevantes para sua cultura? Mas não poderiam os Xavante realizar comentários sobre a prática do ihi mrèmè, sem necessariamente comentarem as falas de outros nessa arena?

E em segundo lugar, isso não exigiria que os agentes de ações de registro fossem mais cuidadosos no que diz respeito aos modos de emprego da linguagem, de forma a que a registros com vistas à viabilidade sejam mais adequados aos mecanismos mesmos da transmissão em uma dada cultura, para que 'proliferem'? Qual seria aqui o efeito dos procedimentos sugeridos pela metodologia do INRC quanto ao emprego de entrevistas (ou seja, perguntas e respostas) com informantes preferenciais?

Lembremos aqui que as narrativas mítico-históricas produzidas por Warodi e gravadas por Laura Graham, que corresponderiam ao que Lévi-Strauss considerou um corpus barroco (pois não põe no mesmo plano as tradições de seu grupo familiar ou social e as obtidas junto a informantes que são membros de clãs diferentes) foram reapropriadas por Riridu e 'proliferadas', havendo sido reinseridas na cadeia de transmissão de 'tradições orais' (na forma de interação mediada pelo discurso no warã por Riridu). Ao passo que o corpus clássico produzido por Arthur Eid, e que em um segundo momento foi reelaborado na forma de um projeto de 'transformação dirigida da oralidade' vindo compor o livro Wamrêmè Za'ra, produziu o 'descaso' junto a seus atores Xavante. Vale ressaltar também o contraste entre a metodologia de apreensão da 'fala nativa' através de 'perguntas e respostas' por Arthur Eid e o foco de Laura Graham, nos "naturally occurring discourses". Ainda que Graham não tenha explicitado os modos como as narrativas de Warodi foram gravadas, imagino que não tenha sido nos moldes de 'perguntas e respostas'. A meu ver, Laura Graham simplesmente 'emprestava' o gravador a Warodi, que produzia então narrativas ao mesmo tempo em que as gravava.

No caso da tese de Arthur Eid, se algumas das narrativas elaboradas durante seu trabalho de campo vieram a compor o livro Wamrémé Za'ra, o que interessa aos seus produtores (os interlocutores de Arthur Eid) parece-me ser mais o potencial 'empoderamento' dali decorrente ${ }^{197}$ do que os 'fundamentos da cosmogonia A'uwê' na forma escrita.

197 Ou seja, o impacto do livro no sentido de valorizar a 'comunidade' e o nome de Pimentel Barbosa enquanto 'pacificadores dos brancos' e 'raiz da tradição Xavante' frente aos warazu (e, potencialmente, frente à outras comunidades Xavante), assim como a possibilidade de acesso a recursos advindos da venda do livro. 
Por outro lado, populações indígenas afirmam temerem a possibilidade de que seus "conhecimentos tradicionais" se extingüam devido ao crescente contato com os 'brancos'. Ao mesmo tempo, é sabido que seu direito à diferença depende do reconhecimento e valorização de formas próprias de conhecer, por aqueles mesmos brancos, distintas de um suposto corpus de conhecimentos 'tradicionais' (ainda que seus 'conhecimentos' devam ser reconhecidos, mas reconhecido também seu dinamismo). Assim, tais populações vêem nas tecnologias de registro (a escrita, o áudio, o vídeo, o computador) a possibilidade de 'guardar' tais conhecimentos para as 'futuras gerações', para que esses não se percam, optando assim por ações de registro de sua suposta 'tradição'. Nesse sentido, populações indígenas introjetaram o que é esperado deles pelo 'senso comum', vindo produzir 'compilações de conhecimentos' através de projetos que, ao fim e ao cabo, se produzem 'empoderamento', não interessam seus próprios sujeitos. O fato é que, em geral, tais compilações, se realizadas com a participação dos indivíduos na forma de 'coletivos' que não correspondem aos 'coletivos' tais como se elaboram nos modos de interação considerados adequados na vida cotidiana nas aldeias, produzirão conteúdos que não Ihes instiga ${ }^{198}$. Nesse sentido, de que modo produzir registros do que é 'relevante'? O quanto tais registros poderiam despertar, efetivamente, o interesse de seus produtores para além de se constituírem produtos 'para fora'? Seria possível conjugar esses dois 'produtos' (registros para si e para outros) sem que transformemos sujeitos indígenas em um potencial 'nós'?

\subsection{Registros da oralidade Xavante da ordem do 'projeto'}

O livro 'Wamrêmè Za'ra: Nossa Palavra: Mito e História do povo Xavante' (1998), foi elaborado a partir do registro de narrativas de Sereburã, Hipru, Rupawe, Serezabdi e Serenhimirãmi, e de suas traduções por Paulo Sepretaprã e Jurandir Serediwê Xavante, com o apoio do Núcleo de Cultura Indígena de São Paulo (NCI-SP). A edição do texto foi realizada por Ângela M. Pappiani, Cristina M.Simões Flória e Jurandir Siridiwê Xavante; a redação e finalização do texto ficou a cargo de Ângela M. Pappiani.

Segundo seu prefácio, este livro consistiu na primeira experiência participativa Xavante na publicação de 'mitos' e 'histórias' e, de acordo com seus organizadores, segundo um ponto de vista 'propriamente Xavante' 199 .

O livro está organizado em três partes. A primeira parte, cujo título é "Antes de tudo", apresenta narrativas acerca da criação, algumas delas produzidas nos diálogos e

${ }^{198}$ Ou arriscam, pelo fato de em geral, concernirem diálogos interculturais, demandar o emprego de formas discursivas que não trabalhem na construção de coletivos, podendo potencialmente alimentar querelas. $E$ ainda, devido ao eventual deslocamento de enunciados que, gravados, podem chegar aos ouvidos de um público distinto daquele para o qual estavam previstos.

${ }^{199}$ Atente-se para as aspas. 
discussões travadas com Arthur Eid e gravadas durante seu trabalho de campo. Duas das narrativas dessa primeira parte aparecem em versão bilíngüe, e as versões em língua Xavante vêm ocupar um segundo plano, constando de textos menores e tendo sido adotada uma fonte que "imita" o manuscrito.

A segunda parte do livro, "Nossa história", apresenta relatos de eventos do contato entre os Xavante e outros povos indígenas e os brancos. Os diversos eventos são apresentados segundo o ponto de vista de cada narrador. Esta parte do livro é bastante rica, ao trazer tanto as histórias de cada narrador conforme relatadas por seus pais, tios e avós, como suas eventuais opiniões a respeito dos fatos. Através das narrativas ${ }^{200}$ aprendemos como os brancos foram atraídos por meio de recursos mágicos para que trouxessem os instrumentos desejados ${ }^{201}$, assim como os modos como o processo do contato e da 'pacificação dos brancos' foi controlado pelos Xavante, sublinhando o fato de que os descendentes desses 'pacificadores' vivem hoje (à época) em Pimentel Barbosa.

Na última parte do livro há o capítulo "Panorama Histórico", que aponta, segundo divisões em séculos (a partir do século XVI) e depois em décadas (a partir da década de 30), eventos da história Xavante segundo o ponto de vista do 'branco', através de registros dos primeiros relatos concernindo o 'povo Xavante' em jornais da época, a chegada das frentes missionárias, os momentos que marcaram os processos de demarcação de cada reserva, e os projetos desenvolvidos pela aldeia de Pimentel Barbosa, como a data de criação de sua associação e de realização do CD "Etenhiritipá - Cantos da Tradição Xavante".

Em todos os capítulos os títulos aparecem em português e em língua Xavante. O livro também é pontuado por uma série de desenhos produzidos por indivíduos daquela aldeia, que acompanham e ilustram situações dos 'mitos' e das histórias, assim como por pequenos extratos de peças de arte gráfica e fotos históricas, estas últimas provenientes de arquivos do Museu do Índio e do Jornal "O Estado de Minas".

Na apresentação do livro, Ângela M. Pappiani e Cristina M. Simões Floria, assessoras do Núcleo de Cultura Indígena (hoje, IDETI- Instituto das Tradições Indígenas), afirmam que tais narrativas foram relatadas especificamente pelos velhos de Pimentel Barbosa: "outros velhos que também são personagens desta história, por divisões políticas das aldeias, já não vivem em Etêniritipa e não chegaram a participar deste trabalho. Mas da mesma forma são testemunhas deste tempo e devem ter muitas histórias para contar" (1997:14). Ainda na introdução, lemos: "Esses velhos sabem que estão vivendo outros tempos, que o isolamento já não é possível e que podem usar a tecnologia e o conhecimento dos warazu a seu favor (...), e esses velhos sabem que sua voz

\footnotetext{
${ }^{200}$ As narrativas não foram aqui 'multiplicadas', no sentido em que cada uma busca dar conta de um evento, não havendo mais de uma narrativa sobre um mesmo evento.

${ }^{201}$ Machados, facas, espelhos, etc.
} 
registrada pelo gravador, que as palavras transformadas em tinta sobre o papel podem sobreviver ao seu tempo e chegar lá na frente, de um outro jeito mágico, guardando o conhecimento e a tradição para as futuras gerações" (1997:9).

Em relação às 'futuras gerações' dá-se a entender que estas não se referem especificamente aos 'brancos' ou aos Xavante, mas às 'futuras gerações' em geral. Entretanto, o livro tendo sido escrito em língua portuguesa, seu público-alvo primeiro parecem ser os 'brancos'. Mas segundo nos relata Arthur Eid, o livro também foi escrito para ser usado nas escolas indígenas, apesar de a afirmação do autor de que "acompanhando a trajetória do livro Wamrêmè Za'ra dentro da aldeia desde sua publicação, observamos que seu uso pelos jovens ou na escola é muito restrito" (2003:40).

Em relação à proposta do livro Wamrêmè Za'ra, parece-me que servir aos Xavante e aos brancos ao mesmo tempo produz certas "misturas" incoerentes. Pois concomitante à rica apresentação do ponto de vista Xavante a respeito do contato e da criação, sua última parte contém um 'panorama histórico' segundo uma 'linha do tempo' e uma concepção de 'história' ordenada em uma ordem que se quer objetiva, cronológica e factual, que não condiz com a proposta do restante da obra. Pois se na primeira parte as narrativas são expostas segundo pontos de vista individuais, de modo que os relatos se dão na primeira pessoa (mas somente em alguns deles os narradores indicam seus nomes), na segunda parte temos uma rememoração da história na forma de eventos pontuais, na forma de 'informações', não de 'narrativas'. E ainda, os títulos das duas primeiras partes da obra, 'antes de tudo' e 'nossa história' não são traduzidos em língua Xavante, de forma que não sabemos se estas consistem em categorias de 'ordenação' temporal propriamente Xavante ${ }^{202}$.

No que diz respeito à 'autoria' daquelas narrativas, nem sempre apresentada, me questiono se este elemento não corroboraria para o fato de tal obra não promover o interesse de seus sujeitos. Lynn Mário Souza (2001) aponta que é importante atentar para algumas questões no que concerne à escrita de narrativas indígenas. Uma dessas questões refere-se à autoria na tradição oral, na qual, segundo ele, narrativas são vistas como de 'propriedade coletiva do grupo' a que se referem, de modo que se tratariam antes de 'heranças dos antepassados' do que propriamente de produções de ordem individual. Neste sentido, o narrador se posicionaria mais enquanto transmissor do que propriamente autor de uma dada narrativa. Entretanto, como já ressaltei,

202 Em relação aos Wajãpi do Amapá, estes recorrem à noção de 'falas' para a ordenação 'temporal' de narrativas, segundo as categorias de janejarayvukwerã, falas do tempo do criador Janejarã', taimiwerã ayvukwerã, 'falas do tempo dos ancestrais (não nomeados), tamokõayvukwerã, "falas do tempo dos avós (nomeados)", e age'e ayvukwerã, "falas do tempo de hoje". Vemos também que tais categorias, empregadas em um uso 'solto', e não necessariamente segundo estes termos (que poderiam, em contexto, serem substituídos por 'sinônimos' de modo a transmitirem o mesmo sentido) passaram a sofrer maior formalização a partir das experiências de ordenação de materiais para a organização de seu banco de dados, assim como pelos pesquisadores, no âmbito da organização de suas pesquisas. 
Becquelin e Molinié afirmam que "dans la transmission orale, le narrateur est créateur même s'il s'imagine ne faire que répéter. Ce que les acteurs de ces sociétés appellent 'répéter' n'est d'aileurs pas nécessairement une reproduction a l'identique. Ce double rôle empêche à la fois l'imitation exacte et l'innovation totale, puis que le narrateur n'a ni les moyens de la fidélité absolue ni le droit d'inventer" (1993:12). Ou seja, ao atentarse para cada 'criação narrativa' em seu contexto de produção, há uma autoria individual, ainda que não seja ela avançada como tal, ou posta assim em relevo, pelo próprio narrador ${ }^{203}$.

Contudo, que relação poderia ser estabelecida quanto ao fato de os Xavante interessarem-se antes pelos indivíduos do que pelas qualidades artísticas (ou pelos conteúdos) de produção de discursos coletivos? Seria o mesmo caso no que diz respeito à narrativas individuais? ${ }^{204} \mathrm{E}$ no caso de tais narrativas apresentarem-se segundo uma forma escrita, em que se perde a ancoragem no que diz respeito às formas expressivas (e, potencialmente, à identidade dos narradores, quando não são elas apresentadas)? Estabelecendo aqui uma comparação com o caso Wajãpi (em nota acima) relatado, a atenção dos atores não poderia estar voltada menos para o 'conteúdo' da criação individual do que para os próprios sujeitos produtores de discursos, cuja 'importância' passa por valores que não necessariamente repousam nos enunciados, no que tange seus conteúdos, mas em suas 'formas'? Mas vimos também que a atenção não se pousa especificamente sobre as formas em si mesmas, segundo sua qualidade artística, mas devido o fato de que a detenção de tais recursos expressivos por aqueles indivíduos pode ser entendido como uma contribuição (necessária, mas não suficiente) para o fato de virem ser eles, os indivíduos, 'valorizados' ${ }^{205}$ ?

${ }^{203}$ Que irá, de modo geral, remeter ao 'antepassado' específico que haveria testemunhado, ou transmitido, aquela história. Já vimos que quando questionados sobre a proficiência na produção de discursos ihimrèmè, os jovens atribuíam menos importância aos aspectos artísticos da produção de discursos do que aos indivíduos em si, indicando sempre os 'velhos' de sua própria facção como sendo os melhores produtores (2003:165). Apesar de Laura Graham não explicitar as formas como são avaliadas a qualidade na produção de narrativas, parece-me que a atenção dos atores volta-se antes aos indivíduos, estes valorizados, também por deterem os recursos à produção de forma considerada 'adequada' (também esteticamente, enquanto percepção de 'manutenção'). Riridu haver sido considerado uma 'farsa' (por uma facção minoritária) seria decorrente das 'inovações' artísticas de suas performances narrativas e expressivas?

${ }^{204}$ Em relação à hipótese avançada, de as narrativas gravadas de Warodi haverem 'proliferado' através de Riridu não somente devido aos índices formais adequados internos aos seus conteúdos, mas ao fato de se constituírem narrativas de Warodi, 'tio' de Riridu e pertencente à sua mesma facção, assim como pelo fato de haver adquirido um nome de imortal, em sonho.

${ }^{205}$ Ou seja, a possibilidade de tais recursos expressivos contribuírem à 'magnificação' contribuindo para que seus indivíduos 'detenham agência'? Segundo Sztutman (2006) a magnificação concerneria formas de constituição de pessoas singulares, através da acumulação de 'nomes e marcas', de modo que tais pessoas se diferenciariam não em natureza, mas em escala, ao se engajarem na produção de coletivos através do acúmulo de 'agência', i.e. 'capacidade de agir ou de afetar a ação de outrem' (Gell, 1998 In Sztutman, 2006). Expandindo a hipótese de Brenneis \& Meyers (1894) de que a fala em contextos políticos concerne menos em uma forma de coerção ou de tomada de decisões do que de alocação de valores sociais. $O$ quanto narrativas poderiam ser consideradas 'políticas', quando a atenção quanto ao caráter político é desviada das falas para os sujeitos, 'magnificados'? Recorro também aqui ao argumento de Wagner ao discutir formas diferencias de criatividade, quando este afirmou, em relação aos Daribi da Nova Guiné: "It is people, and the experiences and meanings associated to them that they do not want to lose, rather than ideas and things. My 
Ainda no que diz respeito à autoria, Alcida Ramos (2007), em um texto recente, atentou para os modos como populações indígenas vêm atualmente questionando e mesmo impedindo que antropólogos realizem pesquisas junto às suas 'comunidades'. Essa situação seria decorrente do poder que tais populações identificaram nos usos da escrita e de outras formas de registro e divulgação, muito devido ao seu longo histórico de contato com antropólogos (e indigenistas). Indivíduos dentre tais populações, com o advento e fortalecimento de programas de formação escolar ('intercultural, bilíngüe e diferenciada'), aprenderam eles mesmos a redigir cartas e denúncias, assim como a utilizar os recursos de um regime gráfico para potencializar a comunicação entre $\mathrm{si}^{206}$, assim como sua divulgação e auto-representação 'para fora'. Alcida Ramos retrata, então, um histórico de sua própria atitude face essa nova situação de demanda de 'monopólio' indígena por sua própria auto-representação, que iria do 'engajamento ao desprendimento'. Em tal contexto, Ramos identifica uma transformação em curso, em que 'de sujeitos de pesquisa tais indivíduos vêm se tornar 'pesquisadores indígenas', ao haverem 'ganhado consciência de que a pesquisa antropológica tem um forte apelo político' (2007:16). Afirma ainda que: 'tudo indica que começa uma nova era em que povos indígenas no Brasil (e alhures), depois de se apropriarem do papel de atores políticos, estão no processo de se apropriar também do principal produto do etnógrafo, ou seja, as etnografias" (2007:17). Dentre os exemplos apresentados pela autora que 'mostram como podem ser os papéis dos etnógrafos no futuro', Alcida Ramos cita a 'produção literária por parte dos Desana, povo de fala Tukano, e dos Tariana, de fala Aruaque, que receberam recursos para publicar uma série de livros sobre sua mitologia' (2007: 20). E a autora sugere ainda que, devido às dificuldades de sujeitos indígenas em transmitir a 'lógica indígena a um público não-indígena' sem a intermediação do antropólogo, que nesse processo deveria ser empregada uma relação dialógica entre observador e observado, aquela "tão alardeada, mas em geral mantida num vácuo pelos autores pós-modernos, mas que poderia muito bem materializar-se como uma joint-venture na qual o papel principal não cabe mais ao etnógrafo convencional, como de hábito nas etnografias a mais de duas mãos" (2007:20). Por fim, a autora faz dois comentários que considero relevantes para o debate aqui estabelecido. Em primeiro lugar, de que as "auto-etnografias não mostram nenhum compromisso perceptível com o lado acadêmico da disciplina ${ }^{207}$ (...). "Na atual fase de consciência étnica, as auto-

New Guinean friends transfer the names of the newly dead to the newly born, and also find it necessary to invent the deceased in the form of ghosts, so that they are not wholly lost. We do much the same thing with books, which are our 'ghosts', our past, wherein so much of what we call "Culture" lives". (Wagner, 1981, 1726).

${ }^{206}$ Para o exemplo Yanomami de que trata a autora, através do crescente emprego de bilhetes como forma de comunicação entre aldeias e indivíduos.

207 Então porque chamá-las 'etnografias?'. Marylin Strathern, ao discutir 'auto-antropologia', realiza algumas remarcas iluminadoras em relação à proposição de Alcida Ramos a respeito do que esta qualifica 'autoetnografias'. Primeiramente, Strathern se pergunta: 'a quem o conhecimento é dirigido?'. De fato, ao qualificarem-se como 'auto', deveriam supor que se apóiam 'nas mesmas técnicas de conhecimento através das quais as pessoas se conhecem a si, de modo que as técnicas de teorização seriam as mesmas'. Ou seja, quando as formas de conhecer da antropologia não são as mesmas 'formas de conhecer' dos sujeitos 
etnografias parecem dirigir-se à instrumentalização dos recursos étnicos a serem aplicados em contextos da política interétnica" (2007:23). A autora ainda afirma, no que concerne tais 'auto-etnografias', de que "é até possível que a questão da autoria, tão importante para os pesquisadores ocidentais, possa ter um papel bem menor no cenário político das auto-etnografias" $(2007: 24)^{208}$.

Esta proposição vem contrastar frontalmente com o debate a que busquei aqui lançar luz. Inicialmente, o fato de a autora imbricar em um só 'pacote' os usos empregados por populações indígenas e populações 'ocidentais', dentre elas antropólogos, aos instrumentos de um regime gráfico; e ainda, de que os usos de tais instrumentos seriam somente, -e tão somente-, 'políticos' (no sentido da política indigenista, da afirmação do direito à diferença cultural, à igualdade política e à 'auto-representação'), como se as formas políticas 'nativas' e os modos como tais instrumentos podem ser utilizados segundo formas de criatividade próprias (culturais sem aspas), fossem inexistentes. Um segundo ponto concerne o fato de a autora incentivar 'experiências dialógicas' para a produção de 'auto-etnografias' que, como vimos, pode vir fazer dos 'nativos', através do emprego do 'gênero discursivo do antropólogo', um 'igual' ao antropólogo e, ainda, propor que sejam estas as etnografias do futuro. E, por fim, o fato de autora avançar que justamente a 'autoria indígena', 'tão importante para pesquisadores ocidentais', possa ter um papel um papel menos relevante na escrita indígena.

Pergunto-me, na escrita indígena para quem? Segundo o ponto de vista em que o público-alvo seríamos nós, brancos, ocidentais, excluir-se a autoria indígena não significaria considerar cultura, ou seja, formas dinâmicas e processuais com que indígenas, - individualmente-, produzem e transformam conhecimentos e práticas, informados por modos compartilhados de conhecer, em um suposto 'inventário'

pesquisados, o resultado não pode ser qualificado 'auto-antropologia' (que, ao que me parece, somente caberia à antropólogos 'ocidentais' que realizam etnografias junto a outros antropólogos 'ocidentais', porque as questões da antropologia e sua forma de teorização são, em primeiro lugar, baseadas em noções ocidentais como 'sociedade' e 'cultura' e, segundo lugar, porque os quadros teóricos da antropologia são próprios à antropologia, -não aos ocidentais-, categoria, aliás, tipológica, que não corresponde à variedade que tomam formas 'ocidentais' de teorização e de ação). Também porque, na antropologia, a reflexão 'indígena' é incorporada enquanto parte dos dados a serem explicados, e não pode ser tomada como o seu quadro de referência, de modo que há sempre descontinuidade entre a compreensão indígena e os conceitos analíticos que vêm enquadrar a própria etnografia. Para que sejam etnógrafos, os atores indígenas devem ser educados através dos instrumentos e quadros teóricos próprios à antropologia, de modo que mesmo realizando pesquisas 'em casa', estes 'pesquisadores indígenas', em uma situação ideal, não substituiriam formas de conhecer e explicar da antropologia pelas explicações de seus 'pares' ou de seus 'conterrâneos'. A autora sugere que, para qualificar experiências como aquela explicitada por Alcida Ramos sejam adotados outros termos, o abandono de sua caracterização como o 'tradicional gênero etnográfico' a favor de termos mais 'populares', como story ou report. (1987:16-37).

${ }^{208}$ Essa situação se conjuga àquela identificada junto aos Xavante, quando Arthur Eid afirma que "Ao longo desses anos, em minhas conversas com representantes indígenas, ouvi muitos deles contestarem que muitas das interpretações que foram feitas sobre suas culturas eram construções que não correspondiam à realidade e ao modo com que eles compreendem a si mesmos. Isso incluía as traduções e as interpretações sobre elas construídas" (2003:30, ênfase minha). E foi esse argumento que levou aquele pesquisador a buscar realizar uma pesquisa de campo pautada uma 'relação dialógica', uma joint-venture entre pesquisador e interlocutores, e que veio, em um segundo momento, dar lugar ao livro Wamrêmè Za'ra, apresentado como "a experiência participativa Xavante na publicação de 'mitos' e 'histórias', segundo um ponto de vista 'propriamente Xavante'”. 
acabado, modelo de uma dada 'tradição' imutável, 'igualmente' distribuída entre todos os indivíduos? ${ }^{209}$

Não seria justamente o contrário? Pois se a autoria é tão importante para os pesquisadores ocidentais, a atenção aqui é voltada, antes, ao fato de tais pesquisadores serem 'representantes' de idéias, de modo que o que se valoriza são antes as idéias (o lugar por excelência da nossa cultura), elas 'criativas', não os indivíduos em si (Wagner, 1981, Leach, 2003). Parece-me que, entre os Xavante, valoriza-se os indivíduos, não em função de suas idéias 'originais' e 'criativas', mas de sua experiência, de seu acúmulo de vida e de 'notabilidade', justamente por sua cada vez maior proximidade com os modelos de 'ser', 'fazer' e 'dizer' dos always living creators e dos ancestrais.

Naquele contexto, Alcida Ramos parece inclusive diminuir a importância da produção teórica da disciplina (que qualifica como 'da 'busca do conhecimento pelo conhecimento') em detrimento de sua (possível) funcionalidade indigenista e 'política', de promover a condição dos sujeitos pesquisados e 'representados' por seus antropólogos em efetivos agentes, 'autônomos' no que concerne a defesa de seus direitos e sua auto-representação. Que auto-representação é essa (?), se condizente às expectativas antes de seu 'público-alvo', ou seja, de nossas formas 'políticas', em desacordo com seu original? Seria essa uma valorização efetiva?

Algumas questões começam a se delinear a partir deste ponto em relação ao debate acumulado.

Primeiramente, o fato de tais 'produtos' de 'transformação dirigida da oralidade' concernirem antes, experiências voltadas a (certo) 'empoderamento' político; potencialmente 'culturais', e não necessariamente culturais (caso em que as formas da oralidade estariam em acordo com as formas políticas deles). Retomo aqui a caracterização de Carneiro da Cunha quando explicita as diferenças entre 'cultura' e

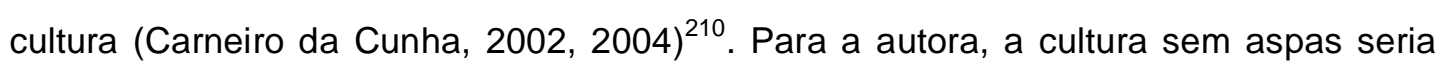

${ }^{209}$ Sally Price (2000), refletindo a respeito do tratamento dado à arte primitiva nos mercados internacionais de arte ocidental nos "centros civilizados", afirma que em geral as obras de arte ditas "primitivas" seriam justamente aquelas cujos artistas são anônimos. Segundo a visão corrente no mercado de arte, tais obras são valorizadas especialmente pelo fato de serem características de uma dada tradição e, portanto, de ordem coletiva e imutável, resultado do trabalho de artistas anônimos e aleatórios, já que todos seriam igualmente capazes de ilustrar a tradição a que pertencem.

210 "Culture has to be understood as operating simultaneously at two levels. For the sake of the argument, let us call them a literal and a meta-level. Although the two are interconnected, it is difficult to ascribe 'literality' to one rather than to the other. Anyway, by 'literal' I mean what anthropologists up to some time ago used to call culture, something that, though dynamic and changeable, would inform values and actions. According to anthropologists, there is an internal organization to culture in that literal sense, an organization that will constrain and inflect changes. At another level, 'culture' as a whole is used diacritically to separate people, to discriminate in both the etymological and the current sense. This is 'culture' as political discourse. (...) I have argued elsewhere that at this meta-level too there is an organization, one that places specific 'cultures' in a mosaic of at once similar and dissimilar units: similar because they are comparable units of the same magnitude (other 'cultures') and dissimilar since it differences alone that allow for organization. Culture and 'culture' both are constrained by their respective organizations, and yet the two levels are not totally 
aquela para a qual sempre estiveram voltados os antropólogos, e cujos aspectos analíticos seriam inconscientes para seus praticantes. Já "cultura" (com aspas) remeteria aos modos deliberados através dos quais grupos 'enunciam' suas culturas e, portanto, as oficializam, a partir de um fundamento em 'identidades culturais' enquanto 'discurso político'.

Daí o fato de que, para serem efetivamente culturais, no que concerne tais propostas de 'valorização cultural' pautadas em registros de 'tradições orais' com vistas à sua viabilidade e ao incremento de sua transmissão, tais registros, me parece, deveriam atentar para as formas locais de interação e de alocação de valores, modos políticos (ou culturais) de gestão daquilo que se constitui importante para os atores indígenas.

De que modos 'enunciados da tradição' poderiam produzir um efetivo empoderamento (ou seja, serem produzidos para o 'outro' tendo em vista parâmetros discursivos próprios, e ainda, a partir do enunciado de tais parâmetros, de modo a que outras formas culturais (e políticas) distintas da nossa, ocidental, possam ser reconhecidas como existentes e, portanto, valorizadas ${ }^{211}$ ?

Assim, a problemática aqui não é a do livro em si, mas a de quem é seu público-alvo. A natureza 'dialógica' do discurso (Bakhtin:2006) deve também ser considerada neste caso. Fala-se para quem? Escreve-se para quem?

Se o livro não foi elaborado para um público-alvo infantil, então a característica 'infantilizada' tende a ser identificada como própria aos Xavante. O que esvazia sua proposta de servir à 'valorização cultural'. Ou seja, ao invés de promover a agência Xavante e seus (múltiplos) pontos de vista em relação à sua ${ }^{212}$ história, termina por produzir um livro para crianças, com 'histórias de ninar'. Ou um livro 'infantilizado' voltado a um público adulto.

Nesse sentido, considero até produtivo o fato de os Xavante não se interessarem pelo livro Wamrêmé Za'ra. Pois a idéia de valor disseminada por quem até hoje deteve e conduziu o que se entende por 'patrimônio' poderia correr o risco de contagiar juízos e formas de ação, vindo a ser perfomada para outros e esvaziada de sentido 'para si'. Isso porque a identificação de seus referenciais míticos e ancestrais com conteúdos, com uma 'história', escrita, e uma só, poderia produzir um esvaziamento de seu sentido em relação à manutenção de formas expressivas identificadas aos ancestrais (e às versões relacionadas aos 'ancestrais' de cada um) e criadores nos âmbitos da 'história

independent from each other". (Carneiro da cunha, 2002:8) No entanto, ambas acepções fundamentam-se em uma noção de cultura que têm nós, antropólogos, como sujeitos da enunciação. Seja quando estudamos outras 'culturas', seja quando distinguimos 'culturas' falando de 'cultura' para nós, ocidentais.

211 E quem sabe nos inspirar, tendo em vista o 'fim do túnel' de formas do político em que o Ocidente atualmente se encontra?

${ }^{212} \mathrm{E}$ ainda, tais propostas tendem a enfocar enunciados indígenas 'sobre si', como se os sujeitos fossem incapazes de discorrer sobre algo além de si mesmos, de 'sua' 'cultura' ou de sua 'história'. Como se ao falar de outros não expressassem formas culturais próprias. 
viva', de sua efetiva participação em eventos de sua vida cotidiana como através de sonhos, festas e interpretações de situações ou eventos 'da natureza'.

Joel Candau (2005), discutindo a noção de Halbwachs (1925) a respeito dos "quadros sociais da memória" atenta para o fato de que "la reconstruction d'un souvenir passe par celle des circonstances de l'événement passé, donc des cadres sociaux ou collectifs dont le plus contraingnant est certainement la langage" (2005:73).

Segundo Candau, quando tais quadros sociais da memória são modificados, os modos de memorização de uma dada sociedade e de seus membros se transformam, para se adaptar aos novos quadros sociais que se substituem aos antigos. Cabem aqui duas considerações. Primeiramente, considerando a noção dos quadros sociais da memória, poderíamos inferir que estes vêm efetivamente sofrendo transformações, em especial no que diz respeito às formas de emprego do 'tempo', com o advento de novas atividades (como a formação de professores, as aulas de que participam as crianças e jovens, a dedicação à organização indígena, a formação de agentes indígenas de saúde, etc) vindo restringir ocasiões para o estabelecimento de relações, assim como os espaços ou contextos de transmissão de conhecimentos e práticas entre e intra gerações. Neste sentido, concordo que ações de salvaguarda possam ser relevantes. Mas ao atentar para o fato ressaltado por Candau acerca da relação entre 'quadros sociais da memória' e 'linguagem', me parece que, justamente, o fato de a 'patrimonialização' ser voltada a um público mais amplo, que não compartilha as formas próprias de emprego da linguagem, acarreta que, se a 'valorização' para fora é bem vinda no sentido do empoderamento de agentes e 'comunidades' indígenas, a salvaguarda, me parece, não deverá repousar sobre os mesmos aspectos, nem segundo a mesma linguagem que o registro, que concerne 'cultura' e 'política' enquanto 'empoderamento', não cultura.

Mas arrisco formas através das quais o empoderamento poderia ser 'cultural' e cultural. Isso porque pode haver parecido, a partir desta exposição, que os Xavante seriam incapazes de discutir sua cultura (suas formas políticas), pois isso acarretaria necessariamente a produção de querelas internas às facções, indesejáveis pelos sujeitos. Considerando a natureza dialógica do discurso segundo Bakhtin, em que as palavras e idéias do outro participam fundamentalmente de interações discursivas mediadas pela linguagem, pergunto-me de que maneira atores indígenas poderiam enunciar o que é mais importante para si de maneira adequada à compreensão 'do outro', mas sem que as idéias e palavras do outro sejam substituídas pelas deles, de forma a que a tradução esteja mais em acordo com seu 'original'. Considerando que os efeitos da ihi mrèmè não são ocultos para seus atores, não poderíamos inferir que estes poderiam efetivamente produzir enunciados acerca dos modos de interação considerados por eles corretos, mas sem que suas interpretações sejam substituídas pelas nossas? 
Nesse sentido, gostaria pensar a noção de 'patrimonialização' enquanto forma de tradução cultural. Essa proposição deverá ser debatida a partir do debate acumulado. Voltemos nossa atenção, agora, para outro local e novos atores: a Nova Caledônia, na Melanésia, e os Kanak. 


\section{Capítulo 4:}

\section{ENTRE TRADIÇÕES ORAIS \\ E REGISTROS DA ORALIDADE KANAK}

\subsection{Apresentação}

As reflexões deste capítulo referem-se aos Kanak, população autóctone habitando a Nova Caledônia, na Melanésia. Adotei aqui o mesmo procedimento do capitulo anterior, estabelecendo um diálogo entre materiais acadêmicos e documentais, visando articular características próprias à tradição oral Kanak e modos diferenciais como se delineiam 'coletivos' Kanak em contextos específicos.

Especificamente, meu intuito foi o de esboçar eventos e contextos que vêm fazer e desfazer noções como de 'identidade' e 'patrimônio' Kanak. Contudo, não foi meu objetivo aqui a realização de um estudo exaustivo a respeito do histórico de deflagração e então consolidação de uma 'identidade política' e de um 'patrimônio (oral)' Kanak, mas sim uma avaliação de instâncias deste processo sob a ótica específica de características de sua tradição oral.

As discussões se pautaram pelas formas próprias à tradição oral Kanak tal como foram caracterizadas pelos estudiosos, assim como por descrições a respeito dos principais eventos e situações que tanto marcaram a história da constituição de uma identidade e patrimônio Kanak comuns na Nova Caledônia, quanto momentos que vêm tornar visíveis a 'instabilidade' daquelas instâncias.

Busquei trazer também a este debate descrições acerca das experiências de registro a que enunciados, narrativas, peças da tradição oral e 'enunciados acerca da tradição' Kanak estiveram submetidos, tanto em âmbitos de pesquisa quanto de projeto de 'transformação dirigida da oralidade'. Desse modo, busquei ponderar a respeito de procedimentos e produtos de registro de atos de fala e de 'tradições orais', assim como de seus efeitos ${ }^{213}$, ou seja, das formas como tais registros são ou foram avaliados pelos seus sujeitos, vindo a ser recuperados ${ }^{214}$ e 'postos a funcionar', - quando 'proliferaram' , ou tendo sofrido 'interrupções', quando rechaçados por seus atores.

\footnotetext{
${ }^{213}$ Como em relação aos Xavante, todos estes efeitos são da ordem de 'eventos'. Nesse sentido, o que proponho aqui são relações possíveis de serem estabelecidas na forma de rizomas, ou seja, enquanto modo não hierárquico, múltiplo, não binário e nem dicotômico de abordagem de fenômenos em relação, ao substituir conexões de causa-consequência por nexos "planos" e semióticos de toda natureza, em que sujeitos e objetos de ordens e escalas diversas, heterogêneos, 'fazem rizoma', ou seja, ligam-se entre si por algum ponto qualquer não pré-estabelecido (Deleuze e Guattari, 2006).

${ }^{214} \mathrm{~A}$ questão relativa à reapropriação de registros aqui é complexa, pois se de um lado narradores podem fazer uso de conhecimentos e recursos expressivos apreendidos diretamente de outros narradores, eles podem também fazer recurso a estes registros, de modos imbricados, como veremos.
} 
Em relação aos registros da 'tradição oral' e de enunciados orais realizados em âmbito de pesquisa acadêmica, as perspectivas teórico-metodológicas dos autores ${ }^{215}$ foram também elas foco de reflexão. No caso de registros realizados em situação de projeto de 'transformação dirigida da oralidade', busquei avaliar as opções e metodologias que fundamentam aquela proposta ${ }^{216}$

Em um segundo momento, na conclusão desta pesquisa, debato questões relevantes que se tornam visíveis quando os 'casos' Kanak e Xavante são visualizados lado a lado, em conjunto, de modo a estabelecer relações e articular aquelas reflexões com as atuais propostas de valorização e salvaguarda de patrimônios imateriais pautadas em ações de registro de 'conhecimentos' e 'tradições orais'.

Ressalto a (já) evidente diferença entre os eventos sobre os quais se pauta este capítulo e aqueles apresentados em relação aos Xavante. Minha metodologia de pesquisa implicou, contudo, que tendo ambos casos sido elaborados em torno das mesmas questões, estes pudessem se tornar comparáveis, ao serem aproximados através dos objetivos e das conexões estabelecidas segundo o ponto de vista do analista.

As principais distinções entre os 'casos' Xavante e Kanak remetem, em primeiro lugar, à escala dos fenômenos considerados. Pois se para o 'caso' Xavante minha análise pautou-se em materiais relativos a uma só aldeia, de Pimentel Barbosa, os materiais para o 'caso' Kanak abrangem tanto toda a população autóctone da Nova Caledônia, como alguns dentre os 28 grupos lingüísticos que compõem aquela população. E ainda, ao contrário do caso Xavante, diversas ações levadas a cabo desde a década de 1970 já vieram esboçar instâncias de 'estabilização' de um coletivo político Kanak, assim como oficializar um 'patrimônio Kanak' comum a toda população autóctone do Território ${ }^{217}$. Ressalto ainda que a constituição deste patrimônio e desta identidade comuns 'Kanak' foram fundamentais à derrocada da demanda pela independência do Estado-nação Kanaky ${ }^{218}$. Deverei fazer referência aqui a eventos da história da Nova Caledônia, assim como à luta independentista, quando tal contextualização se fizer necessária às questões aqui colocadas.

\footnotetext{
${ }^{215}$ Bensa e Rivierre, 1982; Naepels, 1998; Monnerie, 2005; Guiart, 1963; Leenhardt, 1931, 1947.

${ }^{216}$ Em especial o projeto 'Cahiers de littérature orale' levados a cabo no âmbito do Centro Cultural Tjibaou através da revista Mwà Véé, a serem apresentados adiante.

217 Deverei discutir também as instâncias que fazem e desfazem a percepção dos atores quanto a este patrimônio.

${ }^{218}$ Nome atribuído pelos independentistas ao seu futuro país independente.
} 
Segundo Alban Bensa, a população autóctone da Nova Caledônia ${ }^{219}$, composta por 28

grupos lingüísticos, compartilha modalidades de práticas e sistemas de interpretação

${ }^{219}$ Resumo aqui, sinteticamente, caracterizações e eventos relativos à história recente da população Kanak da Nova Caledônia, desde a chegada dos colonizadores europeus. Em 1774, James Cook e a equipe do navio Resolution foram os primeiros europeus a realizarem um reconhecimento das ilhas que formam o arquipélago. Em 1840 temos a chegada da primeira leva de missionários evangélicos, e depois católicos, que irão disputar entre si a cristianização dos 'pagãos indígenas'. Foram os missionários os responsáveis pelas primeiras iniciativas de alfabetização e escolarização da população Kanak, investindo também na supressão de práticas como a guerra, a poligamia, a antropofagia, as festas do Pilou, etc. Em 1853, o almirante Auguste Febvrier-Despointes toma possessão da Nova-Caledônia (Grand Terre) e de suas dependências (ilhas Loyalty, formada pelas ilhas de Ouvéa, Lifou e Maré, e a ilha de Pins), em nome da França. Anteriormente à colonização, a população autóctone habitava aldeias (na forma de alamedas) de tamanho variável ocupando toda a extensão da grande Terra e das ilhas, principalmente os vales e a região costeira. A vinda progressiva de europeus a essa ilha, originalmente concebida enquanto colônia penitenciária, seguida da chegada de levas de colonos imigrantes, dá lugar à espoliação territorial dos grupos autóctones, seu contínuo deslocamento geográfico e, a partir de 1880, seu acantonamento em reservas indígenas sob a tutela da autoridade colonial. $\mathrm{O}$ acantonamento dos Kanak em reservas vem acompanhado da instituição do 'Código do Indigenato' no início dos anos 1880, tendo sido prorrogado até 1946. Aquele código interditava aos autóctones a saída das 'tribos' (como ficaram sendo chamadas as reservas), exceto para o pagamento de impostos através de trabalho obrigatório aos colonos. Face ao acantonamento, populações habitando reservas distintas eram interditas de se reunirem sem autorização de guardas da República (gendarmes), introduzindo dificuldades significativas na manutenção de antigas relações entre linhagens e clãs. Também foram instituídos 'chefes administrativos' Kanak em cada reserva, ofuscando e produzindo uma confusão recorrente entre este e a de 'chefes' (daame) tradicionais. O acantonamento instaurou um cômodo distanciamento físico e social entre Kanak e população colonizadora, que tinha pouco ou nenhum contato com a população autóctone. A população de origem européia da Nova Caledônia teve por certo, durante muito tempo, que os 'primitivos' e sua 'cultura' estavam fadados à morte ou à aculturação. $O$ fim do século XIX e início do século XX foram marcados por duas insurreições contra a dominação colonial: em 1878 e em 1917, ambas violentamente sufocadas, contando centenas de mortos. Em 1931 uma dezena de autóctones é enviada à Metrópole para a "Exposição Colonial", expostos como 'animais selvagens comedores de carne humana', e em seguida 'exibidos' pela companhia de circo 'Hagenbeck' em Frankfurt. Durante a Segunda Guerra, indivíduos de origem autóctone são enviados à Metrópole para participarem no exército francês. Ao retornarem, dão-se conta do contraste entre os valores de 'liberdade, fraternidade e igualdade' exaltados pela República, e as formas como eram considerados pelos colonizadores em seu próprio Território. Em 1946 temos a revogação do Código do Indigenato, o reconhecimento aos Kanak de direitos civis (o direito ao sufrágio viria em 1957) e o início da escolarização laica e obrigatória nas reservas, vindo contribuir à entrada progressiva dos melanésios na vida social e política da Nova-Caledônia 'branca'. Essa abertura promove uma transformação da sociedade colonial acompanhada de um novo processo mudança, ou de degradação da sociedade Kanak, que de algum modo havia conseguido se reorganizar durante o período em que ficou confinada às reservas. As mudanças durante este período foram muito variáveis segundo as regiões e sua história. Mas de maneira geral os efeitos da entrada da população Kanak na sociedade do colonizador foram altamente desestabilizadores, incentivando uma corrente migratória em direção à capital para a ocupação de postos de baixo escalão e mendicância, um crescimento extremo do alcoolismo tanto nas cidades quanto nas tribos, e um sentimento de 'demissão cultural' face à desqualificação da população Kanak pela população européia e/ou 'branca' do Território. A partir do final dos anos 60 , o chamado 'boom do níquel' convida ao aumento gradual da população imigrante (importação de mão de obra incentivada também pelo Estado francês para contrabalançar as diferenças demográficas entre população colonizadora e população autóctone). $\mathrm{O}$ desenvolvimento da exploração do níquel no Território traz benefícios econômicos e sociais às populações de origem não autóctone, aumentando ainda mais a distância social e econômica entre estas e a população Kanak. Tais movimentos sucessivos, assim como a relação de dominação colonial no qual estes se inscrevem, pouco a pouco compuseram uma sociedade marcada por fortes clivagens entre etnias autóctones a alóctones, de modo a manter problemas sociais e políticos duráveis, fundados sobre as dificuldades nas relações entre colonizadores e colonizados. Desde o início dos anos 70 indivíduos de origem melanésia da Nova Caledônia passaram a se organizar em torno da luta por um reconhecimento de sua identidade cultural, pela restituição de suas terras e, finalmente, pela independência do Território. É nesse contexto que surge a proposta do evento 'Melanésia 2000' (Bensa, Alban. "Nouvelle-Calédonie, un paradis dans La tourmente”. Gallimard. Paris. 1990). Em relação à luta política pela independência, podemos distinguir três períodos. O primeiro, politizado e militante, entre 1970 a 1988, que se finaliza com os chamados "Événements" (1984-1988), enfrentamentos entre oponentes e partidários da independência, e que vêm se degenerar em conflitos violentos culminando na tomada de gendarmes da 
que constituem um fundo comum, permitindo considerá-las como relativamente homogêneas do ponto de vista cultural (Bensa, 1982: 21) 220 .

Emprego aqui o termo 'Kanak' em referência aos descendentes dos habitantes de origem melanésia e polinésia que povoavam a Nova Caledônia quando da chegada dos colonizadores europeus. Considera-se que 'Kanak' deriva do termo polinésio 'kanaka', significando 'homem', tendo sido durante muito tempo empregado pelos colonizadores segundo conotações pejorativas ${ }^{221}$, e de acordo com a grafia francesa Canaque. $\mathrm{O}$ substantivo e o adjetivo 'Kanak' passaram a ser adotados a partir do final dos anos 70 e início dos anos 80 pelos próprios autóctones, de acordo com uma grafia própria, visando constituir uma identificação unitária da população face aos colonizadores e às outras etnias minoritárias do Território.

Atualmente, os Kanak se identificam como aqueles que "font la coutume", ou seja, que participam de discursos e trocas cerimoniais (Monnerie, 2005:17) ${ }^{222}$. O uso generalizado do termo coutume, assim como kastom ou custom em outras regiões da Oceania, não significa ser ele aqui pertinente à análise, dado que engloba práticas muito diversas, assim como as concepções que as sustentam ${ }^{223}$. Dentre tais práticas,

República como reféns e na tortura e assassinato de 19 independentistas de origem Kanak (durante a operação 'Victor' que permaneceu 'secreta' até pouco e cujos responsáveis foram anistiados pelo acordo de paz subseqüente). O segundo período, iniciado com a assinatura dos 'Acordos de Matignon' em 1988, marca o fim dos 'Événements', e prevê um estatuto transitório de 10 anos que deveria se concluir em um referendum concernindo a independência, em 1998. Com a aproximação daquela data e o aumento do clima de tensão entre independentistas e "loyalistas", lideranças decidem pela negociação de um novo acordo com o Estado. Assim, o 'Acordo de Nouméa', em maio de 1998, que previu a instituição de uma forte autonomia à Nova Caledônia, sua condição de Coletividade D'Outre Mer (e não mais um TOM, Territoire Outre-Mer) com progressivas transferências de competência da Metrópole ao Território e a construção de um 'destino comum' caledoniano. Os poderes que permaneceram junto ao Estado foram: a segurança, a justiça, o direito geral, a moeda e a política estrangeira. $O$ referendum final sobre o futuro institucional (independência ou continuidade no seio da república Francesa) foi postergado para entre os anos de 2014 e 2018. Em tal contexto, a adesão ao 'sistema costumeiro' e a detenção do saber que ele implica podem se diferenciar consideravelmente de um indivíduo Kanak a outro, sem que as ancoragens relativas à organização social tradicional cessem de exercer um papel relevante para a maior parte das pessoas (Bensa, 1995: 239). Nas 'tribos', e no vai e vem de indivíduos e famílias entre aglomerações urbanas e as 'tribos' em área rural, a prática das línguas vernaculares, a manutenção (relativa segundo as regiões) de uma economia de subsistência e o compartilhamento de valores, conhecimentos e princípios que vêm estruturar as relações entre indivíduos e entre grupos sugerem que fundamentos da 'sociedade' Kanak permanecem operatórios, também em espaço urbano (Bensa, 1995:168). A afirmação da especificidade identitária dos melanésios privilegiou, desde 1988, a criação de novas instituições culturais e artísticas, em particular a ADCK, Agência de desenvolvimento Cultural Kanak e o Centro Cultural Tjibaou, concebido pelo renomado arquiteto Renzo Piano, do qual a concepção e a inauguração em Nouméa, em maio de 1998, receberam um eco midiático internacional.

${ }^{220}$ A comunicação atual entre indivíduos de grupos lingüísticos distintos se dá principalmente através do recurso ao francês; muitos adultos e idosos, contudo, são bilíngües ou multilíngües.

${ }^{221}$ Também em outras partes da Oceania, como em referência aos aborígenes australianos.

${ }^{222}$ No contexto Melanésio, em que prevalecem formas de troca e de relações que vieram caracterizar sistemas como de 'great men' e 'big men', o modelo Kanak é aproximado ao que foi caracterizado como de 'chefferie' (Strathern, M. \& Godelier, M. 1991).

${ }^{223}$...."et 'fair la coutume'c'est cela; c'est un terme générique que les européens donnent à un ensemble de choses qu'ils ne comprennent pas et qui sont les manières d'être Kanak. Pour nous, chaque coutume a un nom précis. On fait telle chose à telle occasion pour dire tel message. Je ne sais pas ce que c'est, la coutume. Je connais des rites précis, qui ont des noms précis. La coutume, je l'ai dit, c'est le nom quelquefois méprisant que les non-Kanak donnent à ce qui font les Kanak. C'est pour eux une manière de 
Monnerie refere-se à centralidade de cerimônias para a vida social Kanak: cerimônias de chegada e de separação (accueil), cerimônias do ciclo de vida das pessoas (casamentos e decessos), cerimônias internas às Maisons (como o ciclo do inhame), cerimônias de encontros regionais, etc. (Monnerie, 2005: 37). Tendo em vista a centralidade destas cerimônias na vida Kanak contemporânea, em especial a cerimônia de accueil de chegada e de separação ${ }^{224}$ e sua relação a aspectos fundamentais de sua tradição oral, deverei abordá-la na análise que se segue. Contudo, ao fazer referência aos enunciados tais como realizados pelos atores Kanak, deverei manter o termo coutume quando por eles empregado, visando situar seus usos.

Este capítulo se organiza em três eixos principais.

Primeiramente, deverei apresentar e caracterizar os principais gêneros da tradição oral Kanak e sua implicação no que diz respeito a contextos e modalidades de interação. Deverei me pautar aqui nos trabalhos de Bensa e Rivierre (1982), e Monnerie (2003), que se dedicaram, respectivamente, a uma 'antropologia do discurso' alinhada a uma análise da organização social Kanak, e a uma antropologia de 'atos de fala e de gestos', segundo um enfoque em 'cerimônias'. Aqui, deverei recorrer ainda à obra de Michel Naepels (1998) ${ }^{225}$ que, ao confrontar uma situação atual, a restituição da posse de terra aos Kanak espoliados de seus territórios desde o final do século XIX, irá consagrar sua análise aos aspectos que vêm imbricar formas e conteúdos da tradição oral Kanak à configurações diversificadas de relação entre sujeitos e coletivos pertencentes simultaneamente à 'maisons' (espaços de co-residência), e à linhagens e clãs. Aquele autor buscou relacionar o período anterior à colonização a uma condição presente, com vistas a descrever uma paisagem complexa de deslocamento e intersecção de valores entre um sistema de relações e outro.

Em minha análise, essa última obra deverá ser abordada segundo dois pontos de vista distintos. De um lado enquanto bibliografia para as caracterizações concernindo formas de reeelaboração identitária através da dimensão histórica da prática do accueil ('acolhida') e sua intersecção com o gênero de discursivo cerimonial vivaa e, de outro lado, segundo um enfoque em sua metodologia de campo, nas formas como enunciados de seus interlocutores foram registrados e trazidos ao corpo do texto de sua obra, assim como as avaliações de seus interlocutores quanto a tais registros, concernindo seus potenciais 'efeitos'.

dire qu'ils ne comprennent rien à cet ensemble des choses" (Tjibaou, Jean-Marie, em entrevista à Alain Plagne, 6 de maio de 1985 em Paris. In: Bensa, A. e Wittersheim, E. La Présence Kanak.1996, Odile Jacob, Paris, p. 202)

${ }^{224}$ Que engloba outras práticas cerimoniais, ao marcar seu inicio e seu fim.

225 "Histoires de Terres Kanak" (1998). 
No que diz respeito a sua metodologia de registro de enunciados orais Kanak, a obra de Naepels é resultado de uma pesquisa de campo que consistiu em diálogos entre o pesquisador e seus interlocutores da região de Hoiaïlou acerca das relações entre aspectos de sua tradição oral e modalidades privilegiadas de interação envolvendo indivíduos e 'coletivos' em contextos específicos ${ }^{226}$. O autor pauta sua metodologia em uma antropologia de inspiração 'dialógica', de modo a trazer para o corpo do texto enunciados de seus informantes, que deverão assim, em um segundo momento, se constituírem contrapontos para as perspectivas aqui sugeridas no segundo eixo deste capítulo, quando de minha análise do 'mito' de Téa Kanaké.

O segundo eixo deste capítulo consiste na descrição e reflexão em torno de uma 'criação' narrativa elaborada por Jean-Marie Tjibaou, porta-voz cultural que irá se tornar uma liderança política representativa dos Kanak e dos independentistas da Nova Caledônia. Esta 'criação', cuja análise deverá sintetizar algumas das proposições aqui avançadas, corresponde ao 'mito' de Tèa Kanaké, encenado durante o evento 'Melanésia 2000', e registrado em sua única obra 'Kanaké, Mélanésien de Nouvelle Calédonie' (Tjibaou e Missotte: 1976). Para a apresentação e análise deste 'mito', e sua participação na constituição de uma 'identidade' e 'patrimônio' comuns 'Kanak', deverei operar uma descrição sintética de seu contexto de ocorrência, o evento 'Melanésia 2000 que teve lugar em 1975, e de aspectos deste evento que ganham contornos relevantes na reflexão a ser aqui realizada. Aquela 'criação mítica' foi interpretada por alguns autores como uma 'invenção patrimonializadora' voltada à construção de uma 'comunidade cultural Kanak' para fins de ordem política ${ }^{227}$. Ao elaborar minha análise a partir deste evento e desta criação do 'mito' de Tèa Kanaké, irei debater também interpretações que foram feitas a seu respeito.

As palavras de Jean-Marie Tjibaou ${ }^{228}$ 'proliferam' hoje, tendo se tornado uma referência para reflexões e iniciativas de ordem cultural e política levadas a cabo pela população Kanak da Nova-Caledônia. Buscarei sustentar a afirmação a respeito do que caracterizo como uma 'proliferação', através de exemplos baseados em Monnerie (2005), e nas propostas atuais do Centro Cultural Tjibaou, divulgadas na revista Mwà Vèè, sob responsabilidade daquele Centro.

Um de meus interesses nesta narrativa de 'Téa Kanaké' concerne o fato de Jean-Marie Tjibaou haver tanto se apropriado quanto se inspirado, para sua 'criação', de narrativas 'coletadas' e compiladas por Jean Guiart ${ }^{229}$ e Maurice Leenhardt ${ }^{230}$ durante os anos em que realizaram pesquisas junto a esta população autóctone. Se narrativas 'coletadas'

\footnotetext{
${ }^{226}$ Dentre tais contextos, a de disputa pela posse da terra.

227 Alban Bensa (1995: 290-307), Caroline Graille (2001).

${ }^{228}$ Assassinado em 1989 por um radical independentista após a assinatura dos Acordos de Matignon, em 1988.

${ }^{229}$ Guiart, Jean Structure de La chefferie em Mélanésie Du Sud », Paris, Institut d'Ethnologie, 1963.

${ }^{230}$ Leenhardt, Maurice. « Documents neo-calédoniens ». Paris, Institut d'Ethnologie, 1932.
} 
por Maurice Leenhardt e por Jean Guiart serão apropriadas e reelaboradas por este líder político, gostaria de propor aqui, à contracorrente, que certos aspectos do desenvolvimento mesmo das reflexões e das ações postas em prática durante o evento Melanésia 2000 por aquele líder cultural podem ser apreciadas como inspiradas, antes, nos modos 'valorizados' de relação entre 'coletivos' diferenciais Kanak. Tais formas diferenciais e, sobretudo, contextuais, se tornam visíveis através do enfoque nos gêneros e respectivas formas, conteúdos e modalidades de interações segundo informadas por sua tradição oral.

O último eixo a ser apresentado e discutido aqui consiste nas atuais propostas operadas no âmbito do Centro Cultural Tjibaou, em especial os Cahiers de littérature orale, estruturados em torno do projeto de 'coleta e salvaguarda do patrimônio oral e imaterial Kanak'. Uma das ações deste projeto consiste na publicação, a cada nova edição, de narrativas de sua 'literatura oral' registradas tanto recentemente quanto outrora. Estas consistem em narrativas registradas por agentes-coletores Kanak e por pesquisadores, em especial Maurice Leenhardt. Essa revista também realizou entrevistas junto aos sujeitos Kanak a propósito das medidas atuais de valorização cultural pautadas na coleta e salvaguarda da tradição oral Kanak. Algumas dessas proposições também deverão ser aqui consideradas, no sentido de levantar, juntamente com o restante dos materiais, questões pertinentes acerca de projetos de valorização e salvaguarda de 'patrimônios imateriais' pautados no registro de 'tradições orais' e 'conhecimentos'.

Sublinho serem tais eixos os principais pontos de reflexão desta análise. Contudo, estes não deverão ser abordados de maneira linear, mas discutidos ao longo do capítulo conforme relações ou rizomas tornarem-se visíveis, aqui e ali.

\subsection{Gêneros da Tradição Oral Kanak}

Grande parte das pesquisas desenvolvidas junto aos Kanak da Nova Caledônia se desenvolveu em torno dos 'fatos da parole'. Isso porque, segundo Alban Bensa, "les traces les plus visibles de la vie des Canaques d'autrefois (cases ${ }^{231}$, allés immenses, sculptures, etc) ayant été eradiqués par la colonisation, une ethnologie moins visuelle qu'auditive s'impose... une ethnologie du discours"(1995:262). Michel Naepels, em uma via comparável, refere-se assim à sua abordagem: "...autant dire que dans la pratique ethnographique l'observation n'est pas toujours le mode dominant de recueil des données" (1998:15). Atos e cerimônias, em especial segundo sua forma 'tradicional',

${ }^{231}$ O termo 'case', casa, é em geral empregado para designar as casas redondas, também chamadas 'maisons'. O termo maison, como veremos, é empregado para designar o espaço da co-residência e o conjunto de grupos (linhagens e clãs) que ali habitam. 
quando descritos na literatura etnográfica, o foram na sua maior parte através de descrições realizadas por informantes e não pela observação do etnógrafo.

Bensa e Rivierre (1982) privilegiaram a coleta e a análise de narrativas 'míticohistóricas' de um só narrador, produzidas para os pesquisadores, em detrimento de gêneros dialógicos que colocam em interlocução indivíduos e grupos pertencendo a coletivos diversos. Leenhardt $(1930,1932)$ trabalhou a partir de descrições e narrativas escritas pelos próprios informantes, assim como a partir de suas próprias observações $(1947)^{232}$. Naepels (1998), ao contrário, apoiou sua análise em enunciados concernindo reflexões e interpretações de seus informantes produzidos para o pesquisador, e em francês, acerca das relações que vêm imbricar gêneros da tradição oral Kanak a modalidades de conformação identitária de grupos, visando relacionar uma situação anterior à colonização a um contexto atual, marcado por conflitos e disputas ${ }^{233}$. Já Dennis Monnerie, em La Parole de Notre Maison (2005) vai realizar uma análise de atos e discursos segundo sua forma atual, através de uma metodologia de 'observaçãoparticipante' e um enfoque em 'cerimônias'. Segundo este autor, "les actes cerimoniels de la vie Kanak, qu'eux même considèrent comme étant au coeur de leur vie sociale d'aujourd'hui, de leur définition en tant que Kanak, sont bien vivants et fort vivaces" (2005: 28).

Uma questão importante se impôs para fins desta análise: o fato de os estudiosos haverem realizado pesquisas em regiões distintas da Nova Caledônia. Enquanto Bensa e Rivierre trabalharam na região centro-norte da Grande Terra, junto a interlocutores de língua cèmuhî e paîci, Monnerie realizou sua pesquisa na região de Hoot ma Whaap, de língua nyelâyu, no extremo-norte dessa ilha e Naepels realizou sua pesquisa na região de Houaïlou, na costa leste da Grande Terra, de língua ajië.

A partir desta revisão bibliográfica pareceu-me que há, via de regra, um fundo comum no que diz respeito às práticas cerimoniais e às modalidades que informam gêneros da tradição oral, compartilhados por todos os grupos Kanak da Nova Caledônia. O que dificultou minha pesquisa, por outro lado, foi o fato de os autores realizarem suas análises a partir do emprego de categorias lingüísticas locais, de modo que os termos utilizados diferem entre si.

\footnotetext{
${ }^{232}$ As contribuições de Maurice Leenhardt não serão consideradas aqui, mas sim na segunda parte deste capítulo.

${ }_{233}$ À época de sua pesquisa na região de Houïalou (1993-1994), conflitos em torno do sujeito da terra opunham seus diferentes habitantes, envolvendo uma multiplicidade de atos de enunciação contraditórios. Tais debates e contestações situam-se no seguinte contexto: os 'événements' dos anos 1984-1988, ligados à reivindicação independentista, suscitaram a partida da grande maioria de colonos rurais europeus dessa região da costa Leste da Grande Terra. As terras abandonadas por aqueles que partiram foram readquiridas pelo Estado, e um organismo público, a ADRAF (Agence pour Le Développement Rural et l'Aménagement Foncier), ficou responsável de sua redistribuição gratuita aos seus ocupantes originais, mas sob a condição de consensos locais a respeito do reclamante (de modo que toda contestação do proprietário 'em vista' provocava a paralisação do procedimento de atribuição).
} 


\subsubsection{Gêneros narrativos}

Bensa e Rivierre ${ }^{234}$ (1982) irão apresentar as principais características de dois gêneros da tradição oral Kanak que se elaboram na forma de narrativas histórico-míticas ${ }^{235}$, os cíhêdéé e os jèmà. ${ }^{236}$ Segundo esses pesquisadores, 'a significação destas histórias aparece estreitamente ligada a seus contextos de enunciação, ou seja, à realidade social e histórica dos quais são, ao mesmo tempo, produto e expressão'(1982:8). Deriva daí que os autores optaram naquela obra por uma exposição prévia dos princípios da organização social Kanak para dar conta da análise dos textos recolhidos junto a seus informantes.

Segundo o termo vernáculo da língua cèmuhî, os jèmà correspondem a uma parole histórico-mítica centrada sobre um grupo, que busca dar conta dos estatutos e dos papéis que os coletivos de um mesmo conjunto político aceitaram distribuir e compartilhar ${ }^{237}$. Já os cíhêdéé consistem em 'histórias ou contos de aparência

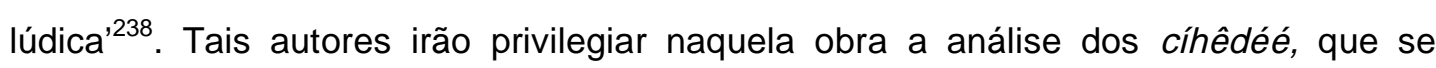
constituem, fundamentalmente, em narrativas ou ditos de um só narrador, não supondo

\footnotetext{
${ }^{234}$ Bensa, A \& Rivierre, J. C. Les Chemins de L'Alliance. 1982, Paris, SELAF, Pacifique 1.

${ }^{235}$ Cito aqui um extrato de Bensa relevante no que diz respeito às relações entre narrativas 'míticas' e 'históricas' Kanak: "Envoyé em Nouvelle Calédonie pour collecter em langue Kanak des énonces formalisés (contes, poésies, récits, etc), je ne pouvais qu'imaginer y reccueillir des echantillons de cette 'pensée mythique' dont Il était convenu de considérer qu'elle était l'apanage des sociétés 'sans écriture' et 'sans histoire'. Tel ne fut pas ma surprise d'enregistrer (ou de noter sous dicté) des histoires, appellé en paici jèmà, qui ne ressemblait guère aux mythes amérindiens sur l'origine du feu ou de la cuisine. Mes interlocuteurs Kanak racontaient comment leurs ancêtres, à partir d'un site fondateur, avaient migré sous l'effet des guerres, des alliances, puis de la colonisation européenne et du cantonnement dans les réserves. Certes, le toutes premières phrases de quelques récits mettaient en scène des événements extraordinaires (lézard nageant dans la mer et s'accrochant à un rocher, transformation d'animaux en humains, lune déposant sa dent sur un rocher, etc.) mais cette forme legendaire cédait vite place à des noms d'ancêtres et d'habitats, jalons bien visibles d'itineraires qu'il était donc possible de parcourir et cartographier. Parfois même, certains historiens Kanak, comme Emmanuel Naouna, s'efforçaient de dater les déplacements, en comptant les générations reliant les gens d'aujourd'hui aux derniers ancêtres dont le souvenir était conservé. Ainsi lune, soleil, anguille, rocher, etc., apparaissaient ou non au début d'une narration prenant très vite un tour historique et mettant en avant une conception lineaire du temps. Le narrateur se rattachait ainsi aux fondateurs de son clan, voire de l'humanité Kanak tout entière par un récit d'allure parfaitement historique qui non seulement le situait en regard des autres clans, mais allais-je vite comprendre, évoquait directement ses intérets sociaux et politiques actuels »(Bensa, 2003 :46-47 in : Mokkadem, Hamid, 2005 :113). Deverei discutir essa proposição adiante.

${ }^{236}$ Segundo aqueles autores "a compreensão da tradição oral aqui supõe um conhecimento prévio da organização social Kanak”. Dentre suas principais características, os autores ressaltam o "papel estruturante da residência e das referências espaciais na construção, sempre provisória, de grupos de parentesco. $O$ sistema social aqui também é fortemente trabalhado pelas implicações contraditórias da reciprocidade (troca matrimonial, equilíbrio de prestações) e de hierarquia (distinções entre ranques, constituição de 'chefaturas'). Na sociedade kanak, a instabilidade de posições sociais abre a via para práticas competitivas incessantes e complexas, das quais participam diversos tipos de narração/narrativa' (1982: 7).

${ }^{237}$ Os autores ainda acrescentam que 'plus souvent cet accord sur les positions de chacun fait défaut et les prises de parole n'interviennent qu'après des discussions ou des temps de reflexion parfois longs " (Bensa e Rivierre, $1982: 15)$.

${ }^{238}$ Os autores recolheram também os chamados pwööti (paroles), proposições mais livres, reflexões acerca de eventos, instituições e de narrativas anteriormente registradas e livradas à escuta de seus interlocutores.
} 
a participação da assistência na construção textual da narrativa através de interlocução com aquele que narra ${ }^{239}$.

Os cihêdéé, traduzidos pelos autores por 'conto' ou 'história', são, em princípio, narrativas ditas para 'fazer dormir' as crianças, ou enquanto esperam a refeição da noite. Ao anúncio de um cíhêdéé, a expectativa da assistência é por uma narrativa animada e 'cheia de humor', que aquela deverá escandir ou entoar, com a boca fechada, frase após frase. Os protagonistas destas narrativas são animais, personagens mítico-ancestrais ou representantes de grupos conhecidos e expressamente nomeados o que, segundo os autores, pode conferir aos cíhêdéé uma significação bem além do simples divertimento. No entanto, a forma estereotipada do gênero, sua retórica própria e as figuras que utiliza tendem a orientar o interesse do auditório para seus aspectos lúdicos ou estéticos. Alusões a realidades subjacentes, assim como as intenções mais 'sérias' e 'precisas' do narrador tenderiam a permanecer em segundo plano, deixadas à apreciação de quem 'Ihes sabe compreender'.

Os jèmà, ao contrário, se querem verdadeiros do começo ao fim. Quer relatem as origens de unidades de parentesco ou a conformação de grupos de co-residência locais, tais narrativas, ao inverso dos cíhêdéé, não têm como objetivo uma expressão lúdica voltada à diversão do auditório. Consistem antes de uma 'parole' que, sob a 'cobertura' de um apelo ao passado, se situa no centro da ordem social atual para dar conta dos fundamentos e das relações internamente a um conjunto político ${ }^{240}$. Sempre inserida em um contexto preciso, os jèmà nomeiam e localizam seus atores, aderindo

\footnotetext{
${ }^{239}$ Mulheres foram 'tradicionalmente' excluídas dos âmbitos em que se realiza a transmissão de narrativas históricas internamente a uma família. Mas conhecem e produzem cantos e contos para crianças.

${ }^{240} \mathrm{Em}$ relação à organização de espaços de residência, que vêm informar agrupamentos políticos locais, temos o amu ou 'país' (pays), que consiste na unidade territorial a mais vasta a qual grupos locais podem pertencer, marcado pelo predomínio de uma língua e delimitado por elementos específicos da paisagem (montanhas, rios, litoral). O amu vêm receber o nome de um mwa (clã) ou maison, correspondente ao nome do clã mais numeroso naquele território ou do clã que identifica o local como sendo o lugar de emergência de um ou do mais antigo ancestral do clã, ou de seu 'totem' (mas membros daquele mesmo clã podem se encontrar dispersos em outros amu). Uma maison (exceto na região Norte da Grande Terra, organizada em 'sociedades locais' em que não predomina a regra de exogamia) é considerada como uma unidade patrilinear e exogâmica fundada em laços de consangüinidade, mesmo que formada por clãs e linhagens de origens diversas. Isso porque aqui os campos de parentesco biológico e social se recobrem a todo instante (como veremos adiante). No interior de tais territórios encontram-se diversos espaços de residência mínimos, de famílias nucleares, que tomavam a forma de uma alameda (pomwö), e que vinham gradativamente se expandir com a chegada de novos grupos para formar um conjunto mais vasto, formado por diversas alamedas e chamado pomwaiu ou contenants-de-chefs. O pomwaiu é identificado com um conjunto político, econômico e territorial estruturado e relativamente autônomo, em que há cooperação em trabalhos agrícolas e no calendário cerimonial. Quando me refiro a um agrupamento político, a referência é em geral a este pomwaiu, espaço de co-residência ampliado. Com a colonização e o encerramento de grupos em reservas que não correspondiam a seus locais de ocupação anteriores, essa lógica de organização espacial, social e política foi virtualmente reconstituída, ainda que menos marcada no espaço visível. Em relação aos amu (país) e seus tertres (termo que indica espaços de residência, de referência clânica ou de passagem de outrora, os tertres propriamente ditos concernindo elevações do terreno que marcavam o espaço de construção das casas, em geral identificados pelo nome do tertre ocupando a posição mais alta, a casa do 'chefe'), os Kanak mantém, tanto quanto possível, a memória de sua localização, buscando realizar visitas periódicas a seus próprios espaços de referência, ainda que não possam lá habitar.
} 
às complexidades e acordos situacionais daquelas relações com muito mais precisão do que os cíhêdéé. Sua narração se daria em circunstâncias mais graves e de mais difícil compreensão. Na medida em que comportam as intenções dos narradores, elas são função da composição da assistência e da situação social à hora, definindo o grau de aceitação da narrativa (podendo imprimir ao narrador, face uma dada assistência, a opção entre falar e se calar). A coleta dos jèmà, ainda segundo aqueles autores, é aleatória e por vezes delicada, pelo fato de tais narrativas poderem se constituir prerrogativas de especialistas, e de uma ordem de precedência poder ser estabelecida entre pessoas encarregadas de transmitir as tradições relativas a um mesmo agrupamento político ${ }^{241}$. Em face de tais situações, os jèmà recolhidos assumem formas as mais diversas: podem ser chamados de jèmà fragmentos de um saber sóciohistórico dos quais todos podem eventualmente fazer uso, mas também narrativas substanciais, como aquelas construídas para o pesquisador. Os autores ressaltam que em geral os narradores somente intervinham publicamente após pesaram e repesaram cuidadosamente suas palavras. Em especial em uma situação de pesquisa, em que o registro da parole assim como sua transcrição poderiam ser compreendidas como uma oficialização das proposições e posições apresentadas. Porque dessa maneira o narrador se via como podendo perenizar, em sua vantagem, uma representação normativa de uma ordem social habitualmente instável e contestada. Segundo Bensa e Rivierre, em uma sociedade onde nenhuma posição é unilateral nem detida de uma vez por todas ${ }^{242}$, o estatuto de cada grupo é adquirido provisoriamente ao termo de diversas estratégias que se resolvem na elaboração de identidades sociais e políticas complexas, das quais a tradição oral participa ativamente.

A identidade dos grupos é constituída através da história de deslocamentos e de estadias em diversas aglomerações residenciais. A cada local, lugar de origem, de passagem ou de instalação temporária correspondem patronímicos e toponímias dos quais os narradores fazem uso seletivamente em suas narrativas segundo as relações que pretendem privilegiar ou ocultar, seja para confortar sua posição atual, seja buscando se inserir vantajosamente alhures ${ }^{243}$. Assim, as narrativas fundadoras jemà

\footnotetext{
${ }^{241}$ No caso de agrupamentos políticos e residenciais complexificados, que ultrapassam a família nuclear (pomwö) tais como os pomwaiu, estes vêm reunir famílias de origens diversas ligadas por laços de parentesco agnático (biológico ou social) ou aliança. À essas diversas famílias são atribuídas funções e prerrogativas específicas, conferidas pelos primeiros fundadores ou pelos mais antigos ocupantes: de diplomacia, encarregados de ritos agrários, guardiões de magia de guerra ou de saúde, sentinelas, e oradores.

242 Pois se pode ser ao mesmo tempo 'chefe' e 'sujeito' segundo o quadro de referência escolhido. A chegada de 'estrangeiros' tendeu no mais das vezes a conduzir os primeiros ou mais recentes ocupantes a ceder a posição de 'chefe' e a ingressar a dos 'sujeitos' do grupo local, sem que o grupo do recém 'posado' chefe perdesse sua posição e suas relações no espaço anteriormente ocupado. Tal prática é caracterizada pelo termo accueil, em francês. Apresentarei cuidadosamente tal prática, a seguir.

${ }^{243}$ Isso porque há duas unidades que coexistem, segundo princípios distintos, mas que buscam se integrar em um todo coerente: uma de tipo linhageiro, através de uma genealogia possuindo realidade biológica; outra clânica, em que linhagens se ligam primeiro por referência biológica a um ancestral comum, em seguida pela associação deste ancestral a um ou alguns tertres d'origine (elevação onde eram construídas as casas dos primeiros fundadores do lugar, marcadas hoje por espécies vegetais como a araucária e
} 
tendem a situar os membros de cada clã (e linhagens) que compõem a unidade residencial do narrador no espaço local e, simultaneamente, legitimar as hierarquias que ali predominam. Tais narrativas, que podem tomar a aparência de discursos gerais sobre a aparição do primeiro homem e dos ancestrais do clã, são, segundo tais autores, teorias políticas de uso local. Os jèma ${ }^{244}$ seriam, neste sentido, a expressão sempre reelaborada de pensamentos e práticas políticas. Sua compreensão supõe assim o conhecimento das regras do jogo social e político, ou seja, a elucidação dos princípios de constituição e de segmentação dos diversos tipos de agrupamentos dos quais a coresidência (ou segundo a abrangência do 'coletivo' em um dado contexto) é feita.

Os cíhêdéé, segundo aqueles autores, poderiam a um primeiro olhar escapar àquele modo de apresentação, ou seja, à sua função 'política'. Pois este gênero retira sua eficácia da encenação cômica ou dramática de um afrontamento ou do difícil estabelecimento de uma aliança. Assim, o 'texto' pode assumir a aparência de uma fábula descontextualizada da qual o auditório extrairia uma 'moral'. Entretanto, e freqüentemente, o cíhêdéé se inscreve diretamente, mas de maneira esquemática, em um campo social apreciável através de imagens, patronímicos e toponímias. Desse modo, através da reconstituição sócio-histórica deste gênero, e apesar de seu aspecto literário, os autores irão apontar de que modo pode este veicular, também ele, uma mensagem política. Pois através de sua feitura imagética, ele oferece a possibilidade de enunciar, através da alusão codificada, aquilo que as conveniências exigem em geral que se cale: a origem incestuosa de certo grupo ou linhagem, a procedência estrangeira de um chefe, a ruptura de uma aliança, a covardia ou a coragem de uns e de outros. Para denegrir ou para relembrar o que se têm como fundamental, o recurso à alegoria e ao tom humorístico mantêm uma fluidez e uma distância que atenuam o porte daquilo que é dito, a partir de uma perspectiva diversa daquela avançada pelos jèmà.

Um dos elementos fundamentais que distingue os cíhêdéé dos jèmà é o fato de que, enquanto os primeiros consistem em narrativas 'privadas' e familiares, veiculadas no espaço doméstico, elas podem portar sobre a história do grupo do narrador, sua

coqueiros), em função de um itinerário representado como uma linha de filiação. Linhagens que guardam a memória de um mesmo tertre d'origine podem se dizer pertencentes a um mesmo clã (organizados a partir de genealogias míticas, genealogias espaciais e itinerários). O fato de a 'genealogia' de constituição de tais tertres d'origine ser fixa e conhecida por todos, e organizada em função de um ranque de antiguidade (primogênito/caçula) permite que a associação de sua linhagem (segundo modalidades específicas) a tertres primogênitos venha melhorar sua posição anterior.

244 "Ni acquise, ni a l'origine véritablement heritée, la position de daame ('chefe') est plutôt reçue, comme un cadeau que les maîtres de la terre font au lignage étranger en vertu d'une décisison (pî-hwô) prise hors de lui. Ce geste n'a en effet rien d'obligatoire. Il conclut, ou pas, un débat auquel prennent part les lignages déjà installés dans le terroir. Au terme de la discussion, il peut être décidé de ne pas recevoir le nouveau venu, de l'integrer à un rang ordinaire ou bien de le 'poser chef' (ne daame). Dans ce cas, on l'assimile aux plus anciens du terroir dont il prend le nom. Il deviendra alors interdit d'evoquer l'origine étrangère du daame. Son intronisation scelle, entre tous le groupes du 'pays' (amu), un contrat dont les conditions sont mémorisées par un récit fondateur, le jèma » (Bensa, 1995 :70-71). 
linhagem e clã, mas também sobre outros grupos do espaço da co-residência, assim como sobre suas intersecções anteriores com outros grupos para além do espaço político da co-residência atual. Já os jèmà, que possuem o caráter de uma narrativa pública (de acordo com a assistência a cada contexto) irão discorrer sobre a história (contratual) e o lugar dos diversos atores e grupos no espaço político concernido a coresidência atual ou contextos mais amplos. Assim, os jèmà, que se apresentariam como uma parole política e estruturante centrada em torno de um grupo, podem aparecer, segundo os autores, como um discurso voluntarista e mesmo fictício. Ao contrário, o cíhêdéé, apresentados como um 'conto lúdico', levariam em conta as relações entre diversos grupos, ou seja, fragilidades e tensões reais, tanto atuais quanto de outrora ${ }^{245}$.

Bensa e Rivierre mostravam-se interessados, sobretudo, quanto à história 'real', factual e cronologicamente organizada, que poderia ser extraída do conteúdo das narrativas orais (em especial quando caracterizaram os jèmà como potencialmente fictícios, ao focarem sua análise nos cíhêdéé), para a reconstrução da história concreta de deslocamentos e alianças relativas aos grupos (clãs, linhagens e famílias) de que fazem parte seus narradores e, complementarmente, a de outros grupos com quem estiveram em contato $^{246}$. Os autores irão, em sua análise daqueles textos, buscar reconstituir os trajetos e relações entre os grupos concernidos, através do

\footnotetext{
${ }^{245}$ Alhures, Bensa irá relacionar as variações em torno da narrativa histórico-mítica a partir de um de seus temas centrais, a da 'enigmática' figura do daame/chefe (posição originalmente ocupada pelo 'fundador do lugar', mas sistematicamente cedida ao grupo mais recentemente instalado em certa localidade; assim há duas posições 'nobres' que marcam o espaço e o agrupamento político: o de daame ou 'chefe', e o de 'maître de la terre', o fundador do lugar ou mais antigo ocupante).

Nas narrativas histórico-míticas proferidas pelos representantes dos fundadores do lugar ou pelos mais antigos ocupantes, o daame é originário do mundo selvagem. Homens ou mulheres, tendo partido caçar, pescar ou buscar novos clones de carás e inhames, encontram uma pedra, uma planta ou um animal que Ihes intriga. A captura, trazida para casa, logo se transforma em um jovem que, através dos medicamentos administrados por seus pais adotivos, cresce rapidamente, vindo então a receber o título de daame. Mas a integração deste novo jovem nem sempre é bem-sucedida. São os contos cihêdéé que irão freqüentemente glosar a difícil inserção no grupo local deste personagem proveniente do 'mundo natural'. Por outro lado, narrativas fundadoras jèma devem, por definição, legitimar o sucesso do empreendimento, ao mesmo tempo em que vêm sublinhar sua significação 'profunda'.

Segundo aquele autor, a acolhida de um estrangeiro e sua elevação ao ranque de daame parece consagrar, na simbólica do mito, a influência que seus anfitriões entendem exercer sobre ele. Os fundadores do lugar, guardiões dos ritos agrários, fazem do daame uma planta que vem enriquecer sua coleção ou uma caça que eles pouparam e que, transformada em uma criança, é por eles alimentada e criada. Assim a expressão èwa-daame em língua chêmuhí, 'enfant-chef', empregada nas narrativas ou paroles tradicionais, estipula marcadamente essa relação de dependência do daame face àqueles que se dizem seus 'pais e avós' (caa me ao). O daame é o 'filho' por eles 'posado', o que os Kanak resumem geralmente ao afirmarem que 'le chef n'est rien sans ses sujets'.

Já nas narrativas cíhêdéé avançadas pela família do próprio daame, é toda outra imagem que se impõe: os daame serão aqui os 'filhos do sol. À imagem do simples 'pedregulho' encontrado na floresta e tornado daame pela indulgência dos fundadores, se opõem a figura gloriosa do astro do dia que vai atravessar os céus em direção àqueles a serem por ele representados (1995:122).

246 Em um Atlas publicado em 1981 pela ORSTOM, Bensa irá descrever o itinerário de dispersão de três clãs ("Références spatiales et organisation sociale dans le centre-nord de la Grand Terre et Itinéraires des clans Wéélèt, Garratu et Göièta (carte)" planche 18. Atlas de La Nouvelle-Calédonie et sés indépendences, Paris, Orstom.
} 
conhecimento da língua e da análise, com o auxílio de seus interlocutores 'savants', dos sentidos que informam as metáforas e os patronímicos e toponímicos empregados nas narrativas cíhedéé ${ }^{247}$. Contudo, parece-me que esse tipo de análise só foi possível pelo fato de os autores trabalharem com informantes isoladamente e, portanto, com um gênero discursivo 'interno' ao âmbito familiar, produzido tanto para divertir as crianças como para relembrar trajetórias e aspectos honoráveis (ou depreciativos) relacionados ao histórico de seu 'grupo' (e daqueles com quem estiveram em contato) de forma alusiva e imagética.

Essa questão é bastante importante aqui. Quais são os contextos e modos de acesso às formas e conteúdos da tradição oral empregados por pesquisadores e a que modalidades de 'relação' e/ou 'informação' correspondem aqueles gêneros, tendo em vista que a tradição oral concerne modos de interação, mediados pelo discurso, considerados adequados a dados contextos? $?^{248}$

Jean Guiart privilegiou enquetes breves, convocando reuniões em que circulava a parole (Guiart, 1963). Para tanto, este autor apoiou-se nas reflexões já desenvolvidas por Maurice Leenhardt a este respeito. Segundo Guiart, "[Maurice Leenhardt]

247 O próprio Bensa irá remeter, alhures, ao resultado deste trabalho de enquete como da ordem do 'artefato': "altérations produites artificiellement lors d'un examen de laboratoire" (1995:29). Isso porque o autor afirma que toda documentação que pôde reunir entre os anos de 1973 e 1978 se distingue pela preocupação de seus interlocutores Kanak de verem restituídas as terras das quais a colonização lhes havia expulsado um século antes. Assim, a fervorosa atividade intelectual de seus interlocutores, decididos a pôr todo seu saber e habilidade retórica a serviço da restituição de seus direitos sobre a terra (Bensa, 1995:2829, ênfase do autor). Essa questão é bastante relevante no caso de constituição de arquivos ou bancos de dados 'alimentados' por registros de fragmentos de narrativas da 'tradição oral' realizados em momentos anteriores. Por vezes certo gênero da tradição oral pode parecer predominar em um dado período tendo em vista os difusos interesses (de reivindicações políticas, econômicas, territorias) dos próprios interlocutores em um dado momento de sua história, que podem vir marcadamente influenciar ou desviar os objetivos teóricos precisos a que se propuseram pesquisadores de 'tradições orais'. E ainda, quando Lévi-Strauss caracterizou o chamado 'corpus clássico', em que o colaborador executa as indicações do etnólogo; ele mesmo se torna etnólogo quando busca constituir uma coletânea tão completa quanto possível, na qual põe no mesmo plano as tradições de seu grupo familiar ou social e as de membros de clãs diferentes. Ademais, esses documentos são dispostos numa ordem que tenta ser objetiva" (1986:150) tais corpus clássicos concerniriam também em "modos mais ou menos diretos de validar reivindicações territoriais, políticas ou econômicas" (idem). Relevante ainda o fato de Bensa haver lhes caracterizado como 'da ordem do artefato'. E ainda, é preciso atentar para o fato de pesquisadores abrangerem, de modo geral, uma região ou localidade restrita e de forma não exaustiva, privilegiando certos interlocutores (savants) em detrimento de outros. Nesse sentido, ações de registro realizados em situações de pesquisa devem ser vistos como parciais, por sua própria natureza. No caso de ações atuais de registro de tradições orais voltados à salvaguarda, ou da compilação de registros de outrora, seria preciso uma atenção voltada à quais elementos outros podem ou puderam estar em jogo quando interlocutores privilegiam este ou aquele aspecto de suas 'tradições orais'. Nesta pesquisa meu interesse volta-se para quais aspectos de tais 'tradições' registradas foram privilegiadas pelos próprios Kanak em contextos específicos, tendo em vista seja a constituição de um 'patrimônio' e identidade 'próprios' e específicos a certos 'coletivos', sejam eles comuns aos diversos grupos lingüísticos do Território. Veremos também de que modos registros produzidos em uma dada época, segundo contextos específicos, podem vir a ser questionados, em outros momentos, pelos membros de tais comunidades.

${ }^{248}$ Essa questão adquire contornos relevantes quando consideramos as atuais propostas de valorização e salvaguarda culturais pautadas no registro de 'tradições orais'. Quem deverá realizar os registros? De que modos? Quais âmbitos devem ser registrados? Quais aspectos e contextos são considerados relevantes pelos próprios atores para a salvaguarda de sua cultura e de seu patrimônio e quais aspectos são considerados como devendo ser excluídos, e por quê? O quanto tradições orais correspondem, ou não, à modos de interação discursiva 'adequada' quando o interlocutor é um 'outro'? 
connaissait les contradictions entre les informateurs cherchant à affirmer chacun le prestige de son clan $^{249}$...je fûs amené à tenter d'échapper en un premier temps aux déformations, dues à l'isolement d'entretiens personnels ${ }^{250}$, pour amener chacun à ouvrir son dossier en public, de façon à ne rien recueillir qui ne fût acceptable pour tous. Les protestations individuelles n'ont jamais manqué de se produire ensuite et à l'écart, m'apportant alors l'énoncé des divergences...aussi une vue, nouvelle pour moi, de la valeur à accorder à certains textes traditionnels, tels que les vivaa, les discours du pilou $^{251}$ »(Guiart, $1963: 17$, ênfase minha).

Monnerie (2005 : 28-29) optou por uma análise de cerimônias em seus próprios contextos de ocorrência, voltando sua atenção para atos e gestos, trocas e discursos cerimoniais, de modo a não restringir sua análise aos enunciados de seus informantes. Isso porque este autor afirma que, segundo seus interlocutores Kanak, a observação das cerimônias lhes permitia compreender as relações sociais entre pessoas e grupos ali concernidos. Se aqueles interlocutores não podiam afirmar os nomes dos grupos implicados, podiam descrever as relações em jogo entre os grupos e indivíduos em interação, ao atentarem para tomadas de posição e atos de fala e de troca durante tais cerimônias.

Naepels (1998), trabalhando na região de Houaïlou, irá chamar a atenção para as diversas formas que pode assumir a narrativa histórica, correspondentes aos jèmà e cíhêdéé apresentados por Bensa e Rivierre e chamados respectivamente virhénô e vinimö em língua ajië. Naepels irá também destacar a importância de contextos e âmbitos de interlocução em que se dão tais discursos e suas modalidades, ao evidenciar, também ele, as contradições manifestas entre narrativas produzidas individual e publicamente, e os discursos cerimoniais coletivos chamados vivaa na região de Houaïlou.

Segundo Naepels, narrativas Kanak são sempre históricas. O autor relata que todo encontro de indivíduos ou grupos Kanak é seguido da questão: "Vârâ Xe-wè na vârâ?". "Você caminha, de onde vem tua marcha?". A questão 'quem é você?' é sempre enunciada na forma de um 'de onde vem você?'. Do mesmo modo como Bensa e Rivierre, Naepels caracteriza a narrativa histórica como uma tecelagem de conjuntos de nomes de ancestrais, de lugares de origem, de passagem ou de residência, que definem uma história privada e específica ao narrador. Entretanto, segundo aquele autor, aquelas narrativas históricas formuladas a pedido do pesquisador, através de

\footnotetext{
${ }^{249}$ Atente-se para o fato de que é sempre o prestígio de seu próprio clã, e não a difamação da versão de outros clãs.

${ }^{250}$ Seriam tais modalidades propriamente 'deformações' ou simplesmente variações contextuais, já que as informações correspondem, a cada caso, à formas e conteúdos de transmissão ancoradas em formulações distintas de 'coletivos' a cada instante?

${ }^{251}$ Deverei discutir o gênero da tradição oral 'vivaa', também chamado 'discours du pilou' ou 'discours sur le bois', adiante.
} 
situações de entrevista, põem em cena outros grupos além daquele do narrador, grupos estes que se encontram segundo modalidades diversas de relação face ao do narrador: agnática, de aliança matrimonial ou de conflito, passado ou presente. A história tende assim a se declinar em um itinerário privado, mas com um número variável de intersecções com trajetos de outras famílias. Ponto fundamental a esta análise concerne o fato de que, segundo Naepels, seus interlocutores mostravam-se sempre reticentes em explicar detalhes de pontos da história que concernem outras linhagens e clãs $^{252}$. Em relação e esta questão, Naepels relata, assim como Guiart, que a boa vontade de seus interlocutores dependia notadamente dos contextos em que se davam as próprias situações da pesquisa: entrevistas coletivas suscitavam versões de narrativas que insistiam sobre a aliança ou a proximidade entre os clãs ali representados (narrativas virhénôljèmà), em detrimento das diferenças de seus itinerários ou de episódios históricos que lhes opuseram. Inversamente, era somente a sós, pesquisador e interlocutores, e quando os últimos estimavam contar com a discrição daquele, que certos indivíduos aceitavam, por vezes, falar mais sobre o que sabiam da história de outras linhagens ou clãs ${ }^{253}$. Em todo caso, Naepels insiste sobre a importância que tomam em tais narrativas históricas os nomes próprios, nomes de lugares ou de ancestrais, que seriam verdadeiramente próprios e dos quais a literalidade mesma é portadora de sentido e identidade, remetendo a episódios específicos. Um fato relevante no âmbito da pesquisa de Naepels era de que aqueles nomes remetiam à uma multiplicidade de exegeses, de modo que através da trama comum as análises do significado de um nome eram também elas largamente contraditórias. Assim, para os Kanak, a literalidade mesma dos nomes próprios citados nas narrativas históricas abre para a possibilidade de divergências massivas de interpretação da história, correspondendo, segundo o antropólogo, e naquela situação de disputa e debate $a b e r t 0^{254}$, à mesma quantidade de recursos para o conflito.

Daí a importância aqui da apresentação de um gênero em que há a participação de atores de diversos grupos, discursos chamados vivaa ou discours sur le bois ${ }^{255}$ (na

\footnotetext{
${ }^{252}$ Que parece contradizer, em parte, as afirmações anteriores, a respeito dos modos como cada grupo intenta privilegiar nas narrativas a situação de seu próprio grupo, linhagem ou clã. Imagino que tais narrativas tratem sempre das posições de seu próprio grupo, mas não de outros. Veremos adiante também a questão da memória, em que atores guardam especialmente a memória de eventos históricos de sua própria linhagem e clã, em detrimento de outros. Discutiremos também aqui a noção de 'respeito' avançada por alguns de seus interlocutores. Relembro aqui o fato de os Xavante também negarem comentar tanto suas falas como a de outros no warã.

${ }^{253}$ Alguns, tendo em vista um contexto atual, de oficialização de certa versão da história a partir da disputa pela posse de terra. Outros, por temerem pelas afirmações de outros interlocutores em relação à história de sua própria linhagem ou clã. De qualquer forma, Naepels afirma que tais tomadas de palavra a respeito da história de 'outros' não eram nunca desprovidos de inquietude. Tal inquietude será apresentada adiante, com o recurso à algumas das entrevistas que lhe foram cedidas a este respeito.

254 Segundo novos contextos de relações, também através de formas expressivas e discursivas não correspondendo a gêneros de sua tradição oral. Deverei discutir este ponto adiante.

${ }^{255}$ Chamados 'discours du pilou' por Guiart (1963) já que as festas do Pilou, que reuniam uma grande quantidade de grupos provenientes de linhagens e clãs distintos eram uma das principais ocasiões do pronunciamento de tais discursos.
} 
região de Houaïlou). Esses discursos cerimoniais têm como referência central a figura do accueil. Seja em situações atuais de encontro entre grupos, seja no que diz respeito aos procedimentos de outrora quando do deslocamento de clãs, linhagens ou famílias, o accueil consiste em uma prática cuja lógica é central à compreensão das relações entre grupos Kanak, e de aspectos fundamentais de suas tradições orais.

\subsubsection{Cerimônias e o accueil}

“Autrefois, les clans étaient des voyageurs” (Monnerie, 2005 :24).

"Ao fim de seu caminho, um viajante pronuncia algumas palavras, oferece uma moeda a seu anfitrião, que lhe responde do mesmo modo lapidar. Só então este lhe convida a se sentar, a tomar um café ou a compartilhar uma refeição". (Monnerie, 2005:25).

Esta descrição concerne a cerimônia de accueil em sua forma mínima, podendo adquirir feições bastante complexas em especial quando da chegada de um ou mais grupos de pessoas. Anteriormente aos procedimentos formais da cerimônia de accueil (chamada thiamm na região norte da Grande Terra em que trabalhou Monnerie), visitantes e anfitriões fingem se ignorar: não se apertam as mãos, nem se falam. Se os grupos não se conhecem, estes vêm freqüentemente acompanhados de alguém conhecido por uns e por outros e que, em geral, possui um caminho entre eles ${ }^{256}$. Este homem dirá as palavras de apresentação, enquanto um dos visitantes oferece uma prestação cerimonial ${ }^{257}$, ao que o representante dos anfitriões the responde apresentando, também ele, uma prestação, e que vem significar sua aceitação. Através deste gesto aqueles que chegam reconhecem a existência de uma autoridade local. Entre os Kanak sempre se é acolhido de alguém que acolhe. Tais gestos e discursos são, em toda a Nova Caledônia, os procedimentos os mais correntes e dentre os mais significativos da vida social Kanak, capazes de serem complexificados e, como veremos, transformados e inovados (Monnerie, 2005:25).

Esta chegada e este accueil são como uma coreografia, acompanhada de uma série de discursos que descrevem as relações entre as duas metades em cerimônia: relações internas às metades que se reúnem e às metades entre si (Monnerie, 2005: 27). Geralmente, em um primeiro discurso formalizado, o orador daqueles que chegam

\footnotetext{
${ }^{256}$ Que corresponde a uma função e à prerrogativa específica, dentre outras (como a responsabilidade pelos ritos propiciatórios que favorecem o crescimento dos tubérculos, a guarda de magias particulares para a saúde, - e, em tempos idos, para a guerra-, a de mensageiros, de sentinela, etc.). A função de guardiões dos sentiers coutumiers corresponde indivíduos pertencentes a grupos que, instalados na periferia do terroir, eram responsáveis tanto pela diplomacia quanto pela proteção, segundo seu papel de guerreiros. Tais especialistas, hoje em que a guerra desapareceu, servem de intermediários diplomáticos de um terroir a outro (Bensa, 1995:33).

${ }^{257}$ Pedaços de tecido, moedas ou dinheiro, cigarros ou tabaco, fósforos, açúcar, etc.; antigamente tais prestações concerniam moedas de concha, tecidas em um fio e, por vezes, machados de jade. Em tais trocas, prima-se pela reciprocidade e o equilíbrio de prestações.
} 
declama as etapas do caminho que levou seu cortejo ${ }^{258}$ até o local de seus anfitriões. Em seguida, segundo uma fórmula sintética e um gênero preciso da tradição oral Kanak, conhecido como vivaa (ou discours sur le bois na região de Houaïlou ou hoor na região de língua nyelâyu), ele descreve a organização de sua sociedade. Discursos são então realizados pelos dois lados, quando são proclamadas as intenções e as relações implicadas pela cerimônia. As pausas realizadas após o primeiro discurso e durante os discursos subseqüentes são dedicadas à circulação das prestações cerimoniais, e comentadas naqueles discursos ${ }^{259}$. A partir de então, ambos grupos fazem parte de um mesmo 'coletivo', naquele contexto. Quando da chegada de um novo grupo, aqueles que já realizaram a cerimônia se apresentam juntos no discurso cerimonial, como parte de um mesmo coletivo e assim por diante, até que se realizem as cerimônias de separação. As relações entre os recém-chegados e seus anfitriões, tornados naquele contexto 'um só coletivo', são tecidas através daquelas trocas de palavras e de bens cerimoniais $^{260}$.

\footnotetext{
${ }^{258}$ Segundo Monnerie, os gestos dessa chegada e sua forma de cortejo apresentam-se como gestos de guerra, dada a potencialidade da não-aceitação do grupo recém-chegado pelos anfitriões e do caráter outrora potencialmente disruptivo de tais encontros. Hoje, se subsiste a virtualidade do conflito em tais gestos, a guerra deixou de ser uma modalidade de resolução de conflitos em detrimento de outras formas de disputa (conflitos em torno de versões divergentes da história face à disputas pela posse da terra, disputas no campo da política de Estado, acusações de feitiçaria e, em casos extremos, assassinatos) (Monnerie, 2005:127).

${ }^{259}$ Bens idênticos doados e recebidos em quantidades no mais das vezes equivalentes. O porte de tais prestações é sempre amenizado naqueles enunciados. Segundo Alban Bensa, para as estratégias de manutenção ou aquisição de uma posição (ou ranque) elevado ou de certa potencia política, a acumulação de bens materiais, de terras ou de produtos alimentícios não é aqui preponderante. A apreciação da relação ao mundo material põe o acento sobre a circulação antes que sobre a acumulação de bens. A circulação, através de dons e contra-dons, empréstimos sem interesse ou doações sem contrapartida no momento imediato, seja de terras, de produtos, de crianças (adoções temporárias ou definitivas), de esposas ou bens preciosos ('moedas' de concha e, em tempos idos, machados de jade), exprime e/ou estabelece relações sociais. A importância de um homem ou de um grupo varia em relação proporcional ao volume de suas relações que à suas riquezas em bens ou mesmo à posição (ranque hierárquico primogênito/caçula) que detém localmente. Todas as estratégias de ascensão política começam pelo bom entretenimento de relações que são herdadas com o nome e o ranque de sua linhagem: é preciso visitar seus parentes, em especial seus tios maternos, assim como aqueles com os quais se partilha ou se partilhou um mesmo espaço de referencia (itinerário ou grupo de tertres de origem) (Bensa, 1995: 289). Segundo Jean-Marie Tjibaou: "il y a la conception de la réussite de la vie: où est le prestige ? dans le système mélanésien, pour être un homme prestigieux, le prestige c'est de donner. C'est l'envers du monde capitaliste! Ici, on dit, on apprend aux enfants à economiser, á capitaliser. Dans notre système, si vous faites cela, vous devenez petit... parce que vous n'avez pas de relations. Vous êtes obligez a vous couper de la communauté. Vous ne pouvez pas honorer vous oncles si vous avez beaucoup et que vous ne donnez pas. Les gens savent, et si vous ne donnez jamais rien, le jour où vous devez faire une célébration, vous n'aurez rien... le gens ne sortent pas, ils restent chez eux ou disparaissent " (Tjibaou, 1996 :108).

260 'Les gens expliquent qu'ils 'font la coutume' (dons et contra-dons), non seulement pour se proteger des agressions directes d'autre mais aussi pour se premunir des attaques eventuèlles des morts du clan visité. Les échanges céremoniels qui accompagnent toute relation sociale réaffirment d'autant plus les liens positifs qui doivent unir les groupes que la situation peut toujours évoluer vers le conflit et la rupture " (Bensa, $1995: 47)$
} 


\subsubsection{O accueil em sua dimensão histórica e os discursos cerimoniais vivaa}

Em "Histoires de Terres Kanaks" ${ }^{261}$ Michael Naepels irá apresentar a prática do accueil em sua dimensão histórica: os complexos procedimentos que implicava, e as conseqüências daquela prática no que concerne a reelaboração identitária dos grupos que dela participavam.

No que diz respeito à tradição oral, se o histórico de tais procedimentos poderia ser relembrado de modo imagético e alusivo, internamente ao âmbito familiar, através das narrativas cihêdéé, os resultados de tais reelaborações identitárias eram legitimados publicamente através das narrativas histórico-míticas jèmà ${ }^{262}$, e performados em cerimônias através de um gênero dialógico específico, os vivaa (chamado hoor na região norte da grande Terra, em língua nyelayou).

Na referida obra, o autor também apresenta e discute, através do recurso à palavra de seus informantes, as conseqüências da vivência desses discursos e enunciados num sistema de relações que é outro, que envolve disputas atuais em torno da posse da terra. Os enunciados de seus informantes deverão ser trazidos à baila em um segundo momento, na segunda parte desta análise. Apresento primeiramente o accueil em sua dimensão histórica, e suas implicações na tradição oral Kanak.

Em sua análise, Naepels ressalta que é preciso perceber os jogos de relações imbricados na produção de tais discursos vivaa, o que pressupõe refletir a respeito das dinâmicas sociais Kanak e das construções de ordem política operadas também através de discursos, e que seriam a reafirmação, através de seu caráter público, de uma verdade contextual e disputada a ser reconhecida localmente.

No que diz respeito às narrativas históricas acessadas pelo autor através de entrevistas com seus interlocutores Kanak, Naepels indica que os deslocamentos evocados naquelas narrativas tiveram lugar na época pré-colonial ou imediatamente contemporânea à colonização. De 1880 em diante os Kanak foram acantonados em reservas das quais não podiam sair sem a autorização dos gendarmes, guardas da República. Anteriormente, tais deslocamentos podiam implicar todos os níveis da organização segmentária: clãs, linhagens, famílias nucleares ou indivíduos. No mais das vezes, estes deslocamentos eram provocados por conflitos concernindo a chefatura (problemas de sucessão ou tentativas diretas de eliminação do chefe daame ${ }^{263}$ ) ou mulheres (adultério ou violação, que colocavam em causa relações de aliança entre

\footnotetext{
${ }^{261}$ Michel Naepels. "Histoires de Terres Kanakes ».Éditions Belin. Paris. 1998.

43 Em língua ajië, vinimö e virhénô, respectivamente. Deverei manter aqui os termos cíhêdéé e jèmà para a manutenção da fluidez do texto.

${ }^{263}$ Chamado örökau em língua ajië.
} 
clãs). Para além da migração, tais conflitos podiam também acarretar em guerras, que chegavam a reunir diversos clãs, já aliados ou reunidos especialmente para a ocasião. Esses deslocamentos podiam também ser solicitados por demandas para a resolução de conflitos internos a espaços de co-residência, ou demandas por competências específicas (eficácia guerreira ou mágica, segundo a reputação dos clãs), de modo que grupos podiam ser convidados a virem se instalar junto aos demandantes.

A instalação em um novo espaço de residência tomava a forma do accueil mais ou menos 'coagido' de acordo com os motivos do deslocamento (expulsão ou partida voluntária) a cada caso. Os ocupantes de um lugar conferiam terras de habitação e plantio, assim como um estatuto aos novos-vindos. Havia no 'accueil duas modalidades possíveis de tratamento do estrangeiro: ou se fazia dele um aliado ou um agnático.

No primeiro caso, o accueil podia dar continuidade a uma relação de aliança ${ }^{264}$ preexistente ou ser a ocasião de seu estabelecimento. Tal relação mantinha uma clara distância identitária e estatutária entre os grupos, que se casavam entre si. Os anfitriões cediam esposos ${ }^{265}$, ao mesmo tempo em que certo número de bens, prestando um auxílio na instalação dos novos-vindos: eram cedidas terras de plantio, tertres ou poderes mágicos (prerrogativas, 'medicamentos' para a doença ou a saúde, etc).

Uma segunda modalidade consistia na integração agnática, de modo a incluí-los à dos anfitriões, em geral os fundadores do lugar ${ }^{266}$. O accueil, nesse sentido, podia constituir na ocasião de uma completa reorganização social local. O termo empregado para designar esta integração é a mesma utilizada quando da adoção de uma criança: uxöwî: 'fermer dans la marmite', fechar/encerrar na marmita ${ }^{267}$, mas que seus interlocutores traduziam livremente por 'effacer le nom', 'effacer le passé': 'apagar o nome, apagar o passado,268. De fato, esta integração suscitava a mudança de nome do

\footnotetext{
${ }^{264}$ Em língua ajië: vibéé. Este termo designa a aliança de casamento e o conjunto de relações de ajuda mútua e de assistência que ela suscita entre aliados.

${ }^{265}$ O que vinha contribuir para a instalação dos novos vindos que, ao cederem esposas, poderiam então assumir a posição de 'tio materno', posição de prestígio assim como aquelas de daame e de 'maître de la terre".

${ }^{266}$ Maîtres de La terre, chamados kavûû nèvâ em língua ajië.

${ }^{267}$ A adoção/cessão de crianças constituindo uma prática corrente entre grupos Kanak, segundo uma lógica de dom/contradom. De uxö: cozinhar no vapor, e-wî: sufixo indicando a idéia de fechamento, encerramento; em referência ao bougna: prato tradicional em que carne ou peixe, acompanhados de batatas-doces, carás e inhames, são embebidos em leite de côco e embrulhados em folhas de bananeira e então cozidos sobre pedras quentes.

${ }^{268}$ Cabe aqui um esclarecimento importante, no que se refere ao contextual 'apagamento do passado'. O passado não é completamente apagado porque a memória dos patronímicos e das toponímias, que remetem a eventos da historia dos clãs concernindo locais e ancestrais, e das relações de aliança entre clãs tende a permanecer (especialmente através das narrativas cihêdéé), de maneira variável também em função dos modos de transmissão próprios à tradição oral (que deverei discutir adiante). Segundo Tjibaou, "le foncier, ces sont des archives Kanak": "il y a des itinéraires. Je passe d'abord par tel endroit. Et a tel endroit, je rencontre un tel clan. Et je n'ai pas le droit d'aller directement. Je passe par tel clan, celui qui est l'ambassadeur, qui doit porter, qui doit m'introduire. Tout ça, c'est des points dans l'espace, des noms des clans, mais des noms des clans qui sont inscrits dans l'espace, sur le terroir. Et il suffit de me dire les noms, les points nommés dans l'espace, ça dit les relations entre les clans. II y a un autre système aussi, c'est le
} 
grupo acolhido. O ponto essencial é que, segundo esta modalidade, a história dos acolhidos era assimilada àquela do grupo anfitrião. Seu verdadeiro passado era dissimulado, assim como seu verdadeiro nome, sem que tais fatos fossem, contudo, esquecidos por todos ${ }^{269}$.

Todo grupo de residência reunia assim acolhidos e acolhedores. O 'equilíbrio' local resultante, segundo Naepels, repousava sobre a diferença de estatuto entre o acolhido, tornado então 'chefe', e o anfitrião, chamado 'fundador do país ${ }^{270}$. O accueil reconfigurava assim os grupos e seus estatutos, definindo uma nova configuração política e modificando a história das famílias concernidas. Havia lá um procedimento que o autor caracteriza como 'contratual', vindo estabelecer os acordos recíprocos, que eram selados através de trocas de palavras e bens preciosos ou prerrogativas, e que suscitavam, ao fim e ao cabo, um consenso local e público. Segundo o autor, o pano de fundo de tais acordos era constituído pela avaliação recíproca dos 'poderes' de cada grupo implicado: poderes de guerra e poderes mágicos, e das alianças que tais grupos detinham em relação a outros grupos no exterior. Assim, este contrato consensual não diferia de uma espécie de 'tratado de paz', que vinha também definir uma partilha funcional: o recém-chegado, tornado 'chefe', vinha se constituir o interlocutor prestigioso do grupo de co-residência em direção ao exterior, àquele a quem se deve dirigir com o mais profundo respeito, mas também aquele que seria visado em caso de

nom des arbres, les noms des oiseaux, les noms, les noms. Ou encore, on utilise les noms des lieux. On dit: celui qui habite un tel endroit. On a chez nous l'habitude d'appeler les gens par le lieu. Chez moi c'est Kamo Pakaavat. Pakaavat c'est l'endroit ou j'ai ma case. Alors pour ne pas dire mon nom les gens qui me respectent m'appelleront Kamo Pakaavat. Cela fait des complications pour les gens qui font des recherches sur le terrain, parce que les gens ont toujours plusieurs noms. On les appelle par le nom de l'endroit où ils habitent, il y a aussi le prénom; ils ont quelques fois plusieurs noms. Les noms de famille donnés à l'administration française lors de l'établissement de l'état civil sont souvent très différents des noms qu'utilisent quotidiennement les Kanak" (Tjibaou, 1996:111). Segundo Mokkadem, " II y a une difficulté majeure, la divulgation des noms. Le patrimoine idéntitaire et le capital relationnel de l'individu sont corrélatifs de la pluralité des noms. Il existe un titre respectueux, le toponyme. Et des noms donnés à un individu, qui vont lui conférer des droits, des entrées dans les chemins mentionnés.ll est inconvenant de nommer par ce nom-là les personnes. Existe aussi le nom générique de la lignée. À cette panoplie des noms, se greffe souvent un surnom, diminutif affectif ou qualifiant une propriété morale ou physique. Les noms sont aussi liés a des stratégies. Un clan en adopte un autre [através do accueil] et lui confère un nom attribuant des droits. Ce clan peut reprendre son nom d'origine s'il se sent lésé (...) le terroir n'est pas neutre. Il est nommés et identifié par des histoires précises et mémorisées. L'identité d'un clan se ressource à ce patrimoine foncier. Cela n'interdit pas des conflits fonciers entre clans qui ne cessent de polémiquer autour des noms » (Mokkadem, 2005 : 87). Nesse sentido, um conjunto de eventos de acolhida, se pode adensar os enunciados históricos em um dado contexto, não impede que estes se ramifiquem em outros contextos, através da rememoração (ou adoção) de nomes anteriormente 'apagados'. Assim, um clã pode ser 'acolhido' diversas vezes seguidas e fazer recursos a pontos estratégicos (relacionados a ancestrais e tertres cada vez mais recuados no tempo) de seus trajetos anteriores, ou 'apagando' outros (em especial quando acolhidos em locais distantes dos de sua origem). Indivíduos Kanak qualificam tais práticas, amplamente 'aceitas' e recorrentes, como forma de 'garder la qualité de son tertre lignage' (Bensa e Rivierre, 1982:95).

269 "À mesure que des nouveaux groupes arrivent dans l'agglomeration résidentièlle, les ex-etrangers s'intégrent au group des fondateurs, mais un souvenir très précis est gardé de l'ordre d'arrivé de chacun " (Bensa \& Rivierre, $1982: 91$ ). Tais fatos eram transmitidos internamente às famílias, também através do gênero cíhêdéé.

${ }^{270}$ Note-se aqui a inscrição do modelo ‘Kanak' ao do 'estrangeiro-rei'. Sahlins, M. Ilhas de História.1990. 
guerra $^{271}$. Quanto aos fundadores, eles eram formalmente menos visíveis, mas conservavam o domínio ritual sobre o espaço e sobre a produção ${ }^{272}$. As duas posições 'nobres' (de 'chefe' recém-instalado, e de 'fundador do país') da hierarquia social também ficavam marcadas na organização espacial das alamedas residenciais; a casa da 'chefatura' estando situada no alto da alameda, mas não sendo em geral habitada pelo chefe, e a casa do fundador na parte mais baixa da alameda. Em torno de tais posições nobres vinham se reunir um conjunto de posições de servidores ou 'sujeitos' ${ }^{\text {273: }}$ membros de clãs e linhagens encarregados da caça, da pesca, de ritos agrários, da construção das casas, de magias de saúde, de morte ou de guerra. A cada estrangeiro instalado como 'chefe', correspondia uma realocação na ocupação residencial: enquanto o novo 'chefe' vinha ocupar a posição mais visível, o antigo 'chefe' vinha se reunir aos antigos 'sujeitos', de modo a the conferir cada vez maior antiguidade. Um dos pontos fundamentais ressaltado por Naepels concerne ainda o fato de que a persistência de um suposto 'equilíbrio' dependia profundamente da transmissão, internamente a cada grupo, da história que o fundamentava ${ }^{274}$.

Naepels irá ressaltar como a colonização afetou a natureza daqueles modos de 'equilibrar relações': o acantonamento, o estabelecimento de uma organização administrativa, e transformações nas modalidades de transmissão daqueles conhecimentos históricos ${ }^{275}$. A criação das reservas obrigou brutalmente que grupos

271 "Le 'chef', comment peut-on l'appeler chef puisque ses soi-disant 'sujets' disent: "sans nous, ce type-là n'est rien"? D'ailleurs, il ne prend pas des décisions. Ceux qui décident, ce sont les anciens. Il y a sans arrêt ce double representation du 'chef'. II est à la fois quelqu'un de statut élevé, quelqu'un que l'on respecte et le 'garant' de l'accord qui a été conclu à son sujet entre les clans du terroir. On lui construit une case, dans laquelle il n'habite pas, qui est la case de la chefferie. Le 'chef' est un personnage dépendant, comparé à un enfant. On parle pour lui. Mais tous les rituels vont converger vers lui. On va lui offrir les premiers ignames. Dans l'agriculture Kanak chaque phase importante est ponctuée d'une magie particulière et d'un don cérémonial au 'chef'. Le maîtres des ignames, - bien disctinct des maîtres de la terre-, assument cette charge. En mars, il présente la première igname au 'chef'. Son repas autorisera tous les gens de la tribu a faire le même. Quand il commencera à débrosser son champ la période des travaux agricoles sera ouverte. Le chef a été decrit comme le 'calendrier vivant du terroir' (Bensa, 1995 :37). "Les mythes donnent a ce personnage une origine minérale, végetale ou animale : cailloux, fougères et lézards trouvés dans la brousse et rapportés près du foyer se transforment en des hommes qu'on elève et qui, plus tard, reçoivent la chefferie. Et celle-ci prends corps à travers le corps même du souverain. Autrefois, avant l'arrivée des blancs, le chef était périodiquement nourri de la chair de ses sujets. Dans le clan regnant se préparait chaque année un homme qui acceptait de s'offrir en sacrifice et, par là, contribuer à la santé et a la fecondité du chef, garantes du bien-être de tous » (Bensa, $1995: 60$ )

${ }^{272}$ Assim a posição de maître é característica não de sua dominação (no sentido de que as decisões eram tomadas por todos os anciãos dentre os antigos ocupantes), mas de seu domínio ritual (já que habitavam o local de emergência de seus próprios ancestrais, detendo assim prerrogativas rituais sobre o espaço e a produção, distribuídas entre as famílias co-residentes).

${ }^{273}$ Em ajië: kâmöyaari: literalmente 'homem pequeno' de kâmö: homem e yaari: 'pequeno'.

${ }^{274}$ Pois, como afirmaram Bensa e Rivierre, 'plus souvent cet accord sur les positions de chacun fait défaut et les prises de parole n'interviennent qu'après des discussions ou des temps de reflexion parfois longs " (Bensa e Rivierre, $1982: 15$ ).

${ }^{275}$ A transmissão se dá particularmente na família, através do pai, dos irmãos do pai e, sobretudo, do pai do pai. A transmissão varia também em função da curiosidade e do interesse que demonstram ou demonstraram crianças ou jovens, assim como do respeito por eles manifesto em relação às prescrições práticas decorrentes da narrativa histórica. Assim, é no interior da família ou da linhagem (segundo o gênero cihêdéé, nas regiões paîci e cemuhi, e vinimö em língua ajië) que se transmitem narrativas de adultério, de guerras, de roubo de nomes, de antropofagia, de reorganização política violenta, mas segundo a confiança que demonstra aquele que transmite em relação a este ou aquele de seus descendentes, para 
que viviam separados vivessem juntos. Tais deslocamentos forçados em reservas deram por vezes lugar a procedimentos de accueil e de recomposição local segundo sua forma 'tradicional'. Ao mesmo tempo, as modalidades mais freqüentes de resolução de conflitos, a migração e a guerra, tendo-se tornados impossíveis após o acantonamento, fez florescer disputas e acusações de feitiçaria. A instituição de chefes administrativos nomeados pelo Estado fez, em muitos casos, 'escapar' a designação do chefe segundo as lógicas locais. Daí que posições 'nobres' não têm mais hoje o caráter evidente que já vieram apresentar. Enfim, o estabelecimento do estado civil escrito tornou quase impossível as transformações de identidade que tinham lugar nos procedimentos de integração agnática. Vale ressaltar que após o fim do Regime do Indigenato, em 1946 e em diante, certo número de migrações tiveram lugar no sentido de escaparem a um conflito local, por vezes em direção à capital Noumèa, mas também em direção à outros espaços de co-residência, segundo a lógica tradicional de alianças matrimoniais.

Atualmente, reinando a confusão entre 'chefes' e chefes administrativos e a ausência de possibilidade de fazer reinar um consenso quanto à 'ordem local' e de evitar a disseminação de versões divergentes da história no âmbito de debates concernindo as disputas pela terra, parece que a manifestação principal dos estatutos de uns e de outros se dá por ocasião das tomadas de palavra que têm lugar em contextos cerimoniais. As cerimônias principais ocorrem por ocasião de encontros entre grupos,

fazer dele o melhor uso de modo a não se expor a ataques segundo uma utilização considerada disruptiva de um saber polêmico: "dans le monde mélannésien, ton savoir c'est l'arme de guerre. Tu dois frapper l'ennemi quand tu dois frapper, tu ne dois pas sortir ton savoir comme ça " (extrato de entrevista, julho de 1993 in $1998: 142)$.

Entre o período colonial e o momento contemporâneo houve uma extrema variabilidade de possibilidades em relação à transmissão: de uma transmissão sistemática e deliberada à opção não menos deliberada de um silencio obstinado, além da indiferença demonstrada pelas gerações antigas ou atuais em relação a este saber. Quando da irrupção da dominação européia, uma das situações mais freqüentes consistiu na perspectiva de que a única liberdade possível viria da aceitação da nova ordem instituída pelos franceses (e pelos missionários). Esta aceitação, em sua forma mais radical, suscitou um silenciamento da transmissão do saber histórico, visando a 'desobstrução' da vida dos jovens em relação a problemas estrangeiros ao mundo dos 'brancos'. Mas ela também subsistiu na dualidade. A integração num universo estrangeiro podendo se constituir em mais um mecanismo de melhoramento de sua posição social local pela ocupação de novas posições de prestigio (administrativas ou religiosas).

Segundo Naepels, os Kanak encontram-se hoje em uma situação paradoxal: a transmissão tendo se realizado de forma bastante desigual, o saber histórico, outrora já importante, tornou-se crucial em um contexto de reivindicação de posse de terra, assim como da promoção atual da 'cultura Kanak' através da valorização dos chamados 'coutumiers'. Observam-se atualmente verdadeiras enquetes individuais: adultos que vêm consultar os homens mais velhos de seu clã ou seus tios maternos, tentativas de encontrar membros de famílias aliadas às suas, mas separadas de longa data, reconstituição ou preenchimento de lacunas relativas aos deslocamentos ou mudanças de nome através do recurso à pesquisas realizadas por antropólogos, etc. Enfim, segundo Naepels tais enquetes podem dar lugar à larga margem de interpretações pessoais, ou à 'invenções'. Os indícios dos quais se dispõe, quer provenientes de sonhos, de narrativas de um terceiro ou de exegese de nomes próprios podem servir de pontos de apoio à reconstituição hipotética da história de uma linhagem ou de um clã. Assim, versões contraditórias da história regional são ainda mais aumentadas. Parece-lhe que nos casos de transmissão parcial, aquilo que era primeiramente esquecido era a história de outros clãs, ou a ancoragem cognitiva das relações de respeito, auxílio mútuo ou dominação. Quando a preservação do equilíbrio local supõe a boa transmissão do saber, que permite renovar e manterem vivos os acordos sobre as posições sociais no espaço da co-residência, seu esquecimento promove a multiplicação de versões divergentes da história, a confusão entre estatutos nobres, o que suscita, nesses novos contextos, conflitos particularmente tensos. 
em casamentos, enterros e cerimônias de encerramento do luto. Tais cerimônias se desenvolvem junto à família anfitriã, ou à família agnática do falecido ou do noivo, que reúne em torno de si próximos e aliados a fim de oferecerem dons à família da esposa (no caso de casamentos) ou do tio materno do morto ${ }^{276}$, acompanhados também estes de seus próximos e aliados. Tais cerimônias constituem-se atualmente, segundo Naepels, o lugar de afirmação identitária pública a mais significativa da vida social Kanak. Face uma reunião de clãs sem equivalente na vida de todos os dias, uma série de discursos são proferidos, nos quais os laços históricos entre os grupos presentes são objeto de profunda reflexão pelos seus participantes para serem, então, magnificados, rememorados, eufemizados ou simplesmente ignorados. De tal modo que tais eventos são a ocasião da afirmação de uma ordem que se torna publicamente conhecida; os discursos desviantes dando lugar à protestos e discussões, em outros âmbitos.

Assim a importância dos discursos públicos vivaa, enquanto manifestação de uma versão atual, contextual e autorizada da história e, portanto das relações atuais internamente a espaços de co-residência, assim como entre clãs, linhagens e famílias visitantes. Naepels propõe que no espaço cerimonial, a enunciação dos vivaa é o lugar da trama da verdade quanto à organização social em um dado contexto.

Os vivaa consistem em listas de nomes de ancestrais ou de tertres (alamedas residenciais), que são relacionados a certos clãs, e/ou à certas linhagens. Segundo cada caso, é apresentada ou não, ou de maneira vaga, uma indicação da paridade entre nomes de ancestrais e de alamedas ou tertres, e nomes de clãs. Tais discursos operam uma trama da verdade e da ordem social, no sentido de estarem longe de serem transparentes ao conjunto de seu auditório, e ao requererem, para serem interpretadas, um saber desigualmente partilhado. Isso porque a localização das alamedas residenciais citadas nem sempre é conhecida, assim como a história de certos ancestrais que têm seus nomes enunciados. Ainda hoje chefes de família conhecem ou buscam conhecer todos ou parte dos nomes correspondentes à sua própria linhagem e clã, e por vezes também os de outras famílias. Os nomes remetem também, através de toponímias e imagens, a locais relacionados a episódios da história

\footnotetext{
${ }^{276}$ Segundo Tjibaou: "le principe de la vie, c'est la mère, c'est la mère qui donne la vie. Le père donne le personnage, le statut social, la terre. Le vie est donné par le sang, le sang c'est la mère qui le donne, et les proprietaires du sang sont ses frères, ses pères. Alors je reste toujours duel. Je ne suis jamais individu. Je ne peut pas être individu. Le corps n'est pas un principe de'individuation, le corps est toujours la relation. (Leenhardt a bien compris beaucoup des choses, heuresement!) Et les proprietaires de ce partie de moi, ce sont mes oncles maternels. Je ne suis jamais moi, je suis en reference à, en reference à mes oncles. II n'y a person qu'en reference à. Dans ce contexte là, l'homme qui est reussi c'est l'homme qui garde bien les alliances d'un côté et de l'autre. Avec les pères et avec les oncles. Quand un enfant vient au monde on donne des cadeaux a la mére, au côté de la mère. Quand je me blesse, je dois faire a mes oncles un geste d'amende honorable, sinon je vais devenir malade, je vais maigrir, bientôt mourir. Le jour de la mort, on va se ressembler pour faire ensemble l'affaire du deuil, mettre ensemble les cadeaux, donner aux oncles maternels, on va rendre la "dépouille »; ça appartient aux oncles maternels, on va la rendre ". (Tjibaou, 1996:108)
} 
e a eventos considerados como relevantes na história dos clãs. Dois elementos são importantes ali: quem é citado ou não para um dado espaço de residência, e em qual ordem. Pois nomes de ancestrais ou de alamedas prestigiosos (ou sórdidos) podem ser relembrados, 'esquecidos' ou apropriados, e com eles a parte da história que recobrem e o estatuto que implicam. Enfim, a ordem de nominação dos clãs em um espaço de residência dado remete a seu estatuto local, de maneira complexa: assim, o primeiro clã citado pode ser, segundo o caso, o do fundador do local ou o do chefe. Na medida em que a enunciação é pública, ela toma um caráter de oficialização que a transforma em um lugar possível de humilhação ou de homenagem ${ }^{277}$.

Note-se que estas listas constituíam precisamente o objeto de um trabalho de recomposição quando dos procedimentos de integração agnática, por decisão comum: quando o accueil suscitava uma reorganização local, a modificação das relações sociais implicava aquela dos discursos cerimoniais ${ }^{278}$.

O espaço cerimonial aparece deste fato como um lugar no qual a importância social do saber histórico, assim como a percepção acerca de divergências de versões da história podem se manifestar publicamente. Em certos casos, indivíduos ou grupos podem aproveitar essas ocasiões para ancorar seu estatuto ou melhorar sua posição, através da introdução de um nome de tertre ou de ancestral prestigioso em um vivaa quando se imagina que este foi esquecido por seus verdadeiros 'proprietários' ${ }^{279}$ ou ainda, da

\footnotetext{
${ }^{277}$ Naepels traz ao corpo de seu texto um exemplo de vivaa :

"J'elève les gens issus de Yéé et Mii et Êêno et Gu e Rhea et Aatëë et Tëë et Ėrhuadéwé et Töia et Duba et Tëë et Mavui et Néwabwéré (13 nomes de ancestrais), et qui sont de l'autre côté les Tëvèyû et Mèyikwéö et Ëribwa (3 nomes de clãs) ;

J'elève le gens issus de Karé et Mavui et Kayarhéru (3 nomes de ancestrais) dans Wéxa et Néba, et de l'autre côté Raruaxiyi et de l'autre côté de l'eau Yavinawai (4 nomes de tertres);

J'elève les gens issus de Nékérö et Bürü et Mimö et Varui et Kuayè et Gwâmee (6 nomes de ancestrais), qui ont donnée naissance à Kaviyöibanu (nome de clã); leurs serviteurs à cet endroit sont les gens issus de Kacëë et Kapödúrú (2 nomes de ancestrais) ; qui forment de l'autre côté les Mèyikwéö Töwanii (nome do regrupamento de clãs).

J'ai dit ». (Naepels, 1998:78).

(extraído do vivaa de Nérhëxakwéaa, setembro de 1993, traduzido por Naepels).

${ }^{278}$ Assim como das narrativas mítico-históricas jèmà, que se apresentam como 'verdadeiras' em seu conteúdo de acordo com a assistência composta a cada caso. Vimos também que as narrativas jèmà, selam o contrato de instalação de um novo-vindo posado chefe, de modo a que em sua enunciação é interdita a evocação de sua origem estrangeira. Vimos, entretanto, que em sua versão 'mítica' (que diz respeito a um primeiro evento), fundadores do país privilegiam a narrativa fundadora que atesta a condição do 'chefe' como aquela de um elemento do mundo 'natural' 'coletado', adotado e criado, um filho que recebe então a posição de daame. Já a versão concorrente (avançada em geral pela família do 'chefe') privilegia uma situação presente, em detrimento do procedimento que deu lugar à tal situação, ressaltando a posição prestigiosa e o significado profundo e ritual do chefe no espaço do terroir, enquanto representante 'vivo' do calendário cerimonial. De qualquer forma, o chefe é sempre assimilado aos 'plus anciens du terroir dont il prend le nom. Il deviendra alors interdit d'evoquer l'origine étrangère du daame. Son intronisation scelle, entre tous le groupes du 'pays' (amu), un contrat mémorisé par un récit fondateur (jèma) (Bensa, 1995 :7071).

${ }^{279}$ Isso porque indivíduos e famílias compreendem seu pertencimento a um mesmo clã através de um parentesco social regido por itinerários e genealogias míticas, em que tertres d'origine são associados a posições (ranques) primogênitas/caçulas; e o pertencimento a certa linhagem e família através de parentesco biológico. Quando do deslocamento em direção a um espaço de co-residência distante de seu local original, uma família podia reelaborar (o que ocorria no mais das vezes) sua identidade ao se apresentar como ligada a um tertre d'origine mais prestigioso. A esse modo de reelaboração identitária vinha
} 
persuasão de próximos ou aliados no âmbito de uma reivindicação de posse da terra. O apagamento público de uma parte da história é passível de revisão, cada um pode sempre se fazer o exegeta de nomes citados em discursos e de trazer à luz fragmentos da história. O que não vem a ser sempre o caso. Naepels cita casos em que "todos sabem que tal 'chefatura' de tal tribo (espaço de co-residência, aldeia ou antiga 'reserva') é detida por um grupo que 'roubou' seu nome atual, e que não era mais que um grupo de 'servidores/sujeitos' bem acolhidos em seu atual local de residência. Mas o peso demográfico do grupo, seu papel em instâncias da administração, a importância de suas alianças ou seus supostos poderes de magia podem interditar toda contestação de seu estatuto" (1998:147). O enunciado público testemunha um momento de uma organização local que se legitima em um discurso histórico, mas que pode ser modificado a todo momento.

Ressaltemos aqui, ainda, as possibilidades criativas inerentes à memória e ao esquecimento articuladas às formas de transmissão próprias à oralidade. Essa questão deverá ser discutida adiante.

\subsection{A noção de Maison na construção identitária de grupos}

James Leach (2003) chamou a atenção para a noção de palem entre as populações de língua Nekgini habitantes da Costa Rai da Papua Nova Guiné. Sua impressão inicial do aspecto aparentemente caótico da organização social dos falantes de Negkini derivava do fato de o termo klen (clã), - empregado pela população local em inglês pidgin-, portar pouca relação sistemática à descendência. $O$ autor irá notar, em relação à organização dos clãs, que se a regra de casamento preferencial é entre primos cruzados, um terço dos casamentos operava-se junto a mulheres a quem os homens classificavam como 'irmãs' ou 'mães' (2003:127). Já palem, termo da língua empregado pelos habitantes para traduzir klen, "describes a kind of fulcrum to a generative system of kinshipconnection based not on descent, but on co-residence and co-operation" (2003:127). E ainda: "a palem, as well as being the word for the pre-eminent social grouping among Negkini speakers, is also the name for a ceremonial house construction"(2003:128).

Consideradas as diferenças fundamentais entre as modalidades de constituição de palems entre falantes do negkini na Papua Nova Guiné e modalidades relativas à constituição de grupos de co-residência Kanak, podemos propor aqui um paralelo produtivo entre a noção de palem e a importância da noção Kanak de 'maison' ou mwa

se somar a possibilidade de fundação de um novo espaço de residência que tomava o nome de um tertre d'origine ancião e primogênito. Segundo a expressão de certos informantes, essa prática servia a 'garder la qualité de son tertre lignage'(Bensa e Rivierre, 1982:95). Desse modo, diversos representantes de um mesmo tertre-lignage podem ocupar, em aglomerações residenciais diferentes, a posição de primogênitos daquele tertre-lignage. 
(em língua paîci), nomeada de acordo com o nome do clã mais numeroso ou que identifica o local como seu sítio de origem. A importância da co-residência na elaboração do parentesco é avançada tanto por Monnerie (2005) quanto por Bensa e Rivierre (1982).

Segundo Monnerie, "maisons, [assim como chemins, étapes, portes], ces figures sont des veritables institutions sociales informant significations et actions, vis-a-vis desquelles se definissent, pour une part considerable, les actes, les reflexions, l'experiences et les prises de position des personnes et des groupes sociaux" (2005: 39). Este autor ainda acrescenta que 'ce que nous, anthropologues, nommons une 'société locale' [ou grupo local] est souvent conceptualisé par les Kanak en terme de 'Maison'”.

Uma das principais diferenças entre a região Dui ma Bai no centro-norte da Grande Terra, e a região de Arama em que trabalhou Monnerie, dita Hoot ma Whaap, é que enquanto a primeira apresenta um dualismo matrimonial entre dois grupos amplos e não-localizados, Dui e Bai, a região de Hoot ma Whaap estabelece relações entre sociedades (ou grupos) locais ${ }^{280}$ (a regra de casamento não prevalecendo aqui). Daí o fato de Monnerie conceitualizar maison em relação à 'sociedades locais' e não a grupos patrinileares e exogâmicos, correspondentes à região centro-norte ${ }^{281}$.

Ainda segundo Monnerie, as expressões 'grand case' ou 'grand maison' são preferencialmente adotadas por 'dignitários' e 'conhecedores' Kanak, os chamados coutumiers, em detrimento do que em francês Kanak é chamado 'chefferie' ou 'grand chefferie' (2005:72). Segundo este autor, a expressão maison refere-se, ao mesmo tempo que à uma construção, - a grande casa redonda da 'chefatura' que ocupa o local mais alto da alameda-, à uma organização social local e ao espaço de uma vila ou aldeia, ou seja, aos espaço de co-residência, delimitados pelos toponímicos e patronímios que se referem às portas e aos caminhos que diferenciam 'sociedades (ou grupos) locais' vizinhos. Ressalte-se ainda a afirmação de Bensa e Rivierre, em relação à região de Dui ma Bai, acerca do 'papel estruturante da residência e das referências espaciais na construção, sempre provisória, de grupos de parentesco' (1982:7). Segundo estas autores, "le groupe local politiquement structuré ne cesse de s'affirmer dans le langage homogéneisant de la parenté consanguine"(1982:91).

\footnotetext{
${ }^{280}$ Segundo Monnerie, "le principe fondamental de distinction entre les sociétés Hoot et les sociétés Whaap est celui de l'antériorité de leur implantation sur la Grande Terre, les premiers ayant, dit-on précédé les seconds (...). En bref, entre Dui ma Bai et Hoot ma Whaap, deux ensembles régionaux qui partagent la caractéristique d'être acéphales, les différences sont considérables. Elles tiennent, d'une part, à la place, structurante (Dui ma Bai) ou non, des mariages au plan régional et, d'autre part, à la définition même des deux pôles de chacune des ces régions: dans Dui ma Bai, ce sont des groupes exogames non localisés et dans Hoot ma Whaap, des sociétés locales" (Monnerie, 2005: 24). Emprego o termo 'sociedade' de acordo com o autor.

${ }^{281}$ No que diz respeito à região de Dui ma Bai, e parafraseando o aspecto 'caótico' da organização social a respeito dos klen avançado por Leach, Leblic (2000) mostrou que enquanto $50 \%$ dos casamentos segue a regra prescrita, há um taxa de $22 \%$ de endogamia e $16 \%$ de casamentos fora do sistema. Ou seja, aqui também a noção de 'grupos exogâmicos' constitui-se como um tanto caótico.
} 
Assim, levando-se em consideração as modalidades do accueil a que se referiu Naepels (1998), podemos ressaltar aqui a importância da co-residência tanto no que diz respeito à 'genealogia espacial' que informa o histórico de trajetórias e de relações entre clãs, linhagens e famílias como, e especialmente, no caso das reformulações identitárias quando de integrações agnáticas, que vinham acompanhadas de reformulações nos discursos cerimoniais vivaa. O que me parece relevante, segundo todos esses dados, é o aspecto sempre reatualizado da identidade de clãs e linhagens que, se pautadas em um princípio de 'parentesco', concernem, considerando-se o accueil e a integração agnática, em coletivos decorrentes, antes, da co-residência, que sustentam uma genealogia propriamente 'espacial', imbricada à importância relativa em função de sua suposta 'antiguidade'.

Vista à distância, a paisagem da Nova Caledônia é marcada por uma série de linhas, trajetórias que vêm se cruzar em toda sua extensão, chamados sentiers coutumiers (trajetos que se constituem prerrogativas de indivíduos e grupos precisos, que possuem a 'potência' de relacionar países ou amu vizinhos) e 'caminhos da aliança', percorridos pelas mulheres, e que vinham ${ }^{282}$ marcar as relações de aliança entre clãs, agregados na forma de espaços de co-residência ou Maisons. Há ainda pontos concebidos como 'portas', que delimitam os espaços de referência de maisons ou amu distintos. Nesta paisagem, alguns pontos são mais relevantes e expressamente nomeados: tertres d'origine, tertres identificados como tendo sido fundados pelos primogênitos de cada clã. Somam-se aqui ainda locais demarcados por patronímicos e toponímias, que remetem a eventos específicos da história das relações entre clãs, ou locais em que se encontram enterrados ancestrais de cada clã, assim como locais nomeados a partir da história recente.

Jean Marie Tjibaou oferece uma descrição imageticamente rica das relações entre a paisagem e a memória mítico-histórica de indivíduos e grupos nesse espaço propriamente rizomático ${ }^{283}$ que é a Nova Caledônia (a Kanaky):

"Ce qui apparaît fondamental dans la société Kanak, c'est le mythe. Le mythe est un récit à caractère légendaire sur l'origine d'un clan. Il faut se dire que chaque clan se considère comme le centre des relations qui existent entre les membres d'une même tribu et qu'en conséquence l'origine d'un clan est perçu comme l'origine du monde environnant. En effet, l'ensemble du réseau est perçu à partir du point précis qu'est le tertre [d'origine] sur un plan spatial, et la position sociale au niveau du système hiérarchique de la tribu» (...). "Si le terme d'histoire implique la notion du temps

\footnotetext{
${ }^{282}$ Ou vêm. Tais caminhos da aliança e sentiers coutumiers têm sido reelaborados, adequando-se à conformação dos espaços urbanos e das estradas, também com a 'retomada' da posse de parcelas da terra por grupos Kanak.

${ }_{283}$ O modelo deleuziano do rizoma (Deleuze e Gauttari, (2006/1980:28), segundo Mokkadem (2005), inspirou-se nas civilizações da Oceania, a partir do artigo de André-Georges Haudricourt 'Nature et culture dans la civilisation de l'igname: l'origine des clones et des clans" (1964).
} 
conceptualisé et donc objetivé, il faudrait alors parler ici du passé de tel ou tel clan. Ce passé évidemment ne se traduit pas en termes linéaires, à partir de rails quadrillés, comportant des cases numérotées de 1 à $1975^{284}$, et dans lequelles viennent se ranger les événements, mais ce passé se traduit par des couches successives d'événements et des paysages. Ce passé se présente comme une coupe de terrain faisant apparaître des couches superposées de matériaux divers. Ces couches d'epaisseurs différents et des lignes qui les délimitent n'apparaissent pas avec la même précision. Mais l'essenciel, c'est quelle s'ouvre au regard sur en même plan. On peut en prendre la mesure d'un seul coup d'oeil. Ces diverses couches prennent l'apparence de paysages successifs. Ces paysages peuvent se présenter soit avec le même support spatial, mais avec des décors et des scènes qui variant suivant les événements, soit avec des paysages totalement différents. Il y a certes une forme plus élaboré du passé et du clan dans la génélogie ${ }^{285}$. Et cela est intéressant. Mais cela n'illusione que à l'etranger [ao mundo Kanak]. En effet, en enonçant sa liste des noms, le hérault ne déconnecte jamais le nom du tertre [d'origine]. II suffit de lui demander de restituer les noms dans l'espace pour qu'il le fasse immédiatement. Parmi la série des paysages ou des tableaux qui s'offrent aux regards, les uns sont plus nets, les autres moins. Cette différence de clarté n'est pas liée à l'ancienneté ou à la nouveauté, mais aux empreintes laissées par les souvenirs, ainsi qu'à la précision ou à l'imprécision des traditions orales qui se transmettent. Il faut noter également qu'en ce qui concerne le passé d'un clan donné, les images, comme dans un film, apparaissent en gros ou en petit plans suivant ce que veut dire le narrateur. Ainsi, l'etranger [acolhido por um clã] fera disparaître complètement sa véritable origine et son mythe sur un tertre aux environ de son habitat actuel » (Tjibaou, $1996: 62,73)^{286}$.

Considerando-se as formas de constituição e disjunção identitária histórica próprias aos 'coletivos' Kanak, vislumbramos aqui um necessário e recorrente 'esquecimento' de ancoragens relacionadas a trajetórias e relações de outrora, em especial no caso do accueil e de integrações agnáticas que se 'estabilizam'. Por outro lado, como vimos, toponímias e patronímicos 'abandonados' em um dado contexto, podem ser retomados em outras situações por novos 'coletivos', de forma que um grupo pode 'tomar carona' nas trajetórias e linhas de relação de um outro, dando continuidade à antigas relações, representadas agora por novos sujeitos. Ressalte ainda as interferências e novas

\footnotetext{
${ }^{284}$ O texto foi escrito no ano de 1975.

${ }^{285}$ Narrativas mítico-históricas que buscam dar conta de todo o trajeto de uma certa linhagem ou clã, podendo se apresentar segundo os gêneros cíhêdéé (mais imagéticos) ou jèmà, segundo a assistência e o contexto de narração.

${ }^{286}$ Optei pela inserção deste grande trecho pois deverei discutir as diferenças entre Jean Marie Tjibaou e Alban Bensa quanto a importância de referentes 'míticos' para os Kanak (ver por exemplo nota 25). Também para apresentar ao leitor, mais uma vez, a autoridade poética de Tjibaou.
} 
possibilidades do processo colonizador no que diz respeito às modalidades de transmissão ${ }^{287}$.

No que concerne a transmissão oral propriamente dita, Monod-Becquelin (1993:34) já havia afirmado que 'memória e esquecimento são, juntos, dois fatores totalmente positivos. É o esquecimento que introduz elasticidade e flexibilidade, -mudança-, através e na performance individual que articula assim memória coletiva e esquecimento individual". O esquecimento é, nesta configuração, o motor mesmo da criatividade, "um dos fundamentos de toda ficção ao nível do imaginário e do discurso" (Zumthor, 1988:110) ${ }^{288}$. Gostaria ainda de relembrar um outro elemento relevante neste processo de memória e esquecimento Kanak na produção de speech acts originais. Dentre tais speech acts, já vimos que quando do deslocamento (permanente ou temporário, na forma encontros cerimoniais) em direção a um espaço de co-residência distante de seu local original, uma família podia reelaborar (o que ocorria no mais das vezes) sua identidade ao se apresentar como ligada a um tertre d'origine mais prestigioso; ou em que a um espaço de residência recém-fundado podia-se atribuir o nome de um tertre d'origine ou ancestral, com vistas à 'garder la qualité de son tertrelignage' (Bensa e Rivierre, 1982:95). Assim, as linhas dessa genealogia espacial tanto ramificam quanto recuam, se dobrando sobre si mesmas em pontos distanciados do espaço e do tempo, ou saltam de uma linha à outra, ao 'pegar carona' em outros traçados, através da accueil.

\subsection{Novas formas discursivas para velhas relações: deslocamentos}

Essa mobilidade espacial, 'identitária' e de ocupação de posições de prestígio de outrora, da qual os Kanak têm perfeita clareza ${ }^{289}$, vêm tornar extremamente complexa uma situação contemporânea de disputa pela posse de terra pautada em modalidades discursivas distintas das formas do 'político' Kanak, que se delineiam segundo

\footnotetext{
${ }^{287}$ Produzindo também novas modalidades de transmissão como o recurso a documentos, e outras ancoragens hierárquicas e de status (ver nota 63), potencialmente passíveis de serem reinseridos na tradição oral. Em relação à viabilidade dos conhecimentos veiculados através da tradição oral, Naepels realiza uma ponderação relevante face à atual disputa pela terra: "l'éventuelle disparition des récits est fonction de l'importance que chacun accorde à ces histoires dans la vie locale, par rapports à d'autres enjeux parfois jugés plus mobilisateurs. Mais II me semble que tant que la question foncière será posée, II ne faudra pas craindre la disparition des histoires que y sont liées, et qu'on peut même prevoir la multiplication des versions si des cadastres coutumiers sont mis en place " (Mwà Véé, n40 pg. 14-15). Ou seja, o conflito é, também ele, razão de incremento da transmissão, de 'revalorização' do saber considerado 'tradicional' para novos (e velhos) fins.

${ }^{288}$ Em relação à noção de ficção, Zumthor, ao analisar uma série temporal de textos medievais na forma escrita de 'frozen speeches' (Boyer,1990:115) e à medida de sua transmissão, chama a atenção para o fato de que 'realidade' e 'ficção' são, no Ocidente e até o século XV, um único discurso da memória, descrevendo como a autoridade poética transcende aquela dos fatos (Becquelin, 1993:34). E ainda, se o narrador não possui nem os meios de fidelidade absoluta, nem o direito de inventar, a noção de ficção aqui refere-se tanto as possibilidades criativas inerentes ao sistema quanto à relativa liberdade poética de cada narrador; não a um sistema de avaliação próprio à tradição oral. Deverei debater melhor este ponto adiante. ${ }^{289}$ Que, apesar de sua ancoragem factual' dar-se através de deslocamentos concernindo a co-residência, irá sempre fazer referência, antes, à clãs e linhagens.
} 
modalidades de relações e empregos de gêneros adequados à sua tradição oral. isso porque a ADRAF propõe que em debates 'democráticos', no âmbito de reuniões, sejam produzidos consensos locais a respeito do reclamante, e que supostamente deveriam concernir o grupo do primeiro "maître de la terre" ou "fundador do país. Soma-se ainda o fato de tais disputas convergirem justamente para esse coletivo da co-residência ou maison (agrupados nas antigas reservas) que se quis oficialmente, através de gêneros da tradição oral de caráter público (jèmà e vivaa) apresentar-se como um 'coletivo' coerente.

Ao mesmo tempo, se o maître de la terre junto com os mais antigos ocupantes atribuía ao estrangeiro a posição de 'chefe', tal decisão visava, também, o resguardo de si e dos seus, já que o 'chefe' tornava-se o representante oficial do grupo para fora, aquele que seria visado em caso de feitiçaria ou de guerra, de ação violenta com vistas a ascensão a uma posição de prestígio. Fazer hoje do 'maître de la terre' a posição mais visível e proeminente não consiste em desmontar a instituição do 'chefe' daame como o personagem que representava um agrupamento político 'para fora'? Tornar pública e propriamente enunciada a posição do chefe como 'estrangeiro acolhido' não consiste em proclamar publicamente aquilo que o gênero jèmà, enquanto forma narrativa, mas especialmente enquanto modo correto de enunciação pública de um contrato em um dado agrupamento político pedia que se calasse? Inclusive, tal enunciação não viria ela colocar em xeque a posição de um 'chefe' entendido como ponto focal para onde convergem todos os ritos, o 'calendário vivo de um terroir' ?

Outra questão também se faz aqui presente: o quanto tais 'fundadores' possuíam 'tradicionalmente' direitos de 'propriedade' da terra? Segundo Bensa e Rivierre, "si les plus anciens occupants d'un terroir détiennent des prérogatives rituelles et politiques, il nous semble toutefois hasardeux de laisser penser, en usant a leur endroit de l'expression "maîtres du terrain ", que ces personnes détiennent ipso facto une autorité dans le domaine foncier » (1982: 109).

Assim, temos de um lado a importância 'tradicional' da antiguidade, fonte de prestígio do qual decorre o fato de as famílias, linhagens e clãs buscarem, sempre que possível, a melhoria de sua posição ao atrelarem sua linhagem ou clã a um nome de tertre primogênito $^{290}$. No que concerne a tradição oral, já vimos como a produção de narrativas histórico-míticas jèmà constituíam-se (de acordo com a assistência a cada

\footnotetext{
${ }^{290}$ Que, me parece, atesta a importância de produção de sempre mais proximidade com os ancestrais e a 'fonte' de surgimento do totem de seu clã, proximidade esta que então se constitui fonte de prestígio e potencialidade do estabelecimento de relações entre humanos. Se em relação aos Xavante tal 'proximidade' entre humanos e 'ancestrais criadores' é produzida através da percepção de continuidade de formas expressivas e discursivas, assim como através do sonho, em que ancestrais são 'trazidos' ao tempo presente nos cantos da-nopre, no caso Kanak parece-me que a proximidade com os ancestrais deriva ou do atachamento a uma localidade propriamente 'espacial' de surgimento do primeiro ancestral, ou de uma performatividade de 'atos de fala', em que atribuir um nome de um tertre ancestral à um espaço de residência recentemente criado produz o mesmo efeito de proximidade, de modo que o nome 'cria' a relação.
} 
caso) uma ocasião privilegiada de inserção de nomes de tertres ancestrais prestigiosos de modo a elevar o ranque de uma família, grupo ou linhagem ${ }^{291}$.

De outro lado, lembro que a importância de um homem ou de um grupo variava mais em relação ao volume de suas relações que à suas riquezas em bens materiais ou mesmo ao ranque que detém localmente. Assim, estratégias de ascensão política dependiam especialmente do bom entretenimento de relações herdadas com o nome e o ranque de sua linhagem (Bensa, 1995: 289). No que concerne a tradição oral é preciso, de um lado, conhecer os patronímicos e toponímias (e sua localização) decorrentes das narrativas históricas de seu próprio grupo e sua relação com outros grupos localizados no entorno ${ }^{292}$ de seu espaço de residência (aprendidas 'em casa', através dos cihêdéé), informações a que se faz recurso quando em visita a seus parentes, em especial a família do tio materno, assim como aqueles com os quais se partilha (ou partilhou) um mesmo espaço de referencia (itinerário de grupo ou tertres de origem). Naquele contexto de interações ampliadas, vislumbramos a relevância da atualização de relações através dos discursos vivaa, proferidos em cerimônias de accueil quando da visita de um grupo por outros.

No entanto, se tradicionalmente a oposição entre um ranque elevado e inferior atravessava toda a sociedade sem, portanto, corresponder ao exercício de uma autoridade (no sentido da tomada de decisões) ${ }^{293}$, mas de um valor, e em que a posição de maître correspondia àquela de um 'domínio' ritual e não de uma 'posse' no sentido da propriedade, vimos como a 'restituição de posse' da terra pela ADRAF constitui-se uma espécie de atribuição de uma 'autoridade' e de um 'reestabelecimento' da 'verdade' e da 'justiça', mas de uma 'verdade' e de uma 'justiça' que nunca existiram de fato, dada a mobilidade espacial e identitária de famílias e grupos associada ao 'acobertamento' da origem sempre estrangeira do daame, segundo a linguagem homogeneizante do parentesco consangüíneo ( na região Dui ma Bai) a partir da coresidência e do acúmulo gradual de 'crescente antiguidade'.

Vimos que a colonização fez escapar a distinção entre 'chefe' e 'chefe administrativo', assim como interferir na transmissão, tanto no que diz respeito à sua forma (quanto à sistematicidade e às modalidades de transmissão, como a atual propensão a enquetes

\footnotetext{
${ }^{291}$ Segundo a expressão de certos informantes de Bensa e Rivière, essa constituía uma prática adequada voltada a 'garder la qualité de son tertre lignage'(Bensa e Rivierre, 1982:95).

${ }^{292}$ Sublinho aqui que essas relações não são concêntricas, ou seja, marcadas por relações de vizinhança, e sim políticas, entre grupos mais próximos ou distantes entre si (articulados por 'embaixadores' detentores dos caminhos), sem que os mais perto sejam "acolhidos" necessariamente. Vimos inclusive como "l'etranger [acolhido por um clã] fera disparaître complètement sa véritable origine et son mythe sur un tertre aux environ de son habitat actuel » (Tjibaou, $1996: 73$ ).

${ }^{293}$ Decisões concernindo o espaço da co-residência eram tomadas pelo conjunto de anciãos, dignitários e homens de saber reconhecido (Bensa, 1995:22).
} 
individuais e o recurso aos sonhos ${ }^{294}$ ) quanto a seu conteúdo (confusão em relação ao 'chefe' tradicional ou administrativo, esquecimento da história de outros clãs ligados ao seu por relações agnáticas ou de aliança). E ainda, temos hoje o imperativo da posse da terra, dada uma situação atual em que o crescimento demográfico vem dificultar de maneira significativa a manutenção da vida nos antigos espaços correspondentes às 'reservas' em razão da escassez de áreas próprias ao plantio, assim como em função de disputas locais entre grupos e famílias, que vêm colocar em xeque aquilo que os próprios Kanak consideram como o 'respeito'295.

A noção de 'respeito', a qual irei discutir adiante, relaciona-se à 'tradicional' interdição de enunciação em relação à história de outros clãs e linhagens, justamente devido ao fato de que, em geral, se um grupo era 'acolhido', era porque seu passado deveria ser, naquele contexto, 'apagado'. 'Respeito' também pela posição de 'chefe', detentor de um estatuto elevado e do qual dependem todos os outros habitantes de um espaço de residência, já que todos os rituais convergiam em sua direção. A chefatura tem seu 'corpo' representado pelo corpo do soberano: sua saúde e sua fecundidade são fiadores do bem-estar de todos os membros do espaço de co-residência (Bensa, 1995: 60). Por fim, 'respeito' ainda pelo fato de a mobilidade de famílias e grupos depender também do bom entretenimento de relações, que passava pelo emprego correto da parole em situações de interação mediadas por formas expressivas e discursivas adequadas, em que relações entre grupos eram magnificadas, justificadas, rememoradas, eufemizadas ou simplesmente ignoradas, mas em que disputas e dissensos não eram ou são, nestes contextos, nunca enunciados.

Segundo a atenção adotada nesta pesquisa para formas expressivas e discursivas da tradição oral, gostaria de lançar luz para este novo contexto e essa nova forma discursiva, relativa a debates concernindo a posse da terra. Retomando aqui as caracterizações dos principais gêneros da tradição oral acima expostos, poderíamos delinear ou esboçar, esquematicamente, os coletivos a que tais gêneros concernem. Primeiramente os cíhêdéé, que dizem respeito às narrativas transmitidas internamente às famílias, que buscam dar conta dos eventos mítico-históricos e de deslocamentos, tanto no que concerne seus aspectos honoráveis quanto depreciativos, daquelas mesmas famílias e de outros clãs e linhagens com que estiveram em contato.

Em segundo lugar, as narrativas jémà, que, se se apresentam como narrativas históricas (ou hitórico-míticas), irão reconstruir um suposto passado a partir das relações presentes entre grupos e famílias de um mesmo espaço de residência. $E$ ainda, em que 'famílias' acolhidas e inseridas em um novo coletivo vêm ter seus passados 'apagados' e reelaborados de acordo com o 'coletivo' que lhes acolheu.

${ }^{294}$ A referência aos sonhos como forma de transmissão só foi apresentado por Naepels neste contexto atual. Assim, não sei se sonhos constituíam ou não forma considerada adequada pelos Kanak de aceder aos conhecimentos históricos.

${ }^{295}$ Ou ao que Jean Marie Tjibaou refere-se como uma 'inspiração' ou 'ética', como veremos adiante. 
E, finalmente, os discursos cerimoniais vivaa que, ao abranger 'coletivos' de espaços de co-residência diversos, buscam localizar naqueles discursos os 'coletivos' em interação de modo a magnificar e relembrar relações passadas. No caso de tais relações concernirem aspectos depreciativos, tais relações eram eufemizadas e ignoradas, mas nunca ali enunciadas.

Vemos nesse sentido como 'coletivos' diversos se elaboraram, conforme formas de interação adequadas à tradição oral, de modos que a atenção esteve sempre voltada à produção, à manutenção, ou à justificação de 'coletivos' de acordo com seus contextos, mas não à sua 'desconstrução' enunciativa. Vimos ainda de que modos, em contextos de 'entrevistas isoladas' com este ou aquele pesquisador (nos casos de Jean Guiart, Maurice Leenhardt e Michel Naepels), se estes buscavam melhorar a situação de seu próprio clã junto aos pesquisadores, estes evitavam discutir eventos da história relativos à outros clãs e linhagens se, porventura, vislumbravam o risco de tais enunciados chegarem aos ouvidos daqueles outros coletivos, ressaltando a importância do que chamam, em francês, o 'respeito' (em especial pelos hoje chamados coutumiers, como veremos adiante).

Destes fatos, vemos a situação de ambivalência em que se encontram os Kanak atualmente. De um lado, entretêm as relações de modo considerado adequado, em que o prestígio advém também do 'bom uso' da produção de enunciados segundo 'coletivos' e âmbitos de interação apropriados aos gêneros da tradição oral, e que vêm participar na qualificação dos chamados coutumiers ${ }^{296}$; ou reivindicam a 'posse' da terra junto à ADRAF, o que demanda a participação em 'debates' propriamente ditos entre as famílias em disputa, debates estes em contradição com as formas valorizadas de

\footnotetext{
${ }^{296}$ A partir dos Acordos de Matignon, a Nova Caledônia passou a ser dividida em 8 'aires culturelles'. Cada um desses 'aires' é regido por um Conseil Coutumier (oficialmente conhecido como Conseil Consultif), e que reúne 'grands chefs" (ou 'aînés suprêmes'), oradores, dignitários de cada região, assim como homens de saber reconhecido. Neste sentido, ao 'tradicional' prestígio de um coutumier advindo seja de sua ocupação de uma posição 'nobre', seja segundo prerrogativas 'tradicionais', seja por seu 'saber reconhecido' associado ao emprego de formas adequadas de expressão em cada contexto, vem derivar uma posição reconhecida hoje pela ocupação de uma posição política de Estado, regida pelas noções de democracia e justiça. O Acordo de Nouméa (1998) dará a estes conselhos de dignitários Kanak (os chamados 'coutumiers) a denominação oficial de "Conseils Coutumiers". Segundo Monnerie, dentre as atividades de tais Conselhos, a perpetuação ou o reestabelecimento da 'verité' dos procedimentos sociais Kanak ocupa um lugar de primeiro plano. Uma das prioridades de ação de tais conselhos é o de fazer coincidir a função de 'grand chef' àquela de chefe administrativo, o que implica em tornar explícita a organização social que sustenta o papel do 'grand chef e que varia de acordo com cada 'sociedade local'. Em tal tarefa, os dignitários Kanak têm encontrado grandes dificuldades, ligadas especialmente ao 'segredo' e à 'tradicional' 'cobertura' dos conhecimentos, assim como às transformações consecutivas à colonização (deslocamento de populações e encerramento em reservas) e aos conflitos entre pessoas e entre grupos. Segundo Monnerie, o Conselho de Hoot ma Whaap, deste fato, optou pela adoção de uma 'visada pedagógica', ao insistir na participação de todos, adultos, jovens, mulheres e crianças nas reuniões dos Conselhos, tendo em vista a perda dos conhecimentos que ameaça as gerações mais jovens, de modo que novas exigências se impõem para a transmissão e a difusão de conhecimentos sobre a 'cultura' e a sociedade Kanak. Monnerie relata ainda que quando foi lançado o programa "Études des Sociétés kanak" (programa interdisciplinar de pesquisa devendo contribuir à formação de jovens pesquisadores Kanak, iniciado a partir dos Acordos de Matignon), membros do Conselho efetuaram prestações cerimoniais para se conciliar com seus ancestrais, a fim de autorizar a transcrição de narrativas as quais o conhecimento era tradicionalmente reservado a poucos (Monnerie, 2005:21-22).
} 
tecelagem de relações entre grupos políticos, justamente segundo o imperativo atual de enunciação da 'verdade dos fatos'.

Tais debates relativos à posse da terra, além de se elaborarem conforme um emprego de formas de linguagem pautada numa tradição democrática ocidental informada pela noção de indivíduos modernos e iguais que produzem enunciados de acordo com disposições pessoais e subjetivas ${ }^{297}$, e também segundo uma noção de 'maximização do valor' potencialmente regulada pela proposta de construção de 'consensos' ${ }^{\text {'98 }}$, não leva em consideração que, nos âmbitos de discursos próprios à tradição oral Kanak, os 'conteúdos' de discursos se adequavam, a cada caso e a cada contexto, aos 'coletivos' variáveis ali em interação, de modo que tais variações coexistiam, segundo Bensa, de forma a não se contradizerem, pois as avaliações dos atores pautavam-se também pelas relações entre 'que é dito' e cada uma daquelas conformações de 'coletivos'. Em novos contextos discursivos, indivíduos e coletivos que antes não vinham se opôr abertamente, pela ausência 'tradicional' de tais contextos, nessas situações se 'desmancham', podendo apresentar-se como 'indivíduos modernos' ou constituindo novos coletivos. Isso porque tais debates vêm também chamar outros atores e sistemas de relações, como o pertencimento de indivíduos e grupos de origem autóctone à partidos políticos, à opções religiosas distintas ${ }^{299}$, ou aliados (em casamento, parcerias econômicas ou políticas) a antigos colonos ou setores da sociedade mais ampla da Nova Caledônia.

Não cabe aqui a discussão da problemática relativa à restituição da posse da terra aos Kanak (e de outras conseqüências do complexo deslocamento e intersecção de valores entre um sistema e outro) ${ }^{300}$. Meu interesse é antes o desenvolvimento de uma reflexão, a partir daquelas caracterizações a respeito das relações entre gêneros, formas e conteúdos da tradição oral e modalidades de relação entre coletivos em contextos específicos, sobre as formas de constituição de noções como de 'patrimônio' e 'identidade' Kanak comuns em determinadas situações, para além de suas múltiplas clivagens.

\footnotetext{
297 Tal esfera pública teria como fundamento a noção de construções discursivas individuais, cujas proposições são concebidas segundo princípios de racionalidade, verdade, legitimidade, sinceridade e autenticidade (Habermas, 1984, 1987).

${ }^{298}$ Deverei discutir melhor a problemática produção de 'consensos' sob a ótica de sua tradição oral adiante.

${ }^{299}$ Cite-se ainda que a 'transmissão' de uma certa confissão religiosa (católica ou protestante) seguiu as linhas de relação tradicionais entre clãs, mas de modo a produzirem também 'rupturas' aqui e ali. Assim, clãs que possuíam tradicionais relações de aliança, mas espacialmente distantes entre si, podiam se perceber, em um dado momento, como havendo adotado confissões distintas, vindo então romper as antigas relações de casamento e de adoção de crianças entre aqueles clãs.

${ }^{300}$ Para ilustrar a complexidade deste debate cito aqui uma afirmação do diretor geral da ADRAF : "Toute la question est de savoir si le positionnement qui est formulé par l'individu, le clan ou la tribu correspond bien a une réalité anterieure, s'il ne s'agit pas d'une construction nouvelle circonstancielle qui repose partiellement sur des parcelles de legitimité ou encore s'il ne s'agit pas d'une extrapolation de principes anciens sur des questions nouvelles comme les projets économiques qui surgissent aujourd'hui" (Louis Mapou, directeur général de l' ADRAF. Revista Mwà Vèè n40, juin 2003, p.6).
} 


\section{5 A constituição de um 'patrimônio' e 'identidade' Kanak: ontem e hoje}

Antes de realizar a caracterização e análise do evento Melanésia 2000 e da elaboração do 'mito' de Téa Kanaké por Jean-Marie Tjibaou, gostaria aqui de fazer uma parada com vistas a situar duas questões de fundamental importância ao debate a ser realizado neste capítulo. Primeiramente, chamar a atenção para a relevância dos chamados Acordos de Matignon na história política, social e cultural da Nova Caledônia.

Em segundo lugar, gostaria de lançar luz ao debate de longa data em curso entre antropólogos e especialistas, a respeito das continuidades e descontinuidades entre ações identificadas como pertencentes à ordem da cultura ou da 'coutume', e aquelas da ordem do 'político' e da 'política'. Este debate concerne ainda avaliações quanto às relações entre uma demanda pelo reconhecimento do direito a terra e à valorização da 'cultura' autóctone no início dos anos 70 , e a derrocada do movimento pela independência do Estado-nação Kanaky, nos anos 80.

\subsubsection{Retorno à história}

No que diz respeito às relações entre o Território e o Estado francês, assim como entre população autóctone e população de origem européia do Território, sublinho aqui o profundo contraste entre o momento atual e um contexto anterior, marcado pelos primeiros esforços voltados ao reconhecimento e à valorização da 'cultura' autóctone. $A$ principal transformação significativa nas relações entre população autóctone e o Estado francês, assim como o efetivo reconhecimento ou institucionalização de uma 'cultura' e identidade Kanak só foram ocorrer a partir dos chamados Acordos de Matignon, que tiveram lugar no ano de 1988. Tais Acordos influíram de modo considerável na 'oficialização' de um patrimônio e, portanto, na formalização de uma 'identidade' Kanak, através da criação de instituições especialmente dedicadas à 'cultura Kanak' e do apoio de recursos financeiros advindos da Metrópole.

O momento transitório entre aqueles dois períodos, de 1984 a 1988, foi de relevância crucial $^{301}$ à história política da Nova Caledônia. Aquele período é hoje caracterizado como dos "événements".

\footnotetext{
${ }^{301}$ Desde fins dos anos 70, mas principalmente a partir dos anos 80, a Nova Caledônia passava por um acirramento na demanda pela restituição das terras pela população de origem autóctone, assim como por um aumento das disputas entre loyalistas, -que defendiam a manutenção da Nova Caledônia no seio da República e o status quo em relação à propriedade da terra-, e independentistas, estes últimos em sua maioria de origem autóctone. Alguns eventos ocorridos nesta época tiveram importância histórica crucial para o futuro do Território. Resumo aqui tais eventos de maneira sucinta. Em 1984, 7 loyalistas de origem francesa armaram uma emboscada em Hienghène, no nordeste da Grande Terra, enquanto forma de pressão política (face ao boicote às eleições municipais por parte dos independentistas), durante a qual 10
} 
Se a assinatura dos Acordos de Matignon veio marcar o fim dos événements, a Metrópole, contudo, não cedeu o passo à causa independentista mas, tendo em vista a manutenção da paz civil no Território irá propor um engajamento, durante dez anos, em uma política dita de 'reequilíbrio' econômico, político e cultural. Aquela política visava reduzir as desigualdades entre a população autóctone e o restante da população do Território através do investimento em ações de reconhecimento e valorização da identidade e cultura Kanak, participando na formalização de um 'patrimônio' oficial Kanak, posto em cena pelo futuro Centro Cultural Tjibaou.

Assim, se anteriormente àquele Acordo ações como o evento Melanésia 2000 demandavam o reconhecimento da 'existência cultural' Kanak e valorização de suas 'formas de vida', o período pós-Matignon irá não só ver um reconhecimento, mas uma dotação orçamentária significativa voltada ao recenseamento exaustivo, à valorização institucional do 'patrimônio cultural' autóctone, e o apoio ao desenvolvimento da criação artística contemporânea ${ }^{302}$. Assim, a política francesa de 'reequilíbrio' adotada na Nova Caledônia a partir de 1988 associada à uma política pública de descentralização de

independentistas Kanak foram mortos, dentre eles dois irmãos de Jean-Marie Tjibaou. Em 1987, os 7 autores dos assassinatos foram julgados pela suprema corte de Nouméa, tendo sido considerados inocentes pelo veredicto final. Indivíduos de origem melanésia habilitados a participar no júri, por uma manobra política, foram impedidos de contribuir com seu voto. Parte da população de origem européia irá comemorar o ganho de causa em uma grande festividade nas ruas de Nouméa, considerando o veredicto uma vitória simbólica contra a luta independentista. Tal evento irá alimentar ainda mais as tensões entre a população de origem autóctone e a população 'branca' de origem européia. A partir deste evento, o período final dos 'événements' viu a degeneração de uma demanda que até então havia se desenvolvido de maneira pacífica em seus contornos gerais, através de boicotes à eleições, de reuniões voltadas à articulação política entre líderes independentistas em outras partes da Melanésia e do mundo, assim como a busca de apoio junto à opinião pública e representantes do estado Francês na Metrópole. Contudo, no ano de 1988, dois dias antes das eleições presidenciais que irão opôr Jacques Chirac e François Mitterrand, um grupo de 19 Kanak independentistas toma 22 guardas da República como reféns, visando chamar a atenção da opinião pública francesa para sua causa em um momento relevante para a história política da França. A situação irá, contudo, complicar-se, quando o Estado francês decide pela intervenção armada na resolução do conflito (a imprensa havendo sido interditada ao local), evento que ficou conhecido como o 'Ataque à gruta de Ouvèa'. Militares franceses, enviados da Metrópole à colônia para pôr fim àquela situação (operação 'Victor' determinada pelo Ministro do Interior Bernard Pons com o suposto conhecimento de François Mitterrand) irão capturar, e torturar indivíduos Kanak, em especial jovens de uma das aldeias das redondezas de Ouvèa, a fim de descobrirem onde estavam mantidos os reféns. Após a libertação dos reféns, sem que nenhum deles tivesse sido ferido ou morto, os 19 independentistas são assassinados sumariamente. Tais eventos foram divulgados algum tempo depois pela pequena imprensa, mas foram ocultados da população metropolitana durante o período imediatamente posterior às eleições. Em detrimento de tais eventos sangrentos Jean-Marie Tjibaou, representante oficial da causa independentista e da luta pelo reconhecimento cultural kanak, opta por um acordo de paz entre independentistas e loyalistas no território, que culmina nos Acordos de Matignon (que têm como cláusula a anistia dos militares responsáveis pela morte dos independentistas). Pouco tempo depois, em junho de 1989, Jean-Marie Tjibaou será assassinado por um independentista contrário aos resultados dos Acordos de Matignon e à manutenção da dominação da Nova Caledônia pela República.

${ }^{302}$ Segundo Raymonde Moulin, tais transformações estiveram ligadas também a um redirecionamento da ação cultural na França a partir das iniciativas do ministro Jack Lang em 1982. Os principais paradigmas que estruturam a política cultural e artística francesa na década de 80 , segundo aquele autor, irão enfatizar a 'democratização cultural', que denuncia a desigualdade de acesso à 'cultura' e, de outro lado, o relativismo cultural, que contesta a hegemonia de uma cultura savant e se propõe a revitalização de 'sub-culturas' populares, regionais, étnicas, etc. Nessa paisagem, o autor assinala o aumento sem precedentes de investimento na área cultural, assim como a transferência de competências e iniciativas culturais em direção a instâncias regionais na França, através de uma descentralização institucional e geográfica que irá beneficiar também os departamentos e territórios de além mar (DOM-TOM) (Moulin, 1992:87). 
iniciativas culturais e valorização de culturas populares e 'étnicas' na Metrópole, estendida em seguida à seus territórios e departamentos de além-mar, irá favorecer a emergência de novos instrumentos institucionais, como a instalação de serviços culturais nas administrações das províncias, assim como a criação de algumas instituições dedicadas aos Kanak, como a Agência de Desenvolvimento da Cultura Kanak (ADCK), em 1988, e o Centro Cultural Tjibaou, inaugurado em 1998. Desse modo, a paisagem 'cultural' da Nova Caledônia será profundamente dinamizada, ao ser dotada de instrumentos institucionais e receber o apoio de financiamentos públicos. Através das ações de recenseamento, de preservação, e de valorização de 'cultura Kanak', vêm então a ser oficialmente institucionalizado um 'patrimônio' associado à uma 'identidade' comum Kanak (Graille, 2001:12).

No entanto, como ressalta Bensa (2006:198), se o centro Cultural Tjibaou foi construído após repetidas demandas do líder independentista Jean-Marie por um espaço dedicado à cultura Kanak, a política de apoio da Metrópole à construção daquele Centro não irá compartilhar a mesma proposta. Isso porque, se para os Kanak o Centro deveria se constituir um local dedicado ao patrimônio propriamente autóctone, agentes metropolitanos vêem esse espaço como um lugar de divulgação e promoção de produções culturais contemporâneas, e da Oceania de modo geral. Em um diálogo reportado pelo autor, este nota o contraste entre as afirmações do representante Kanak e de um representante do ministério francês, durante as reuniões de planejamento da organização e estrutura do Centro. Enquanto o primeiro afirma que « nous souhaitons que le centre culturel permette à notre culture de trouver toute sa place dans son propre pays. Il faut savoir qu'en vertu de l'article 75 de la Constitution française, nous sommes régis par um statut dit de 'droit particulier'303 qui prend juridiquement acte de notre specificité historique. Nous entendons donner à ce particularisme toute sa force d'expression politique". O representante do governo francês irá afirmar: "Certes, mais au-delà de ces príncipes votre tache est de donner à voir des oevres d'art kanak et, plus largement, océaniennes. Ces exposés sont les meilleurs gages de votre présence dans le monde contemporain" (2006:200). Assim, se os Kanak esperavam que o Centro contribuísse à valorização de uma cultura e identidade propriamente Kanak, o Estado que vai financiá-lo o estima como um espaço dedicado à toda memória e criação artística da Nova Caledônia, inserida no contexto mais amplo da Oceania. Bensa irá ressaltar ainda as dificuldades de justaposição de memórias marcadamente autônomas, de colonizadores e colonizados, em especial em um contexto em que não

\footnotetext{
${ }^{303}$ As constituições de 1946 (art.45) e 1958 (art.75) atribuem aos originários dos 'Territórios de Além Mar' (1946) ou aos 'cidadãos da república que não possuem o estatuto civil de direito comum' (1958) um 'estatuto pessoal' que Ihes reconhece o direito de se administrarem segundo seus próprios costumes, em matéria de sucessão, matrimonial, e de ocupação territorial. Este é o caso de todos os Kanak da nova Caledônia, a menos que tenham renunciado a este estatuto (Bensa, 2006:200).
} 
há consenso entre as idéias de uns e de outros acerca do futuro político do país ${ }^{304}$. Muitos indivíduos Kanak chamam hoje ao Centro de "coquille vide,305, pelo fato de encarnar localmente uma matriz artística importada do Ocidente (Graille, 2001: 15).

\subsubsection{Localização do debate}

O segundo ponto que gostaria de discutir aqui concerne a existência de um fervoroso debate entre especialistas e estudiosos da população Kanak no que diz respeito às continuidades e fraturas entre um período anterior e um período atual em relação à cultura Kanak, assim como entre o que é caracterizado como da ordem da coutume em oposição ao que caracterizam como da ordem da 'política'. Este contraste se elabora em três grandes eixos.

Primeiramente, há autores, como Alban Bensa (1995, 2006) e Caroline Graille (2001), que irão avançar o caráter propriamente político-independentista do movimento cultural, que teria carecido, para sua legitimidade, a elaboração prévia de um 'patrimônio' e 'identidade' Kanak unitários. Este 'patrimônio' haveria sido constituído através da seleção de traços e símbolos cuidadosamente escolhidos dentre um suposto 'passado tradicional comum', enquanto uma 'instrumentalização política da memória' (Graille, 2001: 3). Segundo Graille, a demanda por um 'reconhecimento cultural' se fundamentou em representações ocidentais modernas ancoradas na noção do 'bom selvagem' pervertido pela civilização e o progresso, ao proporem uma visão nostálgica e idealizada do passado pré-colonial. Entretanto, ainda segundo Graille, o intuito não consistia em um retorno às suas antigas formas de vida, mas a constituição de um 'nós' Kanak globalizante em contraste com 'outros' não-Kanak, tendo como base um passado comum idealizado. Ou seja, segundo tal abordagem as demandas por reconhecimento e valorização cultural operados desde os anos 70 consistiriam somente e tão-somente um instrumento identitário a serviço do político, ao 'encarnar' uma memória comum e um pertencimento coletivo a um mesmo povo, para a legitimação de um 'teto' político com vistas à independência (Graille, 2001). Nesse contexto, Graille irá distinguir dois períodos ao analisar os contextos políticos nos quais aparece, e então se afirma uma noção de patrimônio Kanak. O primeiro, politizado e militante, de 1970 a 1988, e o outro, pacifista e quase-consensual, a partir da assinatura dos Acordos de Matignon, em 1988. Chamo a atenção para este partage temporal pois, em minha

\footnotetext{
${ }^{304}$ Bensa cita um diálogo durante uma reunião entre os diversos responsáveis pelo planejamento do Centro, em que o representante do Ministério francês afirma: "em optant pour la création d'un fonds d'art océanien, votre image va s'inscrire dans le dispositif mondial de la création artistique', ao que o representante institucional Kanak responde: "nous éprouvons quelque gene à nous trouver ainsi placés sous les feux de la rampe. Notre société releve moins du spetacle que du partage; car l'essentiel de notre culture reste de l'ordre de l'immatériel, de l'insaisissable. Il faut donc équilibrer cette mise en vitrine par des projets plus patrimoniaux et documentaires qui, dans la bibliothèques par exemple, compenserons les risques de réification muséographique " (Bensa, 2006 :203). Ou seja, o verdadeiro 'patrimônio', imaterial segundo o representante Kanak, não é passível de 'exposição' museal, mas de projetos 'patrimoniais' e de 'documentação'. Deverei discutir este ponto adiante.

305 'Concha vazia'.
} 
própria análise, tais períodos serão também contrastados, mas por razões diferentes das daquela autora. Desse modo, autores como Bensa e Graille vieram contribuir para a teoria da 'invenção cultural' enquanto parte de um engajamento político em condições contemporâneas (Hobsbawm \& Ranger,1984).

Vale ressaltar ainda as distinções entre os dois principais estudiosos da 'civilização Kanak': Maurice Leenhardt e Alban Bensa. Enquanto este último qualificou o trabalho de Leenhardt como uma 'teologia' e uma 'etnolingüística primitiva' (Bensa, 1995: 242), Bensa, ao realizar descrições complexas da tradição oral e das organizações sociais Kanak irá, contudo, descrever práticas culturais segundo uma e uma só categoria de 'filosofia política'. Segundo este autor, "les kanak agissent selon des stratégies, comme tout le monde, ou, en tout cas, comme nous....Le Kanak qui prepare um ressemblement coutumier joue un jeu tout à fait analogue à ceux que nous jouons dans le champ universitaire, à l'occasion, par exemple, d'une eléction" (ibid: 259). Qualificada como uma 'antropologia do discurso' (ibid: 244), sua abordagem será diametralmente oposta àquela de Leenhardt, para quem os Kanak, segundo palavras de Bensa, "avaient avec le texte un rapport sans distance, immédiat, par une confusion de la parole, de l'action et de l'être" (ibid: 259) ${ }^{306}$.

Alban Bensa, alinhado à abordagem sociológica de Pierre Bourdieu, concebe o 'político' como categoria universal, segundo a visão de que os Kanak agiriam como indivíduos modernos, em que enunciados e discursos, inclusive no âmbito dos gêneros próprios à sua tradição oral, foram vistos como produções de ordem individual e subjetiva pautadas por estratégias com vistas à 'maximização de valores'.

Se uma parte dos dados sobre os quais se apoiou esta pesquisa pautou-se em obras daqueles autores alinhados à abordagem da 'invenção cultural', deverei debater e confrontar tais perspectivas na análise que segue, ao descrever e analisar o Festival Melanésia 2000 e a elaboração do 'mito' de Téa Kanaké, com base nas caracterizações a respeito dos gêneros, formas, conteúdos e modalidades de relação implicadas em sua tradição oral.

Volto rapidamente aqui às outras configurações que assumem aquele debate. Assim, uma segunda abordagem irá privilegiar e evidenciar os esforços voltados à valorização cultural e de reconhecimento e inclusão sociais da população Kanak enquanto objetivos em si, e em que a demanda pela independência haveria se elaborado a posteriori (Missotte,1995).

\footnotetext{
${ }^{306}$ Pareceu-me que Leenhardt buscava avançar, através de suas ricas análises semânticas a respeito das variações contextuais de significados atribuídos á noção de parole e seus empregos na qualificação de formas de ação (através de exercícios de tradução que costumava realizar com seus 'informantes'; também de tradução da Bíblia), o aspecto 'performativo' de atos de fala, quando o termo 'no' ou 'ewëke' (em línguas Houaïlou e Lifou, respectivamente), são empregados no sentido de ação e de 'tradição' (i.e.:'La parole qui dure) (Do Kamo, 1937).
} 
E finalmente, uma terceira abordagem, como a adotada por Monnerie (2005), buscará demonstrar de que modo os atores Kanak hoje realizam uma distinção entre a 'política' e outros domínios da vida que eles colocariam em relevo no âmbito da reivindicação independentista: a culture e a coutume (a que chamam 'wado me weeng' na região norte da Grande Terra). Monnerie, ao chamar a atenção para a importância da consideração do tempo longo da história (não restrito somente aos últimos 40 anos) demonstra como parece haver ocorrido uma mudança recente de perspectiva pela parte dos Kanak. Segundo aquele autor, se um movimento político independentista deu origem a um movimento 'cultural', este último irá, em seguida, se colocar como distinto do político e mesmo reivindicar uma anterioridade em relação àquele (Monnerie, 2005:190) $)^{307}$. Isso porque, segundo Monnerie, as continuidades prevalecem sobre as rupturas nas declarações de seus interlocutores Kanak quanto às etapas que levaram à criação do movimento independentista ${ }^{308}$. Deste modo, em seus relatos, os interlocutores de Monnerie irão avançar as continuidades de uma luta política contra a dominação colonial que têm sua origem desde os primeiros tempos da colonização. No que diz respeito ao segundo movimento, que concerne o partage por eles avançado nas relações entre a esfera política e a coutume, e sua reelaboração contemporânea segundo a qual a luta pelo reconhecimento e valorização culturais seriam anteriores à reivindicação política, Monnerie irá, através da descrição e análise dos modos como cerimônias Kanak são transformadas para serem utilizadas nas relações com o mundo moderno e as forças da colonização, buscar dar conta das ações e significados a elas atribuídos pelos atores Kanak no momento atual. A simbólica da accueil de 'recepção' e inclusão do estrangeiro posado 'chefe', associada à demanda de reconhecimento da uma 'autoridade local' fundada em sua relação ancestral com a terra, será identificada por Monnerie nos modos atuais através dos quais os Kanak elaboram as relações entre colonizadores e representantes das Igrejas e população autóctone, em especial no âmbito de cerimônias Kanak empregadas em contextos expandidos e 'modernos'. Esta proposição deverá dialogar com a análise a ser avançada a respeito do evento

\footnotetext{
307 Esta perspectiva será de grande valia à análise que se segue, mas segundo um ponto de vista distinto daquele adotado pelo autor (especificamente, sua constatação acerca da anterioridade da 'política' sobre o 'político' - ou cultural), ainda que se apoiando em diversas de suas considerações. Pois se Monnerie fundamenta sua análise em atos, gestos e cerimônias, meu enfoque se restringe à caracterização relativas à formas, conteúdos e contextos de tradições orais, a partir de uma pesquisa bibliográfica.

${ }^{308}$ Tal movimento se esboçaria, segundo aquele autor, no percurso que se inicia com as primeiras revoltas que marcaram o século XIX e XX, que irão logo colocar em causa a presença colonial sob a forma de combates contra os estrangeiros que se apropriavam das melhores terras. Em seguida, teríamos as reflexões conduzidas pelos antigos combatentes da Segunda Guerra, que vão confrontar suas experiências na França metropolitana quanto às relações e idéias de "igualdade, liberdade e fraternidade" com sua situação de colonizados em seu próprio Território. Ainda neste percurso, Monnerie ressalta a passagem progressiva de um 'loyalisme', - dominante no período entre guerras e até meados dos anos 60-, em direção a uma reivindicação independentista, de início minoritária, e então majoritária, a partir de meados da década de 70. Nos anos 80, a aceleração final e a passagem a formas de ação mais e mais reativas seria resultado tanto do confronto à reações racistas em âmbito local quanto do engajamento militante de uma nova geração de jovens Kanak, influenciados pelo segundo movimento de demandas de descolonização no plano mundial.
} 
Melanésia 2000 e da 'criação' do mito de Tèa kanaké por Jean-Marie Tjibaou a ser realizada a seguir.

Após esta apresentação geral dos debates que informam as interpretações a respeito da constituição de uma 'identidade' e 'patrimônio' Kanak na Nova Caledônia, apresento o evento Melanésia 2000, e minha própria reflexão dos fatos.

\subsection{Melanésia 2000, 'Tèa Kanaké', Jean-Marie Tjibaou}

O evento 'Melanésia 2000' teve lugar em Nouméa, capital da Nova Caledônia, entre os dias 3 e 7 de setembro de 1975. Também chamado 'Primeiro Festival de Artes Melanésias da Nova Caledônia', o evento contou com a participação de mais de 2.000 autóctones vindos de diversas regiões da Grande Terra e das ilhas Loyalty ${ }^{309}$. Este festival tinha por objetivo cristalizar 'esperanças de uma população aspirando ao reconhecimento de sua existência e de sua cultura' (Journal de La Société des Océanistes, 1995: 1). Se, posteriormente, o Festival 'Melanésia 2000' foi caracterizado por seu interesse 'independentista', nenhuma referência nesse sentido encontra-se nos textos oficiais do evento. Sua proposta surgiu enquanto continuidade de medidas que já vinham sendo levadas a cabo por lideranças Kanak no sentido de promover o reconhecimento cultural Kanak pela população de origem não-melanésia do território ${ }^{310}$.

\footnotetext{
${ }^{309}$ A população total, no conjunto do evento, havendo sido estimada de 50.000 pessoas, entre Kanak e caledônios de diversas origens.

${ }^{310} \mathrm{Um}$ dos únicos registros oficiais existentes hoje a propósito do Festival consiste no panfleto de lançamento e divulgação da proposta, chamado 'Melanésia 2000: Festival d'expréssion mélanésienne' (Nouméa, maio de 1975). Devido à importância desse dossiê a respeito dos propósitos do evento, transcrevo-o aqui na íntegra:
}

\footnotetext{
"Pourquoi un festival mélanésien? La motivation profonde de ce festival est la foi en la possibilité d'instaurer un dialogue plus profond et plus suivi entre la culture européenne et la culture autochtone. En effet, la coloration et la saveur du 'Caillou' (termo coloquial para referir-se à Nova Caledônia : 'pedrinha') ne peuvent être donnés que par l'acceptation et une certaine assimilation de la culture originelle du pays. Je me permets en effet de faire le rêve qu'en l'an 2000, le profil culturel du Calédonien comportera aussi bien des élements de la culture européenne que de la culture mélanésienne. Mais pour que cette symbiose se réalise, un préalable est necéssaire. C'est la reconaissance (re-naître-avec) réciproque de deux cultures dans ce qu'elles ont de spécifique. Sans cette base, nous continuerons dos a dos notre dialogue de sourds.

Objectifs du festival d'expression mélanésienne:

1. 'Pour un dialogue nouveau :'Au-delà du festival mélanésien, la perspective qui se profile à l'horizon est celle d'une grande manifestation d'expression culturelle calédonienne pour 1980. Je la vois comme une imense fête de la culture, un festival où toutes les communautés de ce territoire viendraient offrir au public calédonien ces patrimoines divers qu'il doit reconnaître comme une richesse unique qu'il doit assumer avec fièrté. C'est en effet de cette rencontre que pourra naître une culture nouvelle calédonienne. 'Mais la realisation de ce projet exige une préparation. Le groupe mélanésien surtout, doit retrouver sa fièrté dans une personnalité culturelle que les circonstances historiques du peuplement l'ont amené à renier par fidélité a une échèlle de valeurs nouvelle qui aujourd'hui le laisse sur sa faim...

2. 'La culture Canaque aujourd'hui : 'le deuxième objectif du festival est d'une part de faire l'inventaire du 'matériel culturel' dont dispose actuellement la groupe mélanésien de Nouvelle-Calédonie et d'autre part, de définir la philosophie de l'art de vivre autochtone. En d'autres termes, cet inventaire doit répondre aux soucis suivants: 'quelle est aujourd'hui la situation de la culture canaque ? quelle est le contenu de ce message?'
} 
Jean-Marie Tjibaou ${ }^{311}$ foi uma figura fundamental na organização daquele evento. Uma das questões que guiou Jean-Marie Tjibaou, durante toda sua história como liderança cultural e política foi: "Comment, mais comment peut-on être Kanak dans le mode moderne? ${ }^{312}$.

Apesar da importância do evento, dentre seus traços encontram-se poucos documentos. Dentre eles, o panfleto 'Mélanesia 2000', a obra "Kanaké, Mélanésien de Nouvelle-Caledonie" (1976) produzida por Jean-Marie Tjibaou e Phillipe Missotte, assim como a edição de aniversário do Journal de La Société des Oceanistes (1995, ns 100101), dedicada aos 20 anos de aniversário do Festival. As considerações aqui avançadas apóiam-se no conjunto desses documentos.

3. Redécouvrir son idéntité, la condition de l'avenir : 'par son troisième objectif, le festival doit permettre au canaque de se projeter face à lui-même pour qu'il redécouvre l'idéntité qui est la sienne en 1975. D'autre part, le festival peut aider le canaque a reprendre confiance en lui-même et retrouver plus de dignité et de fièrté par rapport au patrimoine culturel qui fait partie de l'expérience et de la richesse de l'humanité. Cette prise de conscience est importante pour 'débloquer' psychologiquemente le mélanésien de son complexe d'inferiorité lié en grande partie à l'insignifience culturelle à laquele il s'est trouvé réduit (les slongans traditionneles étaient 'Canaques convertissez-vous! Civilisez-vous!). Une des conséquences a été la honte de sa personalité propre et le mépris de lui-même qu'il noie dans l'alcool. Au nom de la Foi et da la Civilisation le canaque a dû se renier. Il faut aujourd'hui, parce que les circonstances sont autres, qu'il affirme son droit d'être et d'exister en Nouvelle-Calédonie. 'Si je me permets d'ecrire cela, c'est parce que je suis convaincu que l'on a fait fausse route, et qu'aujourd'hui, la gloire de la "Foi » et de la « Civilisation » seraient d'inviter le canaque a venir au banquet des civilisations, non en médiant déculturé mais en homme libre. Et la participation canaque ne peut être que l'affirmation de sa personnalité à travers da possibilité RETROUVÉE de s'exprimer dans sa propre culture.

4. Le festival doit enfin permettre au groupe européen ainsi qu'aux minorités ethniques du Territoire, de voir, de connaître, et peut-être reconnaître la culture autochtone. C'est elle en effet, parce que autochtone, qui peut donner à la culture du pays la 'coloration' et la senteur du terroir calédonien. Mais pour exister pleinement, la culture, comme le monde canaque tout court, a fondamentelment besoin (c'est vital) de cette reconnaissance du monde ambiant. La non-reconnaissance qui crée la insignifiance ne peut amener qu'au suicide ou à la revolte. J'ai foi en la realisation de ce festival. Je constate en effet, que parmis les français calédoniens et métropolitains, il existe un courant de pensée qui reconnaît sincèrement que la promotion culturelle est une donnée essentielle d'un développment harmonieux du Territoire. Ce projet qui se veut porteur de l'espoir canaque s'inscrit dans une recherche réelle de dialogue. Je suis autant plus à l'aise pour l'écrire ce-là que je me trouve déjà engagé sur le chantier de la concertation culturelle. L'espoir que sous-tend ce projet est grand...Nous devons, ENSEMBLE, le réaliser pour l'avenir culturel de notre jeunesse et la santé de notre pays. Jean-Marie Tjibaou » (JSO, 1995 : 66-69, ênfases minhas).

${ }^{311}$ Sua biografia é característica da formação das lideranças autóctones na Oceania. Como grande parte das lideranças melanésias, polinésias e papous, Jean-Marie passou de uma infância em meio Kanak à vida política após um trânsito à sombra da Igreja católica. Tjibaou, entretanto, havendo abandonado o seminário, partiu à Metrópole para realizar seus estudos em sociologia e antropologia no Instituto Católico de Lyon e em seguida à École Pratique des Hautes Études em Paris. Tendo sido aluno de Roger Bastide e de Jean Guiart, este se interessa, desde o princípio, por uma 'antropologia aplicada', a partir da constatação da 'alienação e demissão' da população Kanak, convencido da necessidade de lançar as bases de uma ação "que permitisse ao grupo de se refazer uma imagem gratificante de si mesmo". De retorno à Nova Caledônia, Tjibaou põe imediatamente em prática suas reflexões enquanto estudante, vindo participar de diversas atividades associativas. Seu retorno se dá pelo viés da etnologia e por uma reflexão sobre o futuro da identidade autóctone na Nova Caledônia. Jean-Marie Tjibaou dará uma amplitude sem precedentes às iniciativas culturais e educativas melanésias voltadas a remediar o 'mal-estar' da população Kanak, até então operadas no âmbito das Igrejas. O festival 'Melanésia 2000' ocupou um lugar fundamental nas reflexões daquele líder político e 'animador cultural'. Segundo Alban Bensa, "em 15 anos suas ações e palavras revolucionaram completamente a imagem dos Kanak e da Nova Caledônia pelo mundo. Seu pensamento ao longo dos anos revela que a transposição da situação colonial da Nova Caledônia deviria de uma transformação de sua própria sociedade" (Bensa, 1996:16-21, ênfase minha).

${ }^{312}$ Citado por Aimé Cesaire em Tjibaou, 1996:310. 


\subsubsection{Festival Melanésia 2000}

A idéia de realização de um festival partiu da constatação e de uma reflexão continuada a respeito do nível alarmante de consumação de álcool em meio à população Kanak. $A$ hipótese do grupo ${ }^{313}$ que veio dar origem ao Comitê de organização de Melanesia 2000 era de que o alcoolismo consistia em uma 'porta de saída' para um conflito entre dois mundos contraditórios: um que Ihes negava a existência, e outro que lhes incentivava a 'deixarem de ser Kanak' ${ }^{314}$. Segundo seus organizadores, os Kanak enfrentavam um sentimento de ausência de dignidade, conseqüência da recusa de reconhecimento pelos outros setores da sociedade da Nova Caledônia de suas formas de vida e de seus valores e, portanto, de suas razões de viver. Segundo Tjibaou, "la nonreconnaissance qui crée l'insignifiance ne peut amener qu'au suicide ou à la revolte »(op.cit.). Assim, para aquele grupo, uma das condições da mudança pressupunha a restauração da dignidade, que deveria passar pelo reconhecimento, 'face a si mesmos', da riqueza e do valor da 'arte de viver melanésia'.

Assim, segundo Jean-Marie Tjibaou, cabia às diversas comunidades de origem autóctone o primeiro passo em direção aos outros habitantes. Tendo ficado restritas às reservas durante décadas de acantonamento, aquelas populações buscavam reafirmar sua posição enquanto primeiros ocupantes do Território através da demanda pelo reconhecimento à existência cultural a que foram extraídos devido aos fatos da colonização. A proposta daquela liderança era a necessidade de reconhecimento cultural Kanak para uma perspectiva histórica de longo termo para o conjunto do Território, englobando todos os seus contemporâneos em um 'reconhecimento cultural recíproco'. Através do evento, estimava-se que a constatação e reconhecimento da sua cultura pelos outros participantes poderia contribuir à valorização, pelos autóctones, de sua própria cultura, ao mesmo tempo em que colaboraria a confortar ou fazer emergir outras identidades culturais do Território pouco consistentes (imigrantes de Wallis e Futuna, das Ilhas Salomon, indonésios, polinésios, etc.).

Quando o plano do conteúdo do Festival foi discutido entre seus colaboradores ${ }^{315}$, as reflexões suscitaram fórmulas criativas de 'apresentação cultural', ao mesmo tempo em que questionavam o que era tido como conveniente ou mesmo cabível de ser exposto em/ao público. Após as decisões acerca de cada categoria ${ }^{316}$, decidiu-se que os 'vivaa'

\footnotetext{
${ }^{313}$ Formado pelo "Mouvement Féminin pour une Souriant Village Mélanésien"; o CeFA, Centro de Formação de Animadores, dirigido por Phillipe Missotte, Jean-Marie Tjibaou e René Richard; e a Direção Territorial da Juventude e dos Esportes, à qual o CeFA estava atachado.

${ }^{314}$ Segundo Missotte, 'obstáculo suficiente para que, se a ambição lhes viesse, esta fosse vã' (1995:12).

${ }^{315}$ Durante a assembléia geral do "Mouvement pour un souriant village mélanésien". Ver panfleto Vers Mélanésia 2000, em nota acima.

${ }^{316}$ Para a categoria 'tradição oral', foram sugeridos poemas, cantos e narrativas, acompanhados de meios de tradução 'plástica', como o 'teatro de sombras'. Para a categoria 'cantos e ritmos', decidiram pelos 'Aé $A e ́$ ', cantos tradicionais entoados pelos velhos acompanhados pela resposta da audiência; e também cantos
} 
estavam descartados das apresentações, visto que, segundo Missotte, a proposta não era nem a de uma 'apresentação' da coutume, nem sua representação (JSO,1995: 20).

Foi prevista uma 'organização participante', para que o evento cumprisse seus objetivos. Assim, 'animadores' foram contratados pelo Comitê organizador para realizarem o trabalho de difusão, cada um responsável por 'animar' um setor geográfico $^{317}$. Cada animador, através do emprego dos devidos sentiers coutumiers ${ }^{318}$, deveria contatar as respectivas 'autoridades costumeiras' de cada comunidade para Ihes explicar o sentido do evento, realizar o repertório de cantos e danças e dos trabalhos de artesanato, e preparar os mini-festivais regionais. Cada um daqueles animadores deveria indicar também de quem vinha essa 'parole'319, com a apresentação de uma prestação cerimonial e de um discurso adequado, que era realizado por ambas as partes. Aquele discurso consistia no pronunciamento de nomes de ancestrais e toponímicos concernindo os sentiers, produzidos de acordo com os interlocutores e voltado à reativação das alianças entre linhagens e clãs organizadoras do Festival e de cada localidade. Deveriam também explicar os objetivos do evento e descrever como estavam previstas as atividades. A partir deste terceiro ponto seria decidido o que deveria ser feito por cada um e o que cada um poderia aportar, definindo

de inspiração mais 'moderna' como a música de harmônica 'para dançar', e os cantos religiosos conhecidos como 'temperanças'.

${ }^{317}$ Mokkadem (2005) irá chamar a atenção para a importância da noção de 'interdependência' nas reflexões de Tjibaou, para os modos como este buscava articular relações com todo e qualquer setor ou agente (do Estado, das Igrejas, das associações) que pudesse de alguma forma contribuir à 'causa cultural Kanak', sem que os objetivos 'outros' desses 'outros' fossem colocados em causa. Podemos fazer aqui um paralelo com a afirmação de Bensa segundo a qual a "importância de um homem ou de um grupo varia em relação proporcional ao volume de suas relações que à suas riquezas em bens materiais ou mesmo à posição (ranque hierárquico primogênito/caçula) que detém localmente. Todas as estratégias de ascensão política começam pelo bom entretenimento de relações" (Bensa, 1995: 289). Nesse sentido Mokkadem relata a importância das mulheres da associação "Mouvement pour um souriant village mélanésien", já que são as mulheres que 'tradicionalmente' detém os 'caminhos de aliança' entre os clãs. Através do emprego daqueles caminhos, Tjibaou pôde potencializar as ramificações quando dos convites aos diversos clãs do Território para a participação no Festival,

${ }^{318}$ O sentier coutumier pode ser definido como a relação social de ligação entre clãs, através de 'trilhas' geográfica e toponimicamente demarcadas, em geral muito antigas e regularmente reativadas por ocasião de cerimônias. Esses 'fios' resultam de diversas alianças estabelecidas através de matrimônio, adoções ou doação de nomes às crianças, caminhos de trocas, etc. Seu conjunto resulta numa rede extremamente complexa, ligando todo o país, com indivíduos possuindo prerrogativas para sua utilização. O conhecimento de tais 'caminhos' e de seus marcadores toponímicos é altamente valorizado, e marcado nos discursos de 'accueil' quando de encontros entre clãs, em ocasiões cerimoniais como casamentos, funerais e de 'encerramento do luto'. Conhecer aqueles caminhos e seus 'marcadores' toponímicos significa, potencialmente, a possibilidade do estabelecimento de relações. Bensa \& Rivierre. Les Chemins de l'Alliance. 1983.

${ }^{319}$ A 'Parole', no em língua houaïlou e ewëke em Lifou é, segundo Leenhardt, ao mesmo tempo palavra, ação e pensamento. A ação que ela anuncia, o passado que ela celebra e a relação que ela ativa, tanto em relação aos ancestrais, quando não se sabe quando ela começou, quando dita os comportamentos, segundo a expressão '/a parole que dure', quanto em relação aos contratos de troca e de aliança. Segundo Leenhardt, 'la société canaque repose sur um ensemble de contrats passés, non points entre personnes mais entre générations. Dans les affaires de mariage, le femme accordé a un clan est un prêt. (assim como 'empréstimos' e dons e contra-dons de crianças para adoção). Elle doit faire retour au clan en la personne de sa fille ou de sa petite-fille. Cette personne qui va remplir une dette est 'la vie de la parole', qui unit ceuxci et maintient la société'. (Leenhatdt, M.1932: 212-236). 
assim a relação entre os 'marcos' da coutume e os elementos culturais do Festival ${ }^{320}$. Foram realizados oito mini-festivais regionais entre fevereiro e agosto de $1975^{321}$ e das 33 comunes de que contava a Nova Caledônia à época, 15 enviariam delegações. Muitos dos 'ausentes' viam a colaboração de europeus na realização do projeto com suspeição. A utilização de meios técnicos 'estrangeiros à sociedade Kanak tradicional' (palco, iluminação, equipamento sonoro, etc) também tendia a gerar dúvidas quanto à 'autenticidade' do evento, e muitos jovens consideraram o evento como uma 'prostituição da cultura'322.

No espaço do evento, correspondendo a seis hectares emprestados pela municipalidade na baía de Nouméa, foram construídas nove grandes casas (Grand cases) ${ }^{323}$, uma para cada aire culturelle ${ }^{324}$, assim como uma décima casa: a Grand Case $d u$ Sud, aquela dos organizadores, e que deveria acolher em primeiro lugar as delegações. A proposta era de que os grupos de cada região, os clãs e linhagens de cada aire culturelle pudessem se deslocar, parar, escutar, transitar por todos os espaços. O festival previa assim o deslocamento e uma noção de 'lugar', de uma maison para cada grupo ${ }^{325}$. Os atores-participantes tornavam-se, assim, 'acolhidos' de delegações anteriores, através do pronunciamento dos discursos cerimoniais de accueil à chegada dos membros de cada nova delegação. Tais discursos eram 'privados', produzidos face aos participantes em cada contexto específico, e anteriores ao início propriamente dito do Festival.

Assim, foram realizados 3 dias de evento 'fechados ao público', permitindo o encontro entre delegações e as cerimônias de trocas de dons e contra-dons, assim como o pronunciamento de discursos cerimoniais de accueil em que as relações e alianças entre os grupos ali representados eram reativados através dos vivaa. Segundo Missotte, 'estes discursos, como aqueles que haviam sido realizados para que se

\footnotetext{
${ }^{320}$ Cada canto, cada dança ou discurso 'tradicionais' pertencem à uma linhagem e, à cada geração, à uma pessoa que é sua depositária, de modo que nenhuma outra pessoa pode lhes apresentar ou realizar sem seu acordo formal. Assim, era preciso demandar a cada responsável para que os cantos, danças e discursos pudessem ser preparados, e também por quem poderiam ser eles realizados (JSO, 1995:57).

${ }^{321} \mathrm{Na}$ Illha de Lifou, na Ilha de Tiga, no Sul, no Norte, na ilha de Ouvéa, na llha de Mare, em Kone, e em Canala.

${ }^{322}$ A maior oposição ao evento veio da parte dos "foulards rouges" e do "Les groupes 1878", grupos de jovens militantes de esquerda de Nouméa, de origens tanto melanésia quanto Caledônia. O ponto de vista da equipe organizadora era de que o objetivo a que se propunham, um encontro de todos os grupos melanésios do Território, em escala sem precedentes, deveria ser cumprido de modo que todos os instrumentos e aparatos técnicos necessários para sua execução deveriam e seriam utilizados. Segundo aquele comitê, 'as ciências e as técnicas constituindo um patrimônio da humanidade, cabe ao grupo cultural de dominá-las e de colocá-las a seu serviço'.

${ }^{323}$ Outro fenômeno concerniu o fato de que, a partir do acantonamento, a construção dessas casas redondas tradicionais ou Grand Cases, imensas construções com mastros centrais, sem o emprego de pregos, haviam sido interditadas. Após o evento, centenas de casas do mesmo estilo foram reconstruídas por todo o território. Boulay, Roger. La Maison kanak. Marseille, 1990, Paris, ORSTOM, Nouméa, ADCK.

${ }^{324}$ Grands Cases: Norte (Arama, Bondé, Bélep, Hienghène); Oeste (Kone, Voh, Poya); Leste (Poindimié, Ponérihouen, Houaïlou); Centro (Canala, La Foa); Sul (Païta, La-Conception, Saint-Louis, ilha Ouen, Ilha de Pins); Lifou; Tiga; e Ouvéa.

${ }^{325}$ As maisons do Festival agrupavam mais de uma maison correspondentes a cada aire régionale
} 
chegasse até o Festival, integravam o evento à história das relações entre os clãs' (1995:80).

Assim, um dia foi consagrado ao artesanato ${ }^{326}$, um dia aos 'jogos tradicionais' ${ }^{327}$ e dois dias aos cantos e danças (organizados em duas categorias: 'tradição oral', e 'cantos e ritmos'), de todas as delegações. Durante duas noites, foi apresentado um 'jogo cênico' criado especialmente para o Festival, uma representação dramática dos eventos da colonização que tinha Téa Kanaké como personagem principal (a ser apresentado e debatido adiante).

Segundo Missotte, "as manifestações que constituíram a profundidade e a densidade do evento começaram e se desenvolveram nos locais de residência das delegações, nos promotores empregando os sentiers, nos mini-festivais. Ao ouvir os testemunhos dos atores, imagina-se o que foram esses gestos e discursos, uma tecelagem imensa e complexa de laços entre clãs e linhagens vindos de todo o Território, abraçando todo o país" (JSO, 1995: 80-81).

Posteriormente ao Festival, segundo Missotte, a revitalização do domínio das cerimônias, dos discursos e das narrativas foi imediatamente perceptível. Os discours sur le bois/vivaa afloraram para e pelos clãs e linhagens Kanak durante aqueles dias anteriores ao início do evento. O próprio Missotte cita que nunca havia visto nem ouvido essas peças da tradição oral. Até então a prática, que requer o fundo do conhecimento Kanak sobre a relação entre os clãs, havia sido dada por abandonada ou esquecida. "Le Festival a été l'occasion de les exposer et chacun a constaté, les jeunes notamment, la prégnance que leur proclamation exerçait sur leur propre groupe » $(1995: 99)^{328}$.

\footnotetext{
${ }^{326}$ Exposição de esculturas ligadas à casa: fleches faîtières: esculturas tradicionais do topo da casa da 'cheferia', no alto da alameda de cada espaço residencial, chambranles, esculturas que emolduram as portas daquelas casas, assim como as pirogues, grandes canoas de dois eixos, armas como os casse-têtes e sagaias, e instrumentos como colheres de taro e piquetes de plantio. Artigos de tecelagem e de cestaria. As pequenas produções destinadas aos turistas não foram descartadas, mas os grupos consultados insistiam na confecção de objetos de uso cotidiano, como moedas de concha, bambus gravados, e na utilização de materiais de confecção tradicionais, como cascas de árvore, ervas, colorantes 'naturais'.

${ }^{327}$ Tiro de fondra, tiro de sagaia, e apresentações de gestos cotidianos como o descasque do coco verde e seco, fabricação do bougna, alimento tradicional em que peixes ou aves, acompanhado de batatas-doce, carás, inhames ou bananas, é embalado em folhas de bananeira, coberto com leite de côco e cozido sobre pedras quentes.

${ }^{328}$ Efeitos do festival segundo Missotte (1995). Os quatro objetivos propostos pelo evento eram: 'um diálogo entre as etnias com a perspectiva de um festival interétnico cinco anos depois'; 'um inventário do 'material cultural' Kanak'; 'a redescoberta pela população Kanak de sua identidade, com o objetivo do restabelecimento de sua confiança e dignidade'; 'uma difusão da riqueza da cultura melanésia e seu reconhecimento pelos não-Kanak'. Dentre tais objetivos, Missotte não viu, em 1995, uma melhoria significativa naquele diálogo entre as etnias minoritárias do Território. O reconhecimento cultural Kanak pelas outras etnias pareceu haver se modificado, em especial no que diz respeito ao emprego dos gestos tradicionais de trocas de bens e discursos formalizados adaptados a novas circunstâncias, entre grupos kanak e não Kanak, em especial em ocasiões cerimoniais ou formais (ver também Monnerie 2005). A importância do evento Melanésia 2000 à época, segundo Missotte, escapou à maior parte dos europeus da Nova Caledônia e de seus aliados, que só reconheceram a posteriori e à 'boca pequena' o sucesso da
} 
Gostaria de discutir a partir deste ponto algumas questões que considero relevantes nesta análise no que diz respeito à constituição de uma 'identidade' e 'patrimônio' comuns Kanak a partir do contexto daquele Festival, relativos a todos os 28 grupos lingüísticos que habitam o Território. De que modo poderíamos considerar as ações que se desenvolveram no âmbito do evento Melanésia 2000 na constituição de um 'coletivo', uma 'unidade' Kanak?

Primeiramente, gostaria de chamar a atenção e discutir as propostas que foram apresentadas em seu panfleto de divulgação, em especial aos modos como são elaboradas e articuladas ali as noções de 'cultura', 'patrimônio' e 'identidade'. Ressalto que Jean-Marie Tjibaou utilizou ali uma série de termos, como 'europeu', 'autóctone', 'melanésio', 'caledônio' e 'Canaque,329, buscando estabelecer referências específicas para as quais buscarei aqui atentar.

O objetivo mais amplo apresentado por Tjibaou naquele panfleto foi 0 do estabelecimento de um diálogo continuado entre a cultura européia e a cultura autóctone, através do reconhecimento mútuo daquilo que cada uma teria de específico ${ }^{330}$. Tjibaou afirma que a partir daquele diálogo continuado e do reconhecimento mútuo ele vislumbrava, para os anos 80 , uma 'grande festa de expressão cultural caledoniana', uma 'nova cultura caledoniana' que deveria surgir através daquela simbiose, de modo que, segundo suas palavras, no ano 2000 '/e profil culturel du Calédonien comportera aussi bien des élements de la culture européenne que de la culture mélanésienne". Nesse sentido, apesar de o panfleto não fazer referência à luta pela independência, vemos aqui um esforço de constituição de um grupo cultural e de uma identidade propriamente 'caledoniana', comum a todos os habitantes do Território. Este grupo, contudo, só poderia surgir a partir do

iniciativa autóctone. A atitude dominante à época foi simplesmente a da não-participação nos atividades do Festival. Para os próprios Kanak, entretanto, foram percebidas mudanças significativas. Houve uma verdadeira revitalização de práticas ligadas à coutume, como a produção de discursos cerimoniais vivaa e a reativação de alianças entre clãs e linhagens que até então haviam permanecido distanciados. Os sentiers coutumiers foram reconfigurados em meio ao espaço urbano, adaptados aos ritmos do emprego do tempo marcados pela modernidade. No que diz respeito ao 'material cultural', um inventário das obras foi realizado por região e por clã. Durante o Festival e após, muitos constataram a vitalidade da produção de objetos cotidianos, da tecelagem, cestaria, redes de pesca, velas de barcos, pirogues, etc. Após o Festival foram construídas Grand Cases por todo o Território, raras nas décadas precedentes. Máscaras voltaram a ser produzidas, em especial pelos clãs do Norte, muito distintas das antigas máscaras 'tradicionais' Um florescimento de novas obras plásticas, musicais e coreográficas tem brotado regularmente, em torno da ADCK, Agence de Development de La Culture Kanak. Se em 1975 restavam alguns poucos escultores de fleches faîtières e chambranles, em 1995 contavam-se já mais de 70, a maior parte produzindo obras de feitura 'moderna'. Há também uma nova geração de pintores. Enfim, "Melanésia 2000 provou aos próprios Kanak que eles podiam viver segundo um mesmo objetivo por mais de um ano, e de que poderiam se reunir de maneira pacífica e em número de milhares" (JSO 1995: 88-100).

${ }^{329}$ Nota-se aqui o emprego da grafia utilizada à época pelos colonizadores, e que naquele contexto era ainda utilizado para referir-se de modo pejorativo à população de origem autóctone.

${ }^{330}$ Atente-se aqui para a noção 'culturalista' de cultura, em que 'culturas' seriam variações (entre traços) de um mesmo fenômeno humano. A partir do reconhecimento daquilo que cada uma teria de 'específico' seria possível a elaboração de uma simbiose, em que o 'caledônio' do ano 2000 apresentaria 'elementos' da cultura autóctone e melanésia. 
reconhecimento da cultura autóctone por seus próprios atores, pois essa 'cultura', segundo Tjibaou, seria a única que poderia prover a 'coloração' e o 'sabor' à Nova Caledônia, justamente porque 'autóctone'.

Entretanto, ainda segundo aquele panfleto, para que a constituição de um 'patrimônio comum caledoniano' fosse possível, seria preciso antes uma preparação, em especial por aqueles a que caracteriza como o 'grupo melanésio'. Tal preparação consistia em reencontrar sua fidelidade em uma 'personalidade cultural' própria. A partir deste ponto Tjibaou passa a empregar o termo 'Canaque' em referência àquela 'personalidade cultural', quando irá discutir o segundo objetivo do festival cujo título é "a cultura Canaque hoje”. Notável aqui é o fato de Tjibaou empregar o termo 'hoje'. Aquele promotor, ao haver realizado uma formação em antropologia na Metrópole e tendo se interessado por uma 'antropologia aplicada', irá buscar as bases teóricas para a formulação de uma proposta de promoção cultural que irá se pautar, fundamentalmente, pela questão da 'mudança'331, que pode ser discernida também através da avaliação de Aimé Cesaire quando este se refere à principal preocupação de Jean-Marie Tjibaou como sendo: 'comment peut-on être Kanak dans le monde moderne?'. Veremos adiante de que modo Tjibaou irá se inspirar, em sua reflexão a propósito da 'mudança', nas proposições e linhas de raciocínio já empregadas por Maurice Leenhardt em seus escritos das décadas de 30 e 40. Não acredito que Tjibaou houvesse formulado uma resposta às suas inquietações, mas sim uma intuição que, me parece, guiou os modos como o Festival foi planejado e então posto em prática.

Tjibaou realiza duas propostas voltadas ao 'grupo melanésio' para a redescoberta de sua 'identidade hoje'. A primeira delas consiste na realização de um 'inventário do material cultural', de que dispõe o 'grupo melanésio' da Nova Caledônia naquele ano de 1975, para identificar 'qual é a situação atual'. A segunda consiste na definição da 'arte de viver autóctone'. Este ponto é bastante interessante, pois ao mesmo tempo em que sugere que o grupo melanésio possui um 'material cultural' diversificado, que precisa ser inventariado, o fato de se 'projetar em face de si mesmo' para redescobrir sua identidade em 1975 sugere que será desse encontro que poderá surgir uma identidade Canaque, a partir da definição da 'arte de viver autóctone, ${ }^{332}$. E então ele se questiona:

\footnotetext{
${ }^{331}$ Segundo Bensa, "Seu pensamento (de Jean-Marie Tjibaou) ao longo dos anos revela que a transposição da situação colonial da Nova Caledônia deviria de uma transformação de sua própria sociedade" (Bensa, 1996:16-21, ênfase minha).

${ }^{332}$ Tjibaou irá tirar partido desta situação para enviar ao ocidente algumas de suas apreciações: 'o modo de vida europeu revela uma 'arte de vida'? Os Kanak não haveriam, nesse sentido, algo a dizer e a aportar? O pequeno não possui os meios de se endereçar ao grande, o insular ao continental, o 'local' ao 'universal'? Como podem os Kanak, produtos de uma história muito particular, contribuir ao enriquecimento cultural da humanidade? 'Si je peux toujour partager avec um non-kanak de ce pays ce que je possède de la culture française, il lui est impossible de partager avec moi la part d'universel contenue dans ma culture'. Tjibaou afirmou: 'notre identité est devant nous' (1996:25).
} 
'qual é o conteúdo desta mensagem?' ${ }^{333}$. Por fim, Tjibaou afirma que será a partir desta 'projeção face a si mesmo' que o Canaque irá retomar sua fidelidade por um 'patrimônio cultural que faz parte 'da experiência e da riqueza da humanidade'. Assim, ao reconhecerem-se em sua 'arte de viver autóctone comum', uma personalidade 'comum' seria redescoberta, assim como a constituição de um só patrimônio, soma do 'inventário do material cultural do grupo melanésio'.

Vemos como Tjibaou perfaz o movimento de um objetivo a outro segundo dois momentos. O primeiro seria a constituição de uma só personalidade cultural Canaque, que seria então reconhecida e valorizada por si mesma, para então poder estabelecer um diálogo e um reconhecimento mútuo face à 'cultura européia', para a constituição de uma 'cultura caledoniana', que deveria, no ano 2000, 'comportar elementos tanto da cultura européia quanto da cultura melanésia'.

Um dos pontos para o qual gostaria de chamar aqui a atenção é para o fato de a questão 'qual é o conteúdo desta mensagem' haver sido realizada no âmbito da redescoberta da 'identidade melanésia' projetada em face de si mesma, de modo que o 'conteúdo da mensagem' é voltado para os próprios melanésios. Parece-me aqui que os modos vislumbrados por Tjibaou para a constituição de uma identidade Canaque abrangente previa modalidades diferentes daquelas que se propunham a constituição de uma identidade 'caledoniana'. Esses dois momentos, de redescoberta e revalorização 'para si' precedentes à valorização para 'o outro' também vieram informar a própria organização do Festival, quando previu 3 dias de encontros entre as 'delegações' fechados ao público.

Enfim, como podemos avaliar a experiência daquele evento para seus participantes? Haveriam eles, naquele contexto, visto a si mesmos como pertencentes à um coletivo comum, perfazendo uma só 'identidade'?

Uma das problemáticas evidentes aqui concerne o fato de a população Kanak abarcar 28 grupos lingüísticos que estiveram durante décadas confinadas a reservas em coletivos definidos de forma aleatória, e tendo permanecido, durante todo aquele tempo, isoladas entre si. Este fato, além de sua cristianização por missionários protestantes e católicos desde meados do século XIX, produziu efetivamente drásticas transformações em suas formas de vida anteriores. Dentre tais transformações, já havia

\footnotetext{
${ }^{333}$ É interessante notar o uso empregado pelo próprio Tjibaou para a noção de mensagem em outro texto e contexto já citado, quando faz referência à coutume: ..."et 'fair la coutume' c'est cela; c'est un terme générique que les européens donnent à un ensemble de choses qu'ils ne comprennent pas et qui sont les manières d'être Kanak. Pour nous, chaque coutume a un nom précis. On fait telle chose à telle occasion pour dire tel message. Je ne sais pas ce que c'est, la coutume. Je connais des rites précis, qui ont des noms précis. La coutume, je l'ai dit, c'est le nom quelquefois méprisant que les non-Kanak donnent à ce qui font les Kanak. C'est pour eux une manière de dire qu'ils ne comprennent rien à cet ensemble des choses" (In: Bensa, A. e Wittersheim,1996 : 202). Deverei voltar a este ponto adiante.
} 
ressaltado a interrupção tanto do estabelecimento de relações de trocas matrimoniais em função dos chamados 'caminhos da aliança', como do deslocamento de famílias, linhagens e indivíduos e suas reformulações identitárias através da prática do accueil. Naepels sublinhou também uma transformação na sistemática de transmissão de conhecimentos, em que os primeiros conhecimentos que pareceram ter sido esquecidos foram as relações de aliança entre linhagens e clãs para além do seu próprio, assim como a transmissão parcial e variável de um grupo a outro a respeito de informações históricas que informam as origens e os deslocamentos de sua própria linhagem ou clã, tendo em vista a opção de 'desobstrução' da vida dos jovens por elementos exteriores ao mundo dos europeus. Efetivamente, uma parte considerável da população Kanak acreditava que era preciso abandonar um modo de vida por outro, e apagar o passado e a memória quanto aos conhecimentos e práticas 'tradicionais'. Sublinho ainda aqui a afirmação de Missotte segundo a qual anteriormente ao Festival este nunca havia visto nem ouvido as peças da tradição oral que são os discursos vivaa ou discours sur le bois. Segundo aquele autor, até então a prática, que põe em ação o fundo do conhecimento Kanak sobre a relação entre os clãs, havia sido dada por abandonada ou esquecida.

Ao mesmo tempo, vimos de que o modo todo encontro entre indivíduos e grupos Kanak, mesmo que envolva poucas horas ou dias, requer sempre a troca de dons e contra dons e a produção de discursos que, primeiramente, descrevem as relações internas aos seus próprios coletivos, e então as relações implicadas entre os dois coletivos em interação, vindo assim a constituir um único coletivo naquele contexto, a partir da noção de accueil.

Neste sentido, meu ponto de vista é o de que o evento Melanésia 2000 consistiu efetivamente em uma situação ímpar, que não corresponde às formas através das quais 'tradicionalmente' eram estabelecidos contextos que vinham proporcionar encontros entre 'coletivos' distintos de modo a demandar a produção daquelas trocas de bens e discursos cerimoniais. Entretanto, considerando-se o longo tempo em que ficaram confinados às reservas, podemos pressupor que tais encontros foram, até 1946, relativamente impedidos de ocorrer, o que vinha silenciar certo gênero da tradição oral pela ausência do contexto e dos atores ou coletivos que vinham demandar seu emprego. Tendo em vista ser aquela a forma considerada adequada pelos atores Kanak para a 'entrada em relação' entre coletivos diferenciados de modo a constituir um só coletivo através do accueil, vemos como todas essas condições foram reunidas tanto nos modos como foram realizados os convites à participação das diversas comunidades no evento, como naqueles primeiros dias de evento 'fechados ao público'. Quando Misssotte relata, a respeito dos discursos e trocas cerimoniais, que "le Festival a été l'occasion de les exposer et chacun a constaté, les jeunes notamment, la prégnance que leur proclamation exerçait sur leur propre groupe » (1995: 99), parece- 
me que os próprios melanésios, pelo fato haverem vivido separados durante tanto tempo, havendo de certo modo interrompido as visitas, encontros e trocas tão recorrentes anteriormente à colonização, desconheciam ou haviam perdido a referência quanto ao compartilhamento de práticas discursivas e expressivas na escala tão ampla quanto a de 28 grupos lingüísticos que perfazem o país. Daí que, parece-me, nem os próprios Kanak davam-se conta, até aquele instante, de efetivamente compartilharem não somente uma prática expressiva no âmbito de todos os grupos, mas de atribuírem grande relevância a tal prática de reativamento de relações históricas entre linhagens e clãs. E, ainda, de perceberem o compartilhamento de uma (suposta) memória comum do sofrimento e constrangimento impostos pela dominação colonial.

Se nessa pesquisa meu interesse pela contextual construção e desconstrução de 'coletivos' Kanak pautou-se nas caracterizações a respeito das formas e conteúdos de sua tradição oral, gostaria aqui de abrir uma brecha voltada à reflexão sobre as articulações entre memória(s) e constituição de identidade(s), importante para a análise que segue. Segundo Howard ${ }^{334}$, dois elementos são preponderantes na constituição da identidade coletiva: a língua e a história compartilhada: «Individuals are alike if they share a common history, if they are "people who have the same story" " (Howard, 1990 : 263). Vimos como um dos elementos que vem efetivamente distinguir as populações autóctones da Nova Caledônia é justamente a variedade de línguas faladas. No entanto, desde a colonização, a população passou a compartilhar uma só língua, justamente aquela do colonizador, o francês ${ }^{335}$. No que concerne à história, Joël Candau ressaltou que o compartilhamento de memórias dolorosas e trágicas durante longos períodos vêm reunir indivíduos em torno de um passado doloroso. "L'identité historisée se construit pour une bonne part en s'appuyant sur la mémoire des tragédies collectives ", (Candau, 1998 : 147). Entretanto, este compartilhamento é uma representação, construída sobre interpretações e reconstruções do passado elaboradas individualmente e 'coletivizadas' através de enunciados e narrativas, conformando uma percepção de 'memória coletiva' de uma parcela da história ${ }^{336}$ que é virtualmente

\footnotetext{
${ }^{334}$ Citado em Bilhaut, A-G (2007: 191-192).

${ }^{335}$ Os autores remetem, contudo, à especificidade desse 'francês Kanak', que, suponho, deva variar de uma região lingüística à outra.

${ }^{336} \mathrm{O}$ quanto $\mathrm{o}$ afastamento e as diferenças entre trajetórias históricas de grupos não vêm produzir distintas memórias do passado e, portanto, de potencialidades de construção de futuros também distantes entre si, descontínuos? Contudo, a reunião dos diversos coletivos Kanak, voltada efetivamente para a 'remediação' de um sentimento proveniente desta história dolorosa comum poderia, nesse ponto, reuni-los em um só coletivo, e naquele dado contexto.

Já vimos no âmbito de discussões a respeito da definição de 'comunidades' próprias ao 'patrimônio imaterial': "it was agreed that a sense of belonging together, or a sense of identity based on ICH (intangible cultural heritage) should be included in the definition of community" (2006:9). Assim, naquele documento 'comunidades' foram definidas como: "networks of people whose sense of identity or connectedness emerges from a shared historical relationship that is rooted in the practice and transmission of, or engagement with, their intangible cultural heritage".

Assim, um contexto 'inovador' que vêm reunir grupos que possuem histórias distintas, mas a percepção de 'uma história' dolorosa compartilhada pode se tornar a ocasião para a constatação do compartilhamento de
} 
articulada $^{337}$. (Veremos adiante a efetiva 'coletivização', e proliferação, de uma representação da história, na encenação de Tèa Kanaké).

Aqui gostaria de retomar este debate segundo a abordagem adotada pela linha de pesquisas de arte verbal, que considera a expressão discursiva enquanto forma de ação social. Uma de suas orientações fundamentais consiste na concepção de que a percepção de continuidade cultural está profundamente imbricada a dinâmicas expressivas próprias, especialmente à prática expressiva e discursiva. Neste sentido, tal abordagem atenta especialmente para a relação entre as formas expressivas e a percepção dos atores quanto à manutenção de tais formas. Isso não significa que as mensagens veiculadas sejam irrelevantes, mas que, para além dos elementos cognitivos e semânticos veiculados nos discursos, como valores, crenças, representações e significados, seria preciso atentar minuciosamente para as formas, contextos e modos de transmissão de significados culturais através de práticas expressivas. Se os conteúdos variam de uma execução à outra, a atenção voltada à manutenção de formas expressivas seria fiadora de um sentimento de continuidade cultural, ao relacionar práticas expressivas passadas a práticas atuais, antigas interações a novas, contextos passados a contextos presentes ${ }^{338}$.

Esta abordagem, ao propor que a atenção deva voltar-se antes às práticas expressivas e discursivas que aos conteúdos transmitidos através de tais formas, se afastou de uma noção de cultura enquanto entidade dinâmica cujas fronteiras seriam delimitadas por 'traços diacríticos', que informariam identidades 'étnicas'. Sua atenção se fixa, antes, nos modos como os próprios atores estabelecem relações entre contextos passados e contextos presentes, sugerindo uma noção de identidade fundada em uma percepção de continuidade de formas expressivas e discursivas através do tempo, ao evidenciar os modos como sujeitos indígenas estabelecem relações entre suas formas de expressão e aquelas de seus ancestrais, e não em contraposição a 'outros' ou à 'outras' identidades, pautada nas diferenças entre traços diacríticos que estabeleceriam seus limites.

uma prática expressiva (discursos vivaa e o accueil) esta, efetivamente 'historicamente' compartilhada por todos os grupos, mas jamais percebida como tal em um nível 'cosmopolita'.

${ }^{337}$ Friedman (1992) em um artigo cujo título é "The past in the future: history and the politics of identity» mostrou de que forma a auto-identificação (formação de identidade) e a construção do passado se relacionam. Para tanto, ele se apóia nos exemplos grego e havaiano. No primeiro caso o autor demonstra como o passado, tal como é definido pelo 'outro' (pelo mundo romano) é utilizado para a construção de uma identidade cultural no presente. No caso havaiano, o passado definido do exterior (pelo Ocidente) é negado, e é a 'identidade cultural' no presente que vem servir à construção do passado. A história toma assim um caráter de disputa: sua apropriação representa uma 'tomada de lugar' no tempo e no espaço, de si mesmo e de sua relação aos outros. O exemplo havaiano dialoga potencialmente com o caso aqui exposto, como veremos adiante.

338 "...l am able to posit that processes of cultural transmission involve the replication of discoursive forms over time. The practice of passing a set of discourse forms from one generation to the next promotes feelings of cultural continuity, even though the messages incoded in those forms may change over time (...) the continuity of forms promotes feelings of persistance..." (Graham,1995:6). 
Poderíamos aqui situar um contraste entre esta abordagem e aquela avançada por Graille (2001), a respeito da anterioridade de constituição de um patrimônio através "da seleção de traços e símbolos cuidadosamente escolhidos de um suposto 'passado tradicional comum'”, que iria embasar a constituição, à posteriori, de "uma identidade unitária enquanto 'teto político' através de uma 'instrumentalização da memória'". Pareceu-me justamente o contrário: que a partir de um passado 'não tradicional' comum (o passado doloroso da colonização), pôde-se constatar o compartilhamento de formas expressivas e discursivas que informam aos indivíduos uma percepção de 'continuidade' cultural (além de, através de seu conteúdo, reuní-los via accuei), vindo produzir, naquele contexto, uma 'identidade comum' Kanak.

Graille sugere ainda que o intuito desta seleção específica de traços e símbolos de um passado comum não tinha por objetivo um retorno às suas antigas formas de vida, mas a constituição de um 'nós' Kanak globalizante em contraste com 'outros' não Kanak. Considerando os modos como Tjibaou avançou ao propor cada um dos objetivos do Festival, parece-me que a constituição de uma identidade comum Kanak, deveria passar, antes, pela compreensão a respeito de qual era o 'conteúdo daquela mensagem', ou seja, as 'maneiras de ser' Kanak no mundo. Alhures, Tjibaou afirmou:..."et 'fair la coutume' c'est cela; c'est un terme générique que les européens donnent à un ensemble de choses qu'ils ne comprennent pas et qui sont les manières d'être Kanak. Pour nous, chaque coutume a un nom précis. On fait telle chose à telle occasion pour dire tel message ${ }^{339}$. Je ne sais pas ce que c'est, la coutume. Je connais des rites précis, qui ont des noms précis. La coutume, je l'ai dit, c'est le nom quelquefois méprisant que les non-Kanak donnent à ce qui font les Kanak. C'est pour eux une manière de dire qu'ils ne comprennent rien à cet ensemble des choses" (In: Bensa, A. e Wittersheim,1996 : 202). A meu ver, foi através das maneiras de ser Kanak, da troca de discursos e de bens cerimoniais, acionados porque efetivamente necessários ao estabelecimento de relações entre maisons, clãs e linhagens, que pôde se constituir uma identidade Kanak não a partir do contraste de traços diacríticos com 'outros' não Kanak (que poderia concernir o segundo momento, ou o segundo objetivo proposto por Tjibaou, de reconhecimento da cultura melanésia e da cultura européia naquilo que elas teriam de 'específico'), mas a partir de sua percepção a respeito de manutenção de formas expressivas ao longo do tempo, que vêm prover um sentimento de continuidade cultural com as gerações ascendentes e a reativação das relações estabelecidas entre 'coletivos' no âmbito daquelas gerações, ainda que haja transformações em seus contextos e conteúdos, adequados à uma nova situação.

No que diz respeito à constituição de um patrimônio Kanak, os diversos grupos ali reunidos puderam realizar um 'inventário do material cultural', ao apreciarem a

${ }^{339}$ Em que, segundo Leenhardt, 'dizer' é 'fazer'. 
variedade de danças e cantos aportados pelos clãs das diversas comunidades, assim como o compartilhamento da produção de objetos da vida cotidiana. Contudo, considero que a 'constituição de um patrimônio' foi efetivamente o da percepção a respeito de um patrimônio propriamente 'imaterial', ou seja, do compartilhamento à escala de todos os grupos do Território de formas próprias de emprego de recursos expressivos e discursivos, assim como das concepções que o fundamentam. Dentre tais concepções, ressalto a importância da noção política de 'anterioridade' que informa o accueil. Isso porque, como vimos, foi através de convites 'personalizados' entre o clã de Jean-Marie Tjibaou e os diversos grupos do Território, a partir da reativação de relações de aliança estabelecidas em tempos idos, que aqueles grupos aceitaram (os que aceitaram) participar do Festival. E ainda, era a este clã que eram oferecidos os primeiros discursos cerimoniais e trocas de bens, para em seguida realizarem discursos vivaa entre cada um dos grupos que vinham se somar ao conjunto da população participando do evento. No que diz respeito à percepção dos atores quanto ao seu 'patrimônio' ser da ordem do propriamente 'imaterial', cito a declaração do representante Kanak responsável pelo planejamento a respeito das funções do Centro Cultural Tjibaou: "nous éprouvons quelque gêne à nous trouver ainsi placés sous les feux de la rampe. Notre société relève moins du spetacle que du partage; car l'essentiel de notre culture reste de l'ordre de l'immatériel, de l'insaisissable. Il faut donc équilibrer cette mise en vitrine par des projets plus patrimoniaux et documentaires qui, dans la bibliothèques par exemple, compenserons les risques de réification muséographique " (Bensa, 2006 :203). Me parece, deste fato, que as reflexões propostas por Tjibaou ainda na década de 70 'proliferaram'. Irei debater este ponto adiante.

Outro elemento relevante a este debate consiste na 'criação' do personagem mítico de Tèa Kanaké por Jean-Marie Tjibaou encenado durante o Festival, e apresentado em sua obra "Kanaké, melanésien de Nouvelle Calédonie" (Tjibaou e Missotte, 1976), os quais discuto adiante.

\subsubsection{A encenação dramática de Téa Kanaké}

O jogo cênico de Tèa Kanaké tinha por objetivo condensar alguns sentidos do Festival, segundo a proposta de seus organizadores. Organizado em três 'quadros' principais que deveriam ser articulados em um todo coerente, farei referência a cada um deles nesta exposição. Seus autores foram Jean-Marie Tjibaou e Georges Dobbelaère, diretor de teatro vindo da Metrópole especialmente para o trabalho de composição da 'peça', a pedido de Tjibaou. O argumento principal da encenação era a exposição da situação de 'redução à insignificância' a que haviam sido relegados os autóctones devido aos fatos da colonização. Missotte, em sua exposição (JSO: 1995), atribuiu àquela encenação um caráter inovador à época, segundo a noção da Nova Caledônia como o 'país do 
não-dito,340. Isso porque a situação de 'insignificância' compartilhada por toda a população de origem melanésia não havia até, aquele momento, sido abertamente enunciada como tal. Segundo ele, 'la revélér explicitement pour la reconnaître etait déjà une innovation'. 'Plus qu'un spectacle, le jeu scénique s'est voulu une introduction à un nouveau regard sur l'autre et sur soi' (JSO, 1995 :89).

George Dobbelaére explica de que modo, a partir dos textos de Leenhardt e das lembranças de Matayo Doui Wetta ${ }^{341}$ ele e Jean-Marie construíram uma 'celebração da história da colonização, ${ }^{342}$. A finalidade era de fazer o espectador reviver um século e meio de história, de modo a concluir-se em uma tomada de consciência acerca das condições atuais e estabelecimento de uma nova forma de concepção das relações entre colonizadores e colonizados, com base em um 'reconhecimento recíproco real'.

O jogo cênico, a partir de sua elaboração em francês e a partir dos escritos de Leenhardt, foi então traduzido para a língua paîci e para todas as outras línguas da apresentação. O Comitê de organização havia decidido que membros de clãs de todo o território e das ilhas Loyalty deveriam participar do jogo cênico, - efetivamente, uma licença teatral, pois, segundo Missotte, é 'pouco provável, mesmo que as relações e contatos entre a Grande Terra e as Ilhas Loyalty fossem freqüentes, que um encontro 'cosmopolita' de tal monta houvesse algum dia tido lugar' (1995:90). Durante as apresentações cada um deveria responder em sua própria língua, traduzida em seguida para o francês. Cada grupo de atores deveria atuar em seu próprio papel, em certos casos os reais proprietários das danças representadas, mesmo que os nomes do clãs durante a apresentação fossem fictícios.

O primeiro quadro buscava apresentar cenas da vida no 'séjour paisible ${ }^{343}$. Oito clãs chamados respectivamente apresentavam dons quando de sua entrada em cena e então uma dança ou um jogo ${ }^{344}$. Quando estavam por fim todos reunidos, estes dançam em seus lugares ao som do batimento de bambus no solo. Começa então a celebração do encerramento do luto de um chefe importante. Os responsáveis pelo funeral (avi) que haviam permanecido junto ao corpo do morto durante todo o processo de dessecamento pela fumaça numa cena ao lado, retornam, suas cabeleiras formando

\footnotetext{
${ }^{340}$ Em referência a obra do historiador Barbançon, Louis-José 1992, "Les pays du non-dit. Regards sur La Nouvelle Calédonie".

${ }^{341}$ Pai da esposa de Jean-Marie Tjibaou.

342 George Dobbelaère escreveu em uma carta de fevereiro de 1975: "j'ai eu soin de noter constamment ces références a Leenhardt, (Notes d'ethnologie néo-calédonien 1935) car on m'aurait accusé d'inventer ces textes et ces ceremonies que je n'ai fait pourtant que collectionner ».(JSO,1995:90).

${ }^{343}$ Leenhardt utilizou diversas vezes essa expressão para designar a aldeia 'Canaque'.

${ }^{344}$ Segundo Missotte: "Tiaoué, chef Du groupe Charles, presentait um discours rithmé et une danse avec des balais d'herbes ; le clan de la poule était joué par des hommes de Canala autour de Jorédié ; le clan du requin par des hommes de Goro autour de Watrone Amabili; le clan du vent par des danseurs du Lössi (Lifou) dirigée par Cö dansait le bua ; le clan du lézard était constitué des danseurs de Hienghène autour d'Adrien Toubene; le clan du fruit Kuni, composée des danseurs de Luecilla faisait le jeu du Ti. "(JSO, $1995: 90)$.
} 
uma espécie de turbante por não haverem sido cortadas durante todo o período de luto. Então, o novo chefe (representado pelo coutumier Emmanuel Neouna), brandindo um machado de jade, apresenta um discurso cerimonial ${ }^{345}$. As mulheres intervêm então ao apresentarem uma dança, jedo, e então todos os participantes dançam juntos o boria, em torno do mastro central.

A primeira parte da encenação finaliza quando a dança é interrompida pela chegada dos franceses, simbolizada por um rufar de tambores. Soldados são então representados por trinta personagens mascarados que marcham, vestidos de uniformes brancos e portando o quepe colonial. Cada um carrega um pequeno fusil. Os soldados carregam três marionetes gigantes, representando respectivamente o missionário, o soldado e o comerciante ${ }^{346}$. O mal-entendido deste primeiro encontro se manifesta assim que os tambores silenciam. O capitão passa os comunicados. Os Kanak oferecem bens cerimoniais. O negociante quer fazer o comércio e o missionário evangelizar. Os três personagens evocam entre si as razões de sua presença: prover as 'benfeitorias' da civilização. O missionário reprova as intenções do comerciante. Segue uma cena de prédica, e em seguida as mulheres, até então de torso nu, são cobertas com a chamada 'robe mission'. A cena seguinte representa cenas dos trabalhos obrigatórios no âmbito do 'código do indigenato'. Os homens, vestidos de farrapos, são requeridos para a abertura de uma estrada. O personagem de Kanaké se revolta. Ele é preso e carregado, suspenso pelos pés e pulsos a um mastro, como uma presa no retorno de uma caçada ${ }^{347}$. O episódio seguinte, da prostituição de Kapo (representada por uma mulher), foi inspirada em múltiplos casos de comércio sexual imposto no contexto dos trabalhos forçados, tanto pela parte de colonos como por funcionários da República. O mercador aparece então vendendo aos trabalhadores Kanak objetos inúteis e mesmo quebrados, e enfim o álcool.

A terceira e última parte da encenação busca traçar o perfil de uma perspectiva de futuro. Cada um dos três personagens, o missionário, o comerciante e o soldado vêm aportar um inhame como dom cerimonial à 'cultura canaque', agora reconhecida.

Segundo Missotte: 'ce troisième tableau était le plus difficile à traiter, d'autant qu'il venait après deux séquénces particulièrment fortes et qu'il s'agissait d'une proposition, dépendant de l'attitude de chacun. Plus engagé, puisqu'il offre une solution d'avenir

\footnotetext{
${ }^{345}$ Mokkadem (2005:141) afirma que aquele discurso, em língua paîci, foi efetivamente um jèmà, revelando ao público histórias de clãs e de 'sub-clãs'. Ainda segundo aquele autor, a morte prematura daquele coutumier foi interpretada por muitos como uma 'sanção totêmica'.

${ }^{346}$ As marionetes foram realizadas na Metrópole. O comitê havia recomendado ao realizador 'moderação' no que concerne o marionete do missionário. Enquanto o soldado e o comerciante são representados de forma 'ridícula', a aparência do missionário era 'mórbida' (Missote, 1995:91).

${ }^{347}$ Esta cena evoca os numerosos movimentos de ressurreição anteriores a 1917. O comportamento de Kanaké evoca revoltas de chefes que foram presos por negarem o fornecimento de homens e mulheres para os trabalhos forçados, em geral em benefício de colonos.
} 
tolérant et pacifique, il est apparu cependant à certains moins convaincant que le reste » (Missotte, $1995: 92)^{348}$.

\subsubsection{O mito de Tèa Kanaké segundo a obra «Kanaké, Mélannésien de Nouvelle Calédonie"}

Para além da invocação do festival, ilustrado por diversas fotos, a obra "Kanaké, Mélanésien de Nouvelle-Calédonie" (1976) se pretende uma apresentação sintética e acessível dos 'grandes traços' da cultura Kanak. O livro foi escrito inteiramente em francês. Jean-Marie recorre aqui ao trabalho dos etnólogos e à sua experiência pessoal, que o permitem elaborar uma imagem do mundo Kanak a meio caminho entre os temas avançados por Maurice Leenhardt e as realidades Kanak contemporâneas ${ }^{349}$. Aquele texto possuiu, retrospectivamente, um caráter premonitório. "Kanakés50, vem antecipar "Kanaky", nome que os independentistas, em 1984, darão ao seu futuro país descolonizado.

Na primeira página daquela obra lemos:

"Kanaké est une des plus puissants archétypes du monde mélanésien. Il est l'ancêtre, le premier-né. Il est la flèche-faîtire, le mât central, le sanctuaire de la grand case. II est la parole qui fait exister les hommes" "Voici Tèa kanaké, voici l'histoire de celui qui est votre chef, il est fort est vous donnera la victoire, il est bon est aidera les infortunés, il est sage et connaît sa lignée " "Aujourd'hui Kanaké vient à vous, chargé d'ans et d'histoire, riche d'une experiénce culturelle unique. II réclame sa part de soleil... ${ }^{351}$ " $(1976: 6)^{352}$

\footnotetext{
348 Segundo Missotte; "même si l'orientation politique se discute, l'intention est, sans rien oublier, et se déclarant seuls responsables du Territoire, de donner l'occasion aux colonisateurs de changer d'attitude et de reconnaître les Canaques dans un partage spécifique aux deux civilisations. Cette position modérée critiqué par les extremistes, peu entendue par les Europeans, et celle d'une véritable négociation procédant d'une vue humaniste des conflits. Dans le concret il fut impossible de trouver des européens qui acceptèrent de venir jouer le partage offert par les Canaques. Deux seulement répondirent à l'appel. En revanche, la foule se précipita pour se joindre à la danse du boria qui, interrompu à la fin du premier tableau par l'arrivée des colonisateurs, reprenait pour la levée du deuil colonial' des Canaques, achevait le représentation dans une manifestation réelement populaire de toutes les comunautés canaques confondues" (Missotte, 1995 :92, ênfase minha). A noção de 'levée du deuil colonial' persiste hoje nas representações de interlocutores Kanak. A mesma expressão aparece em Monnerie (2005), no contexto da prática da accueil em situações 'modernas'.

${ }^{349}$ É difícil avaliar aqui o que é próprio a cada autor, Tjibaou ou Missotte. O capítulo 3 do livro tem por título 'Les áleas de la modernité'. O mémoire d'études realizado por Missotte em 1977, no collége coopératif também tinha este mesmo título. Jean-Marie Tjibaou também já havia refletido a respeito da mesma problemática, seu memoire em Lyon tendo por título L'insertion des populations autochtones dans le processus d'industralisation.

${ }^{350}$ Mokkadem, em sua obra (2005) se questiona: quem é Kanaké? "En fait Téé Kanaké, avec Dui Daulo et Bwae Béalo sont les noms des ancêtres fondateurs des lignées des deux grands ensembles matrimoniaux, Duio et Baï [Dui ma Bai], en pays paicî. Le contenu choréographique extrait la figure de Tée kanaké et, à partir de cette extration, cisèle et façonne une forme identitaire Kanak » (2005:144).

${ }^{351} \mathrm{O}$ 'mito' de Téa Kanaké, na obra de Tjibaou e Missotte (1976), encontra-se diluído entre os diversos capítulos, de modo que não cabe aqui sua restituição completa. Deverei discuti-lo com base nas descrições e interpretações provenientes da literatura antropológica e documental e com base em meus próprios
} 
"Les fondements de l'identité kanake énoncés ci-dessous sont l'expression des concepts tels qu'ils sont définis dans la société traditionnelle. Ils représentent les valeurs culturelles communes aux nombreuses tribus » (1976:7).

No final daquela primeira página lemos, em nota:

"Ce texte courant a été inspiré par des texts traditionnels mélanesiens, en particulier par les pages 54, 60, 112 et 114 de Guiart, Jean. ("Structure de La chefferie em Mélanésie Du Sud ", Paris, Institut d’Ethnologie, 1963), pour les pages 94 a 100 et 124 par des texts recueillis et traduits par Maurice Leenhardt ("Documents d'ethnologie néo-calédoniens ", Paris, Institut d'Ethnologie, 1931).

No que diz respeito à 'invenção' do mito de Téa Kanaké', Alban Bensa irá explicitar os eventos à época do festival Melanésia 2000 que deram origem àquele 'mito', em um relato que aparece na edição comemorativa dedicada ao aniversário de 20 anos do Festival, no Journal de la Société des Océanistes (JSO, 1995:128-131).

Bensa realiza uma contextualização de seu trabalho de pesquisa à época imediatamente anterior ao evento 'Melanésia 2000'. Naquele ano de 1974, o

argumentos, pautados nas caracterizações a respeito dos modos próprios à tradição oral Kanak, segundo a perspectiva da arte verbal.

${ }^{352}$ Lemos ainda, naquela mesma obra: « Ce Qui Peut Survivre de la Culture Kanak

Nous repondrons brutalement: Kanaké. Face à son environment et aux besoins fundamentaux, Kanaké garde une certaine stabilité dans sa manière de se situer dans l'existence. L'igname comme les taros se plantent, se recoltent et se consomment toujours. Face au besoin de sécurité, et de recherche de chaleur humaine, Kanaké sent de plus en plus un besoin de retour aux sources. La présence des esprits restent vivaces au coer de Kanaké. L'experiénce vécu de cette complicité passe par les contingences historiques. Mais elle ne doit jamais être identifié totalement aus institutions écrites, aux rites ou au matériel symbolique utilisé par une époque donné. En effet, ce qui est primordial et qui perdure au-delà des siècles, ce n'est pas cette expérience mais l'inspiration ou l'ethique qui fait surgir cette expérience dans l'histoire. Certes cette éthique s'affine au fil des années et reste teintée par la vie des hommes qui la retransmettent, mais c'est surtout l'inspiration qui la pérennise. En ce qui concerne kanaké et son devenir, il est clair que c'est l'éthique qui inspire la vie de son groupe qui doit survivre. En effet, c'est elle que fait que Kanaké sera toujours Kanaké. Vivre cette éthique, c'est cella qui doit permettre à Kanaké de faire des choix aussi bien dans la tradition que dans les immenses possibilité du monde moderne. Seule cette éthique clairement vue permettra a Kanaké de se créer une nouvelle culture ou un schéma de identification renouvelé. Car cette éthique qui se situe au coer de la culture Kanak s'identifie à l'inspiration culturelles de toutes les groupes humaines. C'est la reponse que chaque collectivité donne aux questions qui rongent les entrailles de l'humanité depuis toujours: qui-sommes nous ? d'où vennons nous ? Où allons nous ? Face à ces questions, il n'y a pas une hiérarchie des reponses et donc des degrés plus ou moins évolués d'humanité, il y a seulement des manières differents de repondre qui engendrent la diversité des cultures, ce qui permet aux hommes de pouvoir s'enrichir muttuelement parce que différents. La prise de conscience est lente mais elle progresse et elle est sans retour. L'art de vivre autochtone qui plonge ses racines au coer des ancêtres sort tout doucement au grand jour. C'est au niveau de l'éthique que la culture Kanak survivra et que Kanaké demeure et demeurera Kanaké, Mélanésien de Nouvelle Calédonie »(1976 :112). “Mais Kanaké doit, pour en conserver l'authenticité, faire un effort constant de prise de conscience quant à l'expression matérièlle et symbolique de son art de vivre. S'il ne prends pas garde, il risque de se retrouver depositaire de rites et de formules vidés de son contenu " (1976: 107-108). 
pesquisador havia trabalhado na compilação de narrativas, poesias e discursos de Emmanuel Nëunââ, também chamado Adië. Em meados de 1975, na região paîci, enquanto tinha lugar um dos mini festivais (foram oito mini festivais regionais que antecederam o grande Festival Melanésia 2000), Alban Bensa encontra Jean Marie Tjibaou e lhe faz um relato do trabalho de 'coleta' da tradição oral operada junto a Emmanuel no ano anterior. Bensa afirma: "Jean Marie Tjibaou aurait souhaité une traduction du 'discours sur le bois' mais j'estimais alors ne pas être encore assez performant pour la fournir rapidement ». E que : “Ces regrettables scrupules de jeune chercheur sont sans doute à l'origine de l'étrange début de l'ouvrage Kanaké : on y voit en effet, substitué aux véritables paroles cérémonielles d'Emmanuel Nëunââ, un récit mythique dû a Firmin Dogo Göröunââ353. Ce jêma raconté en petit comité est sans rapport aucun, par la forme ou par le fond, avec le 'discours sur le bois' clamé par Emmanuel. Tandis que le discours d'Emmanuel - en principe prononcé seulement lors des levées du deuil - présente de manière très imagée la liste de tous les clans et lignages de l'aire paîci, la narration de Dogo Göröunââ a pour principale ambition d'etablir, au moyen 'd'arguments myhtiques', l'ancienneté de son clan sur la côte ouest. Comme nous avons demontré ailleurs ${ }^{354}$, Jean-Marie Tjibaou s'est emparé du thème de ce mythe fondateur très local de Firmin Göröuna pour forger une sorte de mythe national, centré sur le personnage de Kanaké. Inventé pour l'occasion, cet “ archetype ${ }^{355}$ est ancré dans sa terre originelle et tourné vers l'avenir » (JSO : 1995 : 130).

Alhures, Bensa (1995: 290-310) comparou ainda o mito de Tèa Kanaké produzido especialmente para aquela ocasião ao Kalevala, epopéia monumental elaborada a partir da reconstrução de narrativas populares recolhidas por Elias Lonrot e contemporânea à derrocada da luta nacionalista finlandesa. Seu argumento é de que ambos, tanto a narrativa de Tèa Kanaké quanto o Kalevala, constituíam, em sua origem, uma coleção de tradições disparatas e memorizadas de maneira segmentária, que vêm então se condensar em uma obra única, voltada à manifestação da potência criativa do gênio cultural tanto finlandês como Kanak. "En Nouvelle Calédonie, des traditions orales également originalles ont pu, moyennant quelques adaptations judicieuses, soutenir um combat politique dans um moment historique comparable: celui de l'accession progressive d'un peuple à l'independence »(1995:291 ênfase minha) ${ }^{356}$.

\footnotetext{
${ }^{353}$ Uma reelaboração da narrativa publicada por Jean Guiart em sua obra Structure de La chefferie em Mélanésie Du Sud, Paris, Institut d'Ethnologie, 1963, p.143-148.

${ }^{354} \mathrm{O}$ autor se refere ao texto Bensa, Alban. "Vers Kanaky: tradition orale et idéologie nationaliste em Nouvelle Calédonie" In: Chhroniques Kanak, ethnies, vol. 10, n¹8-19. Paris, 1995, 290-306. Esse texto será discutido adiante.

355 "Kanaké est un des plus puissantes archétypes du monde mélanésien » (Tjibaou e Missotte, 1976 :5).

${ }^{356}$ Bensa também faz referência à filosofia política proposta do Festival Melanésia 2000 com base na afirmação de Tjibaou de que "...nous croyons em la possibilite d'echanges plus profondes et plus suivis entre la culture européenne et la culture canaque. Pour que cette rencontre se réalise un préalable est nécessaire : la reconnaissance d'une culture pour l'autre'. Esta afirmação contrasta com outra, do próprio
} 
Para fundamentar seu argumento, Bensa recorre a um esboço dos principais traços que marcam semelhanças, mas especialmente as diferenças entre as diversas populações de origem autóctone do Território: "pertencentes a um mesmo ramo de civilização instalado naquele arquipélago há aproximadamente quatro mil anos, são cultivadores de tubérculos, caçadores e pescadores em rio ou em mar; organizados em linhagens e clãs patrilineares unidos por laços de aliança, promovem importantes trocas cerimoniais. Como todos os melanésios, não estabelecem uma fronteira rígida entre os vivos e os mortos, respeitam os anciãos e representantes honoríficos de clãs e terroirs. Para além destes traços compartilhados, o povo Kanak é rico em diversidades: fragmenta-se em conjuntos políticos (cada um dotado de estruturas específicas mas aberto para outros por casamento ou iniciativas diplomáticas), e vinte oito regiões lingüísticas. Enfim, aos constrangimentos do sistema colonial, espoliações de terra, cristianização, urbanização progressiva, vêm se somar outras clivagens: reservas isoladas, comunidades confessionais distintas, modos de vida diferenciados, partidos políticos, etc." (1995:294).

A partir desta caracterização, Bensa irá esboçar como Jean-Marie Tjibaou constrói sua 'estratégia política' original. Isso porque Kanaké, segundo o autor, "nas raras narrativas recolhidas in situ nas quais aparece, não é um herói exaltando qualquer 'nação' que seja. Na Nova Caledônia, nenhuma narrativa, nenhum mito inscreve seu projeto em uma perspectiva geográfica e política que englobaria toda população da llha ou do arquipélago', 'todos os textos de tradição oral são atos de fala que concernem a história e as estratégias políticas de pequenos grupos, habitantes de certas aldeias. Cada narrativa, propriedade de um narrador preciso, de uma linhagem, de um clã, encontra sua significação prática em um contexto microlocal ${ }^{357 ", ~(1995: 295) . ~}$

Recorrendo à obra de Jean Guiart citada por Tjibaou, vemos que aquele mito de Tèa Kanaké se apóia em duas versões publicadas em língua paîci e em francês, recolhidas na região central da Grande Terra. As citações selecionadas recorrem, de forma abreviada, a passagens de um e de outro texto. Episódios muito ricos em toponímias, ou que evocam o incesto ou a guerra, são deixados de lado; a versão de Tjibaou, contudo, retém os temas da origem da terra, de rochas, montes e árvores primordiais de onde provêm os ancestrais que darão origem aos primeiros homens, ao percorrerem a ilha e espalharem seus descendentes em diferentes regiões. Segundo Bensa, todas

Bensa, quando afirma que será somente três anos após o Festival, em 1978, que "Jean Marie Tjibaou est conduit à radicaliser ses positions, et à revendiquer "L'independence Kanak" au nome de l'Union Calédonienne' (1995:300).

${ }^{357}$ Mas não poderíamos considerar simplesmente que 'cada narrativa encontra sua significação em um contexto', e que a ampliação do contexto também opera transformações na própria narrativa, que não requer necessariamente um 'microlocal'? É como se Bensa considerasse que a cultura Kanak só pode significar em seu pequeno contexto, 'microlocal'. Transposto para outros contextos, não é mais Kanak, é da ordem do indivíduo moderno movido por estratégias, que aliás, ele aponta como característica já do 'microlocal'. 
as variações desta narrativa, com variações locais importantes, tendem a justificar a antiguidade de ocupação dos fundadores em certo local. Sua interpretação é a de que "le leader nationaliste reprend l'argument pour le compte du peuple mélanésien tout entier: aux temps primordiaux les kanak habitaient déjà l'archipel et etaient coutumièrement organisées pour accueillir des groupes extérieurs au pays. L'ancienneté des fondateurs et l'ouverture des premiers occupants vers les étrangers : deux thèmes n'ayaint originellement qu'une signification locale mais auxquels Tjibaou entend donner une portée politique beaucoup plus génerale» (1995:297). O autor afirma ainda que "les kanak n'ont jamais fait de l'histoire de Kanaké une epopée national » (1995:299).

Avanço aqui a hipótese de que Jean-Marie Tjibaou pautou-se por razões 'políticas' de outra ordem, - não no sentido de uma política 'nacionalista' e 'independentista' que, como vimos, só será formulada explicitamente três anos depois, mas de relações políticas - ou culturais-, implicadas nas formas e conteúdos da própria tradição oral Kanak, em especial nos modos como gêneros apropriados vêm engajar 'coletivos' distintos em relação a cada contexto específico de relações. Isso porque, ao realizar uma 'invenção' inspirada na 'narrativa mítica' jémà de Dogo Göröuna (e personificada na figura de Kanaké) e em narrativas publicadas por Maurice Leenhardt (as quais discutirei adiante) em lugar do discurso 'sur le bois' de Emmanuel Nëunââ, Tjibaou não coloca em questão as posições hierárquicas ou a antiguidade de ocupação de tal ou tal grupo. Isso porque, como vimos, os discours sur le bois ou vivaa, discursos de caráter dialógico proferidos durante cerimônias de encontro entre diversos coletivos, impõem a nomeação de cada um dos grupos concernidos através de referência a tertres e ancestrais, estabelecendo descrições de cada uma das sociedades implicadas naquela interação contextual (conjuntos de membros de um dado espaço de co-residência em certos casos, ou da constituição de clãs e linhagens em outros) e sua hierarquia, em especial no que condiz aos contratos entre posições honoríficas relativas aos ranques definidos em um dado conjunto político.

Segundo apresentado no início deste capítulo, o gênero jémà, que foi caracterizado como aquele empregado por Tjibaou em seu 'mito', constitui-se em fragmentos sóciohistóricos ou míticos de que todos podem eventualmente fazer uso, assim como narrativas substantivas construídas para o pesquisador. Bensa e Rivierre afirmaram ainda que tais narrativas jémà poderiam se constituir em 'ficções' (havendo eles mesmos optado pela coleta e análise das narrativas cíhêdéé, que portariam sobre os deslocamentos e as relações históricas 'reais' entre coletivos, no passado e presente, 
transmitidas no âmbito familiar e através do recurso à imagens, toponímias e patronímicos, 'traduzidos' por seus interlocutores savants) ${ }^{358}$.

No que diz respeito ao potencial caráter 'fictício' do gênero narrativo jèmà, gostaria de propor aqui uma outra abordagem, adotada Richard Bauman em seus estudos sobre a prática da storytelling no Texas norte americano. Aquele autor irá propor uma via alternativa, pautada no ponto de vista experiencial do próprio 'nativo' quanto à relação entre 'eventos' e os modos como são eles apresentados na forma narrativa. Segundo aquele autor, "events are not the external raw materials out of which narratives are constructed, but rather the reverse: events are abstractions from narrative. It is the structures of signification in narrative that give coherence to events in our understanding" (1988:5). Ou seja, narrativas são 'atos de fala', que vêm trazer eventos à existência (de uma dada maneira) pelo fato mesmo desses haverem sido enunciados $^{359}$.

Já vimos como a coleta de narrativas cíhêdéé por Bensa e Rivierre vieram compor e embasar a análise tanto da obra 'Les Chemins de l'Alliance' (1982) como prover os dados para a produção de um atlas publicado em 1981 pela ORSTOM, que descreve o itinerário de dispersão de três clãs ${ }^{360}$. A este trabalho o próprio Bensa se referiu, alhures, como da ordem do 'artefato': "altérations produites artificiellement lors d'un examen de laboratoire" (1995:29). Isso porque o autor afirma que toda documentação que pôde reunir entre os anos de 1973 e 1978 se distingue pela preocupação de seus interlocutores Kanak de verem restituídas as terras das quais a colonização Ihes havia expulsado um século antes. Assim, a fervorosa atividade intelectual de seus interlocutores, decididos a pôr todo seu saber e habilidade retórica a serviço da restituição de seus direitos sobre a terra (Bensa, 1995:28-29) ${ }^{361}$. Veremos adiante que, apesar daqueles autores haverem trazido para o corpo de sua obra narrativas de seus interlocutores Kanak, não serão essas as peças da 'literatura oral' a que o projeto de valorização e salvaguarda da tradição oral Kanak, levado a cabo pelo Centro Cultural Tjibaou, vêm publicar na forma dos "Cahiers de litterature orale" (apesar de publicar narrativas 'compiladas' e publicadas por Maurice Leenhardt, assim como narrativas

\footnotetext{
358 "Le jèmà qui se donne d'emblée comme une parole politique et structurante centrée sur un groupe, peut apparaître paradoxalement comme un discours aussi volontariste et légiférant que quelque peu fictif. A l'inverse, le cihêdéé, présénté comme une fiction, prend en compte les relations entre plusieurs groupes, c'est à dire les fragilités et les tensions réelles du système social » (Bensa e Rivierre, 1982: 15).

${ }^{359}$ Relembro aqui ainda a noção de ficção segundo, Zumthor, quando analisou uma série temporal de textos medievais na forma escrita de 'frozen speeches' (Boyer, 1990:115) , e à medida de sua transmissão. Aquele estudioso chamou a atenção para o fato de que 'realidade' e 'ficção' são, no Ocidente e até o século XV, um único discurso da memória, descrevendo como a autoridade poética transcende aquela dos fatos (Becquelin, 1993:34).

360 "Références spatiales et organisation sociale dans le centre-nord de la Grand Terre et Itinéraires des clans Wéélèt, Garratu et Göièta (carte)" planche 18. Atlas de La Nouvelle-Calédonie et sés indépendences, Paris, Orstom.

${ }^{361}$ Remeto aqui ainda ao corpus caracterizado por Lévi-Strauss como 'clássico', "de que os próprios índios são autores ou iniciadores, (em que estes vêm), de modo mais ou menos direto, validar reivindicações econômicas, políticas ou territoriais" (1986:150).
} 
coletadas atualmente). Isso porque, a meu ver, aquelas narrativas, ao haverem se constituído também como recursos empregados por seus interlocutores savants para legitimarem suas demandas pela restituição da posse da terra, irão avançar clivagens entre coletivos Kanak, em especial pelo fato de se constituírem em narrativas cíhêdéé produzidas, tradicionalmente, em âmbito privado, com vistas à transmissão de eventos históricos internos à uma família ou linhagem (segundo seu ponto de vista) e também relativas à outras famílias com as quais estiveram em contato, mas que são adequadas àqueles contextos (ou, em novos contextos, à disputa pela posse da terra).

Relembro ainda a problemática concernente à proposta da ADRAF de restituição da posse da terra pautada em debates, que deveriam produzir consensos a respeito do reclamante, o suposto 'maître de La terre'. Tais debates põe em cena uma situação extremamente complexa, ao exigirem que versões diversas da tradição oral sejam elaboradas em uma 'história única'. Tais versões, pela sua característica de se ordenarem originalmente em referência a um certo coletivo em um dado contexto, enquanto "acúmulos de fragmentos disparatados, conservando cada qual a sua individualidade" (Lévi-Strauss, 1986:151, sobre o corpus barroco), são efetivamente impossibilitadas de serem organizadas em uma única história, consensual, multiplicando conflitos e debates ao requerem uma exigência de verdade factual de acordo com modalidades discursivas próprias ao Ocidente 'moderno'.

Assim, aquelas narrativas cihêdéé produzidas tendo em vista a demanda pela posse da terra não são adequadas a um contexto de 'valorização cultural' que demanda 'enunciados da tradição' que possam avançar um 'coletivo' coerente Kanak.

Retomo ainda a questão colocada por diversos pesquisadores, do fato de indivíduos buscarem, quando de entrevistas individuais, melhorar a posição de seu próprio grupo, assim como debater a posição de seu próprio clã quanto aos ranques que haviam sido avançados em âmbitos de produção discursiva ampliada em contextos próprios à sua tradição oral. Assim, a questão da verdade não é o ponto focal na produção de narrativas ou discursos que envolvem coletivos diversos em espaços de interação entre estes coletivos, mas sim a própria tecelagem ou reestabelecimento de relações de acordo com as formas expressivas consideradas adequadas.

Uma das perguntas que me coloco, então é: a quem é dirigida a obra 'Kanaké'?

Pois se por um lado temos uma apresentação dos princípios fundantes da 'identidade Kanak', poderíamos depreender deste fato que a obra foi escrita tendo em vista um público amplo, 'caledônio', em que as referências textuais ao personagem 'mítico' Kanaké serviriam mais como ilustrações secundárias, como 'citações' imagéticas. Contudo, Kanaké não aparece aqui como um personagem 'mítico' (tal qual aparece nas 
narrativas (tradicionais') meramente citado na obra, mas como uma nova versão pautada em um personagem histórico-mítico que através do emprego do 'nós' condensa uma 'única personalidade Kanak'. No trecho 'Ce qui peut survivre de la culture Kanak' (ver nota acima) pareceu-me que a reflexão voltou-se aos Kanak enquanto uma proposição de futuro 'moderno', pautada numa 'ética' ou 'inspiração' própria à 'tradição', ou à 'arte de viver melanésia': 'Vivre cette éthique, c'est cella qui doit permettre à Kanaké de faire des choix aussi bien dans la tradition que dans les immenses possibilités du monde moderne"(op.cit).

Retomo as caracterizações diferenciais entre cultura e 'cultura', empregadas aqui enquanto ferramenta analítica ${ }^{362}$. Segundo Carneiro da Cunha, enquanto cultura sem aspas seria aquela para a qual sempre estiveram voltados os antropólogos, e cujos aspectos analíticos seriam inconscientes para seus praticantes, "cultura" (com aspas) remeteria aos modos deliberados através dos quais grupos culturais 'enunciam' e, portanto, oficializam suas 'culturas,' a partir de um fundamento em 'identidades culturais', enquanto 'discurso político'.

Gostaria ainda de relembrar aqui a formação em antropologia de Tjibaou e uma de suas reflexões acerca da 'tradição': "Le retour à la tradition est un mythe; je m'efforce de le dire et de le répéter. C'est un 'mythe'. Aucun peuple ne l'a jamais vécu. La recherche d'identité, le modèle pour moi, il est devant soi, jamais en arrière. C'est une refformulation permanente » (Tjibaou, 1996 :185). E ainda : “on ne montre pas devant l'autre (le monde européen) les divergences des conflits internes à la société Kanak »363

Parece-me, assim, que naquela obra 'cultura' e cultura ${ }^{364}$ imbricam-se, ou melhor, que a 'cultura' enunciada enquanto discurso 'político' quer se fundar nos aspectos políticos próprios à cultura, primeiramente para si. Se Tjibaou realizou estudos em antropologia na Metrópole, autores consultados nesta pesquisa (Mokkadem, 2005; Bensa, 1995) ressaltam que seu objetivo não era o desenvolvimento de uma carreira acadêmica, mas

362 "Culture has to be understood as operating simultaneously at two levels. For the sake of the argument, let us call them a literal and a meta-level. Although the two are interconnected, it is difficult to ascribe 'literality' to one rather than to the other. Anyway, by 'literal' I mean what anthropologists up to some time ago used to call culture, something that, though dynamic and changeable, would inform values and actions. According to anthropologists, there is an internal organization to culture in that literal sense, an organization that will constrain and inflect changes. At another level, 'culture' as a whole is used diacritically to separate people, to discriminate in both the etymological and the current sense. This is 'culture' as political discourse. (...) I have argued elsewhere that at this meta-level too there is an organization, one that places specific 'cultures' in a mosaic of at once similar and dissimilar units: similar because they are comparable units of the same magnitude (other 'cultures') and dissimilar since it differences alone that allow for organization. Culture and 'culture' both are constrained by their respective organizations, and yet the two levels are not totally independent from each other". (Carneiro da cunha, 2002:8, ênfase minha).

${ }^{363}$ Reflexão de Tjibaou citada por Mokkadem, Hamid. 2005:64.

${ }^{364}$ Ressalto aqui a proposição de Viveiros de Castro, "intercultural relations or intracultural relations are in strict ontological continuity." (Viveiros de Castro, 2004:2). 
a aquisição, também através do distanciamento do 'mundo Kanak', de 'ferramentas de análise' que o permitissem trabalhar na remediação do 'mal-estar' daquela 'civilização'. Vimos também como um dos seus principais 'mestres' foi Roger Bastide através da proposta de uma 'antropologia aplicada' (à época, interessada pelas questões de 'aculturação'). Assim, Tjibaou articula, na obra Kanaké, dois discursos. Primeiramente, ao apresentar "les fondements de l'identité tels qu'ils sont définis dans la société traditionnelle ", vislumbramos um discurso de 'cultura' enquanto um modo deliberado de enunciar e oficializar sua 'cultura' a partir de um fundamento em uma 'identidade cultural', enquanto discurso 'político'. Há, no entanto, um outro aspecto, propriamente cultural, como veremos, que é a reiteração da 'presença dos espíritos', aquela que deverá inspirar uma ética que perdura para além das transformações históricas': "La présence des esprits restent vivaces au coer de Kanaké. L'experiénce vécu de cette complicité passe par les contingences historiques. Mais elle ne doit jamais être identifié totalement aus institutions écrites, aux rites ou au matériel symbolique utilisé par une époque donné. En effet, ce qui est primordial et qui perdure au-delà des siècles, ce n'est pas cette expérience mais l'inspiration ou l'ethique qui fait surgir cette expérience dans l'histoire. Certes cette éthique s'affine au fil des années et reste teintée par la vie des hommes qui la retransmettent, mais c'est surtout l'inspiration qui la pérennise " (op.cit).

Parece-me aqui que Tjibaou faz referência, quando afirma que a 'experiência vivida desta cumplicidade (a presença dos espíritos) passa por contingências históricas', exatamente à reelaboração constante a que estiveram sujeitas famílias, clãs e linhagens, segundo a prática tradicional do accueil, de modo que, a cada acolhida, os 'coletivos' tinham sua história modificada (assim como os seus ancestrais 'totêmicos', seus 'espíritos') ao serem incorporados à história dos antigos ocupantes. Tjibaou ainda afirma que : Mais elle ne doit jamais être identifié totalement aus institutions écrites (...) En effet, ce qui est primordial et qui perdure au-delà des siècles, ce n'est pas cette expérience mais l'inspiration ou l'ethique qui fait surgir cette expérience dans l'histoire ". Ou seja, para que a 'cultura Kanak' possa sobreviver no 'mundo moderno', a proposta de Tjibaou é de que a atenção de Kanaké deva voltar-se antes à inspiração ou à ética (que informam o accueil e as práticas expressivas e discursivas da coutume), e não à experiência histórica perenisada através do material escrito que, como vimos, permite que aquilo que não se enuncia em contextos de interação mediados pelas formas da tradição oral seja 'fixado', de modo a 'desconstruir' coletivos que, 'tradicionalmente', interessam-se antes por sua 'construção' para frente, e não por sua 'desconstrução' para trás ${ }^{365}$.

\footnotetext{
${ }^{365}$ Alhures, em uma entrevista, Alain Plagne pergunta a Jean-Marie Tjibaou: "Ce qui fait le prestige de la culture Kanak, c'est une importante production littéraire et orale, ce qu'Alban Bensa appelle les récits, contes, légendes. Quelle importance attribuez-vous à ces récits dans la culture Kanak?

J-M Tjibaou : “ C'est avant tout lié au fait qu'il n'y a pas d'écriture » (Tjibaou, 1996 : 200-201).
} 
O fato de Jean-Marie Tjibaou haver optado no âmbito da obra 'Kanaké' por um gênero e modalidades adequadas à própria tradição oral Kanak não pode sugerir a perspectiva de que aquela invenção 'mítica' era voltada especialmente às populações de origem melanésia, e não somente aos colonizadores, como quer Bensa? ${ }^{366} \mathrm{Em}$ especial quando atentamos para os dois objetivos distintos do Festival formulados por Tjibaou: um reconhecimento 'face a si mesmos' anterior a um reconhecimento pelos outros. No que diz respeito à noção de 'verdade' segundo as características próprias à tradição oral $^{367}$, não é relevante o fato de Tjibaou, através do recurso a meios escritos, haver trazido à baila a ancoragem própria à tradição oral, que implica referências acerca da 'autoria' daquela narrativa, mesmo que de modos indiretos (ou seja, ao fazer referência bibliográfica aos pesquisadores, mas que concernem narrativas originalmente autorais, transcritas ipsis literis naqueles textos na forma de frozen speeches (Boyer, 1990:115), com indicação de quem foram seus narradores?).

Bensa ressaltou ainda o fato de Tjibaou haver realizado, no âmbito daquela criação 'mítica', um 'esforço muito pessoal'. Consultando as páginas indicadas da obra de Jean Guiart (1963: 54, 60, 112, 114) sobre as quais Tjibaou afirmou haver se inspirado para sua criação narrativa, pareceu-me que aquelas páginas fazem referência justamente ao histórico dos clãs da região paîci, inclusive ao clã do próprio Jean-Marie Tjibaou (Cibao). Esse dado seria ainda coerente aos modos como foram realizados os convites para a participação das comunidades no Festival. Vimos que tais convites implicavam um grupo 'anfitrião', aquele do próprio Jean-Marie, assim como o emprego dos sentiers coutumiers e de discursos cerimoniais que reativavam as alianças entre seu clã e aqueles 'convidados'. Parece-me que o Festival se propôs uma conjunção, em um novo contexto, de uma cerimônia pautada em formas 'tradicionais', mas em um contexto 'moderno' e ampliado, mas que tinha como ‘anfitrião' o próprio Jean-Marie (na forma de seu clã).

Penso que a eficácia contextual daquele 'mito inventado' e ainda, na forma escrita, consiste tanto no fato deste haver se apoiado nos conteúdos adequados a um certo

\footnotetext{
${ }^{366}$ O próprio Bensa ressalta o fato de Jean-Marie haver optado pela exposição de um mito, 'sans juger préférable d'avancer des arguments scientifiques' (1995:299)

${ }^{367}$ Ou seja, em que não se discute a verdade dos 'fatos', que existiram porque foram enunciados, mas sim os intermediários da transmissão. Jan Vansina classificou oral messages segundo duas categorias. Estas seriam news (novidades) ou interpretações. No caso de news, ou novidades, estas seriam transmitidas ou por um narrador-testemunha ocular (eyewitness), - no caso da narrativa ocorrer em primeira pessoa-, ou trariam em si índices que remetem a um primeiro ator que testemunhou o evento relatado (hear say). No caso de consistirem em interpretações, seria o próprio narrador o produtor original daquela mensagem (Vansina, 1984). Assim, para além de enunciados pertencerem a um ou outro gênero da tradição oral, aqueles índices, internos ao corpo das mensagens, participariam também ao indicarem à audiência ou aos interlocutores os modos corretos de entendimento ou interpretação daquilo que é dito, em função de quem disse. Assim, as interpretações se abertas ao questionamento, irão interrogar o narrador, não a mensagem em si.
} 
coletivo $^{368}$, quanto na ética mesma a que Tjibaou faz referência. Isso porque o próprio Bensa avançou, em outra ocasião, o fato de que em relação à Tjibaou "seus propósitos põem em evidência menos as estruturas sociais do que a experiência que pode ter cada um em relação aos ancestrais, às cerimônias costumeiras, ao espaço, ao tempo" $(1996: 22)^{369}$. Parece-me que essa foi a intuição de Tjibaou a respeito de 'comment être Kanak dans le monde moderne'. Assim, sugiro que a possibilidade de uma 'identidade' unitária Kanak aqui se pautou, no âmbito do Festival e segundo a abordagem da arte verbal, no compartilhamento de recursos expressivos e discursivos que vêm articular formas passadas a formas presentes, contextos passados a contextos atuais. E no âmbito do 'mito' em sua forma escrita, sua opção pelo gênero jèmà e pela seleção de certos conteúdos em detrimento de outros, 'apagou', em situação, potenciais diferenças entre os diversos grupos que foram ali reunidos em torno de Kanaké e de um 'nós'. Um dos pontos importantes ressaltados por Bensa é o fato de que os próprios Kanak "n'ont jamais fait de l'histoire de Kanaké une epopée nationale » (1995:299). Ou seja, de que aquele 'mito', enquanto produção contextual, efetivamente não se conjuga nem 'engloba' em um todo comum outras 'versões' daquela mesma narrativa. Mas como vimos, a demanda de coerência transcontextual, assim como a 'exigência de verdade' factual, são antes nossas do que deles; nenhuma 'narrativa' pautada em formas próprias à oralidade pode se constituir uma (e só uma) epopéia nacional ${ }^{370}$.

Lévi Strauss, ao haver caracterizado o corpus mitológico a que chama barroco, afirmou que este se apresenta na forma de um relato contínuo, segundo uma ordem que se quer resolutamente histórica: "uma história que qualificaríamos de história de eventos (événementielle): nela, a ordem social é, a cada instante, ao mesmo tempo construída e questionada por um devir" (Lévi-Strauss, 1986: 152).

Em relação à história de Tèa Kanaké, performada durante aquela encenação, esta não consistiria, para eles, uma 'história' (dentre outras possíveis), e ainda, uma história que não diz respeito somente ao passado, mas ao presente e ao porvir? Uma história 'aberta'? Walter Benjamin discutiu a noção de 'história aberta' e a relação entre a

\footnotetext{
${ }^{368}$ Entretanto, é o próprio Bensa, um dos principais especialistas nos estudos de tradição oral Kanak, quem afirma que 'c'est dans le rapport entre le dit et les non-dit que se cache le sens du récit' (Bensa, 1995:264). ${ }^{369}$ Este aspecto, muito relevante aqui, será ainda discutido adiante.

${ }^{370}$ Vimos como no âmbito do folclore 'epopéias nacionais' como o Kalevala buscaram reunir um conjunto de traços ou elementos selecionados de um suposto passado comum erigido como a 'alma' de um povo e vindo se tornar uma referência identitária comum; e de que podem, efetivamente, apresentar aspectos próprios à comunicação em sua forma oral, como é o caso das llíada e Odisséia de Homero. Contudo, se a criação 'mítica' de Tèa Kanaké em sua forma escrita adequa-se às modalidades de conformação contextual de coletivos através da seleção de um gênero narrativo adequado, o jèmà, esta narrativa não foi inserida na cadeia de transmissão de narrativas orais .Assim, se ela 'agrega' coletivos de acordo com modalidades corretas, tal coletivo (como qualquer outro, no ponto de vista de tradições orais), só existe naquele mesmo contexto, não para além dele. No entanto, se aquela 'narrativa' não 'prolifera', proliferam as representações por ela avançadas, como veremos adiante.
} 
experiência e memória quando afirmou: "pois se um acontecimento vivido é finito, ou pelo menos encerrado na esfera do vivido, o acontecimento lembrado é sem limites, pois é apenas uma chave para tudo o que veio antes ou depois ${ }^{371}$ "(1996:37).

Parece-me ainda que a encenação do mito de Tèa Kanaké no âmbito do Festival, enquanto uma proposta de rememoração dos acontecimentos da colonização, vem jogar justamente com as articulações entre o 'acontecimento vivido' e o 'acontecimento lembrado', segundo a proposta de uma 'história aberta' de Benjamin, ao propor certo porvir (o reconhecimento da cultura Kanak) ao lembrar um acontecimento vivido de uma dada maneira ${ }^{372}$. E ainda teríamos aqui a característica de uma 'história mítica', ou de um 'mito historicizado', em que, segundo Lévi Strauss, 'essa história tende a assumir uma forma cíclica, ela termina com eventos de um tipo já contado, freqüentemente até mesmo no início do relato (1986:153). Isso porque, como vimos, no início da encenação, quando da chegada dos primeiros estrangeiros, a primeira ação Kanak consistiu no oferecimento de bens cerimoniais, que vêm marcar a relação de accueil. Já a última cena, que diria respeito ao 'porvir', - uma interpretação ou proposta de futuro com base (numa proposta de) passado-, consiste nos colonizadores, missionários e comerciantes oferecendo um dom cerimonial de inhames ao 'povo Kanak', agora reconhecido (como efetivos 'maîtres de la terre', em uma concepção ampliada).

Desse modo, parece-me que os aspectos que Bensa distinguiu ao denunciar a invenção do mito de Tèa Kanaké enquanto uma estratégia ou manobra política 'para outros', ou seja, o fato de o personagem Téa Kanaké elaborar seus atos, nessa nova versão, de forma que não coincide com os 'atos' identificados em seus supostos 'originais', ou dessa nova versão elaborar-se em francês (Bensa, 1995:297); tais argumentos se pautam por uma 'exigência de verdade' e uma concepção de 'política' diferenciadas daquelas dos próprios Kanak. Deste modo, vemos como aquela narrativa consistiu em um enunciado circunstanciado, que não vêm colocar em questão os ranques ou direitos de tal ou tal grupo, com um conteúdo voltado para necessidades do momento e ainda, pautado nas formas da tradição oral. Nesse sentido, considero que, se em um segundo momento, efetivamente, este 'enunciado da tradição' pode ser considerado como da ordem do político, este não corresponde a uma política nacionalista ou independentista, mas a uma política de 'empoderamento', relativa ao reconhecimento do valor de antiguidade e 'dos modos de viver melanésios' primeiramente por seus próprios atores e então por 'outros' não-Kanak. E este aspecto do 'político' só pôde ser eficaz na medida em que, inicialmente, se pautou em formas políticas, -ou culturais-, de relação propriamente Kanak, ou seja, pautada nas formas

\footnotetext{
371 Lembremos aqui a afirmação de Missotte, segundo a qual a encenação de Kanaké «.. s'agissait d'une proposition (...), puisqu'il offre une solution d'avenir tolérant et pacifique » (Missotte, 1995 :92)

${ }^{372}$ Evitando, por exemplo, uma apresentação exageradamente depreciativa do personagem do missionário.
} 
corretas de interação, em que 'o que é dito' varia de acordo com 'quem se diz' através daquelas formas.

O quanto poderíamos considerar os usos da fala (e de sua versão escrita) naquele contexto como da ordem do político?

Brenneis e Myers (1984) buscaram refinar a discussão a respeito dos aspectos "políticos" no que diz respeito às formas e funções da linguagem em relação à "populações tradicionais". Assim, esses autores apontam que a "fala" naqueles contextos políticos seria menos um meio de coerção ou de tomada de decisões do que uma forma de reprodução de relações sociais e de regulação e alocação de valores. A questão relevante, apontada pelos autores, é a de qual valor social é objeto de competição e alocação, e como ele é produzido e negociado. A meu ver, o valor social em competição aqui é a antecedência ou antiguidade da ocupação, que é o valor que guia as relações entre grupos políticos no espaço da co-residência e além, de forma que as duas posições nobres, a de maître de La terre e a de 'chefe' pautam-se, ambas, naquele valor, segundo argumentos que variam de um gênero a outro (ver nota 33). Naquele contexto do mito escrito de Téa Kanaké, tanto a alocação deste valor não é em colocado em causa no que concerne aos diversos coletivos Kanak, a partir do recurso ao gênero jémà, que como vimos, consiste em uma reelaboração pública dos papéis de um dado conjunto político atual (papéis esses, contudo, excluídos da narrativa na forma da personalização deste ou daquele clã), para ao mesmo tempo avançar o valor de 'antiguidade' conjunto, a todos os grupos de origem autóctone. Outro aspecto que me parece relevante aqui, já no âmbito da encenação do Festival, foi o fato de sua proposição de 'futuro' ser a da 'inclusão' 'do outro' nas formas políticas Kanak, e não o inverso. Isso porque, na última cena da representação de Tèa Kanaké, os missionários, comerciantes e representantes do Estado francês vêm oferecer dons cerimoniais aos Kanak $^{373}$. Ou seja, os 'estrangeiros' reconhecem uma autoridade local, e são 'acolhidos' por seus anfitriões. Única possibilidade, do ponto de vista do político (da cultura) Kanak, de constituição de um único 'coletivo', caledônio.

Uma questão que exige, contudo, maior reflexão, reside na articulação operada por Tjibaou entre um recurso a narrativas originalmente 'orais', compiladas por Jean Guiart e Maurice Leenhardt na forma escrita, para serem então recuperadas e 'proliferarem', quanto à sua representação, segundo um aspecto próprio a tradições orais ${ }^{374}$. Pareceme aqui que o fato daquelas 'narrativas' escritas apresentarem-se na forma de frozen

\footnotetext{
373 Poderíamos imaginar múltiplas possibilidades alternativas para este 'ato final', como algo que representasse a 'tomada do poder' pelos Kanak-independentistas, etc..., que estariam mais em acordo com a posição de Alban Bensa (1995:290-307) e Graille (2001), por exemplo.

${ }_{374}$ Veremos como, se a narrativa de Tèa Kanaké segundo a versão de Tjibaou não 'prolifera', as representações avançadas em sua forma de 'encenação' sim, em especial no que diz respeito à inclusão do 'outro' nas formas do político Kanak através dos gestos da coutume.
} 
speeches $^{375}$ (Boyer, 1990:115), desvinculados de análise teórica, veio influir ou possibilitar sua 'proliferação, 376 por Tjibaou. Retomemos aqui caracterizações a respeito do trabalho antropológico e etnográfico de Leenhardt.

\subsection{Dos interlocutores de Maurice Leenhardt à Jean-Marie Tjibaou e após: 'proliferações'}

Est-ce qu'on aurait pu faire Kanaké sans Leenhardt? J.-M Tjibaou: Eh bien non. Ça aurait été très difficile ${ }^{377}$.

Gostaria de chamar a atenção aqui para o que eu caracterizo como uma 'proliferação', ou seja, o fato de narrativas orais 'compiladas' por Maurice Leenhardt serem hoje passíveis de reapropriação e recontextualização no âmbito dos Cahiers de Littérature Orale do Centro Cultural Tjibaou. Voltemos à Leenhardt e seu papel no contexto colonial da Nova Caledônia, assim como aos modos como suas reflexões, mas principalmente seus 'limites', inspiraram as ações e reflexões de Tjibaou.

Leenhardt considerava seu trabalho como um exercício de tradução. Tendo passado 24 anos na Nova Caledônia (1902-1926), seu trabalho evangélico foi considerado teoricamente sofisticado, ao haver introduzido modernas técnicas etnolingüísticas de tradução da Bíblia. Leenhardt intentava que seus discípulos encontrassem 'em sua própria cultura' idéias ou expressões que melhor representassem a 'mensagem' ali transmitida. O missionário incitava a reflexão de seus interlocutores, que podiam levar anos para elaborarem uma tradução que se adequasse a uma concepção original ao mundo 'melanésio'. Aquela mesma metodologia imprimiu as características de suas análises antropológicas. Consideradas 'obscuras', suas reflexões partiam, no mais das vezes, de um meticuloso exame semântico e simbólico da linguagem ritual ou cotidiana. Do Kamo, sua obra mais conhecida, busca oferecer chaves à compreensão da 'noção de pessoa' melanésia. A cada expressão ou termo da língua a que se interessa o autor, este vai buscar situar seus usos originais através de diversos exemplos, para em seguida estabelecer comparações com as formas como tais expressões foram traduzidas para a língua francesa por seus 'informantes-discípulos', também a partir de longos debates com o missionário-pesquisador.

\footnotetext{
${ }^{375}$ E não de fragmentos de discursos tais como aparecem de modo geral em trabalhos acadêmicos de lingüistas e antropólogos, de forma a sustentar proposições teóricas dos autores.

${ }^{376}$ Ou seja, modos como narrativas originalmente orais, quando registradas, podem vir a ser 'retomadas' e reinseridas na cadeia de transmissão.

377 (Tjibaou, 1978). Citado por Mokkadem, 2005:93.
} 
O objeto de seu estudo era a "cultura viva" e os modos como a cultura traduzia mudanças para si mesma e para os outros. $O$ ponto de vista de Leenhardt ${ }^{378}$ à época era de que "os nativos caledonianos em 1914 não podiam mais escolher ficarem sozinhos. Portanto, era importante discutir seriamente o velho e o novo, os problemas da mudança de moralidade”. Tal debate, levando a uma mudança autoconsciente, era o programa do missionário liberal (Clifford, 2000:234) ${ }^{379}$. Interessava-o os aspectos da mudança cultural, os modos como os costumes eram transformados face às condições da conversão, e não estraçalhados pelo colonialismo. Enquanto missionário, Leenhardt atenta para reflexos da mudança nas almas de seus 'informantes-discípulos'380, assim como para aspectos da mudança na 'expressão criativa melanésia'381.

\footnotetext{
${ }^{378}$ Maurice Leenhardt ao mesmo tempo em que foi reconhecido como um dos primeiros representantes e organizadores da etnografia científica na França, sua experiência etnográfica foi considerada singular, pelo fato de haver se realizado segundo pressupostos e objetivos coerentes, antes, com seu trabalho como missionário. Clifford (2000) e Cavignac (2006) sugerem que ele foi não somente o precursor da etnografia francesa, mas o precursor de tudo aquilo que a etnografia 'profissional' iria, dali dez anos, reivindicar: um método fundado na observação direta com estadia prolongada em campo, conhecimento profundo da língua nativa, participação na vida das populações estudadas, estabelecimento de relações afetivas duráveis com seus informantes, etc. Apesar da reconhecida importância atribuída a este pesquisador no contexto da antropologia à época, sua obra foi praticamente esquecida, tendo submergido após a onda estruturalista dos anos 50 e 60. Este fato é atribuído, em geral, à sua abordagem 'culturalista', ao enfocar seus estudos (em especial Do Kamo) nas formas da religiosidade 'primitiva', mesma trilha adotada por alguns de seus contemporâneos como Marcel Griaule e Michel Leiris. Mas ao contrário de Marcel Griaule no que diz respeito às suas proposições abrangentes em relação ao 'homem africano', Leenhardt não tencionava chegar a uma síntese teórica da 'mentalidade primitiva' melanésia, nem elaborar análises comparativas em larga escala como seu professor Marcel Mauss. No que concerne o estruturalismo de Lévi-Strauss, que viria influenciar toda a geração posterior, se Leenhardt dedicou, assim como o primeiro, uma parte de seus estudos ao totemismo, Lévi-Strauss irá se distanciar rapidamente daquela visão 'compreensiva' e de suas expressões 'concretas', para enfocar suas análises antes no totemismo como modo de 'entendimento' (LéviStrauss: 1962) e nas leis gerais do pensamento humano. Maurice Leenhardt seguia, ainda que com algumas ressalvas, a orientação teórica de Lévi-Bruhl a respeito do 'pensamento primitivo' e da noção de 'participação'. As idéias de Leenhardt sobre fenomenologia religiosa foram consideradas pouco usuais, especialmente pelo fato de o autor interessar-se pelas relações entre a linguagem e 'pensamento arcaico' melanésio (Cavignac, 2006: 34). O fim de sua estadia na Nova Caledônia foi atribuída ao seu caráter de 'indigènophile', "um agitador pró-nativos cujo pensamento sobre política e evangelização havia sido considerado 'avançado demais' por seus colegas" (Clifford, 2000: 228). Isso porque tomava freqüentemente o partido dos Kanak, sobretudo em relação a conflitos ligados à terra. Seu caráter inusitadamente anticolonista é sublinhado por Cavignac, já que à época a antropologia era diretamente dependente da dominação imperialista no que concerne o acesso às populações estudadas e, conseqüentemente, aos 'dados' (Cavignac, 2006: 35). Sua obra mais conhecida, "Do Kamo: la personne et le mythe dans le monde mélanésien' (1937), concerne o registro de uma série de palestras proferidas por ele no Collège de France.

379 Tendo escrito uma biografia da vida de Maurice Leenhardt, James Clifford resume algumas considerações a respeito dos pressupostos, abordagens teóricas e do método etnográfico aplicado por Maurice Leenhardt pelas quais se interessa esta análise. O artigo de James Clifford (2000) interessou-me por se focalizar na primeira fase documental da carreira do antropólogo, anterior a Do Kamo.

${ }^{380}$ Enquanto a conversão ao catolicismo privilegia a participação nos momentos rituais (como a missa, o batismo, o casamento), em que o sacerdote é considerado como intermediário ou 'representante' de Deus, evangélicos enfatizam a relação direta entre os discípulos e Deus, e os aspectos morais, interiores dessa relação. Daí Leenhardt não ter em vista a supressão dos rituais e costumes tradicionais em si, mas sim as mudanças de seus próprios discípulos (o que acarretaria a supressão de costumes e rituais por sua própria conta). Leenhardt irá se interessar pelos modos como a mudança 'nas almas' opera transformações nos costumes e rituais.

${ }^{381}$ Como em um dos textos do missionário citado por Clifford: "durante um dos últimos Grands Pilous, em Ponerihouen, uma fraternidade Nèbaye inventou uma dança totêmica que tem sido muito lembrada desde então. Nela, grupos de dançarinos iam e vinham graciosamente, se encontrando, parando, fazendo reverências, formando um círculo em imitação a um peixe existente na área e que vinha de todas as partes e ali se concentrava para se alimentar de algas trazidas pela correnteza. De repente se ouve um tiro de rifle:
} 
Esta concepção dinâmica do processo cultural (atrelado à colonização e cristianização) se refletia no modo como elaborava seu método etnográfico. Isso porque, para o missionário, o próprio processo de registrar informações sobre a tradição estimularia a reflexão por parte de seus informantes ${ }^{382}$. Durante os anos em que trabalhou junto aos Kanak na Nova Caledônia, Leenhardt reuniu um vasto conjunto de textos em língua vernácula. O missionário acreditava que a escrita 'etnográfica', realizada por parte de seus informantes, viria iluminar o valor dos 'modos de ser melanésios', tanto aos olhos dos próprios nativos quanto dos brancos. Previamente à Do Kamo, o etnógrafo produziu uma trilogia que se quis "uma documentação inicial e bem classificada para o estudo da mentalidade melanésia”383. A trilogia é formada por “Documents néocalédoniens 》 (1931), "Notes d'Ethnologie néo-calédoniènne »(1935) e «Vocabulaire et grammaire de la langue houialou » (1930).

É em Documents que seu procedimento de trabalho com foco na tradução fica mais evidente. Através da transcrição dos textos produzidos em língua nativa, o etnógrafo intentava expressar a 'fonte mais verdadeira da expressão melanésia'. Isso resulta do fato de Documents haver sido construído como um empreendimento coletivo, resultado de sua modalidade específica de 'coleta de dados'. No índice da obra constam os nomes de quinze diferentes 'transcritores'. Segundo Clifford, "Leenhardt incentivava uma grande variedade de pessoas a registrar em cadernos de exercícios escolares quaisquer narrativas tradicionais, discursos rituais ou canções" (2002:242). Quando os cadernos estavam prontos, o missionário discutia seu conteúdo com os autores, um processo demorado e intricado. Assim, o etnógrafo não participava no primeiro trabalho de transcrição. Os textos eram elaborados em particular, na língua nativa, por informantes que haviam recentemente aprendido a ler e a escrever. Segundo Clifford, "Leenhardt adquiriu dados nos quais ele está fora do quadro, quando comparados ao grau de envolvimento na apresentação ou na explicitação da maioria dos dados etnográficos" (...) "uma obra como a de Leenhardt é hoje incomumente acessível à reapropriação por parte dos melanésios, já que boa parte dela, de formas óbvias, foi escrita por melanésios" (2002:246). A vantagem de tal abordagem, segundo Clifford, é

os dançarinos se deitam, de barriga para cima. Representação de uma tragédia, a dança significa a morte do totem (representado por este peixe) e de seu grupo no deslocamento da sociedade nativa sob o choque desencadeado pela civilização" (Leenhardt, 1937: 168 in Clifford: 239). Cito este trecho porque ele pode sugerir que 'inovações' em práticas expressivas 'tradicionais', ou encenações dramáticas da história tal como a de Tèa Kanaké já eram correntes desde Leenhardt. Poderíamos supor aqui que esta 'dança' foi elaborada justamente para o pesquisador, como no caso da encenação do 'sonho' de Warodi para Laura Graham mas de forma a 'proliferar' representações para si?

382 "ao mesmo tempo em que preservavam o que era antigo através da escrita, eles se distanciavam dele" (Clifford, 2000: 234)

${ }^{383}$ Definição do conjunto dos três volumes, pelo próprio Maurice Leenhardt, em um extenso Curriculm Vitae elaborado por volta de 1950 (Clifford: 2002, 249). 
a de tornar a etnografia aberta à reinterpretação acadêmica e à reapropriação pelos nativos" (Clifford: 2002: 239) ${ }^{384}$.

Efetivamente 'Documents' concerne uma compilação de frozen speeches dos e pelos próprios nativos, na língua, com a indicação de cada autoria, indicações do clã a que pertence cada narrador assim como, internamente às narrativas 'orais', índices acerca da cadeia de transmissão dos eventos ali narrados. Leenhardt, nas notas de rodapé, vêm ressaltar expressões e termos empregados nas narrativas, de modo a articular a obra com os dois outros volumes do conjunto: as 'Notas de etnologia neo-caledoniana', e o 'Dicionário e gramática da língua houailou'. Assim, tais narrativas compiladas por Leenhardt são vistas como 'originais' pela parte dos Kanak (e potencialmente 'proliferáveis'), pelo fato de haverem sido escritas, diretamente, pelos próprios indígenas. Contudo, não são todas as narrativas ali publicadas aquelas que vêm compor os Cahiers de littérature Orale segundo o projeto de valorização do patrimônio oral Kanak.

Atentando à obra Documents de Leenhardt, em relação àqueles Cahiers, constatamos que os textos publicados no âmbito do projeto de valorização e salvaguarda da 'literatura oral' Kanak, se não irão fazer referência a um único 'coletivo' Kanak (que justamente só pode se constituir em um dado contexto, através da tecelagem de discursos vivaa e de trocas de bens cerimoniais entre pequenos grupos específicos, se ampliando na forma de adensamentos de regiões da rede, não articuláveis em discursos ou narrativas comuns a todos os grupos) ${ }^{385}$, irão avançar, antes, aproximações, que dizem respeito à ancoragem dos diversos grupos em relação a seus ancestrais, assim como a eventos da história que vieram marcar o estabelecimento de relações de aliança entre clãs específicos (e não eventos que os opuseram).

Parece-me que Tjibaou recorreu 'duplamente' à obra de Leenhardt: através de suas reflexões sobre a 'noção de pessoa melanésia' e da 'mudança, ${ }^{386}$, e através do recurso a narrativas orais de autoria Kanak compiladas por aquele pesquisador-missionário. Entretanto, cabe aqui uma ressalva. Se Tjibaou parte à Metrópole para a realização de seus estudos em sociologia e antropologia, já vimos que seu interesse é menos

${ }^{384}$ Clifford cita aqui duas desvantagens: o fato de os textos obtidos estarem separados de seus contextos imediatos de apresentação; e adotando uma perspectiva próxima à de Jack Goody (1977) afirma que 'a escrita implicava num grau considerável de distância autoconsciente em relação aos costumes descritos, e, portanto podia impor um elemento de abstração e um excesso de intelectualização à evidencia etnográfica primeira". Dentre as vantagens, Clifford cita o fato de os informantes estarem sob menos pressão e controle imediatos do que se estivessem na presença do inquisidor com seu caderno e/ou gravador, que em última instância não consegue evitar questões segundo formulações que induzem a resposta.

${ }^{385}$ Ou seja, como já afirmado, a invenção 'mítica' de Tèa Kanaké, se não se constitui propriamente uma versão da 'tradição oral' pelo seu conteúdo inovador (pela exclusão de elementos), é uma versão adequada às formas e gêneros da tradição oral, que, através do emprego do jema, pôde, em um dado contexto, 'apagar' em situação as clivagens entre coletivos.

386 "Le retour à la tradition est um mythe; je m'efforce de le dire et de le répéter. C'est un 'mythe. Aucun peuple ne l'a jamais vécu. La recherche d'identité, le modèle pour moi, il est devant soi, jamais en arrière. C'est une refformulation permanente » (Tjibaou, $1996: 185$ ) 
acadêmico do que pragmático. Seu objetivo foi o de reunir instrumentos de reflexão capazes de lançar as bases de uma ação voltada a remediar a alienação e demissão cultural em que se encontram os autóctones colonizados, para que elaborassem uma nova imagem, 'gratificante' de si mesmos. Mokkadem (2005:116) indica quem foram seus principais mestres: Roger Bastide, segundo sua noção de antropologia aplicada (à época, interessada pela questão da aculturação), os cursos de Jean Guiart, sobre as relações entre o foncier (a ocupação do espaço) e o nome, e a concepção leenhardtiana de pessoa. Leenhardt, tendo sido considerado um agitador 'pró-nativos', foi um dos primeiros e únicos pesquisadores de sua geração a denunciar os abusos da colonização $^{387}$, e a apresentar uma imagem positiva dos Kanak ao Ocidente. À reflexão de Tjibaou, parece que a principal contribuição do missionário consistiu na noção de 'esquema de identificação': "Le principe de la vie, c'est la mère, c'est la mère qui donne la vie. Le père donne le personnage, le statut social, la terre. Le vie est donné par le sang, le sang c'est la mère qui le donne, et les proprietaires du sang sont ses frères, ses pères. Alors je reste toujours duel. Je ne suis jamais individu. Je ne peut pas être individu. Le corps n'est pas un principe d'individuation, le corps est toujours la relation (Leenhardt a bien compris beaucoup des choses, heuresement!). Et les proprietaires de ce partie de moi, ce sont mes oncles maternels. Je ne suis jamais moi, je suis en reference à, en reference à mes oncles. II n'y a person qu'en reference à. Dans ce contexte là, l'homme qui est reussi c'est l'homme qui garde bien les alliances d'un côté et de l'autre». (Tjibaou, 1996:108) ${ }^{388}$.

Assim, a obra de Leenhardt contribuiu à reflexão de Tjibaou acerca das complexidades relacionais da pessoa Kanak, ou seja, o fato de as relações, antes de se constituírem trocas de bens materiais, são trocas entre coletivos que conferem um lugar e um estatuto a cada pessoa, que só existe em referência à eles ${ }^{389}$. Contudo, parece-me que foram os limites do trabalho de Leenhardt que vieram principalmente influenciar as reflexões daquele líder a respeito do problemático apagamento da dimensão de seus ancestrais pela religiosidade cristã. Tjibaou critica Leenhardt por haver negado as 'potências ancestrais' próprias ao Kanak. Justamente pelo fato da 'vocação' de

\footnotetext{
${ }^{387}$ Michel Leiris, autor de 'l'Afrique Fantôme', será um dos primeiros alunos de Leenhardt, considerado-o seu mestre (Cavignac, 2006:39).

${ }^{388}$ Em 1978 em Paris, já como porta-voz da nascente causa nacionalista Kanak, Tibaou irá iniciar seu discurso com a afirmação "Le schéma d'identification culturelle c'est la manière de concevoir l'homme. Je pense que c'est intéressant que Leenhardt ait fait ressentir cela parce que cela rélativise le vérité chétienne occidentale qui dit que [l'homme] est l'âme et corps. Chez nous, on dit que l'homme c'est le sang et puis le personnage, le sang puis le nom »(Tjibaou, 1978a).

${ }^{389}$ Segundo Leenhardt, 'la société canaque repose sur um ensemble de contrats passés, non points entre personnes mais entre générations. Dans les affaires de mariage, le femme accordé a un clan est un prêt. (assim como 'empréstimos' e dons e contra-dons de crianças para adoção). Elle doit faire retour au clan en la personne de sa fille ou de sa petite-fille. Cette personne qui va remplir une dette est 'la vie de la parole', qui unit ceux-ci et maintient la société'. (Leenhatdt, M.1932: 212-236).
} 
Leenhardt ser, sobretudo, missionária, aquele pesquisador não pôde ir além em sua análise. Pois, como afirmou Tjibaou em um colóquio sobre Leenhardt ${ }^{390}$ :

"je dis ça sur un plan culturel et également sur un plan religieux. Et cela ça n'est pas encore une étape que nous avons afranchie au niveau pas seulement en NouvelleCalédonie mais je dirai au niveau de l'ensemble des peuples qui ont eu la civilisation chrétienne. On en est toujours avec la discussion entre Pierre et Paul : est-ce qu'il faut faire des chrétiens ou faire des juifs avant de faire des chrétiens et je dirais que pour nous c'est un peu malheureux que Leenhardt ne soit pas arrivé au dernier sapin parce qu'il aurait pu peut-être reconnaître, il a reconnu, il a reconnu intellectuelment, il a reconnu affectivement mais il n'a pas eu le temps de faire la promotion de la société, parce qu'il est venu avec un arsenal qui est le sien, qui est celui de l'Occident. Parce que c'est une autre affaire mais je dirai qu'au niveau de ses écrits, il n'est pas encore arrivé là. II n'a pas pu arriver à dire que nous ne sommes pas un peuple des sauvages. Non seulement que nous avons une civilisation, une culture, mais que nous avons aussi des références aux divinités, aux esprits, à l'au-delà et ces références-là, c'est elles aussi qu'enracinent la société, qui enracinent en haut, qu'enracinent en bas, qui enracinent dans l'espace et de ce point de vue on n'est pas en contradiction avec la Bible, avec l'èglise. Je dirai que nous, nous ne refusons pas d'accepter tout ce qui est nouveau. Mais il n'y a pas que des saints de chez vous qui ont des élus, il n'y a pas que vous ancêtres qui peuvent être considérés comme des gens à qui on peut faire référence dans l'au-delà si on est croyant et cela que nous revendiquons aussi la place des ancêtres parce que c'est notre société, c'est tout nous. Hier, dans la discussion sur la profondeur, on disait si moi je ne suis pas seulement l'homme qui suis là mais qui je porte avec moi le clan, le sang, les ancêtres, tout le passé, tout l'espace qui fait que je suis homme, une dimension me manque si s'il n'y a pas la reconnaissance de la dimension d'esprit des ancêtres, la dimension multiple et je pense que si Leenhardt avait pu continuer à vivre, on aurait pu peut-être faire des célébrations religieuses avec le pilou, avec le sens traditionnel sans renier Christ et en le faisant nôtre parmi les autres, et en ce moment là, la société peut rester dans sa stabilité parce qu'elle n'est pas remise en cause dans son fondement par des références autres. Je regrette de terminer sur cette note un peu acide mais c'est un peu la recherche dans laquelle je voudrais qu'on puisse continuer »(Tjibaou, 1978) ${ }^{391}$.

\footnotetext{
${ }^{390}$ In Mokkadem, 2005:121, em referência à "texte de treize pages sans titre daté du 13 avril 1978, colloque Leenhardt à Paris, Fonds Cortadellas-Bourret-17J, Nouméa, Service des Archives de la Nouvelle-Calédonie, $1978 »$.

391 Vemos que Tjibaou não possuía as 'ferramentas de análise' que pudessem deslocá-lo dessa concepção 'culturalista'; e ainda, tendo sido inicialmente formado em um seminário católico, o líder cultural não abandona sua confissão cristã, mas reivindica o reconhecimento de seus ancestrais, do fundamento da pessoa Kanak, 'ao lado' dos santos e divindades cristãos. A possibilidade efetiva dessa subsistência na dualidade, na multiplicidade e suas contaminações é uma outra questão, muito interessante, mas que não cabe aqui.
} 
Vejamos assim os propósitos de Tjibaou quanto a 'comment peut-on être Kanak dans le monde moderne':

"La présence des esprits restent vivaces au coer de Kanaké. L'experiénce vécu de cette complicité passe par les contingences historiques. Mais elle ne doit jamais être identifié totalement aus institutions écrites, aux rites ou au matériel symbolique utilisé par une époque donné. En effet, ce qui est primordial et qui perdure au-delà des siècles, ce n'est pas cette expérience mais l'inspiration ou l'ethique qui fait surgir cette expérience dans l'histoire » $(1976: 80)^{392}$.

Ou seja, ser Kanak no mundo moderno pressupõe a manutenção de percepção de continuidade a partir do fundamento de sua sociedade, da relação com os ancestrais e 'espíritos', assim como de uma forma do político ancorada na oralidade.

392 Relembro aqui o extrato de Bensa que contrasta com a concepção de Tjibaou ["Ce qui apparaît fondamental dans la société Kanak, c'est le mythe"(1996:62)], a respeito do lugar dos espíritos e ancestrais míticos no fundamento da sociedade Kanak: "Envoyé em Nouvelle Calédonie pour collecter em langue Kanak des énonces formalisés (contes, poésies, récits, etc), je ne pouvais qu'imaginer y reccueillir des echantillons de cette 'pensée mythique' dont Il était convenu de considérer qu'elle était l'apanage des sociétés 'sans écriture' et 'sans histoire'. Tel ne fut pas ma surprise d'enregistrer (ou de noter sous dicté) des histoires, appellé en paici jèmà, qui ne ressemblait guère aux mythes amérindiens sur l'origine du feu ou de la cuisine. Mes interlocuteurs Kanak racontaient comment leurs ancêtres, à partir d'un site fondateur, avaient migré sous l'effet des guerres, des alliances, puis de la colonisation européenne et du cantonnement dans les réserves. Certes, le toutes premières phrases de quelques récits mettaient en scène des événements extraordinaires (lézard nageant dans la mer et s'accrochant à un rocher, transformation d'animaux en humains, lune déposant sa dent sur un rocher, etc.) mais cette forme legendaire cédait vite place à des noms d'ancêtres et d'habitats, jalons bien visibles d'itineraires qu'il était donc possible de parcourir et cartographier. Parfois même, certains historiens Kanak, comme Emmanuel Naouna, s'efforçaient de dater les déplacements, en comptant les générations reliant les gens d'aujourd'hui aux derniers ancêtres dont le souvenir était conservé. Ainsi lune, soleil, anguille, rocher, etc., apparaissaient ou non au début d'une narration prenant très vite un tour historique et mettant en avant une conception lineaire du temps. Le narrateur se rattachait ainsi aux fondateurs de son clan, voire de l'humanité Kanak tout entière par un récit d'allure parfaitement historique qui non seulement le situait en regard des autres clans, mais allais-je vite comprendre, évoquait directement ses intérets sociaux et politiques actuels " (Bensa, $2003: 46-47$ in : Mokkadem, Hamid, 2005 :113). Se Bensa 'depende' da afirmação do aspecto propriamente histórico que informa a 'sociedade' (pois, segundo seu ponto de vista 'como poderiam os Kanak demandar a independência, se não estivessem 'preparados', se não fossem eles 'modernos?'), Tjibaou propõe o movimento reverso, em que a experiência na e da história, assim como a relação Kanak com o espaço, dependem ou procedem da inspiração ou ética derivada da relação com os ancestrais. 


\subsection{Enunciados acerca da tradição segundo uma abordagem 'dialógica'}

Alain Plagne a J-M Tjibaou: "Ce qui fait le prestige de la culture Kanak c'est une importante production littéraire et orale, ce qu'Alban Bensa appelle les récits, contes, légendes. Quelle importance attribuez-vous à ces récits dans la culture Kanak?

J-M Tjibaou : « C'est avant tout lié au fait qu'il n'y a pas d'écriture » (Tjibaou, 1996:201).

Aqui gostaria de discutir um segundo aspecto da pesquisa realizada por Michel Naepels junto aos habitantes da região de Houaïlou. Este autor afirmou que seu interesse era a realização de uma etnografia de uma situação presente, que concernia as disputas em torno da posse da terra. Entretanto, o autor não realiza uma etnografia das disputas propriamente ditas, mas busca lançar luz às dinâmicas que definem os lugares de influência e conflito nas relações entre grupos e indivíduos, que passa pela compreensão do sentido e do peso do saber histórico e das modalidades de veiculação consideradas adequadas. É desse modo, e com o auxílio das explicações e interpretações acerca de cada um daqueles aspectos fornecidas por seus informantes, e que vêm compor o corpo do texto, que o autor irá apresentar a maneira como se constituem hoje as relações sociais locais, e o lugar aqui das disputas pela terra ${ }^{393}$. Sua intenção naquele trabalho era a de fornecer um instrumento de compreensão da conjuntura geral da Nova Caledônia contemporânea no que toca os Kanak, de modo que a apreensão das experiências sociais pudesse se constituir um utensílio à invenção de formas institucionais e jurídicas mais adequadas (1998: 326). Para o antropólogo, uma descrição completa daquela situação atual supunha não somente a descrição de eventos que se produzem hoje, mas também de eventos passados que são postos em relação com eventos presentes, assim como os sentidos que as pessoas concernidas dão aos seus atos, ao definir o que é possível, pensável e legítimo em um dado momento (1998:17).

O autor realizou sua pesquisa através de entrevistas junto a diversos informantes dessa região, e em francês. Seus interlocutores eram entrevistados ou prestavam depoimentos acerca das modalidades de relação e organização social e identitária anteriores à colonização, acerca da influência das Igrejas, do acantonamento, de

\footnotetext{
${ }^{393}$ Pois Naepels afirma que 'propõe focar seu objeto de estudos menos na 'coerência formal' ou 'funcional' de uma sociedade, na qual o antropólogo se volta para 'informantes' tidos como sábios, cultivados ou coerentes, e considerados como expressões parciais de sua sociedade ou cultura, mas sim, uma pesquisa "em que o antropólogo interessa-se, antes, por 'relações sociais' mais do que pela 'sociedade', por uma situação atual mais do que pelo 'ser intemporal' de uma cultura, e por indivíduos inseridos em situações empíricas, notadamente conflituais, mais do que concebidos como manifestações de uma estrutura" (1998:19).
} 
eventos da história e dos mecanismos postos em prática pelo Estado, e dos modos como estes fatores vieram incidir em um momento atual no que diz respeito às relações entre indivíduos e grupos Kanak. Assim, o autor traz para o corpo do seu texto os pontos de vista dos atores, que são então comentados e vêm participar na construção de sua análise.

Sua pesquisa intentava dar a conhecer certa situação, mas com a precaução de não vir nela interferir, ou limitar o tanto quanto possível sua interferência. Desse modo, Naepels irá trazer os enunciados de seus informantes para o corpo do texto, mas através do emprego generalizado de pseudônimos, ou do que o autor chama de 'uso temperado do anonimato': "Il faut pouvoir discener précisement ce qu'on est en droit de citer dans l'ensemble des entretiens enregistrés ou partiellement noter (...) ne faut-il pas penser que certaines choses nous ont été dites pour nous aider a comprendre les situations, mais certainement pas pour être publiées ? (...) bien des choses nous ont été contées sous le sceau, parfois implicite, du secret »(1998:23) ${ }^{394}$. Essa preocupação concernia também o fato de seus informantes, por vezes, ao contarem com a discrição do pesquisador ou, pelo contrário, apoiados no fato de a publicação poder legitimar uma versão local não-consensual em uma situação de disputa, concordarem em comentar aspectos da história de outros clãs que não o seu para o estudioso. Essa concerne uma situação a que caracterizei nessa pesquisa como 'interrupção', ou seja, enunciados orais registrados em que seus atores têm a clareza de serem eles destinados à outros públicos (distantes de seu local de origem) ${ }^{395}$ e, portanto cuja reinserção na cadeia de transmissão oral não é desejada pelos atores ${ }^{396}$.

394 "C'est seulement par la confiance que certaines personnes peuvent choisir de transmettre certaines aspects de leur savoir. Pourquoi ? À travers l'enqueteur, certaines personnes peuvent désirer transmettre a un déstinataire temporairement absent (les générations futures). Dans ce cas, la mise à disposition de tout est évidemment souhaitable, même si elle n'est pas pour autante facile. Dans d'autres cas, le motif peut être politique, culturel ou réflexif, quand les gens estiment qu'un travail en sciences sociales peut permettre de mettre en valeur la culture Kanak ou peut contribuer aux réflexions actuelles sur l'avenir de la NouvelleCalédonie. Mais dans ce cadre, qui n'est plus patrimonial, il n'est pas rare que soient transmises à l'enqueteur des informations ou des récits qui ne sont pas déstinés à être rendu publiques et qu'il faut manier avec précaution. Par exemple, certains locuteurs peuvent chercher à imposer à travers le chercheur une version locale de l'histoire qui n'est pas consensuelle; ou, au contraire, certaines personnes entrouvent la porte d'histoires qu'il serait tout à fait injurieux de rendre publiques. » (Naepels, 2003. Mwà Véé, n40, pg.15). Nesse sentido, grande parte de seus interlocutores não tinha em vista a acessibilidade imediata de suas contribuições na forma escrita para si, mas sim influenciar o jogo de forças em torno das decisões pela posse da terra ou o estabelecimento de mecanismos reflexivos e institucionais mais adequados à situação complexa da população Kanak à época, no que tange as disputas pela terra.

395 Parece-me, que as narrativas cíhêdéé elaboradas para Bensa e Rivierre (1982) poderiam ser consideradas da mesma maneira. Ou seja, de que os narradores concordaram no registro de suas narrativas históricas próprias ao âmbito familiar tendo em vista a oficialização de seus direitos sobre a terra. Contudo, o fato de terem hoje os kanak acesso a esta obra, e de ali os autores não terem adotado pseudônimos, acarreta que este trabalho seja criticado por alguns Kanak, como veremos adiante.

${ }^{396}$ Relembro aqui que no caso Xavante a situação a que caracterizei 'rechaço' concerniu à interdição de Laura Graham à produção de registros no âmbito das discussões vespertinas intra-faccionais a que se faz uso, também, da forma expressiva e discursiva ihi-mrèmè. Ainda no 'caso' Xavante, o efeito de interrupção ou descaso concerniu o desinteresse demonstrado pelos atores nas narrativas cosmogônicas coletivas produzidas para o pesquisador Arthur Eid para sua pesquisa, e que vieram posteriormente compor o livro Wamrêmé Za'ra, projeto de 'transformação dirigida' voltado à valorização cultural. 
Veremos aqui os modos como certos enunciados avançam uma adequação à noção do 'respeito', seja quando negam prover detalhes concernindo a história de outros clãs e linhagens, seja quando criticam outros narradores que concordaram transmitir a 'pesquisadores', ou àqueles que 'marcaram as histórias nos livros', histórias que concernem 'outros' para além de seu próprio clã. Interlocutores que contaram com a discrição do pesquisador vêm ter seus nomes substituídos por pseudônimos.

Cito aqui alguns extratos de entrevistas bastante evidentes neste sentido.

"Là tu trouves l'histoire à eux chez eux. Moi je donne les histoires a moi seulement " (Lévi Cibëi, 1991 in 1998 :107).

"Oui, parce que c'est vrai que [...] c'est toujours gênant pour un coutumier de parler des autres, et c'est vrai, s'il faut dire la verité, les autres familles qui sont là avec nous maintenant, c'est vrai qu'ils arrivent par, je sais pas, ils viennent parceque ils ont du mal à rester chez eux et ils viennent chez nous. Je dis pas qu'ils font du mal chez eux, ça je ne dis pas, il y a des choses comme ça, mais ce sont des choses que je ne peut pas dire. Maintenant ils viennent, ils viennent là chez nous, et puis ils vivent avec nous » (X, 1991 in $1998: 107)$.

«Pour juger, il faut que le panier soit bien rempli. On peut blesser a mort comme ça [...]. ceux qui detiennent l'histoire n'ont pas le droit de parler. Si tu parles, tu détruis l'autre, mais la malédiction est sur toi. Tes ancêtres avaient fermé la chose " (Honoré Jöpöyöi, 1991 in $1998: 140)$

« Faut respecter les gens, parce qu'il y a toujours des choses qui se passent entre nous Kanak [...] même maintenant, [...] il y a la paix, mais il y a toujours des petits choses qui se passent entre les familles. [c'est pour] ça qu'il faut respecter les autres " (Gôdar Yaari, 1991 in 1998 : 191).

"C'est pour ça que à l'heure actuelle on ne veut plus dire des choses, parce que nous jeunes ne conservent pas, ne savent pas garder les secrets » (Guynemer Karé, 1995 in $1998: 129)$

" Je dirais que si on connait son histoire, [...] c'est à partir de lá qu'on doit le respect à quelqu'un. Mais si on ne connaît pas, il est évident qu'on fait n'importe quoi. Bon la réponse que je peut dire, [...], je dis que 'Els', il ne sait pas son histoire à lui. Parce que s'il aurait sue son histoire, tout ce qu'il fait à 'Fab', il ne lui ferait pas ${ }^{397}$ » (X, 1993 in $1998: 130)$

${ }^{397}$ Os termos 'Els' e 'Fabs' concernem pseudônimos aleatórios empregados pelo pesquisador. 
"C'est pour ça que je dis, il ne faut pas [...] parce que j'ai vu dans les autres [clans] des gens qui recontent des histoires comme ça, ca c'est marqué puis il y a des livres qui ont fait ca, mais [...] je crois qu'ils ont trop menti, il y a des choses qui ne sont pas vrais. $\underline{C^{\prime} e s t}$ bon s'ils ont dit pour eux ${ }^{398}$, mais les choses qu'ils ont parlé de la vallée, mais les choses d'ici, de la vallée, [...] je connais bien, il y a des choses que je connais, peut-être que je connais pas beaucoup mais [...] quand je vois dans les livres, c'est bon ce qu'il a marqué, mais ça ne correspond pas à ce que mon père il m'a dit, ce que les autres vieux ils m'ont dit » (X, 1993 in 1998 :137).

"Donc ça c'est pas des choses à dire, je te dis ça comme ça, mais pour que tu puisses mieux comprendre les choses, par exemple nous on parle pas beaucoup, mais ces choses-là si on sort, c'est des sécrets, ça va les déstabiliser, ça va les remettre en cause, ça va créer des enjeux. On n'a pas le droit de le dire, on se retient. Pourquoi ? Parce que ça appartient au passé et puis les vieux ils appellent, puis ils disent : "Faut jamais dire ça ». Moi, j'essaye de t'ouvrir une petite fenêtre pour te faire comprendre, parce que des choses comme ça, il y en a aussi partout ailleurs, mais c'est des choses que parfois tu trouveras pas. Moi, je t'ouvre quelque chose, comme ça tu comprendras que parfois, [...] il y a des questions, il y a pas des réponses, ou t'arrives pas à comprendre, parce qu'on peut pas te dire (X, maio 1992 in $1998: 142$ ).

Segundo Naepels há, de fato, uma prudência, uma ética do silêncio, em especial por parte dos coutumiers, - dignitários e homens de saber reconhecido -, relativa à 'tradicional' interdição de narradores em trazerem detalhes das histórias de outros clãs, linhagens e famílias para além do âmbito familiar próprio à transmissão de narrativas mítico-históricas cíhêdéé. Assim, tais interlocutores irão avançar a importância da manutenção da relação entre conteúdos e contextos adequados à transmissão ou enunciação daqueles conteúdos. Mas isso não impede que tais interlocutores elaborem reflexões a respeito do porque não devam comentar tais falas. Ao contrário, através daquelas interpretações, podemos vislumbrar o fato de que sua percepção de continuidade cultural, ou de 'ética', pauta-se nas relações que estabelecem entre contextos passados e contextos presentes ("tes ancêtres avaient fermé la chose ", "les vieux ils appellent, puis ils disent : "Faut jamais dire ça »), sugerindo uma importância de manutenção do emprego adequado de formas expressivas e discursivas através do

\footnotetext{
${ }^{398}$ Possivelmente em referência à obra "Les Chemins de l"Alliance" (Bensa e Rivierre, 1982), em que os narradores, através de narrativas cíhêdéé, tiveram o percurso de seus deslocamentos reconstruídos, mas que vêm também versar sobre eventos de intersecção com a história de outros clãs, linhagens e famílias. Note-se que, mesmo achando que o que foi dito sobre as 'coisas do vale' não correspondem ao que seu pai Iha havia transmitido, o interlocutor ainda acha bom que isso tenha sido 'marcado' nos livros, contanto que as 'histórias' versem somente sobre o grupo do próprio narrador.
} 
tempo, a conservação das relações entre formas e contextos de expressão presentes e aquela de seus antepassados e ancestrais ${ }^{399}$.

Vemos aqui de que modo, se a pesquisa antropológica de Naepels não se quis uma pesquisa com foco em 'naturally occuring discourses', mas sim em 'enunciados acerca da tradição', também ela vai dar conta de características da tradição oral no que diz respeito às relações entre formas de interação entre coletivos diferenciados e conteúdos adequados àquelas formas ${ }^{400}$. Assim, se o pesquisador não vai se 'adequar' às formas próprias à tradição oral Kanak (por sua pesquisa se realizar na forma de enquetes, de perguntas e respostas, em francês, etc.), ele também não demanda que estes realizem interpretações a respeito de conteúdos de suas tradições orais segundo uma 'exigência de verdade'. Nota-se, pelo contrário, uma exigência, da parte de (alguns) de seus interlocutores, da manutenção de uma ética ou respeito quanto aos âmbitos adequados de expressão daqueles conteúdos. Assim, os dados sobre os quais se baseia a análise do pesquisador concernem antes interpretações de seus interlocutores a respeito das formas adequadas da 'tradição oral Kanak', do que a virtual formulação da 'tradição Kanak' no que tange seus conteúdos. Não seria este um dos indícios de que as proposições e reflexões de Tjibaou, porque pautadas no propriamente 'tradicional' ${ }^{401}$, 'proliferaram ${ }^{402,}$ ?

Pode-se entrever, assim, modos possíveis de 'criação de espaço' para o debate a respeito de lógicas próprias, em que a 'enunciação da cultura' é substituída por uma enunciação acerca da cultura, que não necessita a constituição de uma identidade e

${ }^{399}$ Ao que me parece, essa atitude já havia sido sugerida por Jean-Marie Tjibaou ao afirmar: "la présence des esprits restent vivaces au coer de Kanaké. L'experiénce vécu de cette complicité passe par les contingences historiques. Mais elle ne doit jamais être identifié totalement aus institutions écrites, aux rites ou au matériel symbolique utilisé par une époque donné. En effet, ce qui est primordial et qui perdure au-delà des siècles, ce n'est pas cette expérience mais l'inspiration ou l'ethique qui fait surgir cette expérience dans l'histoire. Certes cette éthique s'affine au fil des années et reste teintée par la vie des hommes qui la retransmettent, mais c'est surtout l'inspiration qui la pérennise. En ce qui concerne kanaké et son devenir, il est clair que c'est l'éthique qui inspire la vie de son groupe qui doit survivre » (1976: 107-108). Gostaria aqui de propor uma articulação entre esta proposta e aquela avançada por um dos interlocutores de Naepels quando afirmou : «On peut blesser a mort comme ça [...]. ceux qui detiennent l'histoire n'ont pas le droit de parler. Si tu parles, tu détruis l'autre, mais la malédiction est sur toi. Tes ancêtres avaient fermé la chose » (X, 1991 in $1998: 140)$.

${ }^{400}$ Gostaria de ressaltar aqui a distinção entre essa opção e aquela adotada por Arthur Eid, apesar de ambas pautarem-se por uma abordagem de campo dita 'dialógica'. Pois se Eid concebeu o diálogo entre ele e um 'coletivo' Xavante (que não corresponde aos 'coletivos' tais como se elaboram em instâncias próprias à tradição oral), este irá repousar sua atenção nos conteúdos de 'narrativas míticas', com vistas à constituição de um só enredo cosmogônico. Sua atenção voltada a construção de uma 'história única', de modo coerente à sua proposta teórica. Já Naepels elabora sua pesquisa dialógica em interpretações de seus interlocutores acerca das relações entre 'coletivos' e variações no conteúdo de 'tradições orais' próprias àqueles variados coletivos.

${ }^{401}$ Segundo a acepção de 'lógicas e epistemologias próprias, através das quais culturas atualizam e recriam conhecimentos e práticas localmente'. Especialmente quando afirmou: En effet, ce qui est primordial et qui perdure au-delà des siècles, ce n'est pas cette expérience mais l'inspiration ou l'ethique qui fait surgir cette expérience dans l'histoire » $(1976: 80)$.

402 Notemos inclusive a 'intuição' de problemas futuros visualizados por Tjibaou na 'escrita da tradição'. Pois se seus propósitos remontam à década de 70 , àquela época a restituição da posse da terra era ainda da ordem da 'reivindicação'. Essa demanda só será efetivamente considerada legítima e posta em prática pela ADRAF a partir dos Acordos de Matignon, em 1988. 
patrimônio 'únicos', mas sim a percepção dos atores a respeito das formas culturais que vêm influenciar a construção e desconstrução daqueles 'coletivos' a cada contexto. E que não exige que os sujeitos indígenas abandonem seus próprios argumentos (pautados na continuidade das formas empregadas por seus ancestrais, ou no questionamento acerca da cadeia de transmissão) por argumentos científicos, ou pautados por uma exigência de verdade conforme nosso esquema ocidental (e 'da' história factual e cronológica), em que discursos são caracterizados pelas noções de 'racionalidade, legitimidade, sinceridade, autenticidade e verdade' (Habermas, 1984, $1987)^{403}$. Nesse caso, as 'lógicas' em que se foca Naepels, segundo as afirmações de seus interlocutores, não vão questionar o conteúdo deste ou daquele mito ou narrativa histórica ${ }^{404}$, mas interpretações acerca do que é ou não considerado 'adequado' de ser transmitido em um dado contexto, ou seja, lógicas que vêm informar a própria tradição oral. Dentre tais contextos, a situação mesma da pesquisa de Naepels, e o potencial 'risco' ou 'vantagem' vislumbrados por seus interlocutores na publicação de suas reflexões na forma de um livro ${ }^{405}$.

Podemos articular, a partir deste ponto, uma ponderação em torno de propostas de 'valorização cultural'. No capítulo Xavante, eu havia sugerido que a 'salvaguarda' e o 'registro' de patrimônios imateriais, em especial do que é ali chamado 'tradições orais', deveriam ser considerados momentos distintos, que deveriam se pautar, também eles, por procedimentos distintos. Considerando-se a possibilidade identificada pela pesquisa de Naepels, vemos como os próprios atores indígenas, se abordados de maneiras adequadas, podem vir enunciar como sua 'cultura' não conteúdos, mas formas de relação entre aqueles conteúdos e modos de interação próprios às suas 'tradições', assim como as variadas configurações de coletivos que os perfazem. Este aspecto é relevante na medida em que permite que, ao mesmo tempo em que se enuncia o 'propriamente imaterial', este não irá colocar em causa as clivagens que informam diferenças (e semelhanças) entre 'coletivos' segundo o ponto de vista dos nativos.

Considerando-se ainda a caracterização bakhtiniana da natureza pública da circulação discursiva, em que as idéias e palavras do "outro" participam necessariamente nas construções de discursos durante interações mediadas pela linguagem (2006:126), se tais explicações 'para o outro' permitem o 'empoderamento' e o reconhecimento daquilo que informa tanto o dinamismo quanto abre à percepção de 'lógicas e epistemologias'

\footnotetext{
${ }^{403}$ Nesse sentido, se os Xavante não concordavam em comentar as falas dos outros no âmbito do warã, e conforme o fato, já demonstrado, de que os efeitos da linguagem política não são 'ocultos' para seus atores, poderíamos pressupor aqui que os Xavante poderiam, efetivamente, elaborar reflexões distanciadas a respeito de 'porquê' não interessa a eles comentar tais falas.

404 Que, como vimos, são 'fatos' porque ditos, e nesse sentido, não são passíveis de questionamento, mas sim suas fontes de transmissão. Pois, 'eles vêem somente equívoco onde nós vemos contradição; consideram simplesmente que suas versões são mais corretas do que a de seus vizinhos' (Lévi-Strauss, 1986:150).

405 Naepels também se questiona acerca do sentido das transmissões realizadas para o antropólogo tendo em vista as relações e aos jogos de interesse que ele busca examinar.
} 
locais e próprias, o fato de se elaborarem segundo uma linguagem voltada a seu público-alvo (outros) e não à seu público-matriz, implica que tais enunciadosexplicações não interessem aos atores enquanto passíveis de 'proliferação', ou seja, de reinserção na cadeia de transmissão de tradições orais, justamente porque a 'lógica' da oralidade é outra, ao não exigir explicações acerca dos fatos narrados ${ }^{406}$. Mas permite, contudo, uma reflexão por parte dos atores acerca do porquê deva a oralidade ser valorizada enquanto tal, de modo que eles mesmos delimitem o que é cabível de ser 'fixado' por escrito, e o que deve permanecer, ser valorizado e viabilizado no âmbito da oralidade (veremos adiante as reflexões que têm feito os Kanak a este respeito). Assim, a escrita ou o registro deixam de ser a solução (ou, como se quer, a salvação), mas uma opção e, se for o caso, uma opção a ser adotada por eles e não no lugar ${ }^{407}$ (em detrimento) deles.

Se ações ligadas ao patrimônio imaterial contam com a 'valorização' por um público amplo como um dos meios de salvaguarda, somente uma clara distinção entre 'enunciados-explicações' para outros e 'exegeses' próprias à tradição oral podem efetivamente contribuir para que uma não contamine a outra, de modo a que os atores não sejam chamados a proverem explicações de suas histórias e 'enredos cosmogônicos'408.

A pergunta, portanto, é: que formas podem assumir 'tradições orais' registradas que interessem seus atores, que sejam adequadas à reinserção na cadeia de transmissão oral $^{409}$ ? Ou melhor: interessam efetivamente aos Kanak narrativas registradas? São elas passíveis, a partir de seu registro, de serem reinseridas na cadeia de transmissão oral $^{410}$ ?

\footnotetext{
${ }^{406}$ Segundo Walter Benjamin "notar-se-á facilmente a diferença entre quem escreve a história e quem a narra. O historiador é obrigado a explicar de uma ou outra maneira os episódios com que lida, e não pode absolutamente contentar-se em representá-los como modelos da história do mundo (...). A exegese não se preocupa com o encadeamento exato de fatos determinados, mas com a maneira de sua inserção no fluxo insondável das coisas" (1996:209).

${ }^{407}$ Como no caso do livro Wamrême Za'ra, em que narrativas produzidas tendo em vista o objetivo teórico de Arthur Eid, distinto dos objetivos ou interesses propriamente Xavante, são então 'recuperadas', e editadas por 'outros' ao vir compor aquela obra que, obviamente, não irá interessar seus sujeitos.

${ }^{408}$ Relembro aqui uma afirmação de Arthur Eid relativa aos Xavante, segundo a qual "observei que essa visão mais ampla e estruturada da trama cosmogônica não é algo totalmente dado e consciente para os narradores e o tradutor (...) eles não são muito afeitos a ficarem dando explicações sobre seus enredos cosmogônicos" (2003: 35).

${ }^{409}$ Ou seja, segundo as 'convenções mais formalizadas e recorrentes relacionadas à expressão verbal, consideradas em seu contexto cultural' (Finnegan:1992, 3); ou no 'conjunto de expressões orais de uma cultura, se aplicando às interações sociais fundamentais, segundo os modos considerados adequados de sua forma e uso' (Monod-Becquelin, 2005:34).

${ }^{410}$ Isso porque, considerando-se a apropriação das narrativas compiladas por Jean Guiart e Maurice Leenhardt e recuperadas e reelaboradas por Jean-Marie Tjibaou, vimos como, a partir dessa primeira 'proliferação', não houve 'proliferações' subseqüentes da narrativa de Téa Kanaké (para além de se constituir o 'elemento simbólico' que informa o Centro Cultural Tjibaou), mas de representações por ele ali avançadas, através da inserção de sua experiência e interpretação de uma dada narrativa naquela situação, e não das experiências dos indivíduos primeiros que tiveram suas narrativas transcritas ou compiladas pelos pesquisadores.
} 


\subsection{Registros da oralidade Kanak em um 'projeto' de valorização cultural}

Já vimos, dispersos neste capítulo, alguns aspectos que caracterizam o projeto de coleta e publicação de narrativas Kanak no âmbito dos Cahiers de Littérature Orale realizados pelo Centro Cultural Tjibaou em parceria com a ADCK, Agénce de Dévellopment de La Culture Kanak.

Desde seu número 40, que data de 2003, aquela revista têm publicado narrativas correspondendo, a cada edição, à uma região lingüística Kanak. Essas narrativas aparecem naquelas línguas e traduzidas para o francês, na forma de frozen speeches, tentando se aproximar dos modos discursivos orais através de sua transcrição 'ipsis literis'.

Vemos ali tanto a seleção de certas narrativas escritas por indivíduos Kanak compiladas por Leenhardt em seu 'Documents néo-calédoniens' (não todas, como já afirmado), como sua multiplicação, no sentido em que se privilegia a publicação de versões de narrativas produzidas atualmente que, quando versam sobre os mesmos temas que aquelas publicadas por Leenhardt, aparecem juntas em uma mesma edição. Um elemento relevante é o fato de que as narrativas hoje publicadas são feitas com a expressa permissão de seus narradores, que realizam exegeses tendo em vista sua publicação e divulgação para um público amplo. Assim, vemos que há uma seleção prévia pelos próprios atores daquilo que é passível de divulgação e daquilo que deve ser transmitido no âmbito estritamente familiar. De fato, esse aspecto limita, pelos próprios Kanak, o leque de abrangência dos conteúdos narrativos passíveis de fixação por escrito e sua potencial divulgação. As narrativas ali publicadas tendem a versar sobre eventos característicos de uma história mítica, que remetem ao surgimento dos primeiros homens e ancestrais, assim como eventos que relatam circunstâncias que promoveram relações de aliança entre clãs. Narrativas 'históricas' que remetem ao incesto, à antropofagia, à guerra, ou a situações que vieram opor certos clãs não aparecem naqueles Cahiers. Cada narrativa corresponde a um narrador preciso, e são fornecidas indicações acerca do gênero ${ }^{411}$, do 'intérprete' (esse é o termo adotado), sua idade, o local em que foi realizado o registro e sua data, de quem foram os 'coletores', quem operou a tradução, assim como notas que visam situar o leitor a respeito do tema e dos eventos apresentados na narrativa.

\footnotetext{
411 Todos correspondem ao gênero 'narrativas', apresentadas como 'récits'.
} 
Naquela primeira edição $\left(n^{\circ} 40\right)$, os primeiros narradores já consultados prestaram depoimentos a respeito de sua opinião sobre a iniciativa. Desse modo veremos que os pontos de vista avançados a respeito do porquê decidiram contribuir ao projeto de coleta da 'literatura oral' Kanak variam de um indivíduo a outro e de seus entendimentos e intenções quanto à proposta e, especialmente, de quem é seu públicoalvo. $\mathrm{Na}$ edição $\mathrm{n}^{\circ} 50$ foram realizadas entrevistas junto aos 'coletores', os jovens que trabalham nas ações de registro junto aos 'velhos' e coutumiers.

Trago aqui algumas reflexões elaboradas pelos 'narradores' e, em seguida, pelos 'coletores':

$p^{412}$ - "Mais n'y a-t-il pas un risque de soulever plus de problèmes qu'on va les resoudre si on ressort beaucoup d'histoires du passé ?

"C'est là où on doit faire jouer la diplomatie Kanak...ll y a trois formes de passé : le passé qui est enterré, qui est le plus sensible, qu'il ne faut pas remuer parce qu'on risque alors d'allumer le feu et de decléncher la guerre. Le passé secret, qui reste interne au clan, et le passé qui permet de communiquer et de se comprendre... " (Henri Poiroi- Tribu Ouichambo, Mwà Véé,2003: 31)

«... c'est avant tout pour mes enfants que j'ai transmis, pas pour un plus large public...je peut transmettre ce qui je sais à mes enfants, petits-enfants et arrièrépetits-enfants, mais je ne peux pas transmettre ce qui appartient aux autres clans...c'est à chaque clan de définir a son niveau les savoirs qui doivent être transmis...mais en même temps il faut être capable d'apporter des preuves de ce qu'on transmettons...moi, quand je transmets a mes enfants, je peux justifier que ce que je dis est bien réel, on peut le vérifier. Sinon, n'importe qui peut dire et transmettre n'importe quoi ${ }^{413} \ldots$ » (Jean Marie Nîri Neba - Tribu de Amââ de Canala, 2003 :38)

p- « a tu peur que ce savoirs ne se transmettent plus dans l'avenir et qu'ils se perdent?"

" je ne pense pas, car ses savoirs appartiennent aux clans et à la chefferie et, de cette façon, ils seront toujours transmis, si dans ma propre famille il n'y a plus personne pour les recevoir, il aura toujour quelqu'un dans le clan pour perpetuer le travail...j'ai décider de parler pour vous donner toutes ces informations. Ce sont les sprits des vieux qui vous donnent ce travail qui nous appartient, à nous les Kanak. Comme vous travailler au Centre Tjibaou, tout cela nous concerne. Avant vous, d'autres personnes sont venus pour avoir des informations, mais je ne les ai jamais donner... je souhaite que mes

\footnotetext{
412 Pergunta realizada pelos jornalistas na revista Mwà Véé.

${ }^{413}$ Relembro aqui uma questão que já havia sido colocada no capítulo Xavante: O quanto o conhecimento oral transmitido segundo 'caminhos' inadequados não se constitui uma 'farsa', do ponto de vista de seus atores?
} 
enfants et petits-enfants sachent. Lorque je ne sera plus là, tout ce savoir reccueilli sera pour eux. C'est surtout pour mes enfants que je fais cela " (Hilarou Nêjimöö - Tribu Wipwê, 2003:41).

Nesse sentido, vemos as fraturas entre uma preocupação dos sujeitos Kanak para que a transmissão se realize tendo em vista seus filhos, netos e bisnetos ou seu clã, e a afirmações a respeito desse 'saber' concernir aos Kanak em geral. Mas se tais narrativas podem potencialmente tornarem-se 'públicas', não é todo o 'passado' que pode ser ali exposto. Assim, o quanto tais narrativas registradas na forma escrita interessam aos Kanak?

Vejamos as reflexões elaboradas pelos jovens coletores 3 anos depois do início do trabalho, explicitadas na edição n50 da revista MWá Véé (2006: 23-27).

"Le fait même de collecter suscite la curiosité pour la langue et la culture. Sinon, comment les gens, les jeunes, peuvent-ils s'intéresser à leur culture si on n'en parle pas? »(Sébastien Atti, Touaourou-Yaté).

«..maintenant, nous enfants se réfèrent à ce que d'autres (etnhologues, anthropologues, historiens) ont écrits; mais nous écrits à nous? Or il faut que nous enfants puissent se référer à des choses qui ont été écrits par nous, les Kanak. Pour cela, il faut non seulement collecter, mais aussi transcrire...c'est pour cela qu'il faut écrire quelque part, même si on garde cela confidentiel... " (Dominique Oye, Ometteux, Poindimié).

"...nous ne sommes pas dans l'archéologie, nous avons affaire à une matière vivante. Si nous collectons, ce n'est pas pour figer les savoirs une fois pour toutes, c'est pour contribuer à ce qu'ils continuent à vivre en les 'réinjectant' en quelque sorte dans le vécu kanak d'aujourd'hui, et en sénsibilisant les gens à leur intêret...la coutume est au coer même de la collecte... » (Gibert Kaloonbat Téin, Bas-Coulna, Hienghène).

"...c'est vrai que la collecte crée une dynamique dans la mesure où les savoirs collectés sont directement retransmis aux gens de la tribu” (Teddy Dounote, Ouayaguette, Hienghène).

Podemos situar aqui alguns pontos relevantes a partir dessas entrevistas. Primeiramente, que os 'transmissores' têm em mente, como público-alvo primeiro, sua família, seus descendentes. Isso não sugeriria que, para eles, tão importante quanto as 'idéias' é a cadeia de transmissão de tais conhecimentos, as ancoragens que relacionam pessoas, que as situam no tempo e no espaço em relação a seu passado, à 
seus ancestrais ${ }^{414}$ ? Lembremos ainda a firmação de Tjibaou segundo a qual: «Le mythe est un récit à caractère légendaire sur l'origine d'un clan. Il faut se dire que chaque clan se considère comme le centre des relations qui existent entre les membres d'une même tribu et qu'en conséquence l'origine d'un clan est perçu comme l'origine du monde environnant. En effet, l'ensemble du réseau est perçu à partir du point précis qu'est le tertre [d'origine] sur un plan spatial, et la position sociale au niveau du système hiérarchique de la tribu » (Tjiabou, 1996 : 62). Desse modo, não há sentido para os leitores kanak, enquanto fundamento de seu próprio lugar e de sua experiência, 'narrativas' ou 'histórias' que tenham como o 'ponto de percepção' da rede outro 'ponto' que não o seu próprio. Se tais versões são 'interessantes' de serem acessadas, elas não poderão, e se este for o caso, serem transmitidas como suas. Assim, narrativas de outros 'grupos' registradas naquela revista podem ser vistas como 'próprias aos Kanak' enquanto soma de 'pontos de percepção da rede', mas não enquanto narrativas passíveis de 'proliferação' para além do coletivo do próprio narrador.

Em segundo lugar, aquelas 'entrevistas' mostram que os transmissores se inquietam do fato que, quando meramente 'registrado', não há como 'provar', 'mostrar' que efetivamente se 'conhece' ("il faut être capable d'apporter des preuves de ce qu'on transmettons...moi, quand je transmets a mes enfants, je peux justifier que ce que je dis est bien réel, on peut le vérifier"). Ou seja, o quanto narrativas orais podem ser desvinculadas das efetivas pessoas e das situações concretas de transmissão?

Em terceiro lugar, que através da coleta, o conhecimento 'vivo' pode tanto ser 'reinjetado' na vivência atual, como diretamente transmitido às pessoas da tribu (espaço de co-residência), àquelas que acompanham, ao vivo, o trabalho. Nesse sentido, me parece que a coleta e o registro da 'tradição oral' deva ser feito com um enfoque antes no próprio processo de sua realização do que em seus produtos, ao engajar os narradores e coletores através de uma 'novidade', que é o 'projeto' e seus aparatos técnicos. Mas para que seja passível de 'reinjeção' é imprescindível que os agentes da 'coleta' sejam os próprios membros das famílias, clãs e linhagens. E ainda, o contato direto entre 'transmissor' e receptor pode garantir que se adotem as formas adequadas à transmissão oral (não através de 'perguntas e respostas') segundo informada pelos modos de interação da tradição oral, de forma que o que se transmita não sejam somente 'conteúdos', mas as formas expressivas e discursivas que as acompanham. Também me parece que deve caber a cada 'coletivo' a decisão a respeito de se deseja ou não que tais registros sejam realizados, e a quê e a quem são eles efetivamente destinados e as modalidades como tais decisões podem ser postas em prática.

Enfim, parece-me que os Kanak se interessam mais pela própria experiência da produção de registros, pelo fato de requerer encontros propriamente ditos, do que por

414 E a importância da autoria de cada narrativa. 
tais narrativas de caráter 'público' em sua forma registrada. Inclusive se consideramos que "a importância de um homem ou de um grupo varia em relação proporcional ao volume de suas relações que à suas riquezas em bens ou mesmo à posição (ranque hierárquico primogênito/caçula) que detém localmente ${ }^{415}$ " (Bensa, 1995: 289). Pois me parece, deste fato, que o valor ou a importância de um homem irão também depender de seus conhecimentos históricos, assim como retóricos e expressivos, 'potências' para o estabelecimento de relações e somente passíveis de serem postos em prática durante efetivos encontros entre indivíduos e coletivos Kanak. E, justamente, pelo fato de serem tais conhecimentos (conteúdos) aqueles considerados 'valiosos', esses não podem ser tornados 'públicos' através de narrativas históricas publicadas naquela revista.

Decorre daí que não são as narrativas e seus conteúdos, mas contextos e formas corretas de entrada em relação que conformam um 'patrimônio imaterial' que diz respeito à 'tradição oral' compartilhada por todos os Kanak. Talvez derive daí o fato de os Kanak identificarem a si como aqueles que 'font la coutume ${ }^{416}$, ou seja, aqueles que participam de trocas de bens e discursos cerimoniais. Nesse sentido, se um 'coletivo' Kanak não existe para além dos pequenos coletivos contextuais conformados através dos discursos da accueil, há um reconhecimento acerca de uma forma expressiva compartilhada por todos os grupos, em que a ética inspirada pelos ancestrais vêm informar sua experiência histórica. Ao passo que ao Centro Cultural Tjibaou, que intenta reunir 'objetos' e 'documentos' do passado, assim como produções culturais e artísticas Kanak e 'caledônias', como da Oceania de modo geral, muitos Kanak o chamam coquille vide (Graille, 2001:15).

\footnotetext{
415“Todas as estratégias de ascensão política começam pelo bom entretenimento de relações que são herdadas com o nome e o ranque de sua linhagem: é preciso visitar seus parentes, em especial seus tios maternos, assim como aqueles com os quais se partilha ou se partilhou um mesmo espaço de referencia (itinerário ou grupo de tertres de origem)" (Bensa, 1995: 289)

416 Vimos como este aspecto é hoje efetivamente reconhecido. Quando de encontros formais que demandam a presença daqueles dignitários Kanak e de outros agentes de setores da sociedade da Nova Caledônia,como representantes das Igrejas, propositores de 'projetos' assim como representantes do governo francês, estes vêm sempre dar início aos encontros através dos gestos formais da accueil, oferecendo bens cerimoniais e discursos, ainda que em geral em francês, que tanto vêm reconhecer oficialmente uma autoridade Kanak local, como irão descrever, em discursos realizados pelos dois lados, a organização dos 'coletivos' ali representados e as intenções implicadas pela cerimônia (Monnerie, 2005). Ou seja, se a narrativa Kanaké não proliferou, proliferaram suas representações.
} 


\section{Conclusão}

\section{Ou a valorização como tradução ${ }^{417}$}

Amadou Hampâté Bâ, de origem peul, ficou conhecido pelo valioso conjunto de sua obra, fruto de mais de meio século dedicado ao estudo e compilação de peças da literatura oral africana. Seu livro 'Étrange Destin de Wangrin recebeu o grande prêmio literário da África Negra em 1976, e suas publicações são hoje referências para aqueles que se interessam pela arte verbal. Também é de sua autoria a famosa frase "quando um velho morre na África, é toda uma biblioteca que queima" ${ }^{418}$.

Hampâté Bâ empregou ali a metáfora da biblioteca para ilustrar a grande experiência e sabedoria de velhos indígenas africanos, tão rica como a dos sábios ihi Xavante, dos coutumiers KanaK ou dos jovijã Wajãpi. Mas aquela frase vem também esboçar uma confusão recorrente. Ela foi produzida por quem e para quem?

O fato de seu autor ter sido Hampâté Bâ poderia indicar que essa imagem da biblioteca corresponde a uma concepção propriamente peul. Mas pensando bem, será que a idéia de uma biblioteca em chamas tem o mesmo efeito sobre os Xavante, os Kanak, ou os Peul que sobre 'nós', ocidentais?

Essa metáfora pareceu partir de uma consideração a respeito do lugar fundamental que ocupam 'bibliotecas' no nosso imaginário acadêmico e 'ilustrado' ocidental. Tendo a frase sido produzida para nós, seu emprego poderia até parecer coerente. Contudo, traduzir um valor peul (velhos) por um valor nosso (biblioteca) pode acarretar o efeito inverso, ao sugerir que eles atribuem importância similar a bibliotecas e a pessoas. Ou de que o que se perde com a morte de velhos indígenas são 'suportes' de conhecimentos acabados, e não as pessoas e as experiências e sentidos a elas associados.

Nos esforços e nas dificuldades de tradutibilidade de lógicas e valores que residem as principais questões da antropologia. Estas vêm incidir sobre a reflexão que busquei elaborar aqui, relacionada às iniciativas de 'valorização cultural' e, entre elas, aquelas que visam ações de registro de 'tradições orais' segundo a proposta de salvaguarda de 'patrimônios imateriais'. O que está em jogo é tanto o foco da 'valorização', quanto seus sujeitos. Valorização de quem e por quem? Ações de 'valorização' pautam-se por quais noções de 'valor? Valoriza-se aos olhos de quem?

\footnotetext{
${ }^{417} \mathrm{Ou}$ “como pensar a a 'valorização' se seus pressupostos são 'euro-americanos', aplicados 'sobre' outras lógicas e epistemologias?"

418 "Lorqu'un vieillard meurt en Afrique, c'est une bibliothèque entière qui brûle ".
} 
A metáfora de velhos indígenas como 'bibliotecas' parece predominar em diversas iniciativas de 'valorização cultural'. Em especial aquelas que vêm no registro um fim em si mesmo, sem se questionarem se seus conteúdos e modos de apresentação correspondem àquilo que é tido como realmente importante pelos índios ${ }^{419}$. ‘

Aquela imagem tende ainda a promover uma mistura recorrente entre a noção de 'arquivo' e aquela de 'repertório'. Segundo Diana Taylor (2003), o repertório se encarna nas representações, experiências e sentidos das pessoas, e se manifesta através da vivência e da ação. Saberes articulam-se às relações sociais envolvidas em sua criação, sua transmissão, interpretação e reprodução. Já 'arquivos' concernem informações ou saberes em sua forma fixa e acabada, desvinculados de suas bases humanas e, portanto, de sua permanente atualização e transformação.

Esta abordagem é especialmente relevante no que diz respeito a tradições orais, e à crônica confusão entre estas e aquela a que se chama 'literatura oral'. Se a literatura oral concerne narrativas ou ditos originalmente orais, que se apresentam na forma de textos escritos valorizados por suas qualidades artísticas ou estéticas, 'tradições orais' e os conteúdos variáveis ali produzidos, não podem ser considerados desvinculados de seus contextos de ocorrência, das pessoas e de seus repertórios vivos, assim como das relações que implicam. 'Tradições orais' dizem respeito, antes, aos modos corretos de interação social e, em sua decorrência, dos conteúdos e formas expressivas adequadas.

Esse potencial conflito já podia ser identificado na definição mesma de tradições orais, enquanto "convenções mais formalizadas e recorrentes relacionadas à expressão verbal, consideradas em seu contexto cultural" (Finnegan:1992, 3), ou no "conjunto de expressões orais de uma cultura, se aplicando às interações sociais fundamentais, segundo os modos considerados adequados de sua forma e uso" (Monod-Becquelin, 2005:34).

Pois se tradições orais consistem em modos expressivos e discursivos adequados a modalidades de interação segundo contextos precisos, seria de alguma forma possível colecionar 'tradições orais' através de registros? E ainda, o quanto narrativas, discursos e enunciados 'registrados', ao perderem sua relação com seus sujeitos e contextos originais de produção, não deixam de pertencer à categoria 'tradições orais' para se tornarem peças de uma 'literatura oral'?

\footnotetext{
${ }^{419}$ Como em situações em que 'dados etnográficos' produzidos a partir de questionamentos teóricos e segundo metodologias adequadas àqueles enfoques, quando concluídas as pesquisas, 'sobram' na forma de gravações e anotações, em geral fragmentos de 'enunciados orais' ou de 'saberes'. Então o pesquisador (através do 'projeto') vem com a idéia da produção de uma compilação daqueles dados na forma de um livro, pensando que 'vai ajudar para que o conhecimento não se perca'. A quem interessa esse conhecimento fragmentado, descontextualizado e na forma escrita, em primeiro lugar?
} 
A atual acepção antropológica de cultura é de 'formas dinâmicas através das quais indivíduos e grupos atualizam seus conhecimentos e práticas, e modos como tais conhecimentos e práticas são localmente produzidos e utilizados'. Contudo, isso não acarreta que aqueles 'indivíduos' ou 'grupos', 'localmente', vejam a si como um só 'coletivo, 420 .

Atentando-se para modos de interação e formas expressivas adequadas às tradições orais descritas nessa pesquisa, pareceu justamente que aqueles coletivos só se elaboram enquanto 'coletivos' em certos contextos de interação e, especialmente, que estes 'coletivos' não se alinham de modos coerentes quando tomados em seu conjunto ${ }^{421}$.

Há, portanto, uma relação intrínseca entre 'o que se fala', 'como se fala' e 'quem' fala (ou quem 'se fala') em cada contexto ${ }^{422}$. E uma das situações que 'replicaram' entre os casos 'Xavante' e 'Kanak' concerniu justamente o desinteresse de seus atores em tornar explícita, em âmbitos de interação adequados às suas tradições orais, essa disjunção transcontextual entre as formas como se elaboram 'coletivos' ${ }^{\text {423 }}$.

No que diz respeito à suas tradições orais, seu interesse pareceu estar sempre voltado à produção de conteúdos de acordo com formas adequadas àquelas interações, de modo que o foco da atenção vem incidir primeiramente nas relações, e em seguida na produção de conteúdos adequados a elas.

Deriva daí que os Xavante não vêem contradição entre os debates vespertinos intrafaccionais e os discursos polifônicos produzidos no warã; nem entre as potenciais distinções, para os Kanak, entre narrativas mítico-históricas cíhêdéé próprias ao âmbito familiar, e narrativas e discursos públicos jèmà e vivaa. O que é tido como importante do ponto de vista dos atores, é que esses conteúdos produzidos segundo modalidades distintas de coletivos mantenham-se separados entre um contexto e outro.

O que me parece relevante, ainda, é que essa disjunção entre 'coletivos' e 'conteúdos' adequados segundo aqueles coletivos ${ }^{424}$ não é 'oculta' para seus atores ${ }^{425}$.

\footnotetext{
${ }^{420}$ Gallois já havia que 'não é da natureza dos saberes e práticas criadoras de significados culturais serem associados à identidade. Nem é sua função e característica constituírem-se enquanto 'patrimônio' (2005:5).

${ }^{421}$ Segundo Roy Wagner 'consistency is not always maintained from one 'nodal level' to another, and therefore any attempt to put together the whole as a 'system' or 'order' is invariably compromised" (...), 'groups never materialize' [because] sociality is a 'becoming', not a 'become' thing' (1974: 111-112).

${ }^{422}$ Ao considerarmos enunciados como atos de fala, 'coletivos' podem ser decorrentes destes mesmos atos, como no caso dos discursos vivaa no âmbito do accueil Kanak, e do ihi mrémè no warã Xavante.

${ }^{423}$ No caso Xavante, a fratura entre as produções discursivas nas reuniões vespertinas internas às facções em relação à arena política warã; no caso Kanak, as disjunções entre narrativas cíhêdéé produzidas no âmbito familiar e narrativas e discursos 'públicos' jèmà e vivaa. Em relação aos Xavante, Laura Graham afirmou ainda que os atores negavam comentar suas falas e de outros no âmbito do warã (mesmo que a interlocutora é um 'outro'). Em relação aos Kanak, Naepels afirma que seus interlocutores sentiam-se desconfortáveis em remeter a eventos históricos relacionados aos trajetos de outros clãs e linhagens.

${ }^{424}$ Ainda que, segundo Graham, os Xavante não sejam 'metalingüísticamente' conscientes das características formais de suas 'tradições orais'.

${ }^{425}$ Ainda que não a enunciem segundo os mesmos argumentos 'metalingüísticos' e 'teóricos', efetivamente nossos.
} 
Contudo, se Urban (1986) considerou o emprego da linguagem formalizada como um 'sign vehicle', 'a model of and for general solidarity', meu ponto de vista, segundo a mesma abordagem adotada por Laura Graham, é a de que são as formas expressivas quem são consideradas relevantes para seus atores, e não uma pretensa 'solidariedade,426. É a atenção na manutenção dos modelos e exemplos de seus ancestrais que gera e alimenta um sentimento de continuidade através do tempo.

Aquela 'clareza' dos sujeitos quanto à importância da disjunção entre certos 'coletivos' e respectivos 'conteúdos', assim como a atenção dos atores aos aspectos estéticos considerados belos e adequados a formas de interação, me pareceu ser um dos potenciais focos de ações de ações de patrimonialização de bens culturais imateriais, mas que exige, contudo, um 'reconhecimento' prévio e enunciado enquanto tal por si, e então por outros ${ }^{427}$. Pois o exemplo de certas 'entrevistas' segundo realizadas por Naepels sugeriu que, se abordados de formas adequadas, sujeitos indígenas podem efetivamente produzir explicações, múltiplas e segundo os sentidos e associações avançadas por cada um dos atores, acerca do Ihes parece importante; ou seja, 'o respeito' ou a 'ética' à inspiração dos ancestrais, às articulações entre a manutenção de certas formas expressivas e discursivas em dados contextos de interação, assim como seus conteúdos. O que não exige que se apresentem como 'um só coletivo', de modo a proporcionar a substituição dos conhecidos 'enunciados da tradição ${ }^{428,}$ por enunciados acerca da tradição ${ }^{429}$. A atenção e a divulgação a respeito de formas do emprego da parole segundo características estéticas, modos e usos por eles valorizados, não vem exigir a permutação de suas explicações pelas nossas. $E$ ainda, tais reflexões e 'explicações' podem fazer com que os atores valorizem a oralidade em si mesma, em que ações de registro, se este for o caso, tornem-se uma opção deles.

Uma outra questão aqui concerniu: registra-se para quem (ou para que)?

Dentre os dois casos, Xavante e Kanak aqui analisados, a única situação em que a iniciativa de registro partiu efetivamente de um narrador indígena foi a de Warodi. Mas me pareceu que Warodi não tinha em vista, através do registro de suas narrativas, a transmissão de conhecimentos a seus filhos ou netos, ou às futuras gerações. Seu intuito mostrou-se ser a de sua atuação em seu papel de ihi, sublinhando seu valor para si, os seus, e enquanto líder de aldeia. Através do registro Warodi pôde dar

\footnotetext{
${ }^{426}$ Segundo os interlocutores de Naepels : 'tes ancêtres avait fermé la chose', 'les vieux ils disent; jamais II faut dire ça' (1998:147). E segundo reportado por Graham:

"Etepa: of course/it is always we [the elders]/it is always we who enliven the celebrations/and [thus] surpass the other villages.

Sipuba: so our ancestors/our ancestors/ through our lives they will be remembered/like this we will bring down [rise above] the other villages/ we will let our stories be heard/ this is the way it will be" (2003:170).

${ }^{427}$ Considerando-se a natureza pública dos discursos de Bakhtin, em que as idéias e palavras do outro participam necessariamente de discurso mediados através da linguagem, seria necessário, para tanto, que os interlocutores de sujeitos indígenas passassem também a enxergar cultura como algo dinâmico, e não como uma suposta 'tradição imutável'.

${ }^{428}$ I.e: 'culturas' oficializadas a partir do fundamento em 'identidades culturais', enquanto 'discurso político' (segundo nossos termos).

${ }^{429}$ Segundo lógicas e epistemologias próprias.
} 
continuidade aos modos de 'crescer a si' através de cada vez mais proximidade com os ancestrais, tendo inclusive recebido, naquele contexto de interlocução com a pesquisadora, um novo nome de imortal em sonho, Tsiputõri'o. Não seria este um indício de que nossas 'ferramentas' podem ser empregadas para outros usos, para além de nossa (estreita) imaginação, de acumular informações?

Também me pareceu digno de nota as duas 'proliferações' aqui identificadas dizerem respeito a 'narrativas', excluídas do âmbito próprio à 'tradições orais'. Porque tanto narrativas compiladas por Leenhardt quanto aquelas gravadas de Warodi possuíam como característica comum concernirem produções individuais, que não supunham contextos de interação. E parece que foram passíveis de 'proliferação'430 justamente deste fato. $E$ ainda, o fato de terem sido registradas na língua e conforme a ancoragem própria a narrativas orais, que necessitam que os narradores sejam indicados ${ }^{431}$, permitiu que tais narrativas não fossem vistas como passíveis de 'rechaço' ou 'interrupção'.

Efeitos de rechaço foram identificados em relação a discursos e enunciados que, tendo sido produzidos em um dado contexto de interação, com vistas a certos interlocutores, têm seu registro negado quando seus sujeitos supõem que estes enunciados registrados possam ser acessados por outros ouvintes, diferentes daqueles aos quais foram previstos. Ou em casos em que aceitaram que seus enunciados fossem registrados tendo em vista a discrição do pesquisador, como no caso de Naepels e de seu 'uso temperado do anonimato'.

Já efeitos de 'interrupção' concerniram registros que, produzidos de acordo com formas enunciativas de um 'outro'432, se pautaram também por questionamentos distintos daqueles a que dão importância sujeitos indígenas, de modo a não despertarem sua curiosidade ou interesse. Como no caso da pesquisa de Arthur Eid que, segundo uma hipótese propriamente teórica e sua, veio demandar explicações a respeito de 'conteúdos' de narrativas cosmológicas ${ }^{433}$, segundo formas de expressão discursiva que concernem debates em coletivos que não correspondem a nenhum 'coletivo' na vida real (apesar de que juntos, aqueles velhos participam do espaço do warã. Mas ali o 'coletivo' é outro, pautado por interesses outros e pelo emprego do ihi mrèmè). Vimos ainda o potencial desinteresse ${ }^{434}$ dos Kanak pelas narrativas registradas pelo projeto Cahiers de Littérature Orale produzidas pelo Centro Cultural Tijbaou que, ao privilegiarem narrativas 'públicas' sobre a origem dos clãs, não vão interessar a todos os Kanak, que, como observamos, só existem em 'potencialidade' de

\footnotetext{
${ }^{430}$ Deverei discutir em que medida poderíamos qualificá-las como 'proliferações' adiante.

${ }^{431}$ Assim como, potencialmente, a cadeia de transmissão que 'levou' a narrativa até ali.

${ }^{432} \mathrm{Em}$ que sujeitos foram vistos como indivíduos modernos, que têm seus enunciados pautados pelas noções de verdade, legitimidade, autenticidade e subjetividade (Habermas, 1984, 1987).

${ }^{433}$ Que não se questionam porque são fatos.

${ }^{434}$ Esta é uma suposição. Não tive como saber se os Kanak efetivamente se interessam pelas narrativas registradas.
} 
virem se tornar 'um só' coletivo através da prática e dos discursos e trocas cerimoniais de accueil.

Gostaria de ressaltar que aquelas 'proliferações', em que enunciados seriam 'reinseridos na cadeia de transmissões orais' tal como eu havia elaborado em minhas questões para essa pesquisa, não me parecem possíveis, ao menos não como eu as vislumbrava. Pois tanto no caso das narrativas gravadas de Warodi 'recuperadas' por Riridu, quanto nas narrativas compiladas por Leenhardt a que Tjibaou faz uso em sua invenção mítica e cênica de Tèa Kanaké, eu só pude afirmar que elas corresponderam a 'proliferações' em função dos indícios, das descrições de Laura Graham e das referências bibliográficas empregadas por Tjibaou. Considerando-se ainda a noção de repertórios e a flexibilidade e mudança introduzidas pela contribuição pessoal e criativa a cada performance individual, assim como as características próprias à transmissão oral em que 'o narrador é criador mesmo que imagine só repetir' (Menget e Molinié, 1993:12) me parece que, se houve ali 'proliferações', elas corresponderam mais à importância, no âmbito da oralidade indígena, de índices que vêm tornar 'legítimos', aos olhos de seus atores, narrativas e enunciados que fazem recurso a um ancestral nomeado ${ }^{435}$. Mas tanto a narrativa quanto a encenação de Téa Kanaké, como a expressão discursiva de Riridu em suas performances constituíram-se em efetivas 'novidades' (claro, porque sujeitos não são bibliotecas). O que me pareceu ser passível 'proliferação' foram antes representações, estas de autoria individual de Riridu e Tjibaou que, por razões a que a minha razão desconhece, tornaram-se eficazes e passíveis de propagação, fazendo de representações individuais, públicas.

Outro elemento que não pôde deixar de ser notado nos dois casos, foi a eficácia quanto ao emprego de encenações ou representações cênicas enquanto um modo que, se visto como didático e voltado para 'outros', produz efeitos relevantes para si, assim como novas maneiras de tornar representações individuais, públicas. Este aspecto, contudo, mereceria outra pesquisa.

Finalmente, gostaria de retornar à questão da valorização e de suas implicações na tradutibilidade de lógicas e valores. Já testemunhamos os riscos de tais propostas de 'valorização', em especial no que diz respeito à tradução de valores indígenas (como sua relação com seus ancestrais e a importância de seus velhos) a partir de conceitos, termos ou imagens que correspondem à nossas formas de avaliação (em que a noção de valor pode ancorar-se na relevância de acúmulo antes de idéias do que de gentes). Esse movimento contribui ainda para um outro, que seria a de suas explicações serem substituídas pelas nossas, tendo em vista que ações de 'empoderamento' consideram

\footnotetext{
${ }^{435}$ Me pareceu, contudo, que o fato de Tjibaou buscar narrativas relacionadas a seu próprio clã, assim de Warodi ser irmão do pai de Riridu, contribuíram para a 'legitimidade' dessa 'apropriação'.
} 
que populações indígenas, ao serem reconhecidas e valorizadas aos olhos de outros (dos brancos), serão, então, valorizadas por si mesmas ${ }^{436}$.

Vimos o caminho inverso proposto por Tjibaou, em que um reconhecimento do valor da 'arte de ser melanésia' a partir da acepção de 'qual é o conteúdo dessa mensagem,437 deveria preceder um reconhecimento aos olhos dos outros.

Não foi justamente a tradução errônea o foco da crítica de Tjibaou a Leenhardt? Uma tradução que, a partir da explicitação de mensagens bíblicas, demandava que seus interlocutores encontrassem em sua própria língua, em suas representações e segundo suas lógicas, imagens ou mensagens similares para, através de uma astuta manobra, vir 'colar' representações cristãs a termos e conceitos da cosmologia nativa, recobrindo um sentido pelo outro, um valor pelo outro? Ao promover a 'colagem', a similitude e então a (virtual) substituição do valor fundamental que os Kanak atribuem a seus ancestrais e seres totêmicos originais por aquele dos santos e valores cristãos, Leenhardt não veio afirmar, por outros meios, a situação dos Kanak enquanto 'selvagens', enquanto uma civilização marcada pela 'falta', a quem é necessário aportar as 'benfeitorias' da colonização? ${ }^{438}$

Segundo Tjibaou, somente o reconhecimento da 'arte de ser melanésia' segundo seus próprios termos poderia efetivamente responder à questão do 'comment peut-on être Kanak dans le monde moderne. Pois, '"en ce moment là, la société peut rester dans sa stabilité parce qu'elle n'est pas remise en cause dans son fondement par des références autres" (Tjibaou, 1978).

Daí que me parece, que é somente a partir da correta tradução entre lógicas e valores distintos, mas segundo seus próprios termos, que "cultura enunciada" poderia se aproximar de cultura enquanto 'lógicas', a partir do reconhecimento, por nós, de outros valores e de outras formas do político diversos de nossa 'política', inclusive de 'empoderamento' 439 . Mas para isso seria necessária uma primeira transformação de nossa sociedade.

\footnotetext{
${ }^{436}$ Decorre daí a noção de que a etapa de 'registro' das políticas públicas do patrimônio imaterial já seria uma primeira ação de 'salvaguarda'.

437 A 'Parole', no em língua houaïlou e ewëke em Lifou é, segundo Leenhardt, ao mesmo tempo palavra, ação e pensamento. A ação que ela anuncia, o passado que ela celebra e a relação que ela ativa, tanto em relação aos ancestrais, quando não se sabe quando ela começou, quando dita os comportamentos, segundo a expressão 'la parole que dure', quanto em relação aos contratos de troca e de aliança. Segundo Leenhardt, 'la société canaque repose sur um ensemble de contrats passés, non points entre personnes mais entre générations. Dans les affaires de mariage, le femme accordé a un clan est un prêt. (assim como 'empréstimos' e dons e contra-dons de crianças para adoção). Elle doit faire retour au clan en la personne de sa fille ou de sa petite-fille. Cette personne qui va remplir une dette est 'la vie de la parole', qui unit ceuxci et maintient la société'. (Leenhatdt, M.1932: 212-236).

${ }^{438}$ A mesma crítica, menos afiada, contudo, caberia a Arthur Eid.

439 Parece-me relevante a caracterização de Graille (2001) do momento atual da história Kanak como 'pacifista'. Esse elemento não poderia ser associado ao fato de que os Kanak se percebem como tendo sido reconhecidos enquanto maîtres de La terre a partir do atual emprego das práticas da accueil, de suas formas do político, por outros?
} 


\section{Bibliografia}

AGRAWAL, Arun. 1995. "Dismantling the divide between Indigenous and Scientific Knowledge". In Development and Change. 26 (1995):413-439

ANDERSON, Jane. 2005. "Acces and Control of Ingigenous Knowledge in Libraries and Archives.Ownership and Future Use". In

http://www.conservationcommons.org/media/documents/docu-164cij.pdf

ARANTES, Antonio Augusto. 2007. "Diversity, intangible cultural heritage and cultural politics". In M. Featherstone (ed.). Problematizing global knowledge. Londres: Sage.

ARANTES, Antonio Augusto. 2008. "Patrimônio Cultural: desafios e perspectivas atuais". Material do curso (via internet): patrimônio imaterial: política e instrumentos de identificação, documentação e salvaguarda. EAD. Belo Horizonte.

BABADZAN, Alain. 2001. "Les usages sociaux du patrimoine ».In Ethnologies Comparées, 2, (1995): 1-6.

BAKHTIN, Mikhail (Volochinov). 2006. Marxismo e filosofia da linguagem. São Paulo: Hucitec.

BARBAÇON, Louis-José 1992. "Les pays du non-dit. Regards sur La Nouvelle Calédonie ». Nouméa, Editions Nouméa.

BARTH, Fredric. 1969. Ethnic groups and boundaries. The social organization of culture. Boston. Little, Brown and Company..

BAUMAN, Richard e SHERZER, Joel (org). 2000. Explorations in the ethnography of speaking. Cambridge. Cambridge University Press.

BAUMAN, Richard. 1984. Verbal Art as Performance; Prospect Heights: Waveland Press.

BAUMAN, Richard. 1988. Story, performance and event. Contextual studies of oral narrative. Cambridge University Press.

BECQUELIN, Aurore e ERIKSON, Phillipe (org). 2000. Les rituels du dialogue. Société d’Ethnologie. Nanterre.

BECQUELIN, Aurore. 1993. "Temps du récit, temps de l'oubli ». In Mémoire de la Tradition. Société d'Ethnologie. Nanterre.

BECQUELIN, Aurore. e MOLINIÉ, Antoinette (orgs.)1993. Memoire de la tradition. Nanterre. 
BENJAMIN, Walter.1996. Magia e técnica, arte e política: ensaios sobre a literatura e a história da cultura. Obras escolhidas 1. Brasiliense. São Paulo.

BENSA, Alban. 1990. Nouvelle-Calédonie, un paradis dans La tourmente. Gallimard. Paris.

BENSA, Alban. 1995. Croniques Kanak. L'ethnologie en marche.In Ethnies, vol. 10.ed. espécial. $n^{\circ} 18-19$.

BENSA, Alban. 2006. La fin de l'exotisme. Essais d'Anthropologie Critique. Toulose: Anacharsis.

BENSA, Alban. e RIVIERRE, Jean-Claude.1982. Les Chemins de l'Alliance. L'organisation sociale et ses représentations en Nouvelle-Calédonie. CNRS, Secrétariat d'État aux Departements et Territoire d'Outre-Mer.

BENVENISTE, Emile. 1974. Problemes de Linguistique Generale. Paris: Gallimard.

BILHAUT, Anne-Gaël. 2007. Le Reveil de L'immatériel. La production onirique du patrimoine des Indiens Zápara (Haute Amazonie). Doctorat d'ethnologie. Université Paris X, Nanterre.

$\mathrm{BLOCH}$, Maurice. 1975. Political language and oratory in traditional society. London: Academic press; New York; San Francisco.

BOAS, Franz. 2004. Antropologia Cultural. Castro, C. (org, trad). Rio de Janeiro: Jorge Zahar.editora.

BOULAY, Roger. La Maison kanak. Marseille, 1990, Paris, ORSTOM, Nouméa, ADCK

BOYER, Pascal. 1990. Tradition as Truth and Communication. A cognitive description of traditional discourse (Cambridge, Cambridge University Press).

BRENNEIS, Donald e MYERS, Fred R. (eds.). 1984. Dangerous words: Language and politics in the Pacific. Prospect Heights: Waveland Press.

CANDAU, Joel. 2005. Anthropologie de la Mémoire. Armand Colin. Paris.

CARNEIRO DA CUNHA, Manuela e ALMEIDA, Mauro Barbosa de. 2002. Enciclopédia da Floresta. São Paulo. Companhia das Letras.

CARNEIRO DA CUNHA, M. 1986 "Etnicidade: da cultura residual mas irredutível". In Antropologia do Brasil. São Paulo, Brasiliense/Edusp,

CARNEIRO DA CUNHA, Manuela. 2002. "Culture in Politics: intellectual rights of indigenous and local people".In IX Congrés d'Antropologia FAAEE. Barcelona.

CARNEIRO da CUNHA, Manuela. 2004. "Culture" and culture: traditional knowledge and intellectual rights. Marc Bloch Lecture. 
CAVALCANTI-SCHIEL, R. 2007. "Para abordar la interculturalidad: apuntes críticos a partir (y sobre) la nueva educación escolar indígena en Sudamérica”. In Cahiers ALHIM. Amerique Latine Histoire et Mémoire 13.

CAVIGNAC, Julie Antoinette. 2006. "Maurice Leenhardt e o início da pesquisa de campo na antropologia francesa". In Grossi, M.; Motta, A. Cavignac, J (orgs.) Antropologia francesa no século XX. Recife, editora Massangana.

CHOMSKY, Noam. 1973. Linguagem e Pensamento. Rio de Janeiro. Ed. Vozes.

CLASTRES, Pierre. 1974. La société contre l'État. Recherches d'anthropologie politique. Paris, Minuit.

CLIFFORD, James. 1987. Maurice Leenhardt. Personne et mythe em Nouvelle Calédonie. Paris, ed, Jéan-Miche Place.

CLIFFORD, James. 2000. A experiência etnográfica: antropologia e literatura no século $X X$. Rio de Janeiro. UFRJ.

COELHO DE SOUZA, Marcela. 2002. O traço e o círculo. O conceito de parentesco entre os Jê e seus antropólogos. Tese de doutorado. Museu Nacional. Rio de Janeiro.

COHN, Clarice. 2001. "Culturas em transformação. Os índios e a civilização". In São Paulo em Perspectiva, 15(2), 2001.

CRAPANZANO, Vicent. 1991. 'Diálogo'. In Anuário Antropológico 88. Ed. Universidade de Brasília [1991]

CRAPANZANO, Vicent.1979. Prefácio. In Leenhardt, Maurice Do Kamo. Chicago, University of Chicago Press.

DE LARGY-HEALEY, Jessica. 2004. 'Do trabalho de campo ao arquivo digital: performance, interação e Terra de Arnhem, Austrália. In Horizontes Antropológicos. Porto Alegre, ano 10, n²1. Jan/jun.2004

DELEUZE, Gilles; GUATTARI, Félix. 2006. Mil Platôs. Capitalismo e Esquizofrenia. Vol1. Sao Paulo: Editora 34.

DERLON, Brigitte e JEUDY-BALDINI, Monique. 2008. La passion de l'art primitif, enquête sur les collectioneurs. Paris, ed. Gallimard.

DERRIDA, Jacques. 1967. De la grammatologie. Paris : Éditions de Minuit.

DETIENNE, Marcel. 1981. L'invention de la Mythologie. Paris: Galimard.

DETIENNE, Marcel. 2000. Comparer l'incomparable. Paris: Éd. du Seuil. 
difference. Boston, Little, Brown and Company.

DOBBELAERE, Georges. 1995. «Le jeu scénique Kanaké : Témoignage de Georges Dobbelaere, scénographe». In: JOURNAL DE LA SOCIETÉ DES OCÉANISTES.1995.(1-2)

ELLEN, R. \& HARRIS, H. 1996. Concepts of indigenous environmental knowledge in scientific and development studies literature: a critical assessment. extraído da ágina: Avenir des Peuples des Forêts Tropicales/APFT.

FAUZI EID, A. S. 2003 Romhõsi'wa - A criação do mundo segundo os velhos narradores Xavante. Tese de doutorado. Unicamp. Livro (no prelo).

FINNEGAN, Ruth. 1992. Oral Tradition and the verbal arts: a guide to research practices. London, New York, Routledge.

FRIEDMAN, Jonathan. 1992. 'The past in the future: history and the politics of identity'. American Anthropologist (94/4).

GALLOIS, Dominique T. 1994. Mairi revisitada: a reintegração da fortaleza de Macapá na tradição oral dos Waiãpi. São Paul: NHII-USP \& Fapesp.

GALLOIS, Dominique T. 2002. Plano de proteção do patrimônio imaterial dos Wajãpi. In Boletim do Museu do Índio no9 - Documentação outubro, 2002. "Expressão Gráfica e Oralidade entre os Wajãpi do Amapá".

GALLOIS, Dominique T. 2005. 'Os Wajãpi em frente da sua cultura'. In Revista do patrimônio histórico e artístico nacional, v. 32, p. 110-129, 2005

GALLOIS, Dominique T. 2006. Patrimônio cultural imaterial e povos indígenas: exemplos do Amapá e norte do Pará. lepé. São Paulo.

GELL, Alfred. 1998. Art and Agency. An anthropological Theory. Oxford, Calrendon Press.

GIACCARIA, B.; HEIDE, A. 1972. Xavante: povo autêntico. São Paulo: Dom Bosco.

GOLDMAN, Márcio. e LIMA Tânia. Stolze. 1999. Alguma Antropologia. Relume Dumará.

GOODY, J. 1979 (1988). La raison graphique. La domestication de la pensée sauvage. Paris: Editions de Minuit.

GRAHAM, Laura. 1993. A public sphere in Amazonia? The depersonalized collaborative construction of discourse in Xavante. American Ethnologist 20 (4): 717-741. American anthropological Association. 
GRAHAM, Laura. 1994. Dialogic Dreams; Creative Selves Coming into Life in the Flow of Time. American Ethnologist, Vol. 21, n4 (Nov. 1994), pp. 723-745.

GRAHAM, Laura. 1995. Performing dreams: discourses of immortality among the Xavante of central Brazil. Austin: University of Texas Press.

GRAHAM, Laura. 2002. How should an Indian speak? Amazonian Indians and the symbolic politics of language in the global public sphere. In: Indigenous mouvements, self- representations, and the state in Latin America. K.B. Warren, J.E. Jackson (eds.). Austin: University of Texas.

GRAHAM, Laura. 2000. "Os Xavante na cena pública". In: RICARDO, C.A. (org.). Povos Indígenas no Brasil 1996-2002.São Paulo. Instituto Socioambiental.

GRAILLE, Caroline. 2001. «Patrimoine et identité Kanak en Nouvelle-Caledonie ». In: Ethnologies Comparées, $n^{\circ} 2$, (Miroirs Identitaires).

GREGOR, Thomas e TUZIN, Donald. (eds). 2001. Gender in Amazonia and Melanesia: an exploration of the comparative method. Berkeley; Los Angeles; London: University of California press.

GUIART, Jean. 1963. Structure de la chefferie en Mélanésie du Sud. Paris, Institut d'ethnology.

GUMPERZ, John e HYMES, Dell, (eds.). 1972. Directions in sociolinguistics: the ethnography of communication. New York: Holt, Rinehart and Winston; Chicago; San Francisco; Atlanta.

GUMPERZ, John. 1989. Sociolinguistique Interactionnelle: ume approche interpretative. Paris: L'Harmattan.

GUTJAHR, Eva. 2006. "Entre narrativas orais e registros da oralidade Wajãpi". Anais da XXV Reunião da Associação de Antropologia Brasileira. GT 15. Goiânia.

HABERMAS, Jürgen. 1984. The Theory of Communicative Action. Vol. 1: Reason and Rationalization of Society. Boston: Beacon Press.

HABERMAS, Jürgen. 1987. The Theory of Communicative Action. Vol. 2: Lifeworld and System: A Critque of Functionalist Reason. Boston: Beacon Press.

HALBWACHS, Maurice. 1925. Les cadres sociaux de la mémoire.Paris. éditions Albin Michel.

HAMPÂTÉ BÂ, Amadou. 1999. L'étrange destin de Wangrin. Editions 10/18. 
HAMELIN, C.; WITTERSHEIM, E. 2001. Au-delà de la Tradition. Introdução. In La tradition et l'État. Cahiers du Pacifique Sud Contemporain. Paris: I'Harmattan.

HARRISON, Simon. 1999. Identity as a scarce resource. Social Antropology (1999), 7, 3, 239-251.

HAUDRICOURT, André-Georges. 1964. 'Nature et culture dans la civilisation de l'igname: l'origine des clones et des clans" In L'Homme, IV (1), Jan-avril.

HIRSCH, Eric e STRATHERN, Marilyn (eds.). 2005. Transactions and creations: property debates and the stimulus of Melanesia. Oxford, Berghahn.

HOBSBAWM, Eric e RANGER, Terence. 1984. (orgs.) A invenção das tradições. São Paulo. Paz e Terra.

HOWARD, Alan. 1990. Cultural Paradigms, History, and the Search for Identity in Oceania. In : LINNEKIN J. and POYER L. (eds.), Cultural Identity and Ethnicity in the Pacific : 259-279. Honolulu : University of Hawaï press indígenas no Brasil, 1996-2000. São Paulo, Instituto Socioambiental,

INGOLD, Tim (ed.). 1998. Key Debates in Anthropology. London, New York: Routledge.

JOURNAL DE LA SOCIETÉ DES OCÉANISTES.1995.(1-2). 100-101. Musée de I'Homme de Paris. Double anniversaire. Edition Speciale: Melanésia 2000, 20 ans.

LATOUR, Bruno. 1994 [1991]. Jamais fomos modernos: ensaio de antropologia simétrica. Rio de Janeiro: Editora 34.

LEACH, JAMES. 2003. 'Owning creativity.Cultural propperty and the efficacy of Custom on the Rai Coast of Papua New Guinea'. In Journal of Material Culture (8/1). London, Sage publications.

LEACH, James. 2004. Modes of creativity. In Hirsch, Eric \& Strathern, Marilyn (eds.) Transactions and creations: property debates and the stimulus of Melanesia. New York : Berghahn Books.

LEENHARDT, Maurice. 1930. Vocabulaire et grammaire de la langue houialou. Paris, Institut d'Ethnologie.

LEENHARDT, Maurice. 1931. Documents néo-calédoniens. Paris, Institut d’Ethnologie.

LEENHARDT, Maurice. 1935 Notes d’Ethnologie néo-calédoniènne.Paris, Institut d'Ethnologie. 
LEENHARDT, Maurice. 1947. Do Kamo: la personne et le mythe dans le monde mélanésien. Gallimard.

LENCLUD, Gérard. 1994. «Qu'est-ce la tradition ? "In Transcrire les mythologies. Dettienne, Marcel (org). Albin Michel: Paris.

LÉVI-STRAUSS, C. 1984. A estrutura e a forma. In A Morfologia do Conto Maravilhoso. Propp, V. Ed. Forense Universitária. Rio de Janeiro.

LÉVI-STRAUSS, C. 1986. Ordem e Desordem na Tradição Oral. In Minhas palavras. Editora Forense Universitária. Rio de Janeiro

LÉVI-STRAUSS, C. 1989. O Pensamento selvagem. Papirus ed. Campinas: SP.

LIMA e ALVES, Ana Cláudia. 2008. 'A instrução dos processos de registro de bens culturais imateriais. Material do curso (via internet): patrimônio imaterial: política e instrumentos de identificação, documentação e salvaguarda. EAD. Belo Horizonte.

LONDRES, Maria Cecília. 2008. Construção das Políticas Internacionais de Referência para a Salvaguarda do Patrimônio Imaterial. Material do curso (via internet): patrimônio imaterial: política e instrumentos de identificação, documentação e salvaguarda. EAD. Belo Horizonte.

LOPES da SILVA, Aracy. 1986. Nomes e amigos: da prática Xavante a uma reflexão sobre os Jê. FFLCH/ USP, São Paulo.

MALINOWSKI, Bronislaw. 1965. Coral gardens and their magic. Vol 2: The language of magic and gardening. London. Allen and Unwin.

MASQUELIER, Bertand e SIRAN, Jean.-Louis (eds.).2000. Pour une anthropologie de l'interlocution: rhetoriques du quotidien. Paris: l'Harmattan

MAYBURY-LEWIS, David. 1984. A sociedade Xavante. Rio de Janeiro. Francisco Alves editora.

MENGET, Patrick e MOLINIÉ, Antoinette. 1993. 'Introduction'. In Mémoire de la Tradition. Nanterre. Société d'Ethnologie.

MISSOTTE, Phillipe. 1995. «Le Festival Mélanésia 2000 - septembre 1975 : Activation et réactivation socio-culturelle canaque en Nouvelle-Calédonie ». In JOURNAL DE LA SOCIETÉ DES OCÉANISTES.1995.(1-2):59-100.

MOKKADEM, Hamid. 2005. Ce souffle venu des ancêtres....l'oevre politique de JeanMarie Tjibaou (1936-1989). Nouméa; editions Expressions. 
MONNERIE, Dennis. 2005. La Parole de Notre Maison. Discours et Cérémonies Kank aujourd'hui (nouvelle-Calédonie). CNRS èditions, Editions de la Maison des Sciences de l'Homme.

MONOD-BECQUELIN, Aurore. 2005. "La tradition orale n'est plus ce qu'elle était ». In Revue sciences Humaines. [ ${ }^{\circ} 159$ ]. Dossier "Pourquoi parle-t-on? L'oralité redécouverte.

MORGAN, Marcyliena. 2006. Speech Community. In: A Companion to linguistic anthropology. Duranti, A. (org). Malden : Blackwell. P 3-22.

MORIN, Edgar. 2008. 'Edgar Morin ou l'art de décomplexer La pensée complexe'.

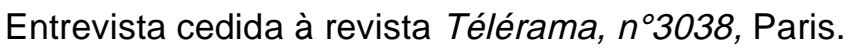

MOULIN, Raymonde, 1992. L'artiste, l'institution, le marché. Paris, Flamarion.

MÜLLER, Regina P. 1976. A pintura do corpo e os ornamentos Xavante: arte ritual e comunicação social. Dissertação de mestrado. Campinas, Unicamp.

MÜLLER, Regina. Mensagens visuais na ornamentação corporal Xavante. In: Vidal, Lux (org.). Grafismo indígena São Paulo: EDUSP, 1992.

MWÀ VĖĖ, revista. ADCK e Centro Cultural Tjibaou. № 43 (jun.2003). Nouméa. Nova-Caledônia.

MWÀ VĖĖ, revista. ADCK e Centro Cultural Tjibaou. №50 (set. 2006). Nouméa. Nova-Caledônia.

NAEPELS, Michel. 1998. Histoires de terres Kanakes.Conflits fonciers et rapports sociaux dans la région de Houaïlou (nouvelle-Calédonie). Paris, Editions Belin.

ONG, Walter. 1998. Oralidade e cultura escrita. A tecnologização da palavra. Papyrus.

PARRY, Milman. 1928. L'èpithète traditionnelle dans Homère; Essai sur un problème de style homerique. Paris, Société d’èditions «Les belles lettres ».

POVOS INDÍGENAS NO BRASIL. 2001. Palavras indígenas: doze narrativas sobre a origem do mundo, a chegada dos brancos e os 55 anos. Instituto Socioambiental, (16-54).

PRICE, Richard. 1983. First-Time: The Historical Vision of an Afro-American People. Baltimore and London: The John Hopkins University Press.

PRICE, Sally. 2000. A Arte Primitiva em Centros Civilizados. Ed. UFRJ. Rio de Janeiro. 
PROPP, Vladmir. 1984. Morfologia do conto maravilhoso. Ed. forense universitária. Rio de Janeiro.

RADCLIFFE-BROWN, Alfred Reginald. 1958. The Comparative Method in Social Anthropology. Chicago: Chicago Universtity Press.

RAMOS, Alcida. 2007.'Do engajamento ao desprendimento'.in Revista Campos (8/1).

RAVAGNANI, Osvaldo. 1978. A experiência Xavante com o mundo dos brancos. São Paulo, Tese de Doutorado. Fundação Escola de Sociologia e Política de São Paulo.

RICOER, Paul. 2000. La mémoire, l'oubli, l'histoire, Paris, Le Seuil.

SAHLINS, Marhall. 1990. Ilhas de história. Rio de Janeiro, Jorge Zahar.

SANT'ANNA, Márcia. 2008. "A política federal de salvaguarda do patrimônio cultural imaterial: diretrizes, resultados e principais desafios". Material do curso (via internet): patrimônio imaterial: política e instrumentos de identificação, documentação e salvaguarda. EAD. Belo Horizonte.

SAPIR, Edward. 1951. "The status of Linguistics as a science'. In. David G. Mandelbaum, org., Selected Writings of Edward Sapir. Berkeley: University of California Press.

SAUSSURE, Ferdinand de. 2000. Curso de Lingüística geral. São Paulo. Ed. Cultrix. 2000.

SEARLE, John. 1970. Speech acts: an essay in the philosophy of language. Cambridge. Cambridge University Press.

SEREBURÃ et alli. 1998. Wamrêmé Za'ra: Nossa palavra. Mito e história do povo Xavante. Ed. Senac. SP.

SHERZER Joel. \& URBAN Greg. 1986. Native South American Discourse. New York/ Amsterdam, Mouton de Gruyter.

SILlitOE, Paul, BICKER, Alan, POTTIER, Johan. (eds). 2002. Participating in Development: approaches to indigenous knowledge. ASA Monographs.no39. London:Routledge.

SILVERSTEIN, Michael, URBAN, Greg, (Eds). 1996 Natural Histories of Discourse. Chicago, London: The University of Chicago Press.

SILVERSTEIN, Michael. 1976. Shifters, linguistic categories and cultural descriptions. In: Meaning in Anthropology. Basso, Keith H., Selby, Henry A., eds. Albuquerque: University of New Mexico Press.

SÍTIO INTERNET do Centro Cultural Tjibaou (http://www.adck.nc/fr) 
SOUZA, Lynn Mario Menezes de. 2001. Da estória a história: a escrita indígena no Brasil. In:Revista da Biblioteca Mário de Andrade. São Paulo, v. 59, 69-72.

SPERBER, Dan. 1996. Le Contagion des ldées. Paris: Editions Odile Jacob.

STRATHERN, Marilyn e GODELIER, Maurice. 1991. Big Men and Great Men. Personifications of power in Melanesia. Cambridge, Cambridge University Press.

STRATHERN, Marilyn. 1987. 'The Limits of auto-anthropology'. In Jackson, A. (Ed.) Anthropology at Home. Tavislock publications, London e New York.

STRATHERN, Marilyn. 1995. 'The nice thing about culture is that everyone has it'. In: Strathern Marilyn (ed.) Shifting Contexts. Transformations in Anthropological Knowledge. Londres, Routledge.

STRATHERN, Marilyn. 1999. "No limite de uma certa linguagem". Entrevista a Eduardo Viveiros de Castro e Carlos Fausto. In: Mana, vol. 5, no.2, 1999.

STRATHERN, Marilyn. 2004. Partial Connections. New York, Altamira Press.

STRATHERN, Marilyn; PEEL, J.D.Y; TOREN, Christina.; SPENCER, Jonathan. 1998. "The Concept of Society is Theoretically obsolete". Debate 1989. In: Key Debates in Anthropology. Ingold, Tim (ed.). London, New York: Routledge.

SZTUTMAN, Renato. 2005. O profeta e o principal. A ação política ameríndia e seus personagens. Tese de Doutorado. FFLCH-USP.

SZTUTMAN, Renato. 2006. De nomes e de marcas. Sobre a grandeza do guerreiro selvagem. Texto apresentado no XXV Encontro da Associação Brasileira de Antropologia.

TAMBIAH, Stanley. 1968. The Magical power of words. Man. New Series. Vol 3. № 2, 175-208.

TAYLOR, Diana. 2003. "Acts of transfer". In: Taylor, D. The Archive and the Repertoire: Performing Cultural Memory in the Americas. Duke University Press, Durham.

TEDLOCK, Denis. 1987. "Preguntas conciernentes a la antropologá dialógica ». In Geertz, C. e Clifford, J. El surgimiento de La Antropologia Pós moderna. São Paulo. Gedisa editorial.

TJIBAOU Jean-Marie.1996. La Présence Kanak. Alban Bensa e Eric Wittersheim (org). Paris: éditions Odile Jacob.

TJIBAOU, Jean-Marie. 1978. "Texte de treize pages sans titre daté du 13 avril 1978, colloque Leenhardt à Paris, Fonds Cortadellas-Bourret-17J, Nouméa, Service des Archives de la Nouvelle-Calédonie, 1978 ». In: Mokkadem, H. Ce souffle 
venu des ancêtres....l'oevre politique de Jean-Marie Tjibaou (1936-1989). 2005:121.

TJIBAOU, Jean-Marie. e MISSOTTE, Phillipe. 1976. Kanaké, Mélanésien de NouvelleCalédonie. Nouméa, Société Nouvelle des Éditions du Pacifique.

URBAN, Greg e SHERZER, Joel.1988. The Linguistic Anthropology of Native South America. Annual Review of Anthropology, Vol. 17 (1988), pp. 283-307.

URBAN, Greg. 1986. Ceremonial Dialogues in South America. American Ethnologist. New series, Vol. 88, n², (jun.1986), pp. 371-386.

URBAN, Greg. 1988. Ritual Wailing in Amerindian Brazil. American Anthropologist 90:385-400.

URBAN, Greg. 1991. A Discourse-Centered Approach to Culture. Native South American Myths and Rituals. Austin, University of Texas Press.

VACHERON, Frédéric. 2006. Lenguas y Tradiciones Orales de la Amazonía. Diversidade en peligro? UNESCO, Fundo editorial Casa de las Americas.

VANSINA, Jan, 1984. Oral Tradition as History. Madison. University of Wisconsin Press.

VIVEIROS DE CASTRO, Eduardo. 2004. 'Perspectival anthropology and the method of controlled equivocation'. In Tipití - Journal of the Association for the Anthropology of Lowland South America.New Orleans v.2. n.2. 2004.

WAGNER, Roy. 1974. Are There Social Groups in New Guinea Highlands? In: Leaf, M.J. (ed.) Frontiers of Anthropology: an introduction to anthropological thinking. New York: D. Van Nostrand Company.

WAGNER, Roy. 1981. The invention of Culture. Chicago: The University of Chicago Press.

WARNER, Michael. 1990. The Letters of the Republic: Publication and the Public Sphere in Eighteenth-Century America. Cambridge, Mass.:Harvard University Press.

WARREN, Kay e JACKSON, Jean (eds.). 2002. Indigenous mouvements, selfrepresentations, and the state in Latin America. Austin: University of Texas Press.

WHORF, Benjamin. 1956. Language, Thought, and Reality: Selected Writings of Benjamin Lee Whorf. Org. John B. Carroll. Cambridge: MIT Press.

WITTERSHEIM, Eric. 2003. Le Retour du politique. Anthropologie et situations (post)coloniales. Nouvelle-Calédonie et Vanuatu. Tese de doutorado. Paris, EHESS. 
ZUMTHOR, Paul. 1988. L'oubli et la tradition. In: Politiques de l'oubli (Paris, Le Seuil), 105-119.

ZUMTHOR, Paul. 1989. La letra y la voz de la "literatura" medieval. Ediciones Catedra.

\section{Documentos citados}

ACCU/UNESCO. 2006. Expert meeting on community involvement in safeguarding intangible cultural heritage: Towards the implementation of the 2003 Convention". Tokyo, Japão.

ONU. 1989. Convenção 169 da Organização Internacional do Trabalho.

UNESCO.1972. Convenção para a Salvaguarda do Patrimônio Mundial, Cultural e Natural.

UNESCO. 1989. Recomendação sobre a Salvaguarda da Cultura Popular e Tradicional.

UNESCO. 2003. Convenção para a Salvaguarda do patrimônio Imaterial. 